This item was submitted to Loughborough's Research Repository by the author.

Items in Figshare are protected by copyright, with all rights reserved, unless otherwise indicated.

\title{
Reflecting on reflection: a case-study of one teacher's early-career professional learning
}

PLEASE CITE THE PUBLISHED VERSION

PUBLISHER

(C) Karl Attard

\section{PUBLISHER STATEMENT}

This work is made available according to the conditions of the Creative Commons Attribution-NonCommercialNoDerivatives 4.0 International (CC BY-NC-ND 4.0) licence. Full details of this licence are available at: https://creativecommons.org/licenses/by-nc-nd/4.0/

\section{LICENCE}

CC BY-NC-ND 4.0

\section{REPOSITORY RECORD}

Attard, Karl. 2019. "Reflecting on Reflection: A Case-study of One Teacher's Early-career Professional Learning”. figshare. https://hdl.handle.net/2134/34494. 


\section{$2 \times 239041$}

\section{University Library}

Loughborough University

Author/Filing Title .............A.R.,.........................

Class Mark

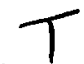

Please note that fines are charged on ALL overdue items.

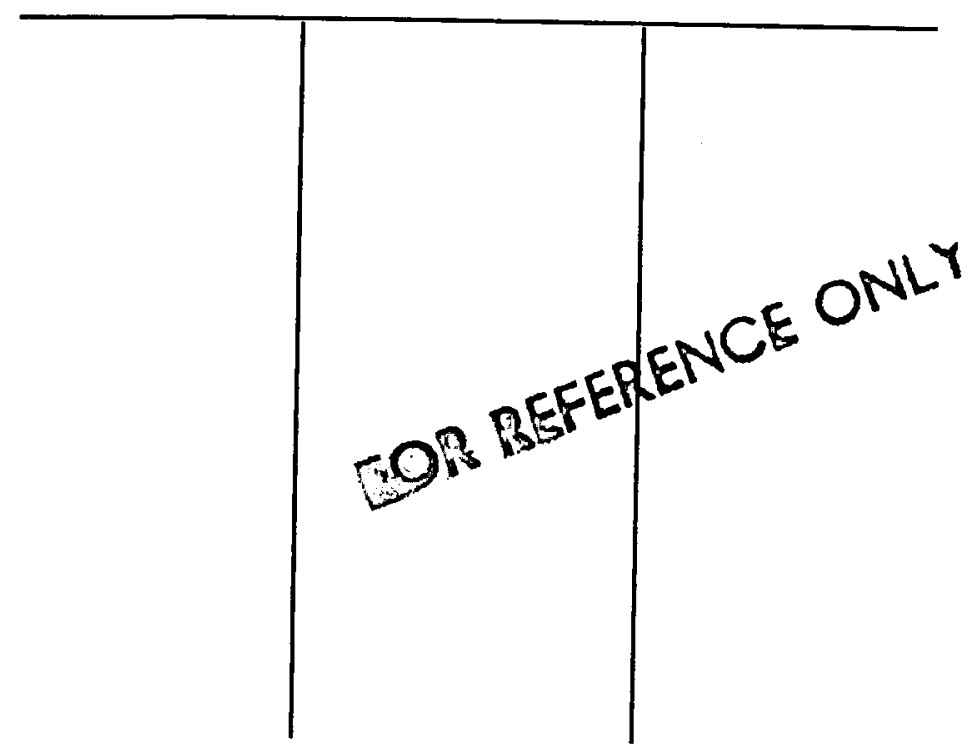





\section{Reflecting on Reflection: a case-study of one teacher's}

\section{early-career professional learning}

by

Karl Attard

Doctoral Thesis

Submitted in partial fulfilment of the requirements for the award of Ph.D of Loughborough University

$28^{\text {th }}$ August 2006

(C) Karl Attard, 2006 


\begin{tabular}{|l|l|}
\hline $\mathbf{D}$ & $\begin{array}{l}\text { Loughlorough } \\
\text { University } \\
\text { Pilkington Library }\end{array}$ \\
\hline Date & JAN 2007 200 \\
\hline Class $T$ \\
\hline $\begin{array}{l}\text { Acc } \\
\text { No. } 0403271452\end{array}$ \\
\hline
\end{tabular}




\begin{abstract}
This research aims to analyse the ways in which one early-career teacher learns through and about professional practice. Data presented in this study are drawn from 30 months of reflective teaching and focus on pedagogical practices, critical reflection upon those practices, and the teacher's ongoing professional learning.
\end{abstract}

The research methods used in this study are a combination of qualitative methods including reflection, action research, and case-study (more specifically, self-study). Also, reflective journal writing has been a useful tool for the teacher-researcher to understand his own development. It is interesting to note that reflective practice was the glue that kept the research process together, while also being the main focus of inquiry. A range of data analysis procedures were undertaken including reflective analysis, narrative analysis, and grounded theory analysis.

Data illustrate the teacher-researcher's understanding of the reflective process, and how understanding the self is important in professional practice. The difficulties of reflective self-study are also highlighted, while aspects of personal professional development are discussed and compared to more formal types of professional development. The key findings are: the importance of teaching experience for the reflective practitioner; the need for the reflective practitioner to engage in internal dialogue and question taken-for-granted professional assumptions; the need to translate new understandings into informed change through action research; the disposition to endure a state of inconclusiveness and uncertainty; and how reflective self-study can integrate theory and practice in the teaching profession. Perhaps the most important finding is that engaging in critical reflection and self-study enables the teacher-researcher to feel a strong sense of control over both his personal and professional lives. Emergent understandings of teacher learning also lead to recommendations regarding teacher education, in particular the need to prepare teacher education students for meaningful engagement in critical reflection and professional learning communities. 


\section{Table of Contents}

Chapter 1 - Introduction

1.1 Background p.1

1.1.1 Introducing Myself - The Teacher-Researcher p.4

1.1.2 Teacher Education in the Maltese Context p.4

1.2 The Research Questions p.5

1.3 Rationale p.6

1.4 Methodology p.7

1.5 Writing Up the Findings $\quad$ p.8

1.6 Research Outcomes $\quad$ p.11

Chapter 2-Research Methodology

2.1 Choice of Method p.13

2.2 Reflection p.15

2.2.1 Experience and Reflection: a symbiotic relationship p.16

2.2.2 Inviting the Reader into the Study p.18

2.2.3 Understanding Reflection through Reflective Inquiry p.19

2.2.4 A Longitudinal Systematic Process p.20

2.2.5 Reflection is what Glues the Entire Process of Inquiry p.21

2.3 Action Research p.22

2.3.1 Action Research is Closely Linked to Practice p.22

2.3.2 Action Research and Reflection: an inevitable partnership p.24

2.3.3 Action Research has Both Practical and Theoretical Outcomes 
2.4.1 Teaching as a Holistic Activity

2.4.2 Context in Case-Study Research

2.4.3 Generalisability in Qualitative Research

2.4.4 Cases as Magnifying Glasses

2.4.5 Case-Study Approach for the Teacher-Researcher

2.4.6 Case-Study Research is Closer to Readers' and Practitioners' Lived Experiences

2.5.1 Developing Professionally through Self-Study Research

2.5.2 Opting for Self-Study Research: why?

2.5.3 Reflection and Self-Study: complementing each other

2.5.4 Is Self-Study Purely about the Personal?

2.6.1 Reflection Vs Technical-Rationality

2.6.2 The Ability to Observe and Notice

2.7.1 My Interpretations throughout this Particular Study

2.7.2 No Interpretation should be seen as Infallible and/or Fixed

2.7.3 The Importance of Personal Interpretation

2.8.1 Writing Narratives: the primary vehicle that aided my reflections and my thinking

2.8.2 First-Order Narratives in Self-Study Research: a way of promoting self-understanding

2.8.3 The Text: a way of capturing the complexity of teaching and the teacher's ongoing development?

2.8.4 Communicating My Interpretations through Narrative Writing: creating causal links 
2.9.1 Different Forms of Validity

2.9.2 Understanding of Social Life

2.9.3 Reflexivity, Authenticity, and Credibility

\subsubsection{Fidelity}

2.9.5 Validity in Self-Study Research

2.9.6 Impact: Is it Engaging and Evocative? Does it Promote Dialogue and Show Potential for Social Action? Does the Account Work for the Reader and is it Useful?

2.10.1 Reflective Analysis p.68

2.10.2 Analysis and Narratives p. 68

2.10.3 Grounded Theory Analysis p.69

2.10.4 A Healthy Contamination p.73

2.11 Ethical Considerations p.75

Chapter 3 - Aspects of Reflective Practice

$3.1 \quad$ Introduction p. 77

3.2 The Role of Experience p.77

3.2.1 Lack of Experience p.78

3.2.2 Is Experience the Essence of Professional Development? p. 80

3.2.3 Moulded by Experience p.81

3.2.4 Revisiting Past Learning p.81

3.2.5 Gaining Experience - Learning Tacitly p.82

3.2.6 Tacit Learning Shapes Our Understanding of the World p.83

3.2.7 Making the Best Use of Available Experience p.83

\begin{tabular}{lll}
$3.3 \quad$ The Process of Reflection & p.84 \\
\hline
\end{tabular}

3.3.1 Understanding Reflection p.85

$\begin{array}{ll}\text { 3.3.2 Stages in My Reflective Process } & \text { p.86 }\end{array}$ 
3.3.3 Reflective Practice as Research Methodology

3.3.4 Usefulness of Emotions in Understanding the Self

3.3.5 The Value of Taking a Systematic Approach towards Reflection

3.3.6 Reflection is Not Fool Proof

3.3.7 Does Reflection Really Promote Professional Development and Change?

3.3.8 Reflection-in-Action/Reflection-on-Action p. 96

3.3.9 A Greater Sense of Control Over my Professional Life

3.4.1 Writing Pushes Thought into Unforeseen Directions

3.4.2 Writing Promotes Further Understanding

3.4.3 The Significance of Language

3.4.4 Keeping the Journal - Pros and Cons

3.4.5 Writing as Inquiry

3.4.6 Reflective Writing - A Longitudinal Meaning-Making

Process

3.4.7 Understanding Professional Development through a Habit of Writing

3.4.8 Self-Confessing Writing

3.5.1 Questioning Promotes Internal Conversation

3.6.1 Challenging the Status Quo through Questioning

3.6.2 Asking the Right Questions

3.6.3 Should I Limit My Questioning?

3.6.4 The Quest for Meaning

3.6.5 Questions should be Critical 
Chapter 4-Learning about the Self through Reflective Self-Study

4.1 Introduction

p. 115

4.2 Learning about My Beliefs and Assumptions

p.116

4.2.1 Aspects that can Induce the Questioning of Beliefs

4.2.2 Questioning Assumptions as Professional Development

4.2.3 But how are Beliefs and Assumptions Formed?

4.2.4 What are the Foundations upon Which Intuitive Practice Holds?

4.2.5 The Impact of Beliefs and Assumptions on Professional Practice

4.2.6 One Example of the Many Previously-Held Assumptions

4.2.7 Consciously Deconstructing my Previous Unconscious Constructions

4.2.8 Taken-for-granted Assumptions in the Private Sphere: a necessary type of learned ignorance?

4.2.9 Professional Assumptions as Dynamic Rather than Fixed and Unchanging

4.3 Reflecting on Private Life p. 130

4.3.1 Questioning is Seeping into My Private Life

4.3.2 My Private Life affects my Professional Sphere

4.3.3 Integrating the Private and Professional Spheres: an important but mined territory

4.4 A Blinded Perspective p.133

4.4.1 Factors that Influence what I can See p.135

4.4.2 An Example of being Blinded p. 136 $4.5 \quad$ Summary p.137 
Chapter 5 - Moving through Rough Roads

\begin{tabular}{lll}
$5.1 \quad$ Introduction & p.138 \\
\hline
\end{tabular}

\begin{tabular}{ll}
5.2 Habit Vs Change & p.138 \\
\hline
\end{tabular}

5.2.1 The Formation of Habitual Routines p.139

5.2.2 Tacit Learning Promotes Technical Routines p.139

5.2.3 Routine Promotes Comfort and Mediocrity p.140

5.2.4 The Importance of Motivation p.142

5.2.5 Finding Myself in Alien Waters: needing to changeneeding to learn p.143

5.2.6 Dynamic Beliefs Promote Continuous Change • p.144

5.2.7 Ongoing Relevant Learning and Continuous Change p.145

5.2.8 To Change or Not to Change: the case for determination p.145

5.2.9 Consciously Abandoning the Easy Route p.146

5.2.10 Changing Established Practice or being Changed by Established Practice? P.147

5.2.11 A Deeper Understanding does not Automatically Result

in Change p.148

5.2.12 Change: a lengthy process p.150

5.2.13 Reflection as a Corrective to Experiential Over-Learning p.151

5.3 Uncertainty: dealing with inconclusiveness $\quad$ p.152

5.3.1 Reflection does not try to Simplify the Complex Nature

of Teaching p.154

5.3.2 Reflection is a Suspended State of Not Knowing p.155

5.3.3 Uncertainty as a Positive Component of Reflective Self-Study p.158

5.3.4 A Tolerance of Uncertainty Promotes Ongoing Inquiry p.159

5.4 Summary p.160 
Chapter 6 - Continuous and Relevant Professional Development

6.1 Introduction p.161

6.2 Formal Professional Development p.162

6.2.1 A Teacher's Perspective on Formal Professional Development

6.2.2 Informal Learning in Formal Professional Development

6.2.3 Technical Rationality and Formal Professional

Development

6.2.4 The Necessity for Professional Development to be Relevant to my Needs

6.2.5 One-Size-Fits-All p. 168

6.2.6 Dissatisfaction with Traditional Formal Professional Development: is there a need for change?

6.3 Personal Professional Development: a road towards lifelong learning p.171

6.3.1 Personal Professional Development: directly relevant to my needs

6.3.2 The Tools for Lifelong Personal Professional Development

6.3.3 A Need for Professional Development to be Ongoing

6.3.4 Reflective Self-Study: highlighting the personal nature of professional development

6.3.5 Reflective Self-Study: a priceless and handy tool towards ongoing development

6.3.6 Personal Professional Development as a Never-Ending Quest

6.3.7 Perceived Problems: a driving force towards deep-rooted change

6.3.8 The Main Difference between Formal and Informal Professional Development

6.3.9 Conditions Inside Schools need to Change if Personal Professional Development is to be Promoted 
6.3.10 The Role of Literature in Personal Professional

Development

6.3.11 Integrating Formal and Personal Professional

Development

6.4 The Teacher-Researcher p.184

6.4.1 Teacher-Research can be Useful to the Wider Community

Chapter 7 - Ways of Enhancing Professional Development

7.1 Combating Isolation

7.1.1 Me: an isolated professional

7.1.2 Valuing Professional Communication

7.1.3 Reflective Self-Study and Collaborative Inquiry

7.1.4 My Search for a Companion throughout my Odyssey

7.1.5 A Critical Friend

7.1.6 Aspects that might Hinder Professional Collaboration

7.1.7 Teacher Isolation: a harsh reality

7.1.8 Collaboration: a tool for diminishing blind-spots while increasing exposure to different viewpoints

7.1.9 The Building of Learning Communities

7.1.10 A Constant Need to Check My Understandings p. 188 p. 188

p.192

p.194

p.195

p. 200

7.2 Integrating Theory and Practice

7.2.1 The Use of Literature: not simply an aid but a central

component of the research process
7.2.1 The Use of Literature. not simply an aid but a central p.201

7.2.2 A Negative View towards Educational Literature

7.2.3 Questioning the Assumptions Surrounding the Use of General Theory p.202

$$
\text { 7.2.3 Questioning the Assumptions Surrounding the Use of }
$$

7.2.4 The Importance of Contextual Knowledge p.204

7.2.5 The Unconscious Creation of a Theory-Practice Gap 
7.2.6 Moving from Practice to Theory to Practice

7.2.7 Acting on my New Understandings: integrating theory and practice

Chapter 8 - Conclusions - Visions for an Improved Future

8.1 Important Aspects of This Study p.216

8.1.1 Experience: essential but not sufficient for professional development

8.1.2 The Reflective Process p.218

8.1.3 Reflective Writing and Conversing with Oneself

8.1.4 Learning about Tacitly Held Professional Assumptions

8.1.5 Moving Towards a Habit of Change

8.1.6 Uncertainty and Inconclusiveness

8.1.7 Paying Attention to My Own Professional Development

8.1.8 An Isolated Teacher-Researcher?

8.1.9 Educational Literature in Personal Professional Development

8.2 Key Recommendations from the Study

8.2.1 Should Pre-service Teacher Education Develop Teacher-Researchers?

8.2.2 The Importance of Experiencing Teaching in Pre-service Teacher Education

8.2.3 Educational Theory in Pre-service Teacher Education p. 228

8.2.4 The Creation of Learning Communities p. 230

8.2.5 The Role of Writing in Learning Communities

8.2.6 Self-Censorship and Emotions

8.2.7 Should the Formation of Learning Communities be Part of the Official Pre-service Curriculum? 
8.2.9 The Results that Lead to Such Recommendations

8.3 Limitations of this Study p. 236

8.4 Future Research Questions Stemming from This Study p. 237

8.5 Experiencing this Research Project p. 237 


\section{Chapter 1}

\section{Introduction}

\section{$1.1 \quad$ Background}

September 2002 and it was time to start worrying. Actually, worries had already haunted me for the past few months. A new syllabus in Physical Education leading up to an examination at Secondary Education Certificate (SEC) level was going to be introduced into Secondary Schools in Malta and this left me wondering what was expected of me and of my future students. I, like all Physical Education teachers in Malta, had no experience of teaching this syllabus and as Bass, Anderson-Patton, \& Allender (2002) argue, a new process inevitably causes some anxiety. Mills (1959) argues that to have experience means 'that your past plays into and affects your present, and that it defines your capacity for future experience' (p.196). Regrettably however, I had no past experience to inform my present practice and once the past stops informing the future, our thoughts seem to move forward in darkness (Gordon, 1991).

When the new SEC PE syllabus was introduced, I had only been a full-time teacher for one year. Hence, not only was I still coming to grips with my new reality (i.e. teaching), but I had to immediately face a new situation; an innovation about which I knew very little. I felt as if I was lost in darkness, and each time I started moving towards the light, I was thrown back into pitch darkness. Such a feeling was exacerbated by the fact that I found myself in total isolation. I was the only person teaching this syllabus in my school and, as a result, I had to fend for myself. I needed to survive but I realised that in order to do so, I had to understand the situation more clearly. This is why I started questioning myself on how best to tackle this new challenge. This lack of certainty led me to think, analyse and understand my situation, to want to learn, and finally get to know what a reflective practitioner actually does. After all, it is some sort of uncertainty, surprise, perplexity or inadequacy that triggers the need for further understanding (Mason, 2002; Sanders \& McCutcheon, 1986; Ghaye \& Ghaye, 1998; 
Zembylas, 2004). Therefore, this new situation 'initially made me a bit apprehensive, although from the beginning I also saw this as a learning and growing opportunity' (Johnson, 2003: p.791).

Ghaye \& Ghaye (1998) cite a teacher who asks the following question: 'How can I support and facilitate my pupils' learning when I am somewhat bewildered and uncertain...?' (p.120). This is indeed very similar to what I was asking myself in this particular moment of change. I had to study myself since I needed to understand my position and my situation better. In short, I felt I had to engage myself in research to improve my professional practice. After all, the practitioner who engages him/herself in research does so with the intent of improving the service s/he offers to clients as well as shedding light on perceived problems in professional practice (Mason, 2002; Stringer, 1996). Reflection and self-study seem to offer promise here since they are based upon the principle of improving one's practice (Guðjónsdóttir \& Dalmau, 2002) and we cannot act upon and improve our practice if we do not learn from our own experience (Ghaye \& Ghaye, 1998; Labaree, 2003). Moreover, acting upon a problem without first analysing and fully understanding it may be more harmful than beneficial (Clarke \& Hollingsworth, 2002; Elmore \& McLaughlin, 1988).

After realising that I had to learn from my own experience if I was to improve my teaching, I started reflecting on ways to go about it. Reflection can be an important instrument when applied to new and puzzling situations since it can help the practitioner to understand the information available (Loughran, 1996). Ghaye \& Ghaye (1998) make the argument that reflection on past experiences 'can be used to inform current planning' (p.2). Keeping a similar logic in mind, I reasoned that reflecting and analysing what I experience today can provide a wealth of personal as well as practical knowledge useful to inform future practice (Elbaz, 1991). Thus, I started interesting myself in 'reflection'. As Ward \& McCotter (2004) argue, 'the value of reflection to the development of teachers has a growing consensus among teacher educators' (p.244). However, I started the process based on the assumption that 'reflection' can inform practice without ever really questioning this assumption. Academics and teacher 
educators who argue for the value of reflective practice try to persuade of the worthiness of reflection by claiming that in order for teachers to improve and understand their practice better, they must engage in critical reflection upon their own experiences (Mayes, 2001; Zeichner, 1994; Grimmett, Mackinnon, Erickson \& Riecken, 1990; Imants, 2002; Shulman, 1992; Liston \& Zeichner, 1990). Most of the literature regarding reflective practice, as noted by Kemp (2001) 'makes the assumption that, by engaging in deep thinking processes, we might gain a deeper understanding of ourselves' (p.347). Yet, like Edwards \& Nicoll (2006), I believe that it is imperative that such professional assumptions are analysed. And it is exactly this assumption that I felt the need to study. I wanted to understand if the assumption that 'reflection' is helpful for the practitioner is indeed correct. After all, postmodern thought challenges researchers to question taken-for-granted assumptions and given truths (Eisenhart, 2001) and one of these assumptions is that reflection and experience can help in personal development and learning (Usher, 1998).

But why should 'reflection upon experience' be a good thing and thus helpful for the practitioner? Stringer (1996) argues that as practitioners 'reflect on their situation, they can conceive solutions to their problems with a degree of clarity that escapes them in the rush and clutter of their day-to-day lives' (p.97). I wanted to understand more specifically how 'reflection' helps the practitioner if the aforementioned assumptions are true since:

Reflection continually emerges as a suggested way of helping practitioners better understand what they know and do as they develop their knowledge of practice through reconsidering what they learn in practice (Loughran, 2002a: p.34).

Hence, my research questions changed some time after I engaged myself in this study. After all, research questions are often polished and sometimes change entirely in the course of a study (Metz, 2001; Turner, 1981; Yin, 2003). This is even more so in selfstudy and action research where the focus of the study is continuously changing as new questions emerge upon which the inquirer needs to focus (WestEd, 2000). As such, in the initial stages of the research, reflection was conceptualised and practised as a tool that helped me understand my new situation, but after a while it also became the subject 
of inquiry since I wanted to learn more about it. Thus, what I aim to learn from my research is how one teacher thinks and learns about and from professional practice through self-study and reflective practice.

\subsubsection{Introducing Myself-The Teacher-Researcher}

My life experience as a student has, in general, been a pleasant one. This might explain why I have been a student for practically 23 years now. I attended two different Catholic schools at Primary and Secondary levels. However, as regards higher education, I opted for state provided education.

I started my initial teacher education course in 1996 at the University of Malta and furthered my studies immediately by undertaking postgraduate study at Loughborough University in the year 2000. After postgraduate study, I decided to start teaching, but I still wanted to further my studies. This led me to start part-time doctoral study in 2002. Now at the age of 27 , while writing this final draft of my thesis, I realise that I never stopped developing myself. Might this be the effect of being fond of learning?

It is probably important to mention that both my parents were teachers and they brought me up in a context where education was one of the most important issues on the family's agenda. They made learning seem fun, and the teaching-learning process was an ongoing affair, especially when I was very young. This undoubtedly left an indelible mark on me and my future experiences with education. I remember that I used to enjoy it when my parents explained something to me, or when they played dumb and wanted me to explain something to them. Indeed, I enjoyed those early years of learning so much that I hope to use the same methods with my own children in the future.

\subsubsection{Teacher Education in the Maltese Context}

In Malta, pre-service teacher education either consists of a 4-year Bachelor of Education (B.Ed) course, or a 1-year postgraduate certificate in Education (PGCE) course; the former being my case. Throughout the four years (B.Ed), theoretical courses are held on campus with student-teachers having six-seek teaching practice rounds in 
years 2, 3 and 4. After successfully completing the course, the only form of formal professional development available to newly-qualified teachers is provided by the Government's Education Division. Such formal courses are mostly compulsory 3-day courses that teachers attended once-yearly. It is important to note here that issues to be tackled during in-service courses are exclusively decided by the Education Division, apart from rare occurrences.

\subsection{The Research Questions}

As Metz (2001) points out, the starting point and most important issue in developing research, is the research question. Consequently, the primary question that moved this study forward is:

How did one teacher learn about his professional practice, in the early years of teaching, through reflection and self-study?

I have addressed this question by actually engaging myself in reflection and by analysing my everyday experiences. I have also kept a record of my professional development to document the nature and range of learning that took place over 30 months. In addition, there are two secondary questions that will be addressed through the research process;

- Can critical reflection on practice help to bridge the theory/practice gap?

- What are the implications of this research for continuing professional development for teachers as well as the preparation of future teachers?

These questions are addressed by reviewing relevant literature to which my reflections on my own practice led me to. Thus I was able to evaluate and compare personal knowledge that arose from and during that practice with public knowledge found in 
educational literature. I also reflect on how I used theory and research literature in my practice. Thus, I will be integrating research literature with personal teacher knowledge that emerges from my reflections. The intention underpinning this research is that detailed illustration of this reflective process may prove to be helpful to others who are delivering or researching teachers' professional learning.

\subsection{Rationale}

This particular research can inform the educational field because research literature concerning the process of teacher development to-date lacks in-depth studies conducted by practitioners in situ over a sustained period of time (Brouwer \& Korthagen, 2005; Day, Kington, Stobart \& Sammons, 2006). Hence, the need for studies of teacher knowledge and teacher learning by individual teachers is suggested, and these studies need to be carried out by examining closely the learning processes involved when teachers engage in practice and development (Verloop, Van Driel \& Meijer, 2001, Brouwer \& Korthagen, 2005). However, as regards workplace learning, Little (2002) argues that 'the field of education has not developed the kinds of fine-grained investigations... that have began to emerge in other occupational arenas' (p.919). Thus, this study does not solely aim to understand how one teacher learns, but also aims to study the methods used in this research as a strategy for teacher learning. This single case-study may make a valuable contribution to the wider educational literature because understanding the learning processes of the human resources available in this field (i.e. teachers) is still very under-researched. According to Goodson (1981):

In understanding something so intensely personal as teaching it is critical we know about the person the teacher is. Our paucity of knowledge in this area is a manifest indictment of the range of our sociological imagination (cited in, Goodson, 1999: p.125).

Verloop et al. (2001) argue that understanding teacher thinking and teacher knowledge can be very useful in improving teaching and teacher education, as well as making educational innovations more beneficial for those involved. As Sim (2004) argues, it is 
more than a century ago that John Dewey claimed that the rationale for educational research should be a serious attempt to understand and help others appreciate and comprehend what teachers and learners do during the process of learning and how this can inform other teachers working in the field. As Geertz (1973) contends, in order to understand what a science is all about, one must look carefully at what its practitioners do, rather than at its theories.

\subsection{Methodology}

Throughout this study I reflected upon lived experience. I kept a record of my reflections in the form of a reflective journal. I reflected after every lesson I had with SEC PE classes. However, I also reflected about my professional practice more generally and kept records regarding in-service courses I attended during the first two years of conducting this research. Writing in my journal was a systematic process throughout the 30 months of research.

I reflected upon most situations in which I was engaged. What I learned from this analysis of lived experience was then used to inform my practice; and so, new learning was emerging continuously. In a sense therefore, my experience alimented my reflective process and my professional growth, but my professional growth was also affecting my practice. Hence, my practice and professional development moved forward in a symbiotic relationship.

A similar process took place with the use of wider educational literature. Through analysing my practice, I pinpointed issues which I needed to learn more about, and professional literature was a useful source of knowledge. This literature acted as food for thought and impacted upon my professional practice and the way I viewed and analysed that practice. The new understandings that emerged from a combination of professional practice, analysis of experience, and the acquisition of ideas from relevant professional literature, affected my future searches for academic literature. 
After engaging myself in reflective practice for 30 months, I analysed my journal entries using grounded theory analysis with a constructivist perspective (Charmaz, 2000). The important point I want to make at this point is that I automatically continued to reflect during and after the data analysis process. The same happened while writing. Reflection had indeed become a professional habit.

\subsection{Writing Up the Findings}

Through undertaking grounded theory analysis, I constructed a number of themes and categories. Although all the learning that took place throughout the study is important for me as a teacher/researcher, it is not physically possible due to word limitations, to represent all my findings in the final write-up. Thus, recalling the research question, I will present my findings in five sub-themes within the overarching theme of critical reflection as a strategy to help teachers 'learn how to learn'. The sub-themes will constitute the 5 chapters where my findings are presented (chapters 3-7). As published research literature has been an integral part of the reflective process throughout this study, it will be written up in the way it was used. Thus, wider literature is presented within the themes to illustrate how it informed the reflective process. The five chapters are as follows:

\section{Aspects of Reflective Practice}

In this chapter, data on experiential learning are presented and discussed. As the title of the chapter suggests, workplace learning is analysed by the practitioner through reflective practice. It is reflection that gave me the opportunity to make the most of my experiences. But the main aim here is to take the reader through my reflective process. This will include important aspects such as keeping a reflective journal, conversing with oneself, and the importance of continuously questioning my learning. This is what I call 'a reflective odyssey'. This means that 'we view teaching and learning problematically, that we question it, look into it systematically and continuously strive to learn from it' (Ghaye \& Ghaye, 1998: p.17). Issues covered will also include how 
writing helps the practitioner in reflective practice, for example by allowing a space for conversation with oneself, through creating a space for questioning professional practices and beliefs, and in organising and comprehending our thoughts and knowledge.

\section{Learning about the Self through Reflective Self-Study}

Through the process of reflective practice, one inevitably engages in self-study. In this particular research I have found myself learning new things about myself, my beliefs, my assumptions, and my actions. However, this learning was not solely concentrated on my professional life. Although targeted at my professional life, reflection affected my private life too.

I also argue for and illustrate in this chapter the enormous scope of reflective practice. Before engaging in reflective practice, I tended to analyse relatively few professional (or personal) experiences and so a lot of learning was lost. I was not even capable of realising that certain issues needed attention and it could be argued that I had a 'blinkered perspective'. Reflective practice however, helped me understand that the first step towards professional learning is to analyse experience from multiple viewpoints. This helped to broaden my perspective on practice, yet perhaps the effect was still limited because no matter how much I observe, analyse, reflect, and write about my experiences, it is impossible to observe and reflect upon all aspects of everyday life in teaching.

\section{Moving Through Rough Roads}

As the title itself implies, personal professional development through reflective practice is not always a straightforward process. One of the main assumptions I made at the start of this study was that by reflecting upon lived experiences of professional practice, I would be able to find answers to my professional challenges and problems. Yet, I found this was not always the case. In fact, from my experience, I would argue that the reflective practitioner rarely finds quick and simple answers. Indeed, through a continuous process of reflection, new problems and issues emerge. Thus, on a number 
of occasions, the number of questions asked and problems perceived outweighed the answers and solutions found. This also led to heightened feelings of needing to make changes to practice and, as is commonly reported change to professional practice is rarely a simple process (Cockrell, K., Placier, Burgoyne, Welch \& Cockrell, D., 2002; Day, 2000; Clarke \& Hollingsworth, 2002; Lockford, 2002; Stringer, 1996; Freedman, 2001; WestEd, 2000).

\section{Continuous and Relevant Professional Development}

At this stage I compare, through my own experience, two types of professional development. These two types of professional development are formal professional development and personal professional development. Formal professional development consists of organised courses that teachers undertake with the aim of improving professional practice. Personal professional development, on the other hand, is a continuous process of learning that is determined by the learner him/herself. I aim to show the reader how a continuous form of professional development that is initiated, planned, and undertaken by the practitioner in professional settings can be desirable and useful. Several methods of workplace learning are analysed at this stage. Thus, I aim to study how personal professional knowledge is acquired and used by a teacher and how this is linked to the context in which the teacher works since 'the optimisation of the outcomes of a process is facilitated by the understanding of that process' (Clarke \& Hollingsworth, 2002: p.947).

\section{Ways of Enhancing Professional Learning}

This research project was based on learning through actually engaging myself in what I am studying. Ironically however, I learned about the importance of professional collaboration through the lack of it. I realised that when reflective practice is individual, many possibilities for new learning are lost, since colleagues' viewpoints and reflections can give further insights. I tried to combat this by using educational literature and research. In a sense, my reflective journal, my research supervisor, together with educational literature, were my much needed critical friends. I learnt much from the continuous use of literature and my findings led me to search around 
particular issues in the literature. This literature then helped me to gain new insights that affected my thoughts and understandings. These new understandings then made me look for other issues; thus, research literature played an important part in my study.

This chapter will also illustrate the ways in which I attempted to bridge the much vaunted theory-practice gap (Cole \& Knowles, 1993; Basile, Olson \& NathensonMejía, 2003; Bartels, 2003; Cobb, 2002; Korthagen \& Kessels, 1999; McNamara, 2002; Cochran-Smith \& Lytle, 2001; DeMulder \& Rigsby, 2003; Stringer, 1996; Ross, 1990; Winch, 2004; Schön, 1983, 1987; Tillema, 2004; Craft, 1996; Weiss \& Weiss, 2001; Hiebert, Gallimore \& Stigler, 2002; Korthagen, 2001; Day, 1999; Campbell, 2000; Hashweh, 2004; Phillips, 1994; Laursen, 1994; Metz \& Page, 2002; Kroll, 2004). Indeed, I will argue that through the process of my reflective odyssey, the 'gap' became non-existent. This was something new for me as I had assumed, to this point, that theory and practice were worlds apart.

\subsection{Research Outcomes}

Ultimately, the objective of this study is to further knowledge about teachers and the ways in which they learn over time through learning about one teacher. The following five points are the aims and outcomes towards which this study is targeted.

1. Knowledge and understanding of how one teacher has learned through reflective practice;

2. An in-depth understanding and illustration of critical reflection on practice as a learning process;

3. Knowledge and understanding of the ways in which one teacher bridged the theory-practice gap by informing critical reflection on practice with wider reading;

4. An analysis of the way in which reflection might be used as an effective careerlong professional development strategy, and an illustrative case-study of the 
way in which methods used i.e. combining reflection, journal keeping, analysing day-to-day experience and narrative analysis, have helped in transforming a teacher into a teacher-researcher who learns from and through everyday professional practice.

5. Suggestions about the ways in which the findings could inform teacher education. 


\section{Chapter 2}

\section{Research Methodology}

This research has features of case-study, self-study, action research, and reflection, and all four aspects will be discussed in this chapter so that the methods used to understand my own professional development as a teacher can be identified.

\subsection{Choice of Method}

Research is done to shed light on a problem or on dimly lit territory. The research methodology used should be the one that offers most promise for greater understanding. Thus, only after defining the area of research should we move onto deciding about the methods of study; and not vice-versa (Mills, 1959; Feur, Towne \& Shavelson, 2002; Borko, 2004). After realising that I wanted to learn about teacher thinking, teacher learning, reflection, and professional development, qualitative research methods seemed to offer huge potential for greater understanding. What is important is that the suitability of any method depends on the kind of research question under investigation and so cannot be judged as appropriate or not if isolated from the actual inquiry (Wilson, 2003; Feur et al., 2002).

In this study I observe and study myself with the intent of understanding what happens when a teacher engages him/herself in 'reflection'. The methods I used to understand the thinking processes and meaning-construction of a teacher through self-study are best explained by the following description of autoethnography:

I start with my personal life. I pay attention to my physical feelings, thoughts, and emotions. I use what I call systematic sociological introspection and emotional recall to try and understand an experience I've lived through...By exploring a particular life, I hope to understand a way of life (Ellis \& Bochner, 2000: p.737). 
Schön (1983) and Ghaye \& Ghaye (1998) affirm that teachers who are reflective practitioners are in fact engaged in research. The process of reflection on teaching is mainly used in action research, for if 'reflection' is to be of any use, it must inform, give rise to possible solutions, and should lead to change and action. Reflective teaching is a cyclical or spiralling process, since by being reflective, teachers observe, question, analyse and make necessary changes to their practice (Pollard, 2002; Ghaye $\&$ Ghaye, 1998). Thus, reflection on past experience is used to analyse and understand lived experiences and this new and presumably better understanding should be applied to inform future practice (Renner, 2001; Ghaye \& Ghaye, 1998; Johnson, 2001). Hence, the outcomes of reflective practice should not be inert but indeed dynamic.

Throughout this study, I observed myself including my behaviour, my actions and my reactions, during SEC PE lessons. I took notice of what was happening around me and immediately wrote down my experience right after the lesson since it seems to be helpful to do so immediately (Mason, 2002; Ghaye \& Ghaye, 1998). These lessons were usually 2 to 3 periods long, each period lasting for 45 minutes. While writing down what I observed and noticed about myself, I also reflected on the events I was writing about, and these reflections were included into the accounts. As a matter of fact, writing emerged to be my most effective tool in recording events, reflecting upon these events, and planning future action. Thus, throughout the study, observation, data collection, analysis, interpretation, planning, and decisions about future directions of the study happened almost simultaneously in an intertwined process.

The word 'observation' itself implies that one is 'looking with a purpose' (Turner, 2001: p.51). When you observe and ponder over an event, you analyse what happened and are able to offer your own interpretations of what you observed. Thus, the data being collected through keen observation are immediately analysed by the observer, and this close interplay, particularly between data collection and data analysis is very important especially in qualitative research (Glaser \& Strauss, 1967; Agar, 1995; Yin, 2003; Freeman, 1994). A while after the study commenced, studying myself was not solely related to my professional sphere, but also started seeping into my private life. 
Consequently, data were not only gathered during the aforementioned SEC PE lessons, as will be evident in forthcoming chapters.

This chapter has the aim of providing sufficient information to enable the reader to judge the merits of the conduct of the study. It is also important to note that I consider this chapter as 'outcomes of learning', in the sense that I have learned about methods of inquiry throughout the study. I wanted to learn how a professional learns, and throughout the research process I had to make decisions on how best to learn as a professional teacher and how these methods could be fruitful for the teacher-researcher in his/her professional development. Methods were therefore not previously decided upon, but their use evolved in parallel with the progression of this study. Thus, most of what is reported below has emerged from the research process itself and depicts the results of studying reflective practice and its use for the professional development of teachers. As argued by Elliott (2005), 'chapters on the experiences of doing research... are instructive and provide helpful insights into the process of analysing and writing which are rarely found in methods texts' (p.168). In this sense, actually conducting research and learning from it, together with learning from my teaching experience are the twin foci of this study. According to Mills (1959), some social scientists 'go about their work in accordance with a rigid set of mechanical procedures; others seek to develop, to invite, and to use the sociological imagination' (p.20). In this study, I attempted to use sociological imagination. I would describe this as letting my questions and doubts talk to me, and then thinking of different ways and methods through which I can obtain information and data that help me answer my questions. Reading about other people's work and ideas, and reflecting upon their views serves the same function since it aliments my reflective practice.

\subsection{Reflection}

An essential consideration about learning from experience is the notion of reflection (Schön, 1983). Reflection is my main vehicle for analysing, understanding, and 
interpreting: but what is 'reflection'? As Loughran (2002a) confirms, a number of diverse definitions are given in the literature and it seems to me that no universally accepted definition exists as yet. I take this as no surprise since people think, reflect, and act in different ways, about different issues, and in different contexts. Put simply, reflection is intentionally inquiring and learning from one's own thoughts, actions and experiences (Mason, 2002; Loughran, 1996), and is thus assumed to provide 'a heightened awareness of the self, acting in the social worlds' (Elliott, 2005: p.153).

Actually, I do believe that most people are naturally reflective since, to a certain extent, almost everybody reflects upon experiences and situations encountered. Similarly, as Zeichner (1994) contends, 'all teachers are reflective in some sense. There is no such thing as an unreflective teacher' (p.18). Yet, this behaviour is not very common, except when it is deliberately used to study some phenomenon or problem (Stringer, 1996). This infrequent use of reflective practice is also evident in professional settings since as Adelman (1989) and Labaree (2003) note, professionals usually argue that they are too busy to reflect on what they do and on the consequences of their actions and decisions. Teachers are no different. Richert (1992) argues that time is 'a precious rare commodity for most teachers' (p.156). Hiebert et al. (2002) and Labaree (2003) point out that teachers do not always learn from their teaching experience not only because of lack of time but also due to the fact that it takes virtually all of their energy just to survive through their everyday practice; but nevertheless, all teachers learn from experience some of the time.

\subsubsection{Experience and Reflection: a symbiotic relationship}

Teacher knowledge is strongly built on individual experience (Verloop et al., 2001; Usher, 1998) and 'as educators we should acknowledge the authority of experience' (Parker, 1998: p.118). The only problem is that this learning is not systematic. Schön (1983) talks about how important it is for reflection to be ongoing, because according to Dewey (1938), teaching and learning are a continuous process of learning from experience. Adversely, people usually reflect on something that happens to them when something is out of the ordinary and is unexpected. When everything seems to be going 
well and the flow of life is considered as normal, there is usually 'no call for reflection' (Dewey, 1910: p.11). Almost half a century ago, Mills (1959) pointed out that:

You must not stop thinking too soon - or you will fail to know all that you should; you cannot leave it to go on forever, or you yourself will burst. It is this dilemma, I suppose, that makes reflection, on those rare occasions when it is more or less successful, the most passionate endeavour of which the human being is capable (p.223).

Yet, in professional circles, systematic reflection, rather than reflection on rare occasions is desirable for optimal learning to take place. As can be seen below, Dewey (1910) defines reflective thought as being systematic and persistent.

Active, persistent, and careful consideration of any belief or supposed form of knowledge in the light of the grounds that support it, and the further conclusions to which it tends, constitutes reflective thought (Dewey, 1910: p.6).

I agree with Dewey's definition and would add that reflection means analysing events, thoughts and emotions, with an emphasis on happenings experienced by yourself or another person. In fact, Dewey (1910) continues his argument by saying that what triggers reflection is personal experience that elicits 'some perplexity, confusion, or doubt' (p.12). Thus, experience itself is what gives us the impetus to reflect and reflection on experience is important since 'teachers' own experience as practitioners naturally emerges as their primary bank of professional knowledge' (Labaree, 2003: p.20).

Therefore, teaching and learning that is fuelled by reflection is evidence-based since experience is both the substance and outcome of reflective thinking (Ghaye \& Ghaye, 1998; Grimmett et al., 1990). Loughran (1996) cites Boud et al. (1985) when highlighting the importance of experience in reflective practice saying that:

Reflection is an important human activity in which people recapture their experience, think about it, mull it over and evaluate it. It is this working with experience that is important in learning (p.3). 


\subsubsection{Inviting the Reader into this Study}

I will now further clarify what I meant when saying that reflection means analysing events, thoughts and emotions, with an emphasis on happenings experienced by yourself or another person. Usually, a person reflects on something $s /$ he has experienced. Yet, it is also possible to reflect on someone else's experience (Meriläinen \& Syrjälä, 2001). Sometimes it is possible to link what you read, hear, or observe with your own experiences but even if this is not possible, you can still reflect on the issues experienced by someone else through descriptions available (Lockford, 2002). As Meriläinen \& Syrjälä (2001) argue, 'reading other people's stories, some of them very touching, is not just reading, but trying to understand and reflect the life of someone else' (p.9). And this is exactly my aim here. By offering some of my experiences throughout my writing, I hope to evoke memories of similar experiences in readers. After all, 'people do not even have to know each other for the social identification to take hold' (Richardson, 1995: p.214), and as Heikkinen (2001) observed, people often reflect on their own experiences that compare to the experiences just dealt with in a narrative. However, although the learning that results from such a human activity is important, it is usually undervalued. Talking about personal experience, Mason (2002) tells us that:

Whenever someone raised an issue or posed a question about the teaching and learning of mathematics, my natural response is to quietly interrogate my own experience. Where a matching experience is not easy to locate, I look for some situation or context which might be analogous. I then put myself through the experience... in order to gain some insight into the issue. This is no more than what everyone does naturally most of the time, but is often overlooked or suppressed in an attempt to conform with imagined standards of research objectivity (p.208).

Thus, I want to invite readers into the text and ask them to reflect about my or similar experiences. I don't want to use a type of formal academic writing where as the writer, I am positioned as the source, the observer, the knower and discoverer, while the audience is seen as a passive receiver of knowledge (Ellis \& Bochner, 2000; Gergen \& Gergen, 2002). Eco (1992) contends that interpretations are generated through negotiation between the reader and the author through the text. This does not mean, however, that readers will interpret the text I produce in the same way as I intended. 
Although researchers and authors try to convey their findings as accurately as possible, it is naïve to think that readers' and researchers' interpretations will correlate perfectly. This is why readers have a central role in such a study.

Assume that your intended meaning is circumscribed by a six-foot circle, in which you are standing; assume that the meaning understood by your reader is another such circle, in which he is standing. The circles, let us hope, do overlap. The extent of that overlap is the extent of your communication. In the reader's circle the part that does not overlap - that is one area of uncontrolled meaning: he has made it up. In your circle the part that does not overlap - that is another token of your failure: you have not got it across (Mills, 1959: p.220).

\subsubsection{Understanding Reflection through Reflective Inquiry}

How can I understand if and how reflection helps the practitioner? I aim to understand 'reflection' by engaging myself in 'reflection'. I learn about something by actually immersing myself and doing it (Griffiths \& Windle, 2002; LaBoskey, 1992) since as Kuhn (1995) argues, I do not have to be intellectually detached to learn about something. Experiencing something is very powerful since experience is the basis for understanding social life (Van Maanen, 1988), and reflection on these experiences is a unique process of better understanding what we encounter (Glaze, 2002; Van Manen, 1990; Feldman, 2002).

According to Mills (1959) information alone is not sufficient. We need something to assimilate information, and that something 'is a quality of mind that will help [us] use information and to develop reason' (p.5). I have interpreted Mills' words to mean that information alone is useless if we do not think about it and create knowledge from it. The same argument holds for experience. It is reflection on observations made and on experience itself that is essential if we are to learn from our own experiences (Loughran, 2002a; Dewey, 1938; Richert, 1992; Ghaye \& Ghaye, 1998). According to Posner (1996), although we learn a great deal from experience, much more learning is gained from reflecting on a particular experience than is derived from the experience itself, because as Mason (2002) argues, 'one thing we seem not to learn from experience is that we rarely learn from experience alone' (p.64). 
Through this study, I want to learn how educational practitioners learn through experience, but I have realised that to understand experiential learning, reflective practice, and how to reflect, I have to experience it. Reflection cannot be taught but learned through immersion. This discussion will be further elaborated in my findings.

\subsubsection{A Longitudinal Systematic Process}

Reflection-on-action is a retrospective view of experiences that develops a better understanding of a situation (Loughran, 1996). Therefore, this study is a longitudinal study aimed at making sense from experience since 'making sense is a retrospective process, requiring time' (Czarniawska, 2004: p.655) especially when studying a particular case (Shulman, 1992; Gomm, Hammersley \& Foster, 2000). Also, time is a necessary resource if I aim to understand, learn, and apply changes to my teaching because as Cockrell et al. (2002) stress, 'things can't just happen like magic. It takes a lot of time and effort to change things in a classroom' (p.45).

Although I started reflecting because I felt awkward and unprepared to tackle something that was out of the ordinary, I continued my professional practice by systematically observing, noticing, recording and reflecting upon day-to-day events, no matter how 'usual' these might have been. As Ghaye \& Ghaye (1998) assert, the reflective practitioner reflects on his/her daily experiences and not just 'on the extraordinary, the exceptional and the one-off' (p.16). When reflection and analysis are systematic, one studies experiences encountered in the daily flow of everyday life. 'This will record the days when not much happened of note, as well as those which seemed to "explode" with activity" (Pollard, 2002: p.49).

It is interesting, although not surprising to note that throughout the study not everything went according to plan, and most of the observations made forced me to question my own reflections and interpretations. However, even the most painful and/or unexpected situations were considered and analysed since I assumed that everything encountered in my everyday experiences could shape and give unintended directions to this study. According to Ellis \& Bochner (2000), the aim is to inspect and document "the moment- 
to-moment, concrete details of a life. That's an important way of knowing as well' (p.737). In any case, while observing and studying humans in a context, researchers cannot shield themselves from the enormous amount of data available to them through what they observe. The good observer notes down every possible detail, even what they think might be of little use, since some of the data become important at a later stage. Also, this allows the researcher to become aware of, and get a holistic picture of unanticipated phenomena (Becker, 1996). As such:

Accident and happenstance shapes fieldworkers' studies as much as planning or foresight; numbing routine as much as living theatre; impulse as much as rational choice; mistaken judgements as much as accurate ones. This may not be the way fieldwork is reported, but it is the way it is done (Van Maanen, 1988: p.2).

\subsubsection{Reflection is what Glues the Entire Process of Inquiry}

The following sections describe methodological processes I have used in this study. It is worth noting (as I hope to highlight) how reflection takes centre stage in each of these processes. As Ghaye \& Ghaye (1998) contend, 'reflection is like the glue that holds the research process together' (p.68). Processes like action research, self-study, and writing help highlight my own reflective thinking throughout the study. It is through these processes, explored hereunder, that I hope to understand as well as inform the reader about how I reflect, why I reflect, and the results of my reflections.

The main aim throughout this study is the quest for meaning as opposed to the search for fact or ultimate truth (Donmoyer, 1985, 2000; Stringer, 1996) since as Donmoyer (1985) argues, any study of reflective practice is about how the reflective practitioner makes sense of the phenomena experienced. Hence, this is a phenomenological study where the spotlight is on the formation and understanding of the subject's meanings (Erben, 1998). As Geertz (1973) highlighted, ' $m a n$ is an animal suspended in webs of significance he himself has spun' (p.5). This search for meaning is carried out through the process of reflecting and trying to understand and make sense of the phenomena experienced both inside and outside the classroom. 
The reflective practitioner discourse... suggests a qualitative, research-based response along the lines, say, of ethnography or action research. Such approaches will focus not on measuring success by outcome... but on exploring the nature of the teaching and learning processes that are taking place (Moore, 1999: p.143).

\subsection{Action Research}

Since in this study I am studying myself, my practice, and the inquiry is ongoing, I decided to use action research. After all, action research is characterised by ongoing inquiry that is self-reflective (Day, 1999). Action research provides 'conditions for continuing action' (Stringer, 1996: p.xvi) and this proved to be valuable in a study where what was being studied was dynamic and continuously changing (Pollard, 2002). After all, anything that has to do with the social world is ever-changing and surely not static and/or mechanistic, and as Stringer (1996) points out, action research is particularly adept at studying social phenomena so conceived. Also, our understandings of social phenomena continuously shift because of the meanings we give to the contexts in which we live, and action research is all about learning from experience and is at the end of the day a search for meaning. As Stringer (1996) comments:

The reiterative nature of action research soon becomes apparent. Where people struggle to implement activities derived from a fixed vision/version of their world, they will soon be confronted by the dynamic realities of the context. To the extent that they can construct and reconstruct their vision, taking into account the increased understanding that comes from each reiteration of the process, so they will successfully negotiate the complex web of meanings, interactions, and discourses that compose social life (p.112)

\subsubsection{Action Research is Closely Linked to Practice}

I personally believe that as professionals, teachers should inform their practice through existing research, while also conducting their own research. Yet, current literature is replete with instances that show that traditional formal research does not have the desired impact when applied to practice since this type of research seems to be unrelated and thus irrelevant to the struggles practitioners face in their everyday 
practice (Stringer, 1996; Labaree, 2003; Ghaye \& Ghaye, 1998; Hiebert et al., 2002). This is exactly what I felt prior to commencing this study and I thus opted to use a research strategy that seemed to offer promise to better understand and improve my practice. According to Stringer (1996), action research is presented as a promising research method that links processes of inquiry to the lived lives of individuals as they come to grips with the problems and tensions that inundate them in their daily lives.

The integrity of what is referred to by Adelman (1989) as the practical ethic professions of which teaching forms part, comes from practitioner reflection upon consequences of known practices and thus reflection on lived experience. The freedom to recommend and try alternative options for action is also an important part of professionalism so conceived. Adelman (1989) continues by saying that action research is the way forward for implementing this reflective process. 'It can be the methodology of enquiry for the practical ethic professions' (p.176). It is often assumed and expected that professionals will apply and draw from traditional scientific knowledge and research to provide answers and solve problems that confront people and their lives (Stringer, 1996). Although this might be valuable, professionals must never forget the individuality of every person and every context; and this is why I believe that action research is valuable, especially for the practical ethic professions. This feeling appears to be shared by other practitioners who feel that action research as a form of personal inquiry is right for them (Guba, 1996). After all:

[Action research] rejects the mindless application of standardised practices across all settings and contexts, and instead advocates the use of contextually relevant procedures formulated by inquiring and resourceful practitioners (Stringer, 1996: p.3).

However, although the initial purpose of action research, self-study and personal reflection is to help the practitioner in understanding and solving the problems $s / h e$ faces, the results of such studies are not solely applicable to the immediate practitioner. Such studies can, and should inform the wider community. Hence, although data originate from the single case, such inquiry may provide insights to the wider 
professional community and be the basis for theorising and knowledge construction (Stringer, 1996).

\subsubsection{Action Research and Reflection: an inevitable partnership}

The fact that as a teacher I was engaged in reflective practice and self-study made the use of action research almost inevitable. On reflecting about my practice, I realised that I was unintentionally involving myself in action research. Several authors (e.g. McNiff, 1993; Anderson, Herr \& Nihlen, 1994; Pollard, 2002; Kincheloe, 1991; Stringer, 1996) highlight the relationship between action research and professional inquiry being carried out by the practitioners themselves. Leask (2001) goes as far as saying that 'action research is a term used to describe reflective practice' (p.278). After all, as Pollard (2002) argues, 'the conception of a classroom-based, reflexive process stems from the teacher-based, action-research movement' (p.15). This allows practitioners to manage their own learning.

All our actions have consequences which can be monitored and analysed. This analysis and the comparison of actual and predicted outcomes constitute a reflective process out of which emerge further options for future actions (Smith \& Geoffrey, 1968). It could be argued therefore, that action research is a budding genre in the field of educational research that encourages an increasingly analytical approach to teaching among teachers themselves, resulting in the creation of more informed personal practical theories (Mills, 2002; Stringer \& Guba, 1999; Labaree, 2003).

All the above cited authors argue that reflection, self-study and action research are intimately related. This interrelationship is further evidenced by Carr \& Kemmis where they define action research as:

A form of self-reflective enquiry undertaken by participants in social situations in order to improve the rationality and justice of their own practice, their understanding of these practices, and the situations in which the practices are carried out... In terms of method, a self-reflective spiral of cycles of planning, acting, observing and reflecting is central to the action research approach (cited in, Ghaye \& Ghaye, 1998: p.65). 
Although the reflective practitioner is inevitably involved in action research, this is not to say that observing, writing down your observations and being reflective is the only way of conducting action research. Actually, it is just one way of carrying it out. In fact, Ghaye \& Ghaye (1998) contend that 'there is no definite and correct way of doing action research. The same can be said of reflecting-on-practice' (p.67). Nevertheless, I believe that reflection upon data gathered is an important aspect of action research.

\subsubsection{Action Research has both Practical and Theoretical Outcomes}

Action research does not solely have practical outcomes. As Stringer (1996) argues, action research 'is designed to encourage an approach to research that potentially has both practical and theoretical outcomes, but does so in ways that provide conditions for continuing action' (p.xvi). Thus, I feel that it offers promise for inquiring into professional practice; especially teaching practice.

I will now apply Stringer's (1996) basic action research routine to illustrate the research process I went through while studying myself.

Look - $\quad$ Gathering of information by observing and noticing.

- $\quad$ Building the picture and describing the situation. This is done by writing my experiences into my journal.

Think - Explore and analyse. This is done by reflecting upon the lived situation.

- Interpret and explain. In this part I theorise and also try to elaborate possibilities for a better future for teacher learning.

Act - In this part of the research process I reflect on the direction my study will take. I plan future observations and on what I ought to focus upon in order to obtain a better understanding. I also implement actions I decided to take and evaluate them. It is at this point that the cycle restarts.

The above description clearly illustrates that observing, collecting data, analysing, interpreting, planning, deciding and evaluating, happened almost simultaneously, and 
not in distinct stages. Yet, the above description is still too tidy to depict what the researcher actually goes through during action research:

As experience will show, action research is not a neat, orderly activity that allows participants to proceed step by step to the end of the process. People will find themselves working backward through the routines, repeating processes, revising procedures, rethinking interpretations, leapfrogging steps or stages, and sometimes making radical changes in direction (Stringer, 1996: p.17).

In action research, one can rarely put step-by-step models into application because in action research, and certainly in the inquiry process used in this study, 'steps' do not have clear boundaries.

\section{$2.4 \quad$ Case-Study}

Action research is inevitably linked to case-study research since action research is often conducted to improve practice by gathering information, analysing, and acting in one particular case. The case-study at the heart of this research is one particular practitioner in the educational field studying himself and his actions while teaching over a period of 30 months. Through this study, I also study, analyse, and reflect about reflection which is the main vehicle for conducting this research but is also the main item under inquiry. Studying the case I was part of has afforded me a unique opportunity since I was able to comprehend the viewpoint of someone inside the social phenomenon being studied rather than studying it as an outsider (Yin, 2003). As a result, the research process has had tangible impacts on my learning, both about my teaching and about the contexts in which I operate. This is of value because 'human behaviour is rarely, if ever, contextfree' (Guba, 1981: p.78). As such, I agree with Shulman's (1992) argument that cases can reveal the working of human minds, including motives, beliefs, emotions, and misconceptions. This is especially true when they are 'first-person accounts, i.e. reports written by someone who is reporting her own experiences, activities, and interpretations' (Husu \& Tirri, 2003: p.350). These, in conjunction with reflective methods also help teachers in gaining: 
Rudimentary knowledge about educational theory and practice to facilitate their survival... and acquire the tools and attitudes that will allow them to grow as professionals (LaBoskey, 1992: p.176).

\subsubsection{Teaching as a Holistic Activity}

Teaching is a combination of an infinite number of variables; but these variables have little significance for practitioners if taken separately. Separating features of teaching in order to learn about them is not the way forward for teacher development since 'it is the interaction among the features of teaching, not their effects in isolation, that give teaching its meaning and character' (Hiebert et al., 2002: p.8). As a teacher, I agree with Fenstermacher's (1994) contention that teachers see teaching situations as a whole. On the other hand, researchers are often accused of making distinctions between a number of features of teaching and treating them as variables, while studying them in isolation (Hiebert et al., 2002; Brophy \& Good, 1986; Becker, 1996). As Doyle (1990) contends, this fragmented view can result in a devaluing of the complexity of teaching. Case-studies however, have the potential of studying complex social phenomena as a whole and thus preserving the holistic and evocative characteristics of real-life events (Yin, 2003). Goode \& Hatt confirm this by arguing that the case-study approach 'is an approach which views any social unit as a whole' (cited in Mitchell, 2000: p.169). Furthermore, Shulman (1992) argues that:

Cases integrate what otherwise remains separated. Content and process, thought and feeling, teaching and learning are not addressed theoretically as distinct constructs. They occur simultaneously as they do in real life, posing problems, issues, and challenges for new teachers that their knowledge and experience can be used to discern (p.28).

This is also confirmed by Stake (2000) and it is the reason why I wanted to study one particular case. Case-study aims to investigate an existing problem within its real-life context, and this makes it grounded in the particular (Yin, 2003). After all, problems in real-life 'do not present themselves in neatly wrapped packages' (LaBoskey, 1992: p.177). 


\subsubsection{Context in Case-Study Research}

Linked to a belief in the holistic nature of teaching is Guba's (1996) argument for decentralisation... 'a movement away from efforts to uncover generalisable "truths" toward a new emphasis on local context' (p.ix). As Labaree (2003) points out, it is problematic to make 'claims that can be extended beyond the particulars of time, place, and person' (p.14) due to the conditions of great complexity found in social systems. Further, Shulman (1992) argues that the details given of the particular context together with the verisimilitude offered by cases serves as a powerful answer to the search for simplistic overgeneralisations. As Wolcott (1995) suggests when speaking in favour of richly contextualised case-studies, 'reporting four diverse ways... does not give us four times as much insight; rather, it raises the question of why we need to know any of this' (p.85-86). For this specific study, I wanted to understand the particulars; the details that are part and parcel of my daily work; and the thought processes one particular teacher undergoes when reflecting about teaching. I believe that by studying and writing about aspects of teacher thinking, self-study, and reflection, I will help readers understand better what goes on as the practitioner develops professionally while engaging in the above methods of study.

There is a strong body of research literature to suggest that macro theories are of little inspiration and of little practical use in the immediacy of the teacher's workplace (Labaree, 2003; Ghaye \& Ghaye, 1998; Stringer, 1996; Hiebert et al., 2002; Carter, 1993; Elliott, 2005). The following comment by Ghaye \& Ghaye (1998), suggests why teachers might refute generalisable research and general theories:

If you think that research is only about the search for generalisations you may also believe that what is being said applies to all contexts of practice. But what happens when you find that, having put your confidence in this research, the research does not fit, does not work, does not help to explain your practice with your own children? (p.56)

I have personally encountered such a situation (especially in my first year of teaching). When faced by this situation I tended to abandon the search for knowledge to be derived from educational research. Thus I agree with Lincoln \& Guba's (2000) 
assertion that for teachers, no overarching generalisations are possible in view of the fact that 'there are always differences in context from situation to situation, and even the single situation differs over time' (p.39). As put forward by Parker (1998) and Usher \& Edwards (1994), teachers are concerned about individual human beings, and thus, 'even statistically significant findings from studies with huge, randomly selected samples cannot be applied directly to particular individuals in particular situations' (Donmoyer, 2000: p.51). Hence, 'the trouble with generalisations is that they don't apply to particulars' (Lincoln \& Guba, 2000: p.27). As such:

For practitioners concerned with individuals, not aggregates, research can never be generalisable... Research can only function as a heuristic; it can suggest possibilities but never dictate action. It may well be the case that case study research can fulfil this function as well, or possibly even better, than more traditional approaches to research (Donmoyer, 2000: p.51).

\subsubsection{Generalisability in Qualitative Research}

Almost two centuries have passed since William Blake argued that 'to generalise is to be an idiot. To particularise is the lone distinction of merit. General knowledges are those that idiots possess' (cited in, Stake, 2000: p.22). On the other hand, case-studies have a lot to offer to readers. As Wolcott (1995) recalls his experience, he writes these words:

For all the concern about method, always a major preoccupation among educational researchers, it may be of interest to note that I was never pressed for the content of what I expected to find, only for the generalisability of my findings: 'What can we learn from a study of just one principle?' (It took two decades for me to recognise the obvious answer: All we can!) (p.107).

Lincoln \& Guba (2000) point out that generalisations are creations of the human mind. They are not found in nature but are constructed by our understandings of the world. We must also pay attention when conducting a case-study not to be naïve and assume that what we experience in one situation is representative of other people's experiences in similar and/or different situations (Gomm et al., 2000). When keeping in mind the argument put forward by Cronbach (1982) that human action and behaviour is not caused but constructed, it is foolish to expect generalisations that resemble those in 
physical sciences. The urge to generalise as Labaree (2003) calls it, should not be the case with teaching, or with any other area that deals with human action and behaviour since we are all unique and any professional and/or study should not assume otherwise (Mason, 2002). Concerning this particular study about teacher knowledge, teacher thinking, and teacher learning, I would like to use the argument put forward by Verloop et al. (2001):

Those who had hoped that, on the basis of a couple of large-scale general investigations into teacher cognition, we would find the holy grail, that is, the essence of teacher knowledge in the general sense, will be disappointed (p.456).

But how can we transfer knowledge and understanding from one situation to another? In Elliott's (2005) words, 'it would clearly be pointless to do research if findings were considered to be completely ungeneralizable' (p.26). However, Stake (2000) and Mitchell (2000) argue that case-studies can also have a generalising effect since they may be epistemologically coherent with the reader's experience and hence, a natural basis for generalisation for the reader. This is not generalisation in the traditional sense. Stake (2000) calls it naturalistic generalisation and this type of generalisation stems from personal experience. Czarniawska (2004), Elliott (2005) and Ellis \& Bochner (2000) suggest that this generalising effect is an operation best determined by the reader and not by the writer. Mitchell (2000) argues that the type of generalisation that occurs from single-case-studies to similar situations is based on logical inference by readers, rather than statistical inference. On the same line of thought, Elliott (2005) argues that:

Qualitative research therefore often adopts what we might call a 'common-sense' view of generalisability such that the reader is left to make up his or her own mind as to how far the evidence collected in a specific study can be transferred to offer information about the same topic in similar settings (p.26).

Therefore, this particular case-study together with the stories I write, can help me in realizing my aim of evoking memories of similar experiences in readers and encouraging them to reflect on their as well as my experiences. Conle (1996, 2000, 2003) calls this type of evoking memories of similar experiences as resonance, and 'this constant evocation of prior knowledge through assimilation contributes to 
vicarious experience' (Conle, 2003: p.12). This, in my opinion, is a very important component of self-study research, because it is through resonance that self-study research diffuses its findings. After reflecting, the reader is free to accept or reject my interpretations because vicarious experience has the potential to prompt further stories and interpretations from the reader (Connelly \& Clandinin, 1990; Conle, 2000). In fact, Bullough \& Pinnegar (2001) argue that 'the aim of self-study research is to provoke, challenge, and illuminate rather than confirm and settle' (p.20), because through this process 'the reader experiences or re-experiences and better understands' (p.16) and it is in this way that my research can be significant and important to others besides myself (Freeman, 1993). Also, Elliott (2005) argues that when analysing the individual case, we can come to deeper understandings of social groups because 'individual stories and personal documents can potentially take us beyond the individual to an appreciation of that individual in society' (p.10). Hence, studies focusing on single cases should not be merely viewed as a closed entity.

This is why I emphasise strongly the need for readers to be critically engaged. Readers should keep in mind the possibility of multiple meanings and interpretations; and this relinquishing of control as an author is desirable if I value and want to promote debate and discussion in the educational field (Gergen \& Gergen, 2002; Barone, 1995). In short, I aim to:

Provoke readers to broaden their horizons, reflect critically on their own experience, enter empathically into worlds of experience different from their own, and actively engage in dialogue regarding the social and moral implications of the different perspectives and standpoints encountered. Invited to take the story in and use it for themselves, readers become co-performers... (Ellis \& Bochner, 2000: p.748).

\subsubsection{Cases as Magnifying Glasses}

Another important reason why I opted to study the particular rather than the general is the fact that there is the need to make the everyday, problematic, lived experience of people facing problems in their real settings, directly available to policy makers (Denzin, 1989b). It can be argued that many policy makers simply do not experience the real contexts in which practitioners work on a daily basis. Thus, a well planned 
case-study can offer policy makers information about particular problems while also giving abundant information about the particular contexts in which these problems are found. Thus, studying the particular can serve as a magnifying glass (Brouwer \& Korthagen, 2005) since studying a case in-depth can offer greater and more specific detail of the particular (Becker, 2000).

Of importance is the fact that before one acts, understanding of the issue concerned is required. Keeping a similar logic, Elmore \& McLaughlin (1988) state that lack of indepth knowledge of teachers and educational practices has turned educational reform into an ineffective effort. Apart from that, successful school reform has been very difficult to replicate across contexts (Berliner, 2002). This is because a general picture of education is incomplete if we do not also understand the particular. As Erben (1998) contends, studying cases and individual lives can give us information that is unavailable in quantitative research and 'this individuality... allows us to deepen our knowledge of the surrounding social context' (p.14). Case-studies are important if teachers, teacher educators, policy makers and education authorities are to understand what actually happens in classrooms. By studying the particular case, I aim to show the reader the life of a teacher engaged in continuing professional development. As Ellis \& Bochner (2000) explicitly point out, the concrete details of what happens in one case, for example in one particular person's life, are very important. This type of knowledge can only be gained through studies that focus on the specific case. As a matter of fact, Shulman (1992) argues that 'the very fact that cases portray real people actually doing something in classrooms in ways that yield real consequences makes them valuable for future (and present) teachers' (p.7). In short, cases are situated. 'They are embedded in contexts of application and emotion, of place and time' (Shulman, 1992: p.23).

\subsubsection{Case-Study Approach for the Teacher-Researcher}

In my case, i.e. being a teacher-researcher, the case-study approach has given me the possibility to collect and analyse data, and decide on future actions within the context of teaching itself (action research). It has also given me the possibility to reflect on what is going on around me (reflection) and to study and understand my thoughts and 
actions, i.e. myself (self-study). Shulman (1992) states that case materials may include observer notes, journals and diaries, and these have indeed been an essential part of my research process.

I would also argue that case-study and reflective practice are also linked due to the fact that those conducting case-study research are provoked 'to reflect on their practice and to become more analytic about their work' (Shulman, 1992: p.9). Thus, case-study investigations seem to help teachers 'to think reflectively and to develop a long-term inquiry orientation toward their teaching' (LaBoskey, 1992: p.178) which is, after all, the main philosophy behind reflective practice. Through case-study, the teacher may look at any area of interest and explore it as broadly and deeply as possible (LaBoskey, 1992), while specific issues can emerge later, as the investigation proceeds. This is exactly what happened in this particular study.

Hence, single-case-studies may be considerably more valuable than has conventionally been believed (Donmoyer, 2000) and the main benefits of case-study research are briefly but vividly depicted by the following words:

From an epistemological perspective, cases may be more congruent with the forms of practical knowledge that undergird the varieties of practice, in teaching and other fields. From a professional perspective, cases may have more immediate credibility and relevance (Shulman, 1992: p.21).

\subsubsection{Case-Study Research is Closer to Readers' and Practitioners' Lived Experiences}

I firmly believe that researchers should communicate with their readers through the text, in a way that is easy and accommodating, while building on the readers' present understandings. Since as Stake (2000) argues, most teachers 'have arrived at their understandings mostly through direct and vicarious experience' (p.19), I think that a case-study where personal experience is analysed has the power to inform by talking the language of teachers (Gomm et al., 2000). Reporting experience and the 
interpretations that arise from it can be more down-to-earth for teachers than are other forms of research that omit experience and context. Therefore:

One of the more effective means of adding to understanding for all readers will be by approximating, through the words and illustrations of our reports, the natural experiences acquired in ordinary personal involvement (Stake, 2000: p.19).

In summary, for maximal understanding to occur, we should communicate and provide necessary information to readers in the mode in which they typically experience it themselves (Lincoln \& Guba, 2000). For practitioners, the context, the situation, and the actor/s are all very important to understanding life in a classroom, and hence, such features cannot be omitted in case-studies (Mitchell, 2000).

\subsection{Self-Study}

Since the main aim throughout this study is to understand how I develop as a reflective practitioner, the inquiry inevitably leads me to study myself. Also, any reflective practitioner is involved in self-study since one inevitably reflects about the self. When analysing the term 'reflection' it implies that we look at and analyse ourselves just as we look at ourselves in a reflected image in a mirror. The postmodern notion that the self is dynamic, thus constantly changing and shifting rather than being unified and unchanging leads to 'new possibilities for qualitative research to focus on the everyday practices by which individuals constantly construct and reconstruct their sense of individual identity' (Elliott, 2005: p. 124). As stressed by Brouwer \& Korthagen (2005), it is those who are engaged in learning who can provide the personal and private information needed to understand the conditions and the processes of that learning. Thus, self-study offers me the potential to explain the process through which I learn, i.e. the reflective process. After all, my main aim is not to understand what I learn, but how I learn. 


\subsubsection{Developing Professionally through Self-Study Research}

Self-study is also a journey of personal and professional development since selfknowledge should be part of our own ongoing learning (Bullough \& Pinnegar, 2001; Mullen, 1994). Bass et al. (2002) and Ghaye \& Ghaye (1998) report participants' experiences with self-study and reflection as a unique way of learning about the self and about one's practice. In Bass et al.'s (2002) words, through self-study, 'I now see myself as a researcher and I am learning all the time' (p.59). It is important to take into consideration the words 'I am learning all the time'. If we assume that self-study promotes learning, and we 'accept that the self is... continually re-newed and reinvented' (Usher, 1998: p.27), then it is no surprise that through self-study opportunities to learn are ever-present.

Being one type of case-study, self-study research generates knowledge that is personal, particular, and context-specific (Hamilton \& LaBoskey, 2002). As Bullough \& Pinnegar (2001) argue, self-studies do not take contexts for granted since the self does not operate in a social vacuum. Actually, nothing is taken-for-granted since the researcher questions and analyses his/her experiences, knowledge, interpretations and established truths. It is the meaning-making that arises from my interpretations, and the analysis of this meaning-making process that positions this study as a self-study (Schuck, 2002). As often suggested (e.g. Fitzgerald, East, Heston \& Miller, 2002; Guðjónsdóttir \& Dalmau, 2002), I engaged in self-study because outcomes were expected that would improve professional practice. As argued by Bullough \& Pinnegar (2001), self-study researchers have the obligation to improve personal learning not only for the self but also for the others involved since 'we expect to find evidence of honestly engaging issues we recognise as central to teaching and teacher education' (p.17). However, self-study allows the inquirer to be both personal and professional since this approach helps in integrating the personal and the professional selves (Bass et al., 2002: p.63). 


\subsubsection{Opting for Self-Study Research: why?}

Bullough \& Pinnegar's (2001) words provide a useful starting point in defining the nature of self-study research:

Self-study as an area of research... is in its infancy. Its endurability as a movement is grounded in the trustworthiness and meaningfulness of the findings both for informing practice to improve... and also for moving the research conversation... forward. Like other forms of research, self-study invites the reader into the research process by asking that interpretations be checked, that themes be critically scrutinised, and that the 'so what' question be vigorously pressed. In self-studies, conclusions are hard won, elusive, are generally more tentative than not (p.20).

Self-study has given me a unique opportunity since it 'seems to be ideally suited to revealing experience-based learning and in tracking the development of the self as learner' (Usher, 1998: p.18). Although I can observe other teachers during professional practice, and although I can ask them what they think about various situations and the meanings they give to these situations, I can never have full access to their thinking process, to their interpretations and to how these are formed. As Mason (2002) argues, as a self-study researcher I am able to pay attention to things that are not directly observable to researchers observing teachers in classrooms. These include 'becoming aware of propensities and habits, judgements and emotions, swings of mood and shifts of attention, alterations in intention and desire, and so on' (p.223). This is because 'there is no clear window into the inner life of a person' (Denzin, 1989a: p.14).

When on the other hand researchers gather teachers' stories as data, the final interpretation of the teachers' stories is carried out by the researcher and not the teachers themselves. Denzin (1993) as well as Becker (1996) argue that behind the attempt to capture teachers' experiences and emotions in their texts, is the social researcher doing the interpreting. It is also argued that such an interpretation by 'the other' can be quite different to what was originally meant by the participant (Denzin, 1989a). But through self-study, my interpretations are original. By this I mean that if I had to write about another teacher's interpretations, I would obviously add a layer of my own interpretations and thus, the reader would be getting the researcher's interpretations of the teacher's interpretations. As such, if my account as a researcher 
'is taken as the authoritative interpretation of an[other] individual's experience, the individual's own understanding of their experience inevitably is compromised' (Smythe \& Murray, 2000: p.321). This would raise 'central postmodernist problems about the researcher's authorship and privilege' (Richardson, 1995: p.215).

When a practitioner interprets a situation, $\mathrm{s} / \mathrm{he}$ has an amount of prior knowledge that stems out from previous engagement in that particular context; but the researcher usually does not have this contextually useful knowledge. As such:

Members... have resources for interpretation that are not readily available to the researchers. This creates a dilemma for which interviews, documents, and supplemental observations provide only partial remedy (Little, 2002: p.921).

As both Eisenhart (2001) and Becker (1996) argue, trying to get to the point of view of 'others' is a vital standard of acceptable social science. Yet, Van Maanen (1988) and Becker (1996) contend that this grasp of the point of view of 'the other', although better than not trying at all, is still far from perfectly accurate. As Conle (2003) states: 'there always are constraints of course, for the teaching story is lived by [the teacher], while it is manipulated by me' (p.9). But through self-study, every experience can be interpreted and understood by the practitioner/researcher in relation to past experiences and past understandings. As Little (2002) argues, 'what any given individual learns of classroom practice, collaboration with colleagues, or being a teacher cannot be determined from [a] single episode' (p.932). Thus, in order to get to a deep understanding of how a teacher learns, we must understand every single chunk of experience in relation to that teacher's life history. Self-study has the potential to achieve this.

Schwandt (2000) refers to Wilhelm Dilthey's work when making the claim that every human action has a meaning and in order to understand the action, we must struggle to get to the subjective thoughts and meanings, as well as the purposes of the actor from the inside. This can be done not by talking about underlying attributes, universal forces, ultimate truths and objective observables but by getting to perceptions and 
understandings that come by immersing oneself in the phenomenon under study (Stake, 2000). Similarly, Polkinghorne (1995) contends that:

The researcher needs to concentrate on the choices and actions of this central person. To understand the person, we must grasp the person's meanings and understandings; the agent's vision of the world; and his or her plans, purposes, motivations, and interests. Attention to the inner struggles, emotional states, and valuing of the protagonist provides important data (p.17).

Kelchtermans (1994) feels that biographical approaches are appropriate here as they 'reveal subjective realities, ideas, feelings, experiences' (p.102). Understanding the personal is valuable in educational research as this helps us learn about how experiences affect teachers, their thinking, and their work, and understanding teacher knowledge can therefore be useful in the attempt to improve teacher education (Verloop et al., 2001; Grimmett et al., 1990). After all:

What distinguishes human (social) action from the movement of physical objects is that the former is inherently meaningful. Thus, to understand a particular social action... the inquirer must grasp the meanings that constitute that action (Schwandt, 2000: p.191).

However, Van Maanen (1988) highlights how difficult it is for an outsider to get to an individual's subjective thoughts and meanings accurately:

I know full well that the understanding I have of their talk and action is not only incomplete, but rests fundamentally on the contextual matters that surround my coming together with particular people, at particular times, for particular purposes, in particular places, and so on...Field data are constructed from talk and action. They are then interpretations of other interpretations (p.95).

Reading these words makes me ask one question: What might be better than self-study to achieve the above? After all, qualitative methods insist that if we are to understand people's everyday actions, reasons and the meanings they give to situations encountered, then we should only attribute to them the ideas they hold, and not impose our views upon theirs (Becker, 1996). Hence, why not opt for self-study research? 'Rich response sampling' according to Miles \& Huberman (1994) is a way of choosing one or more subjects for a study that promise to provide the richest and most 
explanatory data, and studying the self for this particular study seems to offer such rich and deep explanatory information. It is also important to realise that:

There is no longer a tenable position which affords the text one writes about another higher status than the text one writes about oneself. There is no longer some hierarchy where the former has greater objectivity (Parker, 1998: p.116).

This is not to say that including teachers as the other in educational research is a negative move. Far from it, educational research that gives little value to what teachers and students say, feel, and think, is bound to have limited value since the voices of the main actors in education would be omitted (Eisenhart, 2001). Yet, most of the tacit knowledge and assumptions teachers hold, as well as hidden teacher learning, are insufficiently apparent in research efforts to date (Verloop et al., 2001; Day, 1999), because:

Much of the research that has been conducted under the label of research on teacher thinking has focused on merely describing, in a supposedly neutral way, teachers' reflections about their practice (Zeichner, 1994: p.19).

A very useful aspect of self-study research is that it gives me the opportunity to be ever-present, whereas Gomm et al. (2000) argue that whilst studying the actions of others, during 'the period of data collection, the researcher cannot be everywhere at once' (p.110), and as a result, cases rely 'on observations that took place at a number of sampling points, rather than on continuous observation over a lengthy period' (p.109). This is not the case for self-study though. Through self-study, I learn with and about myself, I reflect with/about myself, I eat with myself and I sleep with myself. What is of most importance though is that I think with/about myself. I know exactly what I'm thinking all of the time. Thus, 30 months of self-study are equivalent to over 21,000 hours of observation, analysis, reflection, and monitored thinking. In a sense, this is almost like reality TV! Therefore, being ever-present is made possible by self-study research.

Finally, I agree with Erben's (1998) statement that subjects chosen for qualitative research 'cannot be ascertained through quantitative methods... [and] the consciously 
chosen sample must correspond to the overall aims of the study' (p.5). In this particular study, studying the self promised further understanding when compared to studying other teachers due to the above mentioned reasons.

\subsubsection{Reflection and Self-Study: complementing each other}

It is interesting to refer to the work of Grimmett et al. (1990) and the ways in which they link self-study and reflection in what is referred to as 'self-reflection'. This 'selfreflection' is very similar to the aims of this particular study.

As an ontological phenomenon, self-reflection is concerned with ways of being in the world. It is concerned with the nature of being human and how we come to understand our own existence. Human beings acquire an understanding of themselves through self-reflection, and it is only through life that one can understand life. In using the concepts of self-reflection as a life philosophy and selfreflection as a methodology... [is] to gain insights into the action of teachers, not only as educators but also as adults who share a lived reality with children. To be self-reflective in this sense is to be attentive to the relationship between theory and action (pp.29-30).

Referring to Oberg's work, Grimmett et al. (1990) report that reflection upon the self serves a number of functions. First of all reflection serves to analyse the practitioner's professional practice and actions. Secondly, it helps to analyse the meanings the practitioner him/herself associates with these abovementioned professional actions. Also, by analysing the meaning-making process, the practitioner is able to unravel any underlying assumptions, and thus be able to reanalyse and reconsider his/her actions in light of new understandings that emerge from self-study through reflection. In Schuck's (2002) words: 'it is this emphasis as researcher on my meaning-making of my practice that locates this study as a self-study' (p.329).

Reflection is central to self-study. When we reflect, we are committed to internalise the disposition and skills to study ourselves (Zeichner \& Liston, 1996). Vice-versa, when studying the self, one inevitably ends up reflecting. As argued by Bass et al. (2002) and Hamilton (2002) the self-study process makes me, and keeps me reflecting. Reflection is an important tool to understand ourselves better and it is thus no surprise that reflection is prominent in this particular self-study. I agree with Zeichner's (1994) 
contention that self-study 'must start from reflection upon one's own experience' (p.10).

\subsubsection{Is Self-Study Purely about the Personal?}

According to Bullough \& Pinnegar (2001), self-study research of high quality should engage and be significant to the reader. It should also motivate the reader to reflect and imagine possible futures, have compelling questions and down-to-earth solutions, as well as go beyond the purely personal. As pointed out by Dalmau, Hamilton \& Bodone (2002) self-studies are:

Not simply about telling the world what we have done - they are about facilitating dialogue, creativity, and scholarship... Authors, readers, and participants will have learned something new, reframed issues in their own practice, and developed new questions (p.60).

Thus, self-study should aim at offering understanding of social phenomena through the understanding of the self, and production of valuable insider knowledge about teaching and learning (Bass et al., 2002; Schuck, 2002), and according to Brighouse (2003), 'understanding a discipline from the inside requires participating in it as a practitioner' (p.130).

However, as Zeichner (1994) argues, when a teacher studies him/herself, the focus is not only inwardly at the self, but also outwardly at social conditions that affect the behaviour of the self. After all, every human being living in a society is affected, albeit differently, by the same society in which s/he lives. According to Bullough \& Pinnegar (2001):

It is the balance between the way in which private experience can provide insight and solution for public issues and troubles and the way in which public theory can provide insight and solution for private trial that forms the nexus of self-study and simultaneously presents the central challenge to those who would work in this emerging area (p.15).

Thus, self-study seems to be the answer to Mills' (1959) warning when pointing out that: 
Many personal troubles cannot be solved merely as troubles, but must be understood in terms of public issues... Know that the human meaning of public issues must be revealed by relating them to personal troubles - and to the problems of the individual life. Know that the problems of social science, when adequately formulated, must include both troubles and issues... Within that range the sociological imagination has its chance to make a difference in the quality of human life in our time (p.226).

Whatever we do is influenced by social forces (Stanley, 1993; Usher, 1998; Bochner \& Ellis, 1996; Pollard, 2002; Mills, 1959), and according to Erben (1998) any attempt to separate human action from societal influences 'is to do methodological and symbolic violence to the understanding of lives' (p.13). However, while needing to understand the individual against a societal backdrop, we can certainly use the learning and understanding gained from the study of individual life to better understand wider societal issues. This is because "neither the life of an individual nor... society can be understood without understanding both' (Mills, 1959: p.3).

Although personal knowledge is indeed important, public knowledge is also vital in self-study research. Although, the self-study researcher has pre-conceived assumptions which the study aims to analyse, and although s/he learns through analysis of lived experiences, research articles written by colleagues in the field of social research have a lot to offer to the self-study researcher. Through these sources of knowledge, new insights and ideas might become available. As such, through new understandings, further understandings arise. Another interesting factor is that although the study positions itself as a reflective self-study, most of what emerged from this research project was so in tune with the work of others found in the professional literature, that I constantly felt that my findings were being confirmed by other professionals in the field, and this gave me a greater conviction that this self-study is not only about myself but is connected to societal aspects that go beyond the self. Although educational literature was used in this study to offer further insights and improve possibilities for learning, it has indirectly contributed in comparing and relating my experience against the experiences of a wider community (Mason, 2002). 
Finally, I want to use Fernandes' (2002) words to show why I believe self-study and reflective practice are such powerful tools. 'There is so much to learn from self-studywe ourselves are virtually untapped resources for the future!' (p.75).

\subsection{The Construction of Meaning}

Postmodernists have for long questioned 'reality' in social life. Pallas (2001) for example, puts forward the following questions: 'Is there a single, absolute truth about educational phenomena, or are there multiple truths?...Is knowledge of the world discovered, or constructed?' (p.6).

Van Maanen (1988) argues that 'no longer is the social world... to be taken for granted as merely out there full of neutral, objective, observable facts' (p.93). Instead, Van Maanen (1988) continues, the social world is a human construction. After all, any researcher, especially those engaged in social research will offer interpretations and explanations that originate from their own lived experiences (Stringer, 1996). Also, any social researcher must keep in mind that all people hold assumptions and that different people interpret social phenomena differently. Different interpretations by different people for the same social phenomenon is evident in everyday life. If it wasn't, quarrels, hot arguments, fighting, and wars would be almost inexistent in our world. There is an ancient Maltese saying that states that a hundred people will view one situation in a hundred different ways. Similarly, Stringer (1996) argues that:

The aim of inquiry is not to establish the 'truth' or to describe what 'really' is happening, but to reveal the different truths and realities - constructions - held... Even people who have the same 'facts' or information will interpret them differently according to their own experiences, worldviews, and cultural backgrounds (p.41).

In short, people will account differently due to diverse perspectives of viewing a situation (Wolcott, 1995; Stringer, 1996; Mason, 2002; Elliott, 2005). As Charmaz (2000) argues, these multiple interpretations arise from the fact that knowledge and 
meaning are created by individual human beings. This leads to social realities becoming multiple in nature.

Constructivism alludes to the fact that human beings construct and create knowledge. Knowledge is not somewhere out there to be discovered (Schwandt, 2000; Parker, 1997; Ghaye \& Ghaye, 1998; Young, 1992; Elliott, 2005; Burr, 1995; Pallas, 2001; Pidgeon \& Henwood, 2004; Wolcott, 1995). 'The world, in other words, is not a singular, self-consistent reality but a multiplicity of incommensurable realities' (Parker, 1997: p.117). Also, such constructed knowledge is continuously modified in light of new experiences. Schwandt (2000) contends that human beings are all constructivists if we believe that the human mind is continuously constructing knowledge. In such a line of thought, reflective thinking is irreducibly constructivist since it involves the creation and manipulation of meanings; it is a nonlinear learning process, and a method that helps in understanding problems from the viewpoint of the person undergoing reflective thought (Johnson, 2001; Taggart \& Wilson, 1998).

\subsubsection{Reflection Vs Technical-Rationality}

If we use Schön's (1983) distinction between reflection and technical-rationality, we can see that the former embraces postmodernism while the latter embraces the philosophy of positivism (Parker, 1997). Consequently, the teacher who bases his/her practice on technical-rationality accepts knowledge that is only obtained and discovered through the impartial, investigational, objective and inductive activities of science (Parker, 1997). Such a teacher would probably give higher status to knowledge so conceived and might also dismiss the value of personal knowledge:

In this modern, positivist world the law-like generalisations of science form the foundations of any claims to expertise. The expert becomes one who has grasp of a certain set of law-like generalisations with which to inform and justify his or her decisions (Parker, 1997: p.10).

In such a world, it is objectivity and the world's independence from human meanings that permits teachers to use law-like generalisations to guide their practice. But, according to Parker (1997), such claims are an illusion; a mythology which was useful 
for the evolutionary process of the human being, his creation and his thoughts. In realising that positivism and realism in social science is a mythology, social scientists 'will come to see ways of life, styles of being human, as a matter of choice rather than discovery' (p.150).

The notion of philosophical realism is that 'the objects of sensory perception or of cognition are real in their own right and exist independently of the mind' (Beach, 2001: p.319). This philosophy appears unworkable to me in my role as a teacher, and only recently has this positivist assumption been seriously challenged (Agar, 1995; Gusfield, 1976; Richardson, 1995; Denzin, 1997; Shusterman, 1991; Schwandt, 2000). Anybody who has a basic experience of teaching knows that the abovementioned positivist claims are an illusion (Stringer, 1996; Labaree, 2003; Ghaye \& Ghaye, 1998; Hiebert et al., 2002).

Like Schön (1983), I do believe that the teacher should not act technically by merely putting into practice what is formulated and defined by others outside the classroom context. On the contrary, teachers should learn from their own experiences through reflection and this learning should shape future practice. Hence, it is no surprise that this inquiry into teacher thinking, teacher learning and teacher reflection utilises postmodern techniques in the quest to gain a better understanding of the aforementioned. Using Van Maanen et al.'s words, in this study, 'meanings rather than frequencies assume paramount significance' (cited in, Wolcott, 1995: p.101), because in teaching, no truth exists except the truth we have assigned to our world. In teaching, the meanings and understandings that guide us are not found but created by us and we need to learn about these meanings and understandings by using methods that capitalise upon the natural tendency of human beings to experience and understand experience. In Fuller, Hodkinson, H., Hodkinson, P. \& Unwin's (2005) words, there is:

A growing interest... in theorising the meaning and processes of learning... This has entailed a move away from the concerns of traditional learning theorists who had conceptualised the learner as a receptacle of (taught) knowledge, and learning as a discrete cognitive process that largely ignored its meaning in the 'lived-in world' (p.50). 
This is what this study aims to provide readers with: lived experiences, the meanings of these experiences to the individual, and the possibility for the reader to be engaged with, re-live, and reflect upon these experiences.

\subsubsection{The Ability to Observe and Notice}

Self-study and reflection require the person conducting research to observe and notice. If the researcher fails to notice, then there is little that could be reflected upon, and as a result, little opportunity to gain understanding of the self. The sensitivity and the ability to notice salient moments in our lived lives:

Is not needed in a world of absolutes in which there are facts to be objectively identified and tested by anyone at any time. But noticing makes a great deal of sense in a world in which what matters is sensitive participation moment by moment in a situation which may have some aspects of generality, but which is specific in many of its details. This is characteristic of caring professions generally, and of education in particular (Mason, 2002: p.187).

Mason (2002) continues the above argument by stating that in the objective world of physical science, claims can be verified as true or rejected as false through laboratory experiments. Such a world is surely less appropriate when applied to the human sciences (Mason, 2002; Schwandt, 2000), because 'something which works today in one situation may not work tomorrow in another, and what works for me, may not work for someone else' (Mason, 2002: p.189). Consequently, Bullough \& Pinnegar (2001) argue that human beings cannot be studied as subjects who are 'atemporal (outside of time), determinant (predictable), or static (unchanging)' (p.13). Thus, in Cronbach's (1975) words, it is important to remember that:

Propositions describing atoms and electrons have a long half-life, and the physical theorist can regard the processes in his world as steady. Rarely is a social or behavioural phenomenon isolated enough to have this steady-state property (cited in, Lincoln \& Guba, 2000: p.32). 


\section{$\underline{2.7 \quad \text { Interpretation }}$}

It has been argued that we are constantly interpreting our surroundings and experiences (Turner, 2001). Trying to understand is not an isolated human activity but a way of figuring out our life experiences. Also, 'understanding is not...a procedure- or rulegoverned undertaking; rather, it is a very condition of being human. Understanding is interpretation' (Schwandt, 2000: p.194). This also applies to social research, since researchers try to understand and make sense from available information. Consequently, Wolcott (1995) alerts us to:

Remain ever mindful...that data never speak to anyone, not even the most intuitive of researchers. Whatever sense is to be made is made because some human observer attempts to make that sense (pp.97-98).

\subsubsection{My Interpretations throughout this Particular Study}

In Peshkin's (2000) words, 'I have been engaged in the process of interpretation from the very beginning of my research process' ( $p .9)$. But what is interpretation, especially in the context of this particular study? Again, Peshkin's (2000) words help me in answering this question:

Interpretation is an act of imagination and logic. It entails perceiving importance, order, and form in what one is learning that relates to the argument, story, narrative that is continually undergoing creation (p.9).

Yet, I have experienced different levels of interpretation. There are interpretations that seem obvious; there are interpretations that emerge spontaneously from unquestioned beliefs, and are as such accepted as true; there are interpretations that stem out from a careful analysis of what I experience; and there are interpretations that change due to a careful analysis of previously constructed interpretations. I am not trying to give a typology of interpretations here. All I want is to make a distinction, so that I can explain these different interpretations as I have experienced and undertaken them. 
The first two types of interpretations identified are what I commonly use in everyday life. Some interpretations seem obvious. If for example I see a person who is smiling and/or laughing, my obvious interpretation would be that the person is enjoying $\mathrm{him} / \mathrm{h}$ erself. There are also interpretations that stem out spontaneously from unquestioned beliefs, and are as such accepted as true. Let us take a student who is quiet in class. As a teacher I used to assume that by being quiet, a student was paying attention. This is an unquestioned belief. Thus, following this line of reasoning, according to the teacher's interpretation a quiet student is a good student. However, as LaBoskey (1992) warns, 'because these views are, in the main, personal and nonanalytical, many are inaccurate' (p.176). These interpretations that emerge from prior non-analytical beliefs and knowledge will then in turn act as filters for interpreting new situations encountered (Putnam \& Borko, 1997; Pajares, 1992).

The two other types of interpretations mentioned above involve an attentive analysis of what I observe in my everyday life. These are interpretations that emerge from a careful analysis of what we experience and are very important in reflective self-study since fieldnotes gathered through observation offer 'data' that are not meaningful without the researcher's analysis and consequent interpretation (Pollard, 2002). Through reflection, interpretations were constructed from a careful analysis of experiences, as opposed to spontaneously creating these meanings without actually questioning them. This careful analysis is what distinguishes the reflective practitioner from the non-reflective person. But the process does not stop here. The reflective practitioner must not accept his/her interpretations and understandings of the self as ultimate truth, but must always allow these newly formed interpretations to be replaced by other, more plausible interpretations in the future. Here, as Bohman contends, 'a better interpretation could come along, encompassing the strengths and overcoming the weaknesses of previous interpretations' (cited in, Schwandt, 2000: p.202). 


\subsubsection{No Interpretation should be seen as Infallible and/or Fixed}

From the fact that we always see... everything through interpretation, we must conclude that everything in fact is constituted by interpretation. From the fact that knowledge is perspectival and contextual... it is impossible to distinguish any particular interpretation as more correct, or better or worse, than any other (Schwandt, 2000: p.201).

Believing in, but also doubting your own interpretations that stem from lived experience is important in reflective self-study. Through reflection, learning is ongoing and therefore, no prior interpretation should be taken-for-granted. As such, Ghaye \& Ghaye (1998) argue that we should continuously look back and re-analyse our own taken-for-granted assumptions, professional understandings and interpretations. This is why I believe that there are also interpretations that change due to a careful re-analysis of pre-existing interpretations, and thus, new perspectives are continuously acquired that enhance our old understandings (Meriläinen \& Syrjälä, 2001). The same argument holds for present understandings, since future experiences and their interpretation will change the viewpoint I hold today (Fottland, 2004). Clandinin \& Connelly's (1995) metaphor of 'landscape' describes the professional knowledge held by teachers since a landscape changes and evolves over time. This is how teacher knowledge should be, i.e. dynamic, and it is new interpretations through reflective self-study that keeps professional landscapes changing (Ghaye \& Ghaye, 1998). According to Hayes (2001), 'if research is viewed as an opportunity for learning... changes of perception and understanding... should be welcomed rather than regretted' (p.28).

One must pay attention therefore, not to expect and accept researchers' interpretations to be real; to be the ultimate truth. Blumenfeld-Jones (1995) argues that when reading articles and research reports in the social sciences, we 'often mistake interpretation for fact' (p.27). It is surely a mistaken assumption to view meanings created from personal experiences as 'transparent, masterable and univocal' (Usher, 1998: p.19) and existing 'independently of our lives, our minds and our social and cultural practices' (Parker, 1997: p.21) because 'it is the meaning of our experiences, not the underlying ontological structure of objects, that constitutes the reality we respond to' (Oliver, 1998: p.247). Consequently, we must all acknowledge that there can be no ultimate 
solutions for educational problems; no final answers to teachers' questions; and ultimately, no correct interpretation exists (LaBoskey, 1992; Schwandt, 2000) Consequently, searching for accurate representations of reality is meaningless (Atkinson \& Hammersley, 1998). Instead, educationalists should evaluate research accounts for the insights they have to offer. As Peshkin (2000) and Denzin (1989a) suggest, the real value of interpretations is how useful such interpretations can be in eliciting interest in readers, and thus fuelling debate in the educational field.

Buchmann \& Schwille (1983), Charmaz (2000) and Newman \& Holzman (1997) argue that the meaning-making process is a process that does not have to deal with one or two possible meanings but with a multitude of possible meanings. According to Loughran (1996): 'the more deliberately a teacher considers his or her actions the more difficult it is to be sure that there is one right approach to teaching' (p.3). This happens because the more we analyse and reflect upon our practice, the more possibilities we become aware of. Hence, as a teacher-researcher, I have to acknowledge that my understandings are partial and dynamic; surely not static.

\subsubsection{The Importance of Personal Interpretation}

According to Erben (1998), the bulk of the time in qualitative inquiry is used to interpret data, and this is exactly what happened in this study. Simply reproducing my observations in writing would not have taken up too much time, but writing down my observations and simultaneously interpreting my lived experiences took up much of my time. This was also the case with the final analysis of my journal entries. I do agree with Ghaye \& Ghaye's (1998) statement that 'there is no virtue in trying to describe and fully regurgitate what has happened. The idea is to set out the teaching incident and then to interrogate it through... reflection' (p.86), if learning is to occur. Underlying this philosophy is the fact that in postmodernity 'research on teaching changed from studying teacher behaviour into studying teacher cognitions and beliefs underlying that behaviour' (Verloop et al., 2001: p.442). 
I have come to view the relationship between interpretation/meaning-making and reflective thought as a symbiotic relationship. Interpretation is essential for reflective practice to continue. After all, the reflective practitioner is looking for meanings, understandings and interpretations. Yet, the reflective process helps the person involved to get to more informed interpretations and better understandings through the careful analysis of available information. But if interpretation is personal, then it is irreducibly subjective. Well, I see nothing wrong in that. On the contrary, I think that it is a positive thing; for if self-study researchers and teachers engaging in reflective practice are to understand themselves, their professional practice, their learning, and the contexts in which they find themselves, the interpretation has to be personal. Ellis \& Bochner (2000) ask 'whether we should express our vulnerability and subjectivity openly in the text or hide them behind social analysis' (p.747). Apart from helping both the researcher and the reader to understand the issue under study better, openly stating our vulnerability and subjectivity is a way of keeping us at arm's length from the temptation of speaking in an omnipotent voice. Oliver (1998) asserts that 'any claim of detachment or objectivity by the researcher is a barrier to quality' (p.254) and Koch (1996), Munhall (1994), Glaze (2002) and Gergen \& Gergen (2002) challenge the standpoint of possibly having a neutral and detached observer while arguing that subjectivity should not be seen as a negative attribute. As Van Maanen (1988) highlights, contrary to realist versions of research reports, 'the soft subjectivity of the fieldwork experience... incompleteness, blind spots, and various other obscurities are admitted' (p.91) into confessional writings such as this reflective self-study. Through my research experience I have realised that getting rid of subjectivity, while interpreting a lived situation, is impossible. 'On the contrary, understanding requires the engagement of one's biases' (Schwandt, 2000:p.195).

\subsection{Writing as a Tool for Understanding}

A tool like writing in the form of keeping a personal reflective journal can assist reflection. Writing down your reflections systematically 'helps turn reflection into a 
more coherent and revisitable educational experience' (Johnson, 2001: p.56). This is exactly what I did throughout this study. My reflective journal helped not only record my experiences but was actually the main tool that helped me reflect on my everyday experiences. 'Writing' literally fuelled my thinking.

As regards keeping a journal, Mills (1959) argues that it 'is intellectual production. It is a continually growing store of facts and ideas, from the most vague to the most finished' (pp.199-200). Here the emphasis lies on learning from experience, and thus, on learning and improving professional practice (Ghaye \& Ghaye, 1998; Moore, 1999; Johnson, 2001).

When writing about the self, 'the purpose... is to narrate an edited version of one's life which focuses especially upon articulation and explanation of what it means to each individual to learn' (Parker, 1998: p.118). I experienced journal writing as a unique way of recording observations, as assistance to reflective thought, and as playing an important role in the construction of meanings and interpretations. Also, the act of writing itself prompted me towards ongoing reflection. Similar to a teacher in Zembylas' (2004) study '[I] was constantly engaged in self-reflection - through writing in [my] journal (p.197).

I must also point out that my reflective journal was divided into three sections, these being: 'lesson observations' that included my reflections about experiences with SEC PE classes; my reflections about formal professional development as experienced by myself comprised 'in-service observations'; while 'personal diary' included all other reflections about professional practice that were not directly related to immediate observations regarding the other two sections of my journal.

\subsubsection{Writing Narratives: the primary vehicle that aided my reflections and my thinking}

I have personally realised that the best tool at my disposal to help me reflect on my experiences is narrative writing. As Mason (2002) points out, 'so many authors who 
promote reflection also promote writing as a means of personal development' (p.19). Elliott (2005) points out that 'narrative is... frequently accompanied by a more reflexive methodology' (p.152). It is not simply a way of communicating but a means of creating knowledge through enhanced questioning and more focused thinking (Johnson, 2001; Richardson, 2002; Chetcuti, 2002; Phillips \& Pugh, 2000). In this study, writing emerged 'as a tool for critical enquiry' (Kemp, 2001: p.350), and like Hoover (1994), I felt that writing about an issue helped me understand that issue better. The written accounts were a very important record that permitted me to revisit my thoughts, beliefs, emotions, meaning-making and interpretations in later stages of the research process. Mason (2002) argues that if we want to learn from experience, writing narratives is an effective way of 'digesting experience' (p.62). As such, reflective journal writing gives us the space and time to look back, re-live and re-experience, and reflect upon our daily lives (Ghaye \& Ghaye, 1998). After all, as Mills (1959) contends, simply telling or writing about an experienced event often invites you to describe and explain it.

'A writer communicates his or her subjective understanding of the world via a text' (Czarniawska, 2004: p.663). Writing is one way, if not the primary way of understanding and communicating meanings and interpretations because the language we use helps us think and also share our thoughts with others (Donmoyer, 2000; Oliver, 1998; Emihovich, 1995). Narratives are a natural way through which people do not solely report experience, but engage in the pursuit of constructing meanings that are attached to those experiences (Elliott, 2005). In Phillips' (1994) words:

One reason human activities are meaningful is that they can be seen in narrative terms - we make our own actions, and the actions of our fellows, meaningful by presenting a descriptive narrative (p.15).

Eisenhart (2001) argues that postmodernism sets a challenge of how we can best represent the meaningful worlds that are continuously being created in everyday life. Elliott (2005) argues that: 
There is a long humanist tradition within sociology which stresses the importance of attempting to understand the meaning of behaviour and experiences from the perspective of the individual involved... Narrative... provides a form of communication in which an individual can externalise his or her feelings and indicate which elements of those experiences are most significant (p.4).

Whatever memories I hold are in the form of a story and whenever I recount something that has happened, I do so by engaging myself in a narrative. In short, human beings understand and make sense of their own and other people's lives with the language used in stories and narratives (Polkinghorne, 1988, 1995; Richardson, 1995; Freeman, 1994; Connelly \& Clandinin, 1999; Blumenfeld-Jones, 1995; Clandinin \& Connelly, 2000; Parker, 1997; Phillips, 1994; Conle, 2000; Bruner, J., 1986, 1990; Shulman, 1992; Mullen, 1994; Ghaye \& Ghaye, 1998; Carter, 1993; Johnson, 2003; Czarniawska, 2004; Erben, 1998). According to Oliver (1998):

Because people give meaning to their lives through the stories they tell, it seems appropriate for those who study human experience to use a research methodology that connects with how people construct the meanings of life experiences (p.244).

Let us keep in mind that story and narrative are found everywhere, have been used by practically every culture and have been present throughout human history. Story and narrative have been used to help people make sense out of lived experience and to preserve human knowledge, meaning and interpretations for future generations (Richardson, 1995; Emihovich, 1995). Any particular case in the study of humans is perceived as 'a narrative, a story, a set of events that unfolds over time in a particular place' (Shulman, 1992: p.21) and writing narratives to capture the entirety of my experience was instinctive to me. I find Hardy's words to be very powerful in showing how important narratives are for humans since 'we dream in narrative, day-dream in narrative, remember, anticipate, hope, despair, believe, doubt, plan, revise, criticise, construct, gossip, learn and love by narrative' (cited in, Erben, 1998: p.15), and thus, the study of experience, according to Clandinin \& Connelly (2000), is best carried out through narrative writing. 


\subsubsection{First-Order Narratives in Self-Study Research: a way of promoting self- understanding}

My narratives are what Carr (1997) calls first-order narratives where the author writes about his/her own experiences, as opposed to second-order narratives where the author writes about the experiences of others. Like Meriläinen \& Syrjälä (2001), I perceive writing narratives about myself to have a very close link to reflective practice and selfstudy.

I believe that while writing about my experiences and reflecting on them, I was engaged in a form of constructivism. While writing, I construct meanings, interpretations, new knowledge and understandings. I also test and modify constructions in light of new experiences and new writings (Schwandt, 2000). Thus, writing about personal experiences is desirable and also useful 'in enriching and enlightening further personal experience' (Noddings, 1994: p.358). I explain this by arguing that through reflection and writing, I entered into a conversation with myself and with the text; a sort of internal dialogue (Glaze, 2002; Schön, 1983; Ellis \& Bochner, 2000; Smith, 1999; Ghaye \& Ghaye, 1998; Pollard, 2002; Kelchtermans, 1994; Charmaz, 2000). Personally, I have experienced this internal dialogue where researcher and teacher were constantly conversing. This is also reported by Conle (2000) where she says that 'the roles of researchers and subjects interacted in complex ways as researchers/teachers studied their own practices' (p.54). Like any other conversation, nobody can exactly predict which issues will be tackled and which arguments will be brought forward in such an internal dialogue; and it is this unpredictability that prompted me to keep my reflective stance. As Martin et al. contend:

The main interest in life and work is to become someone else you were not in the beginning. If you knew when you began a book what you would say at the end, do you think you would have the courage to write it? (cited in, Ball, 1990: p.1).

Hence, as Meriläinen \& Syrjälä (2001) point out, writing can thus be regarded as a means that helps our thinking progress, if not a means of thinking in and by itself. As Ellis \& Bochner, (2000) state: 
The stories we write put us into conversation with ourselves as well as with our. readers. In conversation with ourselves, we expose our vulnerabilities, conflicts, choices, and values. We take measure of our uncertainties, our mixed emotions, and the multiple layers of our experience... The text is used, then, as an agent of selfunderstanding (p.748).

\subsubsection{The Text: a way of capturing the complexity of teaching and the} teacher's ongoing development?

Journal writing is also promoted as an excellent way of being able to observe personal learning from experience as well as tracking one's own professional development (Pierson, 1998; Usher, 1998; Golombek \& Johnson, 2004). The self is ever-changing because it is constantly being developed; and narrative, according to Elliott (2005) is a good way of capturing this constant state of change into a written text. In short, the compilation of a reflective journal was an effective way of keeping a record of my thoughts, emotions, frames of mind, and experiences that could be returned to for further learning and understanding (Glaze, 2002; Moore, 1999). However, whereas I agree that journal writing helped in keeping a record of various stages of my own learning, it would be too simplistic to say that through journal writing I was able to observe my own learning, due to the fact that a lot of learning is tacit. Journal writing can indeed help the writer by bringing such tacit learning nearer the surface, but I still believe that not all is visible and observable by the learner him/herself since 'at any moment I think I am wide awake to what is happening, but inevitably there are aspects and details which completely escape me' (Mason, 2002: p.66). Nevertheless, reflective writing offers promise since as a consequence 'tacit knowledge is no longer entirely tacit' (Donmoyer, 2000: p.57). This is because 'the very act of bringing these happenings into language imposes a higher level of order on them than they have in the flux of everyday experience' (Polkinghorne, 1995: p.16).

I would also point out that the main objectives I wanted to achieve through my writing were the same that Renner (2001) chose for his study. In his words:

Three aims drove my investigation. I wanted to enhance my own understanding as part of my personal/professional growth; assist others in understanding the 
intrapersonal aspects of professional development; and reach out to my readers, inviting them to read their own stories between the lines and begin to interrogate their own practice (p.1).

Writing also presents readers with the teacher's thoughts, why the teacher decided to act in certain ways, and his/her emotions. Little (2002) highlights this by talking about the experience of Lampert (2000) who decided to videotape her own teaching because she thought that video would capture the complexity of teaching more than writing would. She argued that such a way of capturing experience would be 'authentic because everything that is going on for the participants seems to be available to the viewer' (cited in, Little, 2002: p.933). However, she soon realised that 'once viewers started to comment on what they saw me doing on the tape, the video seemed to represent so little of what I knew was going on' (cited in, Little, 2002: p.933). Thus, I feel that writing is a tool that helps in capturing the experience in a holistic manner, rather than capturing solely what can be seen by the human eye. Thus, preserving my journal and including parts of it into the final write-up is a way of showing the reader how my thinking, my writing, and my reflections were being created and formed.

In order to describe my own professional development through reflective self-study, process rather than outcome assumes paramount importance. Thus, I need to make available to readers, the process of how experiences were recorded, reflected upon, and analysed, rather than simply showing what type of learning occurred. Like Ward \& McCotter (2004), throughout this study, I made a distinction between 'the process of learning as opposed to merely products of learning' (p.249). Therefore, although learning occurred throughout the research period, I aim to focus on how I learn rather than on what I learn. The importance I attach to process can be seen by the enormous number of times I have used this word; a stark contrast to the rarity of using the word outcome.

Yet, writing was not just highlighting my professional development but was a form of conscious personal and professional development in its own right (Conle, 2000; Meriläinen \& Syrjälä, 2001). This is further evidenced when Conle $(2000,2001)$ argues 
that narrative writing in practitioner research serves two functions. What is written serves as data for the research but the writing itself is the medium for the practitioner's professional development. Finally, I also agree with Ghaye \& Ghaye's (1998) argument that dating my journal entries has enhanced my opportunity to see how I developed professionally over a period of time; turning the journal into a valuable record of how I think, learn, change, and develop (Mullen, 1994; Ghaye \& Ghaye, 1998; Conle, 2000).

\subsubsection{Communicating My Interpretations through Narrative Writing: creating causal links}

A narrative should have an evaluative function; offering valuable information to the reader about how the author interprets and connects meanings to lived situations and experiences. This function is important for this study since I wanted to learn how a practitioner comes to acquire knowledge from experience. According to Elliott (2005):

The evaluative element is arguably what transforms a simple chronicle of events into a fully formed narrative... The evaluation demonstrates what meaning events have for the narrator and makes the point or purpose of the story clear to the audience. It is because the evaluative dimension of a narrative provides insight into how the narrator has chosen to interpret the events recounted that these evaluative elements can be of particular interest (p.43).

Elliott (2005) asserts that 'a narrative must add up to something; it is more than the sum of its parts' (p.48). The missing details are the interpretations and causations as perceived by the narrator. Thus, humans tend to experience a text as a whole rather than sentence by sentence (Richardson, 1995; Bruner, 1990). This connectedness and causation are what give significance and meaning to events, and this is closely linked to how we interpret our own and others' experiences (Richardson, 1995; Usher, 1998). As stated by White (1978), 'no given set of casually recorded historical events in themselves constitute a story; the most that they offer to a historian are story elements' (cited in, Parker, 1997: p.128). It is then the author of the narrative that 'looks for particular connections between events' (Richardson, 1995: p.201). A good example here is given by Elliott (2005) while referring to Forster's work. 
'The king died and then the queen died' is merely a 'chronicle', whereas 'The king died and then the queen died of grief' is a plot because it includes an explicit causal link between the two events in the sequence (p.7).

However, I feel the obligation to point out that causality in this study does not imply that a particular event is inevitably followed by another specific event in all situations. This goes against the notion that individuals create the meanings and the world they live in according to their past learning and lived experiences. Thus, what I imply here is that present events are dependent on previous events, and should be interpreted accordingly. Similarly, new learning, creation of meanings and interpretations should also be evaluated according to prior learning. In short:

If we are told that one event followed another this raises an expectation of causality in our minds, namely that the subsequent event was caused by the previous event. This is not to say that those events will invariably be linked in all situations, but rather that in a particular context (specified by the orientation of the narrative) later events can be read as dependent upon earlier ones (Elliott, 2005: p.11).

\subsubsection{My Experience with Journal Keeping: tiring but valuable}

Regarding the use of reflective journals in doctoral studies, Glaze (2002) points out that little has been written about this topic. Nevertheless, I would like to give a brief description to readers of what happened throughout this study as regards the keeping of my reflective journal, since this is a very important part of my study. When I first decided to keep a reflective journal, I had no idea how much work it entailed. Speaking about students using reflective journals while undergoing doctoral study Glaze (2002) argues that:

A constant theme is tiredness and the need for stamina. Learning takes place against a backdrop of endurance and time constraints with the student striving to juggle demands from the world of work and home life with study requirements. This is seen as a marathon process (p.153).

These words vividly depict what happened to me during the course of this research. I experienced periods of tiredness, frustration, and a lessened motivation due to accumulated tiredness, and this resonates with the argument that teachers are usually so busy that they have little time for their own reflective writing (Conle, 2000; Richert, 
1992; Mason, 2002); indeed making endurance an important aspect throughout the entire process.

I wanted to capture most of my reflections and lived experiences within my journal and thus, I was constantly returning to my computer to write about my reflections. When my computer was not handy, I simply became engulfed by chaotic thoughts that included various interpretations of an event and a number of questions that needed answering. Here, writing served an important function, as Mills (1959) suggested decades ago:

By keeping an adequate file and thus developing self-reflective habits, you learn how to keep your inner world awake. Whenever you feel strongly about events or ideas you must try not to let them pass from your mind, but instead to formulate them for your files... The file also helps you build up the habit of writing (p.197).

But if writing promotes reflection, and keeping a reflective journal builds up a habit of writing, then keeping such a journal also promotes a habit of being reflective; and this makes keeping a journal of great professional value. Also, human experience and human thought can be so complex, chaotic and disorganised at times, that writing narratives as entries into my reflective journal was an effective way of giving some order to my thoughts and reflections (Packwood \& Sikes, 1996; Bruner, J., 1986), since 'words serve the major vehicle of thought and are our best tools for sorting out and organising our worlds' (Meriläinen \& Syrjälä, 2001: p.2).

\section{$2.9 \quad$ Validity}

Validity is a contested concept in social science research based on the argument that one set of evaluations will not serve all forms of research. Becker (1996) argues that quantitative researchers consistently ask questions about reliability and validity, making these the yardstick of good work. Yet, for qualitative researchers the yardstick for good work is different. They are more likely to be concerned, for example, with whether data are based on close systematic observations or only on isolated indicators; whether the 
data include what was not anticipated at the origin of the study; and whether what is being studied is examined holistically or just a number of variables. In this sense, Garratt \& Hodkinson (1998) point out that the set of criteria chosen to evaluate a particular study should depend on the type of methods used in the study. Guba (1996) claims that 'research that might properly be called human inquiry would exhibit deregulation' (p.x). By the word deregulation Guba (1996) tends to claim that conventional methodological criteria used for validating research are meaningful only in studies that assume that there is an objective truth; a concrete and ultimate reality to be discovered. For the same reason Hayes (2001) agues that the conventional criterion of validity is problematic in qualitative research and should be instead understood as credibility and dependability:

The concept of validity can then be replaced by the extent to which the respondents' narratives are credible (whether they stand up to close scrutiny and provide believable accounts) and dependable (whether respondents are genuinely disclosing their feelings, beliefs, ideas, etc.) (p.25).

Contrary to the conventional criterion of validity in research that assumes an objective truth, this study assumes that no ultimate reality exists and every claim we make is dependent upon our subjectivity and our interpretations. Thus, in such a study, conventional understandings of validity appear to be inappropriate. According to Sparkes (2000), the argument that not all research fits nicely with traditional and conventional criteria used to judge social inquiry is especially true for research that uses the self as a source of data.

\subsubsection{Different Forms of Validity}

Of importance is the fact that claiming a reflective self-study research to be valid is not only the responsibility of the researcher, but also of readers as they engage themselves with the text. Also, a reader considers a study valid or not, depending on the purposes and expectations the reader him/herself has. When one analyses the term validity itself, a study where human beings are central is valid when it is useful for the field under study. Thus, when evaluating qualitative research, Sparkes (2002), Eisner (1991) and Richardson (2000) propose criteria such as a substantive contribution to our 
understanding of social life; the aesthetic merit and expression of complex realities; the impact of the study in challenging readers intellectually and emotionally; credibility, and authenticity of the lived experiences encountered in the text; as well as acknowledging the reflexivity and subjectivity of the researcher in the text produced.

Still, the above criteria should only be regarded as recommendations since readers should always be open to new and challenging research. However, readers (be they practitioners or other researchers) should not mistake this openness with uncritically accepting every study (Smith \& Deemer, 2000). As such:

The reader of such research must be willing to trust his or her own evaluation of the data presented, relying on the logic of the report rather than on a simplified formula that assigns specific weighting and specific directionality to each variable (Harry, Sturges \& Klingner, 2005: p.10).

\subsubsection{Understanding of Social Life}

I believe that this research offers insights into how teachers can learn through reflection on everyday lived experiences. Teacher learning is a phenomenon that needs further investigation and through this study, I aim to contribute by showing how a teacher reflects upon, learns from, constructs meaning, and interprets lived experiences. Through reflective self-study I recount the experiences of a teacher who is involved in daily teaching; in this way helping readers understand the social and professional life of a particular teacher. Yet, the reader should be the final arbiter in judging if this study contributes to his/her understanding of the social phenomenon under study, through his/her own subjectivities and biases that arise from his/her past and present experiences.

\subsubsection{Reflexivity, Authenticity, and Credibility}

As a reflective self-study, this research is inevitably a reflexive project, and it is an authentic representation of my experiences and how I interpret them. This is the forte of reflective self-studies, since the experience is not separated from the experiencing subject. Thus, I display my authentic self and how I develop professionally through 
systematically reflecting on lived experiences. So the questions are: Does my writing evoke credibility? Is the reader moved to reflexivity? Although my aim is to induce readers to reflect on my as well as their own experiences, I can never objectively claim that it does. I might be able to encourage all, some, or just a few readers to engage in reflective practice and thus, each and every individual reader has to judge for him/herself if I reach my objective.

The same argument holds true for credibility where 'the narrative is believable when it can be credited with conveying, convincingly, that the events occurred and were felt in ways the narrator is asserting' (Blumenfeld-Jones, 1995: p.25). In short, qualitative research is valid when the study seeks verisimilitude, and evokes a feeling in readers that what is described is lifelike, believable, authentic and possible (Ellis \& Bochner, 2000; Shulman, 1992; Blumenfeld-Jones, 1995; Ellis, 1995). If such feelings are evoked through my writing, then the reader judges the text as worthy of trust and $\mathrm{s} / \mathrm{he}$ can let him/herself be engaged with the text.

In self-study research, Bass et al. (2002) view the researcher as the best judge of the study. Also, according to Carr \& Kemmis, if personal knowledge:

Arises out of one's own rational reflection upon one's own considered action, it may be regarded as authentic. This implies that the actor alone can be the final arbiter of the truth of an interpretation of a considered action and, hence, that the correctness of the interpretation of an action is not a matter to be decided by external reference to rules or principles or theories... The criterion of authenticity thus acts as a defence against the politics of persuasion in educational research (cited in, Parker, 1997: p.133).

However, if my self-study is aimed as a contribution to the educational field, I believe that readers should judge the study's validity for themselves. In this sense, I perceive this reflective self-study to be valid, but the question still remains if readers of this study, especially colleagues in the educational field perceive it as credible, authentic, and believable. However, I have taken steps to show the reader that this is sound research and to help the reader learn from this study, as can be observed in Section 2.9.5. 


\subsubsection{Fidelity}

The criterion of fidelity seems to be of relevance in studies where subjective meanings and interpretations of lived experiences are at stake. This is especially true for a reflective self-study project. However, fidelity is not truth in a positivistic sense, and as Blumenfeld-Jones (1995) argues:

I take truth to be 'what happened in a situation' (the truth of the matter) and fidelity to be 'what it means to the teller of the tale' (fidelity to what happened for that person). Truth treats a situation as an object while fidelity is subjective (p.26).

Hence, fidelity is the truth from the eyes of the person experiencing a lived situation. Fidelity as described by Blumenfeld-Jones (1995) is based on interpretations and incorporates the subjective construction of meanings of lived experiences that the subject has really experienced. Thus, fidelity is important since 'without a factual base, narrative inquiry would run the danger of wild speculation' (Blumenfeld-Jones, 1995: p.27).

But why should a story depict events as experienced by authors? Can't an imagined and unauthentic story evoke readers' reflection, imagination, and emotions? As argued by Phillips (1994), 'to be useful, or effective, or of instructional value, it may be quite irrelevant whether the story is true or not' (p.17). However, in research such as this one, where experience is used to increase knowledge and understanding, improve educational practice, call for further intervention in the future, and understand important aspects such as professional development, Phillips (1994) suggests that we must act on authentic accounts since 'we are more likely to act successfully if we act on the basis of correct information' ( $p .17$ ). Therefore, it is important to portray my interpretations of experiences as correctly as possible, even if my interpretations may differ from those of readers. This is one reason why I include extracts of my reflective journal in the upcoming chapters. As Agar (1995) points out, 'the final book will not read like a novel, but it will offer some raw material and reasoning so that the outsider can evaluate its credibility' (p.126). Also, like Agar (1995) I feel the need, as the author of this text, to assure readers that my writing and reflections are upon truly lived experiences. 


\subsubsection{Validity in Self-study Research}

As the teacher-researcher, I do perceive this study as valid, since 'validation is something that happens in and through one's own experience' (Mason, 2002: p.186). Yet, I believe that such a claim is not enough to make self-study research valid since 'a claim to be studying oneself does not bring with it an excuse from rigor' (Bullough \& Pinnegar, 2001: p.15). Thus, according to Strauss \& Corbin (1990) 'a qualitative study can be evaluated accurately only if its procedures are sufficiently explicit so that readers... can assess their appropriateness' (p.249). Feldman (2003) gives some suggestions of how to make the research process evident and these are summarised hereunder.

1. We need to give clear descriptions of how we collected data, and what methods were used. We also need to explain what counts as data, what data was chosen and/or discarded, and the ways in which this was done.

2. We also need to provide our readers with information on how we constructed our final representations from our gathered data. It is often assumed by the researcher that readers know how a representation came into being from the data gathered. However, this is not always as obvious as some might assume. Providing the readers with information of how data is linked to the final representation adds to the validity of a study.

3. We must also provide detailed information of why we intend to represent a particular study in a particular way.

4. We also need to provide evidence of change. This change could be new ways of seeing things, new insights for an improved future, and new understandings, among others. Put simply, our final representation should highlight the processes through which we develop professionally.

Keeping this particular study in mind, I would add another aspect that might increase the study's validity. The reader should be able to hear the researcher's reflective conversation and how this has affected learning from experience. This is another reason why I include journal extracts in forthcoming chapters. 


\subsubsection{Impact: Is it Engaging and Evocative? Does it Promote Dialogue and Show Potential for Social Action? Does the Account Work for the Reader and is it Useful?}

The answer to these questions of impact as posed by Sparkes (2002) is very simple. If the answer is affirmative, then this research is valuable for the educational field and the practitioners working within this field, and thus, valid. If the answer is negative, then I would argue that this research would have little practical value. As previously argued, generating vicarious experiences in readers might improve the impact of such a study. As argued by Mason (2002):

Validation... is based not on convincing others through rational argument or through the weight of statistics or of tradition, but rather through whether the other can recognise what is being described or suggested, usually through resonance with their own experience, and whether they find that their own sensitivities to notice are enhanced, so that their future practice is... in-formed (p.93).

Peshkin (2000) argues that the best test for the validity of my findings is their utility for others in the field, while Patton (1990) highlights the sharing of understanding as important if a study is to be judged as valid. If this actually happens and the readers are engaged with the text, then the study is adequate and plausible (Connelly \& Clandinin, 1990). However, only the reader can determine if the reading has impact and is thus, evocative, plausible, promotes dialogue and debate, and is useful. In a few words, 'a thesis does not prove validity, [but] merely offers the means for readers to check relevance for themselves in their situation' (Mason, 2002: p.186).

Also, if the aim is new understandings, then I would expect such learning to lead to improvement. What use is new knowledge if we don't use it to change and improve? Keeping the status quo requires no energy and no new knowledge, and I thus argue that research should offer insights into possibly better futures. As a reflective teacherresearcher, I have used this newly acquired knowledge to improve my practice, but I have also used my new knowledge on reflective practice and personal professional development to envision possibilities of how these can be best used in the future for maximal benefit by those involved in the educational field and maybe beyond. This is 
most evident in the concluding chapter where my new understandings are gathered to envision a different future as regards teacher learning.

\subsection{Analysis}

Analysis was an integral part of the entire research process, since reflective practice implies a rigorous ongoing analysis (Pollard, 2002). Consequently, my journal was not only a collection of observations made, but was also evidence of an ongoing analytical process. Such an ongoing analysis shaped the development of my research since the outcomes determined what I would be looking for subsequently. Hence, my observations alimented my reflective and analytical process, while the visions that emerged from the latter processes influenced my practice and what I looked for in the future. As Loughran (1996) says: 'my research and practice continually influence one another' (p.12). My ongoing reflective analysis is well described by Becker's (1998) words as it includes:

Pondering the possibilities gained from deep familiarity with some aspect of the world, systematising those ideas in relation to kinds of information one might gather, checking the ideas in the light of that information, dealing with the inevitable discrepancies between what was expected and what was found by rethinking the possibilities of getting more data, and so on (cited in, Yin, 2003: p.59).

From such a description, it is evident that data collection and analysis are ongoing rather than detached steps in a linear process (Agar, 1995; Freeman, 1994; Yin, 2003). This type of ongoing analysis helped me learn about what I was engaged in, i.e. my professional practice, my surrounding environment, reflective practice, as well as the research methods used. Pollard (2002) suggests that such an ongoing analysis is 'needed to address the issue of how to interpret descriptive data' (p.17) because it is through ongoing analysis that we give meaning to what we observe, and it is the interpretations and meanings we create that promote learning (Ghaye \& Ghaye, 1998). 
However, such an intrapersonal analysis is difficult to describe in words. In Mills' (1959) words:

How do ideas come? How is the imagination spurred to put all the images and facts together, to make images relevant and lend meaning to facts? I do not think I can really answer that; all I can do is talk about the general conditions and a few simple techniques which have seemed to increase my chances to come out with something (p.211).

\subsubsection{Reflective Analysis}

Hollway \& Jefferson (2000) suggest that when analysing qualitative data, researchers should ask the following four questions:

1. What do we notice?

2. Why do we notice what we notice?

3. How can we interpret what we notice?

4. How can we know that our interpretation is the right one?

Unknowingly, similar questions guided my thoughts when analysing everyday experiences and while writing entries into my journal. In short, these four questions resemble the process of reflection itself. Thus, through these four questions I will briefly try to describe how my ongoing analysis progressed. In the first instance, I used to write down my experiences. I simply wrote down what I noticed. Secondly, I wrote why I noticed what I noticed. The reason was usually a perceived problem. Through reflective practice I then mulled the experience over and attached meanings to my own observations. Finally, I planned to evaluate my created meanings and interpretations through an action-research process, which then lead back to observing my own practice. Yet, this is too simplistic to represent the process in its entirety. My reflective analysis will be discussed in further detail in Chapter 3 .

\subsubsection{Analysis and Narratives}

I have used two types of narrative analysis. These are what Polkinghorne (1995) has termed narrative-type narrative inquiry (narrative analysis) and paradigmatic-type 
narrative inquiry (analysis of narratives). The difference between these two types of analysis is that 'analysis of narratives moves from stories to common elements, and narrative analysis moves from elements to stories' (Polkinghorne, 1995: p.12).

\section{- Narrative Analysis}

My ongoing analysis included narrative analysis, and this was mostly used in my reflective journal as a way of recording my experiences. 'Narrative analysis uses stories to describe human experience and action' (Oliver, 1998: p.244) and this is appropriate in a study where I aim to study human behaviour, thoughts, and actions over a period of time. As Erben (1998) contends, narrative analysis offers an 'exegesis of everyday existence' (p.13). Through narrative analysis, I was able to construct meanings and interpret my lived situations through the stories I wrote.

- Analysis of Narratives

Yet, in the final stages of my research, I used another type of analysis. Here, I wanted to learn about the research process itself. While at an earlier stage, I used narratives to help me understand my lived experiences, I now needed to analyse my own narratives of learning that I had constructed throughout the preceding 30 months. I wanted to analyse what I experienced as a reflective practitioner while working as a teacher in order to better understand my own professional development. Such an analysis of narratives 'requires that stories be collected as data and then analysed by identifying aspects of the data as... categories' (Oliver, 1998: p.248). In a sense this analysis is a reflection upon reflective practice; an analysis of ongoing analysis; a self-study of a self-study (Coia \& Taylor, 2002).

\subsubsection{Grounded Theory Analysis}

Polkinghorne (1995) suggests that analysis of narratives 'produces cognitive networks of concepts that allow people to construct experiences as familiar by emphasising the common elements that appear over and over' (pp.10-11). I did this through grounded theory analysis, which is an analytically controlled way of developing theory from data (Strauss \& Corbin, 1990). As such, my reflective journal was extremely useful at this 
stage, because 'for grounded theory work to proceed, the data must first be assembled in some form of permanent record that allows ready access during analysis' (Pidgeon \& Henwood, 2004: p.636). The main reason why I conducted grounded theory analysis was that 'learning has to be given a chance to emerge so teachers need to make a series of entries and then re-read them to search for patterns, themes, issues, conflicts and so on' (Ghaye \& Ghaye, 1998: p.82). Such an analytical process was divided into 4 components.

1. I first reviewed all my journal entries, and identified significant points in lengthy reflective narratives. These significant points were coded as can be seen in the following example.

$8^{\text {th }}$ Sep 2005-p.107-108

- retrospective thinking about learning how to learn

- professional development

- developing reflective awareness and self-study

- stages of reflection

- taken-for-granted assumptions

- reflection and self-study can be used by others in the profession

Strauss \& Corbin (1990) label this initial stage as 'open coding', where while coding a particular incident, the researcher should constantly compare the incident with preceding incidents. It is through such a process of constant comparison that theory starts to be constructed from the data available. Here, 'coding and analysis are interpretive rather than positivistic' (Agar, 1995: p.126).

2. When all entries were analysed and coded, I moved onto analysing the codes in order to discover emerging core categories. Such core categories 'reflect commonalities among codes [and are] identified through the interpretive lens of the researcher, who is already beginning to abstract meaning from the data' (Harry et al., 2005: p.5). Some of these core categories then formed overarching themes, and some of 
the latter will be presented in the results section of this thesis. Not all themes will be presented due to word limitation; however, the most vital aspects that help the reader understand professional development through reflective practice will be included. In Agar's (1995) words: 'samples of raw material together with a discussion of patterns seen in them - become chapters or sections of chapters' (p.125).

3. Another component of grounded theory analysis is the integration of the entire analysis to yield conceptual data and eventually the building of an overarching theory. The integration of themes is presented as a conclusion for this thesis, where theory and recommendations are also presented. As Mills (1959) suggests: 'themes ought to appear together, in relation to one another... usually, in a well-constructed book, it must be done near the end' (pp.216-217). Thus:

At this point the researcher treats the various code clusters in a selective fashion, deciding how they relate to each other and what stories they tell... It is in seeking the interrelationships between these themes that the researcher begins to build a theory (Harry et al., 2005: p.5).

As argued by Pomson (2004) building a study around a number of vibrant themes can make certain issues and dimensions visible 'that would probably be erased in a linear story' (p.658). As such, 'linkages are unlikely to be presented as a listing of hypotheses or in proportional or other formal terms, but will be woven throughout the text' (Strauss \& Corbin, 1990: p.254-255).

4. Throughout this analytical process however, I was also questioning my own data. I was re-reflecting on my own reflections, while also reflecting on my analytic process. After all, it is requested that researchers be reflective when analysing qualitative data (Mauthner \& Doucet, 1998). Thus, the ongoing analysis that I mentioned previously was still taking place. I must point out that reviewing existing literature helped me in putting my data under further examination. Although this component is listed as the final component of my analysis, in reality, it was an ongoing process, i.e. from the coding stage, to the construction of categories, as well as the testing of themes. I found one question that was very useful when using grounded 
theory analysis in self-study research. I continuously asked myself: Do the data highlight my own reflective process, and the continuous struggle to learn? Also, throughout the final write-up, I was still testing the themes through reflective practice, since 'the write-up itself is not a neutral representation of the research findings' (Polkinghorne, 1995: p.19).

The above four points show how grounded theory analysis has led me to a re-analysing process using reflection once again, and in turn I was continuously gathering new data by analysing my everyday experiences. This close relationship between data collection and data analysis helped me in achieving what Glaser \& Strauss (1967) call theoretical saturation. However, theoretical saturation is only partial in this study, since reflective practice is a form of continuous professional development and learning, and as such, is never-ending. Thus, I do not agree that complete saturation is possible. Nevertheless, having enormous amounts of longitudinal data helped me obtain what I would call a satisfyingly extensive saturation point. In any case, 'a considerable mass of data must be assembled and grappled with before central themes will begin to emerge' (Elbaz, 1983: p.129).

My dual role as a teacher-researcher was evident at this stage. Although these two perspectives are inseparable, while coding and observing commonality and trends in the data, I was using a researcher's perspective of analysing the data I had available. When re-reflecting on reflection in my final write-up, I used a teacher's perspective to test the themes. I think this 'dual role' was a 'strength' for the entire process of this study, for both roles helped strengthen each other. The researcher in me helped me to analyse situations that would usually go unnoticed in the busy day of a teacher. On the other hand, the practical knowledge and experience gained in teaching helped me to test my own analysis.

Using grounded theory analysis helped me to pinpoint salient aspects of my life as a reflective practitioner. Such an analysis helped me give shape to the entire research 
process, where personal professional development through reflective practice was the key issue. However, one particular critique is the following:

While some researchers attempt a holistic analysis which seeks to preserve a narrative in its entirety and understand it as a complete entity, other analysis can be described as categorical analysis in that short sections of the text are extracted, classified, and placed into categories for analysis. Whereas holistic approaches attempt to understand sections of the text in the context of other parts of the narrative, categorical approaches do not attempt to preserve the integrity of the whole account (Elliott, 2005: p.38).

As Oliver (1998) suggests, 'if all we took from... stories were the common themes... we would miss all the other possible messages within the... stories, and many exist' (p.250). Although I do agree with these arguments, such a critique does not hold in my case. I am fortunate enough to have the best of both worlds. I do both holistic and categorical analysis while preserving the integrity of the whole account, especially when keeping in mind that $I$ am the whole account. Thus, one extract is inevitably part of my whole narrated life. I understand a small part of my story against the backdrop of my whole and entire story; i.e. my life. Self-study allows me to do this. As Harry et al. (2005) found out:

No single explanation could stand alone. None could be supported or refuted without reference to another explanation with which it interacted. For research concerned with the nuances of human behaviour, we consider this a realistic finding, one that underscores the difficulty of measuring complex social processes (p.10).

\subsubsection{A Healthy Contamination}

As already stated, the grounded theory approach described above was constantly being contaminated by another type of analysis i.e. reflective analysis. This contamination proved useful, as integrating the two forms of analysis proved priceless for this particular study. As Strauss \& Corbin (1990) themselves point out, 'imaginative researchers... will, at times, depart somewhat from what can be termed authoritative guidelines for procedures' (pp.257-258). Thus, grounded theory in my case was used with a constructivist revision, since my own research has shown that qualitative data 
about human behaviour and human learning can never be close to the assumptions made by grounded theory resting on a positivist empiricist philosophy, i.e. 'that a set of social or psychological relationships and processes exist relatively unproblematically and objectively in the world' (Pidgeon \& Henwood, 2004: p.627). As Charmaz (2000) contends:

Diverse researchers can use grounded theory methods to develop constructivist studies derived from interpretive approaches. Grounded theorists need not subscribe to positivist or objectivist assumptions. Rather they may still study empirical worlds without presupposing narrow objectivist methods and without assuming the truth of their subsequent analysis (p.511).

Grounded theory and reflective analysis helped me gain greater insight into how a particular teacher develops professionally through continuous workplace learning. Both types of analysis teamed up in a unique strategy that enabled me to learn as much as possible about my own learning. Such a constructivist grounded theory approach encourages the study of daily experience from the viewpoint of those who actually experience it (Charmaz, 2000) and an ongoing self-study proved to be valuable in this sense, making the following criticism null:

Criticisms of fracturing the data imply that grounded theory methods lead to separating the experience from the experiencing subject, the meaning from the story, and the viewer from the viewed (Charmaz, 2000: p.521).

Moreover, being a longitudinal study, this research seems to better satisfy the criterion of saturation:

The data in works claiming to be grounded theory pieces range from a handful of cases to sustained field research. The latter more likely fulfils the criterion of saturation and, moreover, has the resonance of intimate familiarity with the studied world (Charmaz, 2000: p.520).

Combining these two types of analysis (grounded theory and reflection) was especially evident while coding my journal entries. I could have easily fallen into the trap of mechanically coding line-by-line entries. However, continuous reflection on my entries as well as the analytical process itself prevented such a mistake. After all, interpretation 
was important all throughout the research process, and it was no less important during analysis. Therefore, although grounded theory work provides an important baseline for research work, focusing on mechanically processing the data can occlude the primary hermeneutic element that permeates the research process from start to finish; i.e. interpretation (Alvesson \& Sköldberg, 2000). Hence, as Charmaz (2000) points out, mechanical procedures, like for example reducing qualitative analysis to a simple set of procedures is not an option, since this could easily have made me lose the focus of the entire picture, and like Charmaz (2000), I firmly contend that 'part of interpretive work is gaining a sense of the whole' (p.520).

Through my analysis I want to make my own experience known to others, while showing common and recurring points of my professional journey to readers. In this way, I aim to 'give them the opportunity to generalise from it to their own teaching situation' (Ghaye \& Ghaye, 1998: p.85). This is what Stake (2000) has termed naturalistic generalisation.

\subsection{Ethical Considerations}

When considering that this is self-study research, it is impossible to keep the subject's identity private. This is not a problem for me since as subject-researcher, I consciously choose to disclose my professional life to the reader. As such, I did not require special permission from the university ethical committee because the research was about me and not about pupils or colleagues. Yet, I still asked permission from the head teacher to conduct research as part of my normal teaching; and this I was immediately granted.

However, this makes keeping students' and colleagues' identities more difficult to shield from exposure, since any reference to students or colleagues will obviously refer to a restricted number of persons operating at my workplace. Thus, in all of my diary entries, other characters were given pseudonyms and these were stored securely to ensure nobody could be identified. However, protecting characters' identities was more 
difficult during the final write-up because it was also important not to mention anything (like habits and/or characteristics) that might expose any person in particular, even though it is easy to identify the school where I teach. The only exception here is the head teacher, but he gave me permission to do so. In other cases, data were excluded from the write-up if there was any possibility that an individual could be identified. 


\section{Chapter 3}

\section{Aspects of Reflective Practice}

This and ensuing chapters include extracts from the three sections of my reflective journal; i.e. 'lesson observations' (LO), 'in-service observations' (ISO), and 'personal diary' (PD). Such extracts will be identified with the initials of the relevant section and the date of the diary entry (e.g. PD: 26-10-05).

\subsection{Introduction}

Reflective practice is encouraged in various professional fields (Loughran, 2002a; Schwandt, 2000), but it seems that little is known of what constitutes effective reflective practice (Mason, 2002; Russell, 1993). In this and the following chapters, I aim to identify and analyse different aspects or components of reflective practice, since reflection is not simply thinking about something. In this chapter, data on experiential learning are presented and discussed. The analysis will focus on four key areas: the role of teaching experience, keeping a reflective journal, conversing with oneself, and the importance of ongoing questioning. As a new teacher, it is reflection that gave me the opportunity to learn from my teaching experiences through what I have termed ' $a$ reflective odyssey'. For me, this has meant that 'we view teaching and learning problematically, that we question it, look into it systematically and continuously strive to learn from it' (Ghaye \& Ghaye, 1998: p.17).

\subsection{The Role of Experience}

Experience is fundamentally important in reflective practice since reflection is usually defined as intentional and conscious learning from experience (Mason, 2002; Grimmett 
et al., 1990; Brouwer \& Korthagen, 2005; Richardson \& Hamilton, 1994; MacLeod \& Cowieson, 2001; Richert, 1992; Glaze, 2002). Thus, experience is a pre-requisite if a person is to engage in reflective practice (PD: 26-08-03), because it is upon experience that we reflect (Ben-Peretz, 2002; Ghaye \& Ghaye, 1998; Clegg, Tan \& Saeidi, 2002; Loughran, 1996; McIntyre, 1993; Pollard, 2002; Richert, 1992). Yet, the inverse of this argument is also plausible since, following Houston \& Clift (1990), I would like to argue that:

It is of little use talking about the benefits of being reflective, doing self-study, or writing to understand. We have to learn from experience and only those who engage themselves in the abovementioned will know the benefits that come with such endeavours (PD: 20-06-03).

Professional practice and reflection progress in parallel dimensions; both inform and aliment each other. In fact, I learned by doing throughout this research (Schön, 1987; LaBoskey, 1992). Learning from experience was a phrase I had heard in the past, but I had not appreciated how powerful it could be for my own learning

\subsubsection{Lack of Experience}

As I am in the early stages of a teaching career, my experience is limited. When I was suddenly required to teach a syllabus that was completely new for all PE teachers in Malta, I could not even look for help from other more experienced teachers. Lack of experience made me feel lost and helpless, and these feelings made evident the relationship between experience and tacit learning. On various occasions in my personal diary, I found myself commenting that 'only time will tell' (PD: 03-01-04) suggesting that as time goes by, I will be exposed to new experiences that can shed light on my present questions. For example:

It's like I'm living in a big jigsaw puzzle where nothing has a definite place and nothing has a definite answer. I'm trying to build this jigsaw bit by bit, but I can only know if I'm doing it in the correct way when I get to see the whole picture (PD: 25-01-03). 
Months after writing this journal entry, insecurity caused by inexperience was still an issue. The following diary extract supports Gordon's (1991) claim that if there is no past to shed light on present and future, we move forward in what feels like pitch darkness.

I'm lost in the desert and the sun is shining bright. The weather is too hot and while I'm walking, I simply cannot measure my progress. I do not know if I have enough water to keep me going for the rest of my journey... just because I do not know how much time l've got left to find some sort of safety.

Lost... yes, this is how I feel. Every lesson I have with my SEC PE students is like the walking I just mentioned. Every lesson is a step forward. The SEC PE syllabus is like the desert. I do not know how long it will take me to cover the syllabus just like I wouldn't know how long it would take me to find my safety while lost in a desert. Similarly, the timeframe of the SEC PE course is represented by the water. As time goes by, I have less time to cover the syllabus just like I would have less water in my flask.

This might seem too fatalistic and indeed it is a bit. Yet, this situation would reflect my planning as a teacher teaching the new SEC PE syllabus. I feel uneasy for the simple reason that I can't compare my progress to previous years of teaching since this syllabus is completely new... What I mean here is that I have no definite model that I can compare my work to. There is no precedent (PD: 23-03-03).

A year later, I was 'still moving forward blindly' (LO: 12-03-04) as I argued that 'the only possible way... is by peeping into the future... which until now is not possible' (PD: 29-05-03). However, like Zembylas (2004), I realised that experience is fundamental in informing future practice, and this made me treasure my daily experiences (LO: 02-06-03). It is important to keep in mind however that past, present, and future are not distinct and/or fixed in a teacher's career. All overlap to inform and alter each other as the past informs present and future, while future happenings can always lead to a re-interpretation of the past (Elliott, 2005; Pomson, 2004; Richardson, 1995; Parker, 1998; Dewey, 1910; Usher, 1998; Mills, 1959). Hence, as a new teacher, I understand that my learning is not a linear process, as I construct new learning while deconstructing previous knowledge. 


\subsubsection{Is Experience the Essence of Professional Development?}

Learning from experience is a 'continuous quest for meaning' (Ben-Peretz, 2002: p.316). However, although an important foundation for learning, experience alone is not the best form of professional development (Day, 1999, 2000; Mason, 2002; Ghaye \& Ghaye, 1998; Mills 1959; Stevenson, 2002; Richert, 1992, 2001; Dewey, 1938; Lave \& Wenger, 1991; Fuller et al., 2005; Turner, 2001; Posner, 1996; Loughran, 2002a). Hence, if as teachers we are to develop professionally and become lifelong learners, 'we have to learn by critically analysing our own experiences' (PD: 15-03-04). If we do not, experience alone would eventually limit development (Day, 1999).

Hence, the imperative point to be made about this research is that I did not take experience as canonical but questioned it and the meanings I attached to it. This is the foundation upon which this entire research project is based. After all, 'to be able to trust yet be sceptical of your own experience... is one mark of the mature workman' (Mills, 1959: p.197). In the wider teacher-learning research literature, reflective practice emerges as an important way of supporting practitioners to comprehend their actions and question their tacit knowledge (Loughran, 2002a; Ghaye \& Ghaye, 1998). Perhaps this comes as no surprise given that 'reflection helps the individual to learn from experience because of the meaningful nature of the inquiry into that experience' (Loughran, 1996: p.14). In this way, teaching does not become a routine activity through tacit experiential learning, but a meaningful process driven by the explicit meanings attached to experience. Of importance then, are the interpretations and meanings we attach to our experiences as teachers (Kelchtermans \& Vandenberghe, 1994; Griffin, 2003). Thus, experience is simply regarded as data that the professional analyses (Mason, 2002). For example, as a teacher, I also analysed my experiences as a student and, like Fernandes (2002), I found this to be a useful way of understanding my own students and their learning. As a speaker once told me during an in-service course 'history is a great teacher... if only we listen to it' (ISO: 20-04-04). 


\subsubsection{Moulded by Experience}

Trying to understand my experiences unexpectedly led me to question assumptions and beliefs I had always held. This helped me realise that 'I was conditioned by my previous experiences and beliefs' (PD: 05-11-04). This resonates with the tendency for new teachers to shape their practice on their own experiences as students (Hatton \& Smith, 1995; Brownlee, Purdie \& Boulton-Lewis, 2001; Griffin, 2003). For example, being a strong swimmer myself, I was conditioned because I could not understand those students who had difficulty. This prevented me from facilitating my students' learning in swimming (LO: 30-09-03). Thus, experience shapes who we are and who we become, how we act and react, and how we behave in various situations. As such, any attempt to understand something today is affected by prior understandings of the world; i.e. previous experience and knowledge (Dewey, 1910; Bass et al., 2002; Stevenson, 2002; Fishman, Marx, Best \& Tal, 2003; Richardson, 1996; Van Maanen, 1988; Stake, 2000; Mills 1959; Stringer, 1996). So as a new teacher, it was important for me to continuously develop, while questioning rather than accepting past experiences as a base for professional practice.

\subsubsection{Revising Past Learning}

Experiential learning opened up the possibility of revisiting past learning; learning that could have seemed inadequate or of little practical use at the time. Much of my past learning was in the form of abstract learning (formal schooling) with little chance to link it to the practicality of teaching. But now, with the availability of practical experience, I am re-learning in practice what I had learned in theory. Whatever I have been told, or have read about, I make sense of it according to what I encounter in practice (PD: 12-02-04). Thus, like Loughran (2002a) I have argued that experience acts as a filter since different experiences affect how information is interpreted (ISO: 16-11-04). According to Mason (2002) this is how 'true professionals operate. They draw upon... experience to recognise or reject assertions made to them' (p.12). Thus, it is through experience that teachers become increasingly aware of the complexity of classroom teaching (Labaree, 2003; MacLeod \& Cowieson, 2001; Chetcuti, 2002). My 
experience to date, therefore, shows me that experience is indeed an essential component of professional learning, although not sufficient on its own.

\subsubsection{Gaining Experience - Learning Tacitly}

Moving forward in time, it was clear to me that one year's experience teaching the new SEC PE syllabus was already making a difference: 'I now have a year's experience of teaching this syllabus and I thus feel more confident when compared to a year ago' (PD: 01-10-03). However, I was also concerned that these feelings of relative comfort were a sign that I was beginning to engage in habitual routines; perhaps operating in my 'comfort zone'. Moreover, I realised that there were things I appeared to have learned spontaneously; i.e. even though I had not reflected upon them (LO: 23-09-03). 'In cases that are familiar because of many prior experiences we do not have to stop to remember just what those experiences were' (Dewey, 1938: p.79). This spontaneous learning from experience is a form of tacit learning (Conle, 1996; Williams, 2003; Ghaye \& Ghaye, 1998). It is suggested that teachers tend to act instinctively on tacit learning because such learning unconsciously exposes itself in actions during professional practice (Korthagen \& Kessels, 1999; Ghaye \& Ghaye, 1998; Ben-Peretz, 2002; Checkley \& Kelly, 1999; Conle, 2003). I started realising here that although I was constantly analysing my practice, tacit learning was still an important aspect of my development. However, whether tacit learning from experience results in the establishment of habitual practices is addressed further in Chapter 5 .

Whatever the case, I realised that I had some information that could help with my future practice. I was 'moving forward while giving a glance at the past when needed, for the past is indeed a powerful teacher' (PD: 07-01-04). New ideas emerged through reflecting on my experiences; and experience is important at this stage too since 'further observations and experience are a test for the feasibility of new ideas' (PD: 2009-05). I then re-reflect on 'the changes that were introduced so that I can use them in the future' (LO: 25-03-03). It could be argued, therefore, that improvement is impossible if we are not capable of learning from experience (Ghaye \& Ghaye, 1998). 


\subsubsection{Tacit Learning Shapes Our Understanding of the World}

Kelchtermans \& Vandenberghe (1994) suggest that when teachers make arguments they frequently use their own experiences as examples to underpin what they are saying. On a particular occasion while attending an in-service course, I complained in my journal that course presenters trying to speak about something without having actually experienced it tend to 'live in a world of ideals. They are miles away from everyday realities found inside schools' (PD: 23-04-04). This resonates with Armour \& Yelling's (2004) study as they report a teacher making the following comment about a course presenter: 'I would love to leave you in class today with some of our rough kids' (p.81). In sharp contrast, a different speaker led me to a very different point of view. I commented:

[This speaker] impressed me. He really engages the audience and brings up a number of relevant examples... He then pointed out that he taught for a number of years at primary, secondary, as well as tertiary level. Experience does make a whole lot of a difference (PD: 23-04-04).

According to Dewey (1910):

If the person has had some acquaintance with similar situations, if he has dealt with material of the same sort before, suggestions more or less apt and helpful are likely to arise. But unless there has been experience... confusion remains mere confusion (p.12).

This made me increasingly value experience as an opportunity for learning. I thus wanted to take advantage of such an opportunity as can be seen in this coming section.

\subsubsection{Making the Best Use of Available Experience}

Making the best use of experience in order to learn was my main objective throughout this study. I needed to develop professionally, and, in the absence of other forms of supportive professional learning, daily experience was promising and available. Thus, I needed to maximise the opportunity of learning from experience. Russell (2002) states that teachers do have 'faith in learning from experience' ( $p .75)$. From my experience, I have certainly noticed that my teaching colleagues value experiential learning. Indeed, 
many argue that you become a real teacher only after many years of teaching in real classrooms. The following comment from a more experienced colleague, and my response to it, illustrates this point:

'Nobody becomes a teacher when graduating from university. We become teachers after years of experience...' [colleague]. Suddenly, I was caught up in a web of thoughts. It seems that everybody values experience... and the learning that experience has to offer. Otherwise, why would most employers request that new employees have a number of years' experience? Workplace learning is essential if we are to improve what we do (PD: 18-10-05).

Indeed, studying experiential learning through reflective self-study has led me to identify with Renner's (2001) statement:

I enter a doctoral program to explore the question of how lived experience informs professional practice. Moving into the centre of my own doubts, I discover multiple selves, suffer death and rebirth, and ruminate on the nature of transformational learning (p.1).

These words set the stage for chapters to come for I have learnt through experience that we can learn from experience (Russell, 1993; Richert, 2001). But the question is: How best can we learn from experience? Such a question is central for those who consider that we require a theoretical underpinning for the possible contributions and constraints of teaching experience on teachers' professional development (Oosterheert \& Vermunt, 2003; Ball \& Cohen, 1999; Russell, 1993). Thus, the purpose of this research is clear: to identify various factors that aid or hinder learning from experience as I have experienced them myself.

\subsection{The Process of Reflection}

Based on personal experience of the process and wide reading, I defined the reflective practitioner in one of my journal entries as a professional who 'sees, wonders, contemplates, and tries to explain' (ISO: 23-04-04). Reflection is the method used in this research to inquire into practice as it offers promise in improving teaching practice 
through the analysis of experience (Mayes, 2001; Fottland, 2004; Dewey, 1910; Sweeney, 2003; Loughran, 1996; 2002a; Ghaye \& Ghaye, 1998; Russell, 1993; MacLeod \& Cowieson, 2001; Richert, 1992; LaBoskey, 1992; Day, 2000; Hamilton, 2002; Heikkinen, 2001). Yet, I wanted to understand how I evolved as a reflective practitioner, and this I did through analysing the process of reflective practice as I experienced it. I termed this process of understanding reflection through reflection as a reflective odyssey because:

Similarly to Homer's Odyssey, I never know where my next stop will be... I rarely have proof that I am going in the right direction... and it seems to be a never-ending feat... Like the Odyssey's main protagonist, Ulysses, despite setbacks I keep on striving in search of the right way (Attard \& Armour, 2005: p.197).

\subsubsection{Understanding Reflection}

Because reflection cannot be measured in any systematic way, (Ward \& McCotter, 2004; Moore, 1999) and is not rule-governed or fully described by general theory (Schön, 1983), it can best be understood through engagement with it. In this sense, like Hamilton (2002), 'I present this work not as a completed project, but rather as an example of how one researcher engages in the methodological aspects of... study' (p.110).

In the initial stages of embarking on a 'reflective odyssey', reflection was a difficult task. I had to concentrate to try and reflect on my daily experiences; I had to force myself into it. I am not unique in this, since Schön (1987) reports that when engaging in reflection, confusion is prevalent at the beginning. Nonetheless, just a couple of months later, I realised that I was constantly reflecting.

Alone in the dark while trying to relax, my mind finds itself wondering what's best for my students... Thoughts just rush through my head without having the time to jot them down. When I started thinking about my actions while teaching, my mind was full of rust. My thinking was slow and it took me ages to come up with an idea. Nowadays I consider myself as a reflective practitioner and thinking about my teaching has become second nature to me... When I started teaching the new SEC PE syllabus, I felt as if I was alone in the desert. I did not know what steps to take, which direction to go, and what I would achieve at the end. My only way of 
survival was to reflect upon what I was doing. Today, being reflective is not a way of survival anymore... but a way of life that makes me feel truly professional in what I am doing (PD: 16-03-03).

Thus, my experience with reflection seems to lend some support to Wildman, Niles, Magliaro \& McLaughlin's (1990) suggestion that 'systematic reflection is a learned activity' (p.160). This is why reflection 'has become an integral part of my life...Now that I have started being a reflective teacher, I just cannot stop being one' (PD: 29-0503). Thus, in reply to Brunner's (1994) doubt about whether 'a habit of reflectivity is possible' (p.16), I can answer that in my case it did become a habit, but unlike most habits, it did not become a routine process. Rather, reflection was a habit to the extent that 'I feel undressed if I imagine myself trying to teach without being reflective' (PD: 29-05-03).

\subsubsection{Stages in My Reflective Process}

In the latter stages of this study I looked back on the stages in my development as a reflective practitioner. I was aware that I had progressed through different stages, but I must emphasise that these stages are not well-defined, but merge into each other, as this extract illustrates:

In the beginning of what I have named my reflective odyssey, I used to analyse specific aspects of practice. I then moved on to reflect and analyse general situations that aided or inhibited my learning from experience... At this stage, I also started to reflect on reflection and self-study, and how they can be used for teacher professional development. I then moved on to realise that taken-for-granted assumptions affect how much I can learn from a given situation. As such, I learned that in order to learn I must be able to unlearn these taken-for-granted assumptions. Social values, culture and expectancy now also formed part of what affected my learning and my decisions. I wanted and needed to understand how prior learning and inherited values affected my professional development.

Finally, my development in reflective awareness took me a step further. Understanding that this reflective self-study helped $m e$ in developing professionally, I wanted to understand how certain qualitative research methods used in this study can be of help to others in the profession. I have learned how to learn. Ironically, this is the best lesson I have learned... i.e. how to learn from a variety of sources (PD: 08-09-05). 
Upon reviewing the literature, I encountered the works of Ward \& McCotter (2004), Day (1999, 2004) and Van Manen (1977) where they describe different levels of reflection. In comparing their levels with those that I experienced, I found that there are both similarities and differences. In adapting their work to my particular situation I argue that, at the outset I was engaged in, what I term, spontaneous reflection, where little attention is given to the complexity of teaching practice. Little room is afforded to multiple interpretations. Problems are rarely the main focus, and where they do arise, there is a tendency to put the blame on others; for example blaming students (Kraft, 2002). There is also a lack of questioning at this stage, resulting in little impact on practice. Here, the main aim is survival. As I argued earlier, all professional practitioners, including teachers, are reflective (Zeichner, 1994; Schön, 1983; Grant, 2001) but perhaps for some teachers, the reflective process remains at the level of spontaneous reflection. However, such uncritical reflection is likely to result in the affirmation of habitual practice.

The second level of reflection is technical reflection (Ward \& McCotter, 2004; Day, $1999,2004)$. This can be defined as an instrumental type of reflection because it is used to solve a specific problem of practice without questioning the aspects that bring about the problem. At this level, reflection is about means rather than ends, since the latter are simply given (Ward \& McCotter, 2004; Van Manen, 1977; Parker, 1997; Day, 1999; Zeichner, 1994). This describes the period when I was preoccupied with teaching the new SEC PE syllabus. I just wanted to solve problems of practice I encountered with the aim of improving. However, as reported in the wider literature (Kraft, 2002; Adelman, 1989) this level of reflection rarely results in critical awareness because given ends are accepted uncritically and taken-for-granted assumptions and beliefs remain unchallenged.

The third level of reflection is what Ward \& McCotter (2004) and Day (1999) term dialogic reflection and this is an ongoing form of reflection that promotes the habit of reflection. The focus is on how a person learns rather than what is learned. In this phase of reflection, I started interesting myself in learning how to learn; thus learning how 
reflection helps the practitioner develop professionally. Dialogic reflection is defined as 'a sustained process of asking questions, trying new approaches, and asking new questions' (Ward \& McCotter, 2004: p.252). It is questioning and the search for plausible answers that promotes dialogic reflection. The practitioner also realises that there are multiple competing principles as s/he grapples with the dilemma of which to choose (Grimmett et al., 1990; Day, 1999; Loughran, 1996; Van Manen, 1977; Mason, 2002). It is at this reflective level that assumptions, beliefs, and ends begin to be challenged (Parker, 1997) and this is an important factor if we are to understand practice at a deep level (Loughran, 2002a). However, negative feelings such as frustration also began to emerge during this stage because I started questioning previously held assumptions and professional practice that seemed to be fine when left unquestioned.

Transformative/critical reflection is the deepest level of reflection (Ward \& McCotter, 2004; Day, 1999). At this level the new insights and understandings that emerge from dialogic reflection lead the reflective practitioner to not only question personally held beliefs and assumptions more deeply, but also take into account the effects that wider societal forces have on his/her practice (Day, 1999; Van Manen, 1977; McIntyre, 1993; Pollard, 2002). Moreover, such wider societal forces also impacted on the ways that previously held beliefs and assumptions were built. Ward \& McCotter (2004), argue that the practitioner reaches 'this higher level only after sustained inquiry and selfquestioning during her experience' (p.253). Thus, the growth of the reflective practitioner is a lengthy developmental process (Weiss \& Weiss, 2001; Ghaye \& Ghaye, 1998; Calderhead \& Gates, 1993; Hatton \& Smith, 1995).

As previously argued, reflection is not a set of procedures that are rule-governed and that can easily be applied to practice (Houston \& Clift, 1990; Ghaye \& Ghaye, 1998; Loughran, 1996) nor is it 'a matter of trained, methodical, unprejudiced technique' (Outhwaite, cited in Elliott, 2005: p.37). In short, reflection is best viewed as a socially constructed process and the practitioner must experience reflection to understand reflection. 
I have briefly described these four levels of reflection to help describe my own development as a reflective practitioner. The aim is not to create one over-arching typology of reflective practice but to attempt to report and illustrate some of the levels through which reflection wanders, back and forth. Indeed, my experience through this research supports the suggestion that reflection cannot be reduced to a sequence of steps to be followed or levels to reach (Zeichner \& Liston, 1996). It is certainly the case that in the initial stages of my reflective odyssey I used, almost solely, the first two levels of reflection (spontaneous and technical) and Mills (1959) seems to capture what I felt as I developed:

Older decisions that once appeared sound now seem to them products of a mind unaccountably dense. Their capacity for astonishment is made lively again. They acquire a new way of thinking, they experience a transvaluation of values (p.8).

\subsubsection{Reflective Practice as Research Methodology}

If I try to give a simplistic explanation of how I engaged in the reflective process, it is helpful to refer to the literature on action research for there is an evident link between the two (Reason \& Bradbury, 2001; Pollard, 2002). Firstly, in the reflective process, I observe my practice and reflect on perceived problems, value conflicts, and newly encountered situations. Then I try to analyse the situation from varying viewpoints, giving hypothetical reasons for what happened (Loughran, 1996). Similarly, I consider possible alternatives as solutions to the problems. Finally I try to translate my new learning into action that is relevant for my particular context. The above description of reflective practice is very similar to the ones given by Atwell (1991) and Tillema (2004). Yet, it is important to note that the reflective process is not simply some form of loose experimentation. In teaching there is an ethical imperative to consider the impact of teachers' actions upon students (Ross, 1990; Dewey, 1910; Ghaye \& Ghaye, 1998; Husu \& Tirri, 2003). Importantly, therefore, reflection is helpful because 'reflecting provides the capability to consider possibilities and consequences of ideas and action' (Tickle, 2000). 
My experience of reflection suggests, however, that many existing descriptions of the process are too simplistic. As I noted in my diary: 'Being a reflective practitioner is hard work and is time-consuming... It dissipates energy in trying to find better ways to facilitate students' learning' (PD: 16-03-03). Furthermore, I noted that 'I'm tired... I'm both physically and mentally tired... especially mentally' (PD: 20-05-03). In short, reflection needs personal effort, energy, and time since it is not, at its most productive levels, a spontaneous activity (Gelter, 2003; Humphreys \& Susak, 2000; Houston \& Clift, 1990; Freidus, 2002; Wildman et al., 1990; Ghaye \& Ghaye, 1998; Pugach \& Johnson, 1990). As DeMulder \& Rigsby (2003) contend, 'nothing worthwhile ever comes easy' (p.279).

Then again, there are other side-effects of being a reflective practitioner. First of all, reflection is no magical or miraculous formula, so 'although I do see reflection as a powerful tool for learning, it will not always offer quick and easy answers... sometimes it might offer no answers at all' (PD: 05-06-03). Sometimes, the questions I pose to myself have to be postponed until further observation and analysis of personal practice and, like White (2002), I sometimes start analysing other issues while knowing that 'previous ones were often unresolved' (p.309). Inconclusiveness is certainly part and parcel of the reflective process (Conle, 2000). However, it is the tolerance of being in a suspended state that promotes further inquiry, observation and analyses and as Grant (2001) argues, practitioners who can tolerate ambiguity are better at analysing practice. Another side-effect that was alluded to earlier is that reflective practice can at times be an uncomfortable experience (Hunt, 2001; Humphreys \& Susak, 2000; Day, 1999, 2004; Ghaye \& Ghaye, 1998; Loughran, 2002b) 'because what I learn can easily point out some failures of the past... especially about things I used to think that were the right way of doing things' (PD: 25-03-04). This resonates with the arguments brought forward by Day (2004) and Day et al. (2006) that when a teacher's practices and beliefs are challenged, the teacher inevitably experiences negative emotions. This happened because like Dewey (1910) and Valli (1990) claim, when analysing the taken-forgranted, previous certainties are deconstructed and suddenly become uncertainties, and admitting the possibility of previous misconceptions is not easy. As Wildman et al. 
(1990) argue, 'one of the toughest aspects is hoving to admit the truth when you see it' (p.158). Unfortunately, these negative feelings have an effect on the reflective practitioner because 'the number of diary entries goes down in periods where I feel depressed, frustrated, or angry about something' (PD: 12-02-04). During such moments genuine enthusiasm wanes and like Day (1999) and Mason (2002) suggest, I needed to motivate myself and regain my enthusiasm, rather than give up (ISO: 04-02-04). Hence, although such situations arouse negative feelings, I know that 'that's where the learning is' (Ellis \& Bochner, 2000: p.748). The following diary extract illustrates two of the side effects of reflection (no definite answers, and negative feelings) as I experienced them:

I'm asking myself one simple question... but it seems I will never be able to answer it in a definite way. Do I perceive my life to be so horrible because I've started reflecting a year ago? Is there a connection between being reflective and this horrible feeling of disliking a lot of things? Am I in this existential crisis because I consider myself a reflective practitioner? Well, I told you that I will probably never get a definite answer... but here are some of my hypotheses. First of all I must say that by reflecting I have learnt to question many things that were usually taken-forgranted. Could I be questioning everything that is around me? And if so, isn't it sometimes better to just move on in ignorance? By questioning everything... am I making things that are usually acceptable look horrible? Am I exaggerating my questioning? Should there be a limit to what I should question myself about? (PD: 07-11-03).

The above extract also highlights another two vital components of reflective practice. These are the importance of questioning and the ability of the practitioner to converse with oneself. The number of questions in this extract might seem like overkill but, for me, this was an essential part of reflective practice. As regards conversing with oneself, the phrase 'Well, I told you that I will probably never get a definite answer... but here are some of my hypotheses' shows that while writing my reflections I entered into a conversation with myself. Also, as regards hypotheses, it can be seen that I offered myself a number of hypotheses rather than just one, emphasising again that any experience can be interpreted in multiple ways (Little, 2002). I tried to analyse situations from different viewpoints, as if I had multiple selves talking and discussing certain issues. This is similar to what Loughran (2002a, 2002b) describes as reframing; 
i.e. seeing your practice through others' eyes. According to Costa (1998), this is one of the most challenging of intellectual activities, but essential for reflective practice.

\subsubsection{Usefulness of Emotions in Understanding the Self}

Returning to the aspect of frustration through reflective self-study, I quickly learned to value my own emotions. No human experience is devoid of emotions (Brockbank \& McGill, 1998; Scheffler, 1991) and analysing experiences without giving due value to emotions would undermine both the experience and its consequent analysis (Day, 1999, 2004; Sykes, 1992; Oliver, 1998). Unfortunately however, Day et al. (2006) argue that 'there is insufficient consideration of the strength of their influence' (p.611).

Emotions 'are based on an individual's interpretation of a particular situation' (Zembylas, 2004: p.186) and can act as signs that highlight dilemmas or that situations have occurred that were not as expected (Oosterheert \& Vermunt, 2003; Frijda, 1986). As Miller \& Boud (1996) point out:

Emotions and feelings are key pointers both to possibilities for, and barriers to, learning. Denial of feelings is a denial of learning. It is through emotions that some of the tensions and contradictions... manifest themselves (cited in Ghaye \& Ghaye, 1998: p.81).

However, emotions should not be simply seen as key pointers, since they influence our actions (PD: 03-01-04). When emotionally charged, acting without thinking could be damaging rather than beneficial, as strong emotions might promote irrational action (Edwards \& Nicoll, 2006; Grant, 2001; Zembylas, 2004; Day, 2004). Consequently, emotions should also be reflected upon.

It seems likely that many teachers analyse students' emotional responses to obtain feedback on practice that helps with decision-making (Zembylas, 2004; Day, 2004). For example, when students appear bored, I try to change my way of teaching, but when students are enthusiastic about something, I try to make the most of the situation. Thus, the question to be asked is: why shouldn't I use my own emotions as feedback on my actions? Through reflective self-study, I try to analyse my own emotions just like I 
reflect on students' emotions since 'emotions are actually a driving factor in teacher development' (Golombek \& Johnson, 2004: p.324). Therefore, by paying attention to my own emotions, I was capable of understanding myself better.

\subsubsection{The Value of Taking a Systematic Approach towards Reflection}

As was previously suggested, most teachers probably engage in spontaneous reflection, but reflection is called for spontaneously only in extreme cases of perplexity or surprise (Gelter, 2003; Ben-Peretz, 2002; Grimmett et al., 1990). However, being reflective systematically is promoted as it is not so common and is of utmost importance (Pugach \& Johnson, 1990; Grant, 2001; Weiss \& Weiss, 2001). Systematic reflection is required because it offers opportunities for ongoing professional development. On the other hand, spontaneous reflection is usually triggered as a survival mechanism (PD: 23-0503). My experience urges me to state that 'systematic reflection is a powerful tool and teachers should know how to use it. Without reflection, a teacher is like an unarmed soldier' (PD: 27-05-03).

Through systematic reflection, I was constantly analysing teaching practice as well as personally held beliefs. Sometimes however, these did not blend, and on realisation, guilty feelings emerged. As Humphreys \& Susak (2000) suggest, I needed to alter either practice and/or beliefs. The following is an example of such an instance:

This was a serious mistake from my part and I cannot call myself a professional if such a thing is going to happen regularly. At least I realised what has happened because I am thinking about it. Let's hope I have the courage and will to change (PD: 14-11-03).

This and similar incidents did not discourage me, but motivated me further in wanting to understand myself better as a teacher, because I realised that I had much more to learn.

\subsubsection{Reflection is Not Fool Proof}

As I progressed through my reflective odyssey I realised that being informed is always better than moving forward in ignorance (Golombek \& Johnson, 2004; Day, 1999). No 
wonder that 'researchers on teacher thinking say: be very thoughtful, reflective, selfconscious, and intentional all of the time. This is the secret of good teaching' (Clark, 1995: p.20). Consequently, not only did I start to question taken-for-granted assumptions about my practice, but I also started questioning insights that emerged from reflection itself. However, reflection is not fool proof and the possibility of fooling oneself is still present for the reflective practitioner (Brouwer \& Korthagen, 2005; Fendler, 2003). Thus, I do not make the assumption that 'teachers' actions are necessarily better just because they are more deliberate or intentional' (Zeichner, 1994: p.17). Once I had realised this, I sometimes found myself re-reflecting on my past reflections. This happened mostly when insights and new understandings were made problematic as a result of further observation and analysis of practice. Hence, I regularly asked myself 'is this true, or is it what I want to believe?' (PD: 04-06-04). Chetcuti (2002) sees this as keeping an open mind, describing it as:

An active desire to listen to more sides than one, to give full attention to alternate possibilities, and to recognise the possibility of error even in the beliefs that are dearest to us. Being a reflective teacher means that you keep an open mind about the content, methods and procedures used in your classroom. You constantly reevaluate your worth in relation to the students currently enrolled and to the circumstances. You not only ask why things are the way they are, but also how they can be made better (p.154-155).

Hence, the open-minded reflective practitioner should always be willing to consider new evidence from various sources as this seems to contribute to the ability to reflect critically (Dewey, 1910; Wildman et al., 1990; Ross, 1990). Varying sources of information had the potential to challenge or substantiate my views that emerged from reflection; the result being a thorough re-analysis of my own views. As Mills (1959) contends, I 'try to think in terms of a variety of viewpoints and in this way you let your mind become a moving prism catching light from as many angles as possible' (p.214). This is surely the way forward if I do not want to get stuck in the rut of habitual practice. 


\subsubsection{Does Reflection Really Promote Professional Development and}

Change?

I embarked on a 'reflective odyssey' with the assumption that reflection promotes professional development in ways that help improve professional practices (Ghaye \& Ghaye, 1998; McIntyre, 1993). Yet, as the study progressed I started to question this assumption; in short, the 'healthy' habit of reflecting was itself under investigation:

I just hope that this habit is indeed making me achieve something. Sometimes I doubt it but many times I'm convinced it is helping me with my teaching. What I'm sure of is that it helps me understand certain issues I never thought about before. (PD: 01-07-03).

Yes, reflection indeed helps me in gaining insight into various issues; in bringing to light that which otherwise remains tacit (LO: 30-09-03). Professional development is all about improving professional practice and reflection is exactly this. It is a neverending form of professional development; an ongoing quest for improvement; a learning journey (Hunt, 2001; Grant, 2001; Hatton \& Smith, 1995; Brouwer \& Korthagen, 2005; Ghaye \& Ghaye, 1998). However, I must point out once more that gaining a deeper understanding of something does not result automatically in a change to professional practice (Tillema, 2004; Clegg et al., 2002). It is argued that the main benefit of reflection is that it can promote understanding as well as illuminate various possibilities for action (LaBoskey, 1995; Day, 1999; Sweeney, 2003). Thus, understanding is the first step towards change, for we cannot control and change the things we do not perceive and understand (Mason, 2002; Oliver, 1998; Ghaye \& Ghaye, 1998; Checkley \& Kelly, 1999; Dewey, 1910; Loughran, 2002a). Like Johnson (2001) and Russell (1993) I would argue that reflection is of little use if the learning does not lead to consequences; one of which is improved practice (ISO: 22-04-04). I therefore try to put new learning and insights into practice (LO: 02-03-04).

However, trying to change established practice and working against the status quo is a difficult job. In fact, 'no matter how hard I try, I'm always feeling like I'm swimming against the tide' (PD: 12-02-04). Notwithstanding such difficulties, reflection promoted 
professional learning, and the latter encouraged changes in both my professional and private spheres (PD: 25-04-04).

\subsubsection{Reflection-in-Action/Reflection-on-Action}

Refection can take place prior to teaching in the form of planning which Van Manen (1991) calls anticipatory reflection, while teaching as reflection-in-action, or after teaching while reflecting-on-action (Parker, 1997; Loughran, 1996, 2002a). Yet, depicting the reflective practitioner as someone who has control throughout these three periods of reflection is too simplistic and does not portray the whole reality the reflective practitioner finds him/herself in. When describing reflection-in-action, Schön (1987) states that it is a way of making sense of uncertain situations of practice. Through my experience as a reflective practitioner, like Korthagen \& Kessels (1999) I would argue that this description is more appropriately used to describe reflection-onaction. Furthermore, Schön (1983) contends that:

A practitioner's reflection-in-action may not be very rapid. It is bounded by the action-present, the zone of time in which action can still make a difference to the situation. The action-present may stretch over minutes, hours, days, or even weeks or months, depending on the pace of activity and the situational boundaries that are characteristic of the practice (Schön, 1983: p.62).

In teaching however, classroom decisions are split-second decisions and reflection-inaction is rapid, as the teacher has no chance of halting the helter-skelter of activities ongoing in a classroom, in order to think calmly about the best possible action to take (Day, 1999; Korthagen \& Kessels, 1999). As Saunders (2002) points out, 'teaching... requires intuition, imagination, improvisation: all those spur-of-the-moment, not-to-bepredicted, instinctive and idiosyncratic decisions' (cited in Day, 2004: p.87). Tickle (2000) further elaborates on this in the following argument:

It is also impossible always to judge the effects of action and to assess the nature of newly created situations, because of the rapid pace of decision making and volatile nature of circumstances in densely populated classrooms and schools.

The selection of information may be rapid and impressionistic; the likelihood of information being missed is considerable, and the potential for misjudgement enormous (p.127). 
In my case, I find in my practice that I often decide and act intuitively based on previous knowledge (Day, 2004; Korthagen \& Kessels, 1999), since as Day (1999) argues, 'reflection-in-action is intuitive... [and] focuses upon the identification and rapid solution of immediately pressing problems' (p.27-28). This experience-based intuition is 'deemed an essential part of the teachers' repertoire' (McNamara, 2002: p.22). The reflective practitioner is no different in such situations where $s /$ he is pressed to take split-second decisions. I will reproduce at length one particular extract from my journal that highlights this situation.

While driving my car in the hot Maltese sun I realise that I do not actually think while I'm driving... Whatever I do, I do automatically and never with too much thought... For example, if I turn round a corner and find a car being driven on the wrong side of the road heading towards me, my split-second decision is instinctive... and it is thus instinct that matters most in such situations. Yet, in the beginning of my driving days, I used to think about every little thing I did. The most important point I want to highlight here is that I do not actually think about my driving... but I use my experience... an acquired baggage of useful driving skills.

I believe that the work of most teachers inside the classroom is similar to the driving I just mentioned above... After years of experience, teachers make use of a baggage of previously acquired skills... The difference between an unreflective and a reflective practitioner is the professional questioning and analysing of experiences and this happens mostly outside the classroom and not while actually teaching...

What I want to point out is that reflective practice does have an effect on teachers and on their teaching. It has an effect in the sense that through reflective practices, teachers can make better use of their experiences... and thus, future actions are more informed. However, the actual thinking processes while in the classroom do not change much (PD: 07-09-04).

In this sense, I do agree with Laursen's (1994) contention that Schön's (1983) theory 'cannot without modification be applied to teaching practice' (p.132). When quick decisions are needed, quick thinking and intuition go hand-in-hand. However, few seem to acknowledge the role of intuition in professional practice. Mason (2002), and Edwards \& Nicoll (2006) suggest that intuitive decision-making is another reason why reflection-on-action is important, as through the latter we can stand back and re-assess what happened. Also reflecting-on-action is likely to extend the range of alternatives I have for the next time I act intuitively. In Day's (2004) words: 
As teachers' experiences... increase, alongside the necessary challenge and support through continuing professional development, it is likely that their... growth will be accompanied by the development of... intuition (p.88).

However, reflection-on-action is not free from intuition either. This does not diminish the importance of systematic reflection, but not including intuition into the equation would be stating half the truth. In fact:

I feel that ideas just strike me when I least expect. However, I still believe that systematic reflective practice is desirable. The more I reflect, the more active I keep my mind, and the greater the chance of getting startling new ideas. Some ideas are indeed good; others have to be dropped after carefully analysing them... (PD: 2009-05).

Therefore, intuition is ever-present, and systematic reflection rather than one-off incidental reflection increases the chances of intuitive connections and new ideas (Houston \& Clift, 1990; Van Maanen, 1988). According to Mitchell (2000), studying one's own practice in context 'provides the optimum conditions for the acquisition of those illuminating insights which make formerly opaque connections suddenly pellucid' (p.183). The reflective practitioner can actively look for connections that ultimately give a broad understanding of the phenomenon under study by observing and analysing practice, but these connections are arrived at intuitively and are not actively created by the practitioner (Oosterheert \& Vermunt, 2003; Mason, 2002). My experience resonates with White's (2002) contention that 'bits of information came from a variety of sources, and flashes of insight occurred unexpectedly. Slowly, slowly but satisfyingly surely, my understanding continues to grow' (p.321).

However, although intuition is important, it is not sufficient on its own, for like Talbot (2002), 'I believe that I have learnt in ways not afforded to me simply by intuition' (p.225). Thus, I come to understand intuition as an important factor in classroom teaching, but daily experiences still need to be analysed while reflecting-on-action. On the other hand, new insights that arise from reflection are integrated into my knowledge base, affecting my future intuitive actions. 


\subsubsection{A Greater Sense of Control Over my Professional Life}

Such a continuous cycle of analysing my practice and obtaining deeper understanding to better inform my practice, gave me a better sense of control over my work.

I believe that reflecting on experience helps us analyse and extract what learning opportunities experience has for us... I believe that reflection helps us in better observing what is around us; preserving experiences better (in the form of reflective journals); analysing what happened in lived situations and what we can learn from these; think about how we can use new learning in the future; question our own beliefs, values, and assumptions; and create new knowledge that is always being deconstructed and re-constructed (PD: 18-10-05).

Thus, reflection should 'give us a greater sense of control over our own work and free us somewhat to increase our avenues for alternative action' (Ghaye \& Ghaye, 1998: p.69). As such, every aspect of the life of a reflective practitioner is important in understanding how s/he develops. 'Things believed, values and guiding principles, and things read, done and thought all come under scrutiny. Professional knowledge is reshaped through... reflection' (MacLeod \& Cowieson, 2001: p.242).

\subsection{Reflective Writing}

One of the central techniques recommended in the reflective practitioner discourse is the keeping of diaries or journals by teachers... in which they reflect systematically on their experiences as they perceive them, keeping a record that can be returned to and re-interrogated in the light of subsequent experiences (Moore, 1999: p.135).

Keeping a reflective journal was a crucial tool I used to record my own experiences, reflections, and interpretations (Sweeney, 2003; Chetcuti, 2002; Tillema, 2004; Zembylas, 2004; WestED, 2000; Holt, 2003; Glaze, 2002; Conle, 1996; Schuck \& Segal, 2002; Pollard, 2002; Ghaye \& Ghaye, 1998; Johnson, 2001; Meriläinen \& Syrjälä, 2001; Day, 1999, 2004). Mills (1959) suggests that 'the sociologist's need for systematic reflection demands it' (p.196); and hence, 'the process of reflection should generate a text' (Ghaye \& Ghaye, 1998: p.66). Yet, I came to understand that such a journal was not simply a record of reflections and observations made. It was also a 
driving force for through writing I enhanced my reflective awareness. In short, writing helped me think, reflect, and develop (Kraft, 2002; Golombek \& Johnson, 2004; Loughran, 2002a; Donmoyer, 2000; Johnson, 2001; Armour, Moore \& Stevenson, 2001; Shulman, 1992; Mason, 2002). As I once argued in my journal: 'I write, therefore I think' (PD: 16-05-03). In a study by Bain, Mills, Ballantyne \& Packer (2002), 'some students considered reflective writing as a record of reflective thinking, some as a motivator of reflective thinking, and others as an extension of reflective thinking' (p.189). The following extract highlights how $I$ came to understand the act of writing at a very early stage in my reflective odyssey:

One tool that I found of extreme value in self-study is writing. Writing helps me understand a lot of things about myself. It helps reduce the imbalance I feel between theory and practice since while writing I start thinking critically about my past actions and how these together with educational theory can inform future practice. Sometimes I start writing without knowing exactly what I am going to write about. Eventually, I start tackling various topics and sometimes I even start examining certain issues I never thought about (PD: 20-06-03).

I thus see writing as a way of thinking that helps me in understanding myself; my own actions; my thoughts; my emotions; my experiences (Polkinghorne, 1995; Campbell, 2000; DeMulder \& Rigsby, 2003; Renner, 2001; Elliott, 2005; Kelchtermans \& Vandenberghe, 1994; Richardson, 2002; Meriläinen \& Syrjälä, 2001). Apart from selfunderstanding, self-reflective narrative assists learning because it aids professional thinking (Bruner, 1996; Fottland, 2004; Heikkinen, 2001; Glaze, 2002; Conle, 2003).

\subsubsection{Writing Pushes Thought into Unforeseen Directions}

According to Bain et al.'s (2002) study, 'my thoughts seem to develop as I go along' (p.190) and it is this that turns the journal into a learning tool rather than merely a record of reflective thinking. It often seems to me as if writing has a life of its own (MacLeod \& Cowieson, 2001). It is not me who consciously controls what I write about, but it is the act of writing that leads my thoughts. 'Writing is like a chain reaction. Once I start writing, one thing leads to another and, without realising it, I start writing and reflecting on various issues' (Attard \& Armour, 2005: p.198). It is here that Edwards \& Nicoll's (2006) rhetorical question becomes important: 'Can one reflect 
without language?' (p.122). As Vygotsky (1962) points out, 'thought... does not merely find expression in speech; it finds its reality and form' (cited in, Emihovich, 1995: p.37). This shows that like Caulk (1994) argues: 'writers create and change their ideas as they write' (cited in, Bartels, 2003: p.741). In fact, the stories I write are not a reproduction of reality but are constructed and interpreted by myself as I struggle to reconstruct and give order to the everyday chaotic experiences that are often imbued with initial disorder, difficulty and uncertainty (Van Maanen, 1988; Fottland, 2004; Bain et al., 2002; Mullen, 1994; Charmaz, 2000; Richardson, 1995; Barone, 1995; Beach, 2001; Usher, 1998; Elliott, 2005; Parker, 1997; Ghaye \& Ghaye, 1998; Golombek \& Johnson, 2004; Conle, 2003).

Narratives impose meaning on events and experiences therefore, not only when they provide an explicit evaluation of those events and experiences, but also by the very act of structuring them into a story (Elliott, 2005: p.12).

These created stories are what counted as data in this particular self-reflective research (Bruner, E.M., 1986) and are an illustration that no account is objective, neutral, and bias-free (Ghaye \& Ghaye, 1998). In Potter's (1996) words, 'the world... is constituted in one way or another as people talk it, write it and argue it' (cited in, Schwandt, 2000: p.197). While writing, I was consciously thinking about my personal theories and tacit learning, and these became explicit through the act of writing in the narratives I created (Charmaz, 2000; Golombek \& Johnson, 2004; Donmoyer, 2000; Meriläinen \& Syrjälä, 2001; Coles, 1989; Conle, 1996, 2003; Loughran, 2002a; Osterman, 1990).

Also, narrative helps preserve the complex nature of human behaviour and meaningmaking, since through story we connect events together; thus reasoning how one aspect affects another, rather than leaving individual events as disconnected (Elliott, 2005; Meriläinen \& Syrjälä, 2001; Cooper \& McNab, 2002; Polkinghorne, 1988, 1995; Ghaye \& Ghaye, 1998; Kelchtermans \& Vandenberghe, 1994, Mason, 2002).

\subsubsection{Writing Promotes Further Understanding}

My experience of writing reflections also suggests to me that at times, it is easier to write about something than to talk about it. This is especially true as regards 
experiences that are painful and that arouse emotions such as frustration and anger (PD: 23-10-03). One of the reasons might be that sitting down and calmly reflecting upon a situation offers more time for reflective thought than does talking. Bain et al.'s (2002) experience resonates with mine when they argue that 'when I talk, I do not really think a lot before I talk. I think it is more in-depth when you are writing journal entries because you tend to think about it a lot more' (p.190). Richert's (2001) assertion is also very similar to how I experienced writing: 'I've talked about [this] situation before with colleagues, but in writing about [it], I discovered a new dimension in thinking about [it]' (p.169).

Reflective writing is what Richert (2001) and Loughran (2002a) explain to be the capturing of experience with the intention of understanding and learning from it. When I reflect without writing in my journal, my thoughts start wandering off, and I find it hard to focus on important aspects, as my thoughts leap from one issue to another. In this study, writing afforded me an instance, specifically allocated for focused reflective thinking. However, when conversing, one has a greater possibility of obtaining feedback from others, and this is not possible while writing in a journal. Yet, just as when a person talks about an experience, writing helps me with my questioning, my thinking, and the building of arguments (Meriläinen \& Syrjälä, 2001). In short, reflective writing has provided me with a medium for reflection, critical analysis, and reasoning (Houston \& Clift, 1990; Kemp, 2001; Ross, 1990; Kelchtermans, 1994). After all, 'narrative is... frequently accompanied by a more reflexive methodology' (Elliott, 2005: p.152).

\subsubsection{The Significance of Language}

Self-reflective writing afforded me the integration of actions, thoughts and emotions; because these can be constructed and expressed through the language I use (Emihovich, 1995; Schwandt, 2000; Sykes, 1992; Donmoyer, 2000; Oliver, 1998). Such integration is important because according to Bruner (1984) 'a life as experienced consists of the images, feelings, sentiments, desires, thoughts, and meanings known to the person whose life it is' (cited in, Usher, 1998: p.18), and writing gave me the opportunity to 
understand myself as a teacher in a holistic manner rather than as specific and separate aspects (Golombek \& Johnson, 2004; Oliver, 1998). After all teacher learning is warm, living, and emotional too, and very different to the cold cognitive learning that is sometimes portrayed in the literature (Hashweh, 2004; Day, 2004). I must also point out that writing narratives that incorporated thoughts, emotions, and actions was $a$ natural way that helped me understand my situation better. After all, people, including teachers, use narratives to communicate thoughts; to give interpretations; to understand experience (Czarniawska, 2004; Richardson, 1995; Day, 1999; Kelchtermans \& Vandenberghe, 1994; Clandinin \& Connelly, 2000; Connelly \& Clandinin, 1999; Freeman, 1994; Ben-Peretz, 2002; Conle, 2000; Oliver, 1998). Also, humans are surrounded by narratives and 'children everywhere learn how to listen to and tell stories at very early ages' (Richardson, 1995: p.200). No wonder then, that I experienced the construction of self-reflective narratives as a natural process. Moreover, there are certain aspects of experience, like emotions, that can only be explained and described through narrative (Donmoyer, 2000; Beach, 2001).

\subsubsection{Keeping the Journal - Pros and Cons}

Keeping a reflective journal is not always a pleasant experience (Ghaye \& Ghaye, 1998). Like others, I have experienced it is as a time-consuming endeavour (Schuck \& Segal, 2002; Meriläinen \& Syrjälä, 2001; Mason, 2002; Glaze, 2002; Day, 2004; Conle, 2000; Richert, 1992). For learning to emerge, journal keeping should be a longitudinal process. 'It is unrealistic to think that new, wonderful insights about teaching and learning will emerge, as if by magic, from one or two short entries!' (Ghaye \& Ghaye, 1998: p.86). Also, like reflection, systematic journal keeping does not come spontaneously (Clegg et al., 2002; Meriläinen \& Syrjälä, 2001; Richert, 1992). Nevertheless, the benefits outweigh the costs (WestEd, 2000). Of most importance is that writing about the self is promoted as an ideal way of showing experiential learning and development of the writer him/herself (Mullen, 1994; Hashweh 2004; Usher, 1998; MacLeod \& Cowieson, 2001; Richert, 1992; LaBoskey, 1992), and this is what was needed in a study where I wanted to understand my own professional learning through reflective practice. As one teacher said: 'As I look back at the hours of writing these 
reflective pieces, I realise that they were the true beginning of my transformation as a teacher and an individual' (DeMulder \& Rigsby, 2003: p.278).

\subsubsection{Writing as Inquiry}

Writing was part and parcel of the research process, used to search for deeper understanding. It 'is a method of inquiry' (Conle, 2001: p.22). Writing helped me continuously question myself about various issues (Attard \& Armour, 2005; Chetcuti, 2002; Johnson, 2003). In a particular entry I argued that 'ironically enough, I started writing today to try and find some answers to my problems. Instead, I wrote an incredible number of questions' (PD: 07-11-03). Such questions promoted an internal dialogue (see section 3.5); made me observe certain aspects of practice more thoroughly; and also helped me realise that educational literature could be helpful in my development.

I have come to realise that writing and reflection could not be separated in my research process, as they were inextricably linked. For me, like Meriläinen \& Syrjälä (2001), 'narrative research consists of self-study and reflection for which writing is a crucial means of inquiry' (p.1). No wonder that writing as a means of professional development is frequently promoted in conjunction with reflective practice (Mason, 2002), since stories are epistemologically a genuine way of understanding teaching from the teacher's point of view (Clandinin \& Connelly, 2000; Golombek \& Johnson, 2004). This is especially true when considering that 'you cannot divorce how you think from how you write' (Mills, 1959: p.222) and this is what Ellis \& Bochner (2000) call 'the reflexive qualities of human communication' (p.743). Writing alimented my reflections while my reflections took the concrete form of written entries. Thus, writing and reflection have to go hand-in-hand.

\subsubsection{Reflective Writing - A Longitudinal Meaning-Making Process}

Similar to my arguments upon reflection, after the act of writing, uncertainty and inconclusiveness still prevail. For example: 'after writing this personal entry into my diary I still feel confused' (PD: 30-01-04). Like Van Maanen's (1988) confessional 
tales, my journal entries evidence inconclusiveness, uncertainty, and blind spots. Consequently, I still questioned my own reflective writing as I asked myself if the arguments I wrote were aimed at helping me better understand or were simply making me feel better (PD: 06-02-04). Simple descriptions of events rather than reflective writing might simply reproduce existing beliefs unquestioningly. It is not the act of writing per se but the questioning promoted by the act of writing that helps in acquiring new understandings (Johnson, 2003). As such:

There is no virtue in trying to describe and faithfully regurgitate what has happened. The idea is to set out the teaching incident and then to interrogate it through the process of writing (Ghaye \& Ghaye, 1998: p.86).

After all, writing 'does not inform about facts and events, but about experiences and their meaning for the storyteller' (Kelchtermans, 1994: p.102). It is of little use to simply know the facts and events of classroom life; especially when considering that people spend more than a decade in classroom as students, and maybe more as teachers.

\subsubsection{Understanding Professional Development through a Habit of Writing}

My journal helped me understand my own development since it acted as an ongoing record of my understandings (Elliott, 2005). Hence like Heikkinen (2001), 'from this experience, I came to a conviction it is useful for any teacher to reflect oneself through writing' (p.3). Also, according to Mills (1959) keeping a journal, 'also helps you build up the habit of writing' (p.197). But if writing promotes reflection, and keeping a reflective journal builds up a habit of writing, then keeping such a journal also promotes a habit of being reflective; and this makes keeping a journal of great professional value. In summary, both the process and the product of reflective writing are important (Connelly \& Clandinin, 1990).

\subsubsection{Self-Confessing Writing}

Finally, Gore (1993) argues that 'journals can function as a form of confession and/or therapy' (cited in Fendler, 2003: p.22). I happen to be a Roman Catholic; and not a perfect one at that. I was taught to confess if I've done wrong and want to improve myself. If I plan, or know that I will make the same mistakes again, I simply do not 
confess. Thus, if as a teacher I realise that I can improve my professional practice; then yes; let my personal journal function as a form of confession, with the aim of improving.

\subsection{Conversing with Oneself}

Conversing with someone else offers the possibility of feedback and exposure to different viewpoints. Unfortunately, I felt isolated because I am the only teacher teaching the new SEC PE syllabus in my school. Also, none of my colleagues are on a reflective odyssey and most of them argue that they have too heavy a workload to engage in reflection. In this context, I could not share my reflective journal with anyone, other than my research supervisor, who acted as a critical friend. However, through my daily engagement with reflective writing, I felt the need to converse; to make arguments; to obtain multiple viewpoints; to ask questions and give hypothetical answers. Like Verity (2000), I felt 'the urge to bounce ideas and questions off a virtual interlocutor' (cited in, Golombek \& Johnson, 2004: p.313). In Mills' (1959) words:

I do not know the full social conditions of the best intellectual workmanship, but certainly surrounding oneself by a circle of people who will listen and talk - and at times they have to be imaginary characters - is one of them (p.201).

I started conversing with my reflective journal. In reality, I was conversing with myself, but the journal was situated as the other; a partner in conversation (Meriläinen \& Syrjälä, 2001; Fottland, 2004). The unpredictable course of thinking while writing is very similar to when two or more people converse. During informal conversation, one thing leads to another, and nobody can precisely predetermine the outcome of such conversations. The same happens during reflective writing because reflective journals promote an internal reflective dialogue; a conversation with oneself (Conle, 2001; Pollard, 2002; Ghaye \& Ghaye, 1998; Glaze, 2002; Barone, 1995). According to Ghaye \& Ghaye (1998), conversing with oneself is 'the centre-piece of the whole reflective process' (p.19). Thus: 
I personally think that writing has the power to put the writer in conversation with $\mathrm{him} /$ herself... While writing I start asking questions to myself and hence I try to find explanations and answers to my own questions and classroom practices. This is of extreme importance, especially when a teacher feels isolated. I feel that teachers need to speak about their efforts, frustrations, successes, etc., and when isolation is a reality, I think that writing helps us in sharing these things with ourselves. No... this is not madness. On the contrary, I think it is very helpful and healthy for us as education professionals (PD: 20-06-03).

While writing, it seemed to me that I unconsciously had multiple selves and I constantly made arguments as if I was debating. From the above extract, it is evident that I was defending my argument by saying: No... this is not madness. It is as if someone was accusing me that what I was arguing about was nonsense. Using the plural also made me recognise, in retrospect, that I was conversing with someone. I could have said: 'healthy for me as an education professional', but instead I said: 'healthy for us as education professionals'. Why? The only plausible explanation I can come up with is that I engaged in conversation with my multiple selves. My journal is replete with such examples, especially when I encounter professional dilemmas. The following is just another example:

I have already argued about this before... but now I'm conversing to myself. The following are the arguments brought about by the teacher in me who is falling on the defensive with arguments that are convincing the part of me that is putting forward these accusations (PD: 22-06-03).

I thus agree with Ellis \& Bochner (2000) that the narrative we construct 'displays multiple layers of consciousness' (p.739). It is interesting to speculate the role these multiple selves play. Can these multiple selves play the role of an audience, students, etc., as the need arises? I personally did not only incorporate other people's viewpoints into my thoughts that emerged from informal conversation during my observations, but I also imagined myself in various positions, such as a parent, student, school administrator, and teacher amongst others. In short, 'writing helps us distinguish between our different voices' (Meriläinen \& Syrjälä, 2001: p.4).

But why is conversing with oneself healthy for the reflective practitioner? Bohm (1990) makes the following set of arguments: through dialogue, we disclose assumptions and 
beliefs held, as well as practical theories; dialogue reveals our understanding and our knowledge; and what we learn through conversation may lead us to action. But do these same arguments hold when conversing with oneself? Through my personal experience with reflection and reflective writing, I have come to learn that through conversation with oneself, the aforementioned arguments do hold. As such, 'narrative may also be described as an interactive practice with all the give and take of conversation when it values a multiplicity of voices and perspectives' (Brunner, 1994). Apart from the aforementioned aspects, I agree with the arguments brought forward by Ellis \& Bochner (2000):

In conversation with ourselves, we expose our vulnerabilities, conflicts, choices, and values. We take measure of our uncertainties, our mixed emotions, and the multiple layers of our experience (p.748).

This is exactly what I have argued for in reflection. It comes at no surprise then that Schön (1983) promotes internal dialogue as very important for reflection. Maybe what various fields term as reflection, is simply the ability of the practitioner to converse with him/herself as regards aspects of professional practice while being able to study issues from various angles. However, the ability of the practitioner to enter into conversation with oneself depends on the quality of observation, interpretation, evaluation and open-mindedness (Day, 1999), as well as the ability of the practitioner to tolerate ambiguity, uncertainty and inconclusiveness.

\subsubsection{Questioning Promotes Internal Conversation}

My reflective conversation was aided by my continuous questioning because 'the question always invites a response' (Parker, 1998: p.128). Consequently, the constant questioning that is evident in my journal is a sign of needing 'the other' because the teacher's 'need for an other is reflected in her use of questions in [the] journal' (Golombek \& Johnson, 2004: p.313). Hence for conversation with oneself to take form in reflective writing, 'teachers engage in explicit self-questioning and selfresponding... in exploring problems from different viewpoints' (Pugach \& Johnson, 1990: p.190) as can be seen in the following section. 


\subsection{Questioning}

Questioning is a side-effect of reflecting on one's own practice (Wildman et al., 1990; Schuck, 2002). It is a two-way process, because 'systematic reflection promotes questioning from my part, and questioning encourages me to think of new possibilities. This is where new ideas come from' (PD: 20-09-05). It is not surprising then that questioning is recommended as a strategy that promotes reflective thinking and is considered to be the heart of reflective practice (Roth, 1989; Weiss \& Weiss, 2001; Grant, 2001). Without questioning, the practitioner is not truly reflective because if we do not question, we do not take a second look at experience (Zeichner \& Liston, 1996; Grant, 2001). Questioning is also a means towards dynamic meaning-making, understanding, and insight (Conle, 2003; Mayes, 2001; Kroll, 2004). It is interesting to note that questions were evident in almost every entry I made in my reflective journal and on most occasions I 'asked many more questions than [I] got answers. That might not be a bad thing' (ISO: 23-04-04). This is common when inquiring into practice (Ham \& Davey, 2002; Mason, 2002; Cochran-Smith \& Lytle, 2001; WestEd, 2000). Some questions needed to be postponed until further observations were made; others could not be answered but were still valuable in making me think further about situations. For example, 'after yesterday's lesson, I asked one simple question to myself. The question is simple but its answer is not... and probably no answer exists in the first place' (PD: 25-03-04). It is important to realise that hoping for simple and definite answers to our own questions is naïve (Parker, 1998). The more questions I posed to myself, the deeper the reflection and understanding of the issues at hand. I agree with Guðjónsdóttir \& Dalmau's (2002) statement that 'keeping up the courage to question, and using questioning to search for new frames of reference were important elements... These questions made us deepen our thinking' (p.95). Throughout the study I questioned myself about my observations; my experiences; my actions; my plans; my feelings; my beliefs and assumptions; my philosophy; my thoughts; my new understandings and insights; my learning; societal forces that impinge on my practice; as well as private issues. On certain occasions, I also questioned my questioning and 
the reflective process I was engaged in (PD: 20-06-03). For example: 'Does reflection improve our learning?' (PD: 18-10-05).

It is the questions I ask myself that make my reflections remain incomplete. Questioning made everything problematic, and I was thus in a constant search for new understanding (Pugach \& Johnson, 1990). Besides, I was constantly trying to hypothetically answer the questions I posed to myself, and when I tested such answers in practice through action-research, other, more elaborate and deeper questions cropped up (White, 2002). As such, a question elicits an answer, but the answer also probed further questioning for deeper understanding in a continuous cycle of reflective thinking (Dewey, 1910). Similarly, Yin (2003) contends that:

One insight into asking good questions is to understand that research is about questions and not necessarily about answers. If you are the type of person for whom one tentative answer immediately leads to a whole host of new questions... you are likely to be a good asker of questions (p.60).

\subsubsection{Challenging the Status Quo through Questioning}

Asking questions is the first step towards learning. Without questioning we would not go in search of answers and without challenging the status quo, we would not be capable of changing and learning (ISO: 23-04-04).

As a teacher engaged in reflective practice argued, 'we need to learn to ask questions' (Pugach \& Johnson, 1990: p.201) because 'as long as there is ongoing questioning there is movement' (Mason, 2002: p.92). This made my reflective journal take the form of a never-ending quest for understanding. Thus, 'I'm learning to question everything and this in turn helped me realise that I can always improve' (PD: 19-01-04). When taking this never-ending quest for improvement into consideration, I realised that some of my questions aided me in thinking about hypothetical futures that are different from past and present. Such possibilities for a better future were alimented by new understandings that emerged from the reflective process itself. 


\subsubsection{Asking the Right Questions}

Teachers, like researchers need to develop the ability to ask the right questions (Parker, 1998; Yin, 2003). Throughout my first year as a reflective practitioner, I was constantly asking myself one question regarding the aims of my teaching. I was asking myself which road to take between two differing philosophies. Try as I might, I did not get plausible and convincing answers to my question. I was blinded enough not to realise that these two philosophies could both be integrated into my practice. As such, for more than a year, I was continuously asking one question, but the question was not the right question to ask (PD: 26-09-03; PD: 30-09-03). My question implied a false dualism, and consequently, the solutions I tried to find to my problem did not predict a possible integration of two extreme points on a deceptive continuum. As argued by Griffin (2003), 'sometimes it is hard to see something that is right in front of you' (p.213), and this happened to me by posing an inappropriate question to myself. Hence, a blinded perspective could lead to asking the wrong type of question, and this in turn could further limit what I am able to see; thus limiting my understanding regarding that particular issue. In this case, I had to ask how to integrate rather than which to choose.

\subsubsection{Should I Limit My Questioning?}

Since through questioning I make things that seem acceptable become problematic, I asked myself if there should be a limit to questioning (PD: 07-11-03). Is there a threshold to how many problematic and uncertain situations a person can withstand? Although the practice of questioning myself opened up possibilities for deeper understanding as regards aspects and assumptions that were taken-for-granted, I sometimes found myself in situations where I crumbled under the pressure. Nothing seemed good enough, and I was a frustrated man. Too many painful situations to handle at once made me feel defeated. In fact I argued that 'questioning things seems to have become an obsession. I do think that questioning is indeed healthy... but like alcohol, I think if done in excess, it will be harmful' (PD: 08-11-03). Thus, I also had to learn to tackle a few issues at a time, resist the temptation of wanting to learn about everything all at once, and be patient with my learning (ISO: 23-04-04) because 'if you are overly ambitions and take on too much at once, you can feel overwhelmed when several 
aspects of practice become problematic which previously seemed satisfactory' (Mason, 2002: p.220). As such, I realised that there was a link between negative feelings and the number of questions I posed to myself. When I questioned myself on too many issues at once, my frustrations grew slowly but surely. On the other hand, when I felt defeated and frustrated, my questioning diminished drastically until I felt fine again.

\subsubsection{The Quest for Meaning}

In Gergen \& Gergen's (2002) words, this study 'fails to declare a sacred territory of the undiscussable' (p.19). Everything was questioned, and everything should still be questioned. After all, as I have already argued, questions help me understand meanings rather than search for illusive ultimate truths (Charmaz, 2000; Grimmett et al., 1990). Thus, I want the reader to do as I did: to be curious; to question what is presented, and through these questions, enter into a reflective conversation with him/herself. In short, curiosity is beneficial for the reflective practitioner, because it is curiosity that leads to seeing new possibilities and different futures. As such:

Questioning... if undertaken constructively, supportively and reflectively, is a creative process. It is through questioning, that new possibilities for improving... have a chance to emerge (Ghaye \& Ghaye, 1998: p.11).

\subsubsection{Questions should be Critical}

If reflection is not fool proof, then the practitioner can still fool him/herself if $s /$ he sees only what s/he wants to see. Hence:

It is possible for teachers to be reflective but thoroughly uncritical. Teaching experiences can be distorted, self-fulfilling, unchallenging and constraining. For these reasons alone they need to be questioned critically (Ghaye \& Ghaye, 1998: p.114).

Hence, questions should be critical in nature, and it is these challenging questions regarding our beliefs that lead us to view things from different perspectives. This is all about engaging in transformative/critical reflection. As Johnson (2003) points out, as a teacher, I am in a position of power and authority that allows me the opportunity to push my own agendas based on my beliefs. This is exactly why I wanted to critically 
question my practice and my beliefs since without doing so, practice based on unquestioned beliefs cannot be consciously changed (Kraft, 2002).

\section{$\underline{3.7 \quad \text { Summary }}$}

In this chapter I discussed the fundamental importance of practical experience in professional learning, and how reflection is weakened without the availability of personal experience. I also discussed how prior experiences unconsciously shaped me and my professional beliefs.

I also talked about different stages in my reflective process. I noticed that my writing and the questions I asked myself changed in accordance to the four levels of reflection described in this chapter i.e. spontaneous, technical, dialogic, transformative/critical reflection. In Little's (2002) words, questions became 'more complex and abstract... Each subsequent transformation of the question would require more time, thought, and self-disclosure' (p.927).

Therefore, 'answering... questions depends upon my skills of inquiry, including what specific questions I develop to ask and how I ask them' (Peshkin, 2000: p.6). These skills of inquiry I developed through experience as I engaged myself in reflective practice, reflective writing and conversing with myself, and such skills do not develop overnight but require time (Pugach \& Johnson, 1990). In short, reflective inquiry should be 'a sincere habit of continually asking questions and looking for answers over time' (Ward \& McCotter, 2004: p.254).

Finally, I cautioned the reader that reflection is not fool proof since a practitioner can still be uncritical while questioning various situations. Hence, keeping an open-mind and trying to view issues using different lenses is an important aspect that can diminish blind spots in our understanding. 
In the coming chapters I aim to discuss the various issues presented here in greater detail, while also pointing out how reflective self-study impacted upon my professional development, with all the give-and-take of taking responsibility for my own learning. 


\section{Chapter 4}

\section{Learning about the Self through Reflective Self-Study}

\subsection{Introduction}

As the term reflective self-study implies, it does not only include learning about my own practice, but as Kosnik (2001) contends it also allows me to explore and better understand myself (p.78). Mullen (1994) and Kelchtermans \& Vandenberghe (1994) argue that the self is an important topic of inquiry, if we are to understand how people experience their lives, while Day (2004) contends that 'understanding the self is part of learning to grow personally and professionally' (p.118). This is especially true in the teaching profession where 'self and the professional self overlap' (Kelchtermans \& Vandenberghe, 1994: p.47). In this case, reflective self-study helped me understand and learn about my own beliefs and assumptions; how I learn and develop; and what encourages and/or inhibits my own development. I contend that the most important aspect of reflection is introspection, i.e. the understanding of oneself. Understanding oneself is no simple process however and, from my experience, I would contend that the most difficult person to understand is at times oneself. Sparks (2002b) points out that 'there are dragons that you will run into on your journey, but the biggest dragon you will meet is yourself' (p.6). Therefore, throughout the study I always kept in mind the questions put forward by Usher (1998): 'Is the self fully in control of events and experience? Is the self always transparent to itself or very often opaque, perhaps even unreadable?' (p.20). Sometimes I could not understand what was happening to me, why $I$ acted and reacted in certain ways, and why I had certain behaviours, as the following question ending one of my journal entries illustrates: 'And yet, in front of all this, I feel relaxed. How come?' (PD: 28-05-04). But why should we strive to understand the self? As Dearden (1975) points out, 'the better we know our motives, wishes, purposes, typical reactions... and so on, then the greater is the possibility of bringing our thought under conscious control' (cited in, Parker, 1997: p.127). 
Unexpectedly, reflective self-study also put private issues under the spotlight. As a reflective teacher stated, 'little did I know that I was embarking on a journey that would change my entire life' (DeMulder \& Rigsby, 2003: p.267).

\subsection{Learning about My Beliefs and Assumptions}

As the study progressed, I came to realise the truth of the suggestion that personally held theories, values, beliefs, and assumptions could literally shape my practice, my goals, and the decisions I took (Valli, 1990; Sweeney, 2003; Thurlow \& Stuart, 2004; Johnson, 2003; Kroll, 2004; Seddon, 1994; Clark, 1995; Ghaye \& Ghaye, 1998; Kelchtermans \& Vandenberghe, 1994; Yung, 2001; Moore, 1999; Grimmett et al., 1990). This happens automatically because as Johnson (2003) argues, 'I do not check the person that I am at the door when I enter the class. I come in as a whole person' (p.794). These beliefs and assumptions, if unquestioned and unanalysed, become what Mills (1959) has described as unknown forces that largely control our actions, while not being able to define and describe them. These unknown forces are years and years of tacit learning and, as I have argued previously, prior learning is what constructs the person we are now (Fuller et al., 2005). This is exactly why the taken-for-granted should not remain so, and reflection was fundamental throughout this process of questioning my assumptions because:

Reflective practice is a process that involves a reflective turn. This means returning to look again at our taken-for-granted values, professional understandings and practices. This focus on routines, rituals, on everyday occurrences that make up the bulk of a working day is most important (Ghaye \& Ghaye, 1998: p.16).

Only by making explicit that which was hidden even from myself was I able to challenge and transform my assumptions. It is the levels of dialogic and transformative/critical reflection, as described in Chapter 3 , that help us question our assumptions more deeply, and it is this questioning and transformation of our beliefs and assumptions that help us consciously change and improve our professional practice (Ward \& McCotter, 2004; Day, 1999; Sparks, 2002b). This is an important component 
of reflective self-study (Grant, 2001; Weiss \& Weiss, 2001; Day, 1999; Humphreys \& Susak, 2000).

For reflection to genuinely be a lens into the world of practice, it is important that the nature of reflection be identified in such a way as to offer ways of questioning taken-for-granted assumptions and encouraging one to see his or her practice through others' eyes (Loughran, 2002a: p.33).

\subsubsection{Aspects that can Induce the Questioning of Beliefs}

I would emphasise that the analysis of my taken-for-granted assumptions happened quite naturally through the process of reflective self-study. I did not consciously plan to start analysing my beliefs and assumptions, but this happened as a consequence of the realisation that a discrepancy existed between my values and what I observed in practice. In such situations, I needed to make the problem clear to myself, and such clarification included understanding my practice better, while also going deeper into my personally held assumptions. As a reflective teacher argued:

The conflict I experienced between my beliefs and my practice gave me the motivation to continue my professional development by looking specifically at my values and my values-in-action, on the one hand, and the idea of coming to know my own practice, on the other (Ghaye \& Ghaye, 1998: p.122).

My personally-held beliefs and assumptions were thus under inspection and as Stringer (1996) and Pugach \& Johnson (1990) imply, this increasingly happened in parallel to my developing an inquiring stance. But if reflective writing promotes an inquiring stance through ongoing questioning, the act of writing itself helped me reflect upon my assumptions. Thus, writing was a priceless tool to understand myself (Ashley, 2001; Kelchtermans \& Vandenberghe, 1994).

According to Fitzgerald et al. (2002), collaboration with other teacher-researchers engaging in reflective self-study also seems to provoke the questioning of personal assumptions, and this aspect will be further elaborated in Chapter 7. What is important at this stage is that different viewpoints that can come from collaboration and 
communication with colleagues have the potential of disturbing assumptions with which you have become comfortable. As a student-teacher argued:

At various times during the seminar, we each found ourselves either questioning another student's fundamental assumptions, or struggling to articulate and defend our own assumptions against such questioning from another student. Sometimes these discussions became very uncomfortable. At one point or another, most students found themselves involved in a soulsearching identity crisis that was instigated by the seminar (Metz, 2001: p.15).

Another factor that leads towards the questioning of my own beliefs and assumptions is the reading of existing literature. Some newly acquired knowledge and insights that result from such an endeavour sometimes 'made me consider unlearning years of learning' (PD: 12-05-05). This resonates with Young's (1991) contention that by gaining new insights from educational literature and from other colleagues, 'inaccurate assumptions and problematic interpretations should be more easily revealed, and tenets formerly accepted as given are more likely to be questioned' (cited in, Husu \& Tirri, 2003: p.346). New insights were used to put my own assumptions under the spotlight for further analysis and examination, because what we believe remains unaltered if we do not encounter alternative viewpoints (Kroll, 2004; Schwandt, 2000; Wilson, 2003).

\subsubsection{Questioning Assumptions as Professional Development}

In the early stages of the study I wanted to understand new things that could add to my previous knowledge. As I progressed however, I moved to rethinking and reanalysing what I thought I already knew (Johnson, 2003), i.e. prior learning that had occurred both at a conscious and at an unconscious level. This is valuable for the practitioner's aim to develop professionally. As MacLeod \& Cowieson (2001) highlight:

I constructed an analogy between the creation of my autobiography and the weaving of a tapestry. At the beginning of this story, I believed that I would weave a tapestry of experience together to reveal professional and personal growth. I discovered that the tapestry had already been woven and that my true job was to unravel the threads and weave them back together in a much richer hue (p.252).

Yet, such an aspect of professional development can be a mined territory. Although it is a desirable quest if done slowly but surely, throwing up all our assumptions and beliefs 
into uncertainty may not result in learning, but in frustration and a sense of being totally lost. Thus, the reflective practitioner needs to learn not to question too many personal assumptions all at once and needs to know how to control his/her reflective appetite. Unfortunately, I learned from bitter experience as I found that the best way forward is not to work towards the destruction of all pre-existing beliefs, but towards an unhurried conscious analysis and alteration of the beliefs and assumptions that shape who we are and what we do. The new consciously constructed beliefs and assumptions are constructs-in-use that again help us make daily-life more tolerable and easier to interpret, while being able to take decisions more quickly in the immediacy of classroom life (Stringer, 1996). As Garrison (1996) contends, these are:

Necessary to make our way, however tentatively, in everyday thought, conversation, and action... The point is not to free ourselves of all prejudice, but to examine our historically inherited and unreflectively held prejudices and alter those that disable our efforts to understand others, and ourselves (cited in, Schwandt, 2000: p.195).

All we need to do is bring our assumptions out in the open where we can analyse and alter them. The teacher-researcher is in a position to do this since inquiry obviously entails exploration, and:

Exploration reveals the taken-for-granted visions and versions of reality that make up people's day-to-day life-worlds, bringing their unquestioned assumptions, views, and beliefs out in the open and displaying them for inspection (Stringer, 1996: p.59).

\subsubsection{But how are Beliefs and Assumptions Formed?}

Korthagen \& Kessels (1999) use Gestalt psychology to describe how experiences can lead to subconscious learning that consequently leads to assumptions. They argue that our:

Needs, feelings, values, conceptions, and so forth, together - within a split second create the personal meaning of the situation to the teacher, and - often unconsciously - lead to a behavioural inclination, namely, to react by correcting the mistake and repeating the right solution procedure (p.9). 
The resultant learning is how the person acquires a grasp of a given situation. This is not critically analysed but stored in chunks as Gestalts. They contend that:

For immediate teaching situations this means that the many and multifaceted conditions and events embedded in a given situation are combined into one holistic perceptual identity (p.9).

They also argue that when teachers have no time to reflect and have to act intuitively in the immediacy of the classroom, it is these Gestalts that help the process. Unfortunately, when such Gestalts are formed, there is a tendency to close-down to new learning. When a situation does not fit our existing assumptions we tend to find ways to preserve our assumptions, concluding that what happened was not as expected because of factors we had no control over; or by simply ignoring aspects of data that point towards deficiencies in our beliefs (Russell, 1993; Day, 1999; Mason, 2002). It is thus argued that we actually use our own beliefs to filter new experiences with the aim of making our assumptions become stronger and stronger (Pajares, 1992; Verloop et al., 2001). We unconsciously do all this rather than question the very assumptions that make us expect outcomes that were not achieved. This reinforces our beliefs and assumptions by re-interpreting the experiences that challenge our conventional beliefs, and making them fit our pre-existing beliefs (Coburn, 2003; Day, 1999; Yung, 2001). This comes as no surprise, since what we notice and our own interpretations are influenced and based on our values and beliefs (Peshkin, 2000; Mason, 2002). As Brookfield (1995) maintains:

To some extent, we are all prisoners trapped within the perceptual frameworks that determine how we view our experiences. A self-confirming cycle often develops, in which our uncritically accepted assumptions shape actions that then serve to confirm the truth of those assumptions (cited in, Fendler, 2003: p.22).

\subsubsection{What are the Foundations upon Which Intuitive Practice Holds?}

Most of the time it is intuition that guides the immediacy of practice. Yet, a person's intuition has to have a foundation. It is not neutrally created and is not free-standing; so what are the foundations of a person's intuition? What is the pillar that supports intuitive practice? Through this research I have come to agree with Clandinin \& 
Connelly's (1991) assertion that humans, including teachers act as they do because of lived experience. When this knowledge becomes ingrained as unquestioningly true for the practitioner, then such knowledge takes the form of taken-for-granted assumptions, and every choice and decision is based on an underlying belief (Ghaye \& Ghaye, 1998). Hence, 'teachers' practice is automated or intuitive, dependent on understandings that are not usually articulated' (McIntyre, 1993: p.43). This is why it is important to know which experiences tend to unconsciously survive in a teacher's memory, and how these experiences shape professional actions (Ben-Peretz, 2002).

Tacit learning might be dangerous. If for example, I learn that students of colour are academically weak, this would lead me, intuitively, to treat all such students alike. This surely happens in teaching, and this unconscious and unquestioned learning is what gives form to our taken-for-granted assumptions (Sweeney, 2003). As argued by Donmoyer (2000), despite the differences between groups of students:

Each year teaching became easier; each year I could more easily anticipate the consequences of my actions; increasingly, I could even control events. Generalisation, of one sort or another, occurred... Much of the generalising that occurs at the level of experience occurs tacitly; that is, much experiential knowledge has not been translated into propositional form (p.56).

And yet, it would be folly to argue that assumptions are unnecessary; without them it would be impossible to cope with the infinite variations of human life. What is dangerous is when such assumptions remain unquestioned by the professional practitioner; when they are so ingrained that the practitioner cannot even describe these assumptions; when practice that points to possible deficiencies in our assumptions is selectively dismissed. As pointed out by Marchese (1997), the danger with unexamined beliefs is that:

Once we think we've figured out some corner of the world, we tend to see what we want to see and hear what we want to hear, bending subsequent experience into confirmation (cited in, Thurlow \& Stuart, 2004: p.289). 
Once we reach that point, it could be argued that we are unable to control our beliefs; instead they begin controlling our thoughts and actions. Thus, according to Grant (2001) 'teachers caught in the pressing busyness of their daily routines can with little effort lapse into behaviours based on naïve assumptions and destructive, unacknowledged biases' (p.238). This means that early-career experiential learning tends to have a strong impact on future practice, and this is why experiences and beliefs should be opened-up to continuous investigation.

\subsubsection{The Impact of Beliefs and Assumptions on Professional Practice}

In my journal $I$ argue that 'in order to learn, a person has to analyse things and situations that are seen as normal and common sense in everyday life' (PD: 27-05-03). This is the kind of analysis needed in reflective practice that helps us to go deeper in understanding ourselves and the values which guide our professional practice (Tickle, 2000). The following words by Turner (2001) made me realise that my experiences are very different from my students' experiences. Hence, shaping my practice according to my own experiences and assumptions is unlikely to lead to effective experiences for my students.

You may need to unlearn some of what you know about the classrooms of your adolescence and undergraduate days before you can start to understand today's secondary classrooms. Your experience was probably that of a successful learner, perhaps a keen learner, not a reluctant one. Like many other adults you feel that you know what good teaching is and how classes should be conducted. You may be right in your assumptions but many features of your background may have to be examined and their relevance re-assessed for teaching today's pupils in your classroom (p.52)

In short, if intuitive practice is shaped by our beliefs, and our beliefs are taken-forgranted, unquestioned, and unchanged, then so is intuitive practice. Similarly, if assumptions are flawed, our practice will be flawed too. If we do not question our beliefs, we will simply reproduce such unquestioned beliefs for our students and future teachers and this, according to Haydon (2001) is indoctrination. It is also important to remember that individuals' Gestalts and assumptions usually reflect and reproduce societal assumptions and patterns (Korthagen \& Kessels, 1999). On the other hand, 
'education implies the promotion of rationality and critical thinking' (p.332), and the least we can do as education professionals is to develop such skills and use them in questioning our own taken-for-granted beliefs and assumptions. For this reason, I agree with Valli (1990) that teacher education programs should promote reflective practice while challenging future teachers to examine and make explicit their own assumptions, beliefs and values because:

We are often unaware of how our own belief systems and ideology, i.e. the unquestioned values and assumptions that shape our belief systems impact our actions. It is only through conscious processing and bringing into question our beliefs (i.e. reflection) that we are able to change or transform our practices emerging from these beliefs (Kraft, 2002: p.179).

\subsubsection{One Example of the Many Previously-Held Assumptions}

One of the main assumptions I held at the beginning of this study was that academic certification is one of the most important outcomes of schooling and student learning; a given 'good' towards which teachers should push their students. As a student, I myself learned that all schooling is about is the obtaining of certification. Such a taken-forgranted assumption was ingrained in me by my own teachers as well as my parents. I never questioned myself about this held belief, and it was evident that all my learning was targeted towards obtaining such certification. Most probably, commencing doctoral studies originated from such a belief. Yet, reflective self-study made me question the origins of such beliefs.

I am now asking myself if my perception is right. I was brought up in a culture where education came first and foremost. Maybe no... only health came first. Yet education was up there on the agenda. My parents used to urge me to study and get high marks. They paid a lot of money to see me achieve. However, I remember one of their arguments pretty well. 'If you do not do well at school, you will end up doing manual labour or being a scavenger'. I obviously was taught (at a very young age) that such jobs had low status and a low salary attached to them. Thus, I wanted to become a professional; no matter which profession, as long as it was a profession (PD: 26-08-03).

Analysing the origins of our beliefs and taken-for-granted assumptions is important, because in such a way we can understand our assumptions better. In this case, I realised 
that my values were inherited from those that had an influence on my personal education, and as Moore (1999) asserts, all persons have a baggage of inherited values and assumptions. My own assumption described here is held by many teachers, and this is reinforced by the pressures of having to cover the curriculum on time (Kraft, 2002). I thereby agree with Houston \& Clift (1990) that assumptions originating from tradition will limit what we are able to see, affect how we interpret what we see, and consequently shape our further development. Had I never engaged in reflective practice while, at the same time, teaching students who hold a very different view of education, I would probably have never questioned my beliefs about this issue. The questioning occurred because, as a reflective practitioner, I wanted to understand the conflict I experienced between my beliefs and what I observed in practice. Thus, I would support the suggestion that a teacher's values and beliefs are greatly influenced by the school culture s/he finds him/herself in (Zembylas, 2004; Ghaye \& Ghaye, 1998; Kelchtermans \& Vandenberghe, 1994).

\subsubsection{Consciously Deconstructing my Previous Unconscious Constructions}

It is clear by now that, like Seddon (1994) I have come to believe that reflection can easily be limited by our taken-for-granted assumptions, and the consequence is that our understanding would be only partial. Hence, teacher-researchers ought to 'make the familiar strange, to see with new eyes what they have learned to take for-granted' (Clark, 1995: p.51). If like Usher (1998), Day et al. (2006), Feldman (2002) and Kelchtermans \& Vandenberghe (1994) among others, we recognise that the self is dynamic as we continuously renew, reconstruct and reinvent ourselves through new experiences, then maybe it is time to recognise that as professionals, our values, beliefs and assumptions should, as a consequence evolve too.

If we keep in mind that 'learning means changing into someone different' (Labaree, 2003: p.21), teachers whose assumptions and beliefs remain unchallenged and unchanged will not change practice, thus maintaining the status quo (Thurlow \& Stuart, 2004). As Coburn (2003) argues, there exists a direct relationship between changing beliefs and deep consequential changes in teaching practice. The relationship between 
professional assumptions and change in practice will be further discussed in Chapter 5 . Yet, for the reflective practitioner:

Learning from experience does not necessarily mean that we continue to act in ways that proved to be successful in the past, or refrain from repeating unsuccessful actions. It may just as well mean that we view our experience from new perspectives (Ben-Peretz, 2002: p.322).

This is because what we experience might lead us to question our beliefs, assumptions, and prior knowledge, and through this questioning 'we make the things that give our teaching its shape, direction and purpose more conscious, more knowable and therefore more open to inspection and critique' (Ghaye \& Ghaye, 1998: p.35). In this way, learning is ongoing, and if learning is ongoing, we are continuously under construction; continuously developing and changing; surely not static. This is why I argued in my journal that taken-for-granted assumptions 'affect how much I can learn from a given situation. As such, I learned that in order to learn I must be able to unlearn these takenfor-granted assumptions' (PD: 08-09-05). While discussing the work of Fenstermacher (1980) and Diamond (1988), MacLeod \& Cowieson (2001) point out that:

Teachers need to be encouraged and supported in becoming more focally aware of their subjective beliefs and current professional understandings about teaching. These beliefs and current understandings about teaching should be investigated. They should be made explicit (named) and critically examined. This naming enables a critical conversation with self (p.243).

This is in line with my views as I argue that internal critical dialogue is the way forward if we want to analyse our held beliefs and assumptions. However, the following claim made by Parker (1997) portrays my situation before engaging myself with reflective self-study.

When happily surrounded by our common-sense assumptions, reinforced as they are by normal discourse and furniture of everyday life, it is easy to forget how parochial common sense can be (p.22).

Unfortunately, our assumptions are indeed built on what seems to be common-sense to us, and 'what establishes the authority of common sense is its 'commonality' within a 
social context and not its veracity' (Parker, 1997: p.22). On various occasions I came to realise that my assumptions were flawed, like for example the assumption I held that the most important part of education is certification. Such a possibility makes the need to analyse them even more important. So, upon realising that held assumptions might be flawed, I systematically analysed my present and past experiences until I could understand my situation better, and thus change my assumptions to a point where they could better explain what was happening around me. Yet, when one assumption is changed, it triggers a process where others are also questioned. This is how the questioning of beliefs and assumptions becomes a process, as it has a cascade effect. 'Relatively small changes in one's perception of reality entail the risk of generating many more changes, which may be profound' (Oosterheert \& Vermunt, 2003: p.163). This is easier said than done though, because changing one's own beliefs is not easy, however open-minded the reflective practitioner might be (Thurlow \& Stuart, 2004; Oosterheert \& Vermunt, 2003; Sweeney, 2003). But what makes unlearning so much harder than learning? When talking about beliefs and assumptions, Verloop et al. (2001) argue that 'it is important to realise that teacher cognitions have taken years to take shape and are, consequently, not easily changed' (p.454). The following words by Goldhammer (1966) precisely depict how I have, through the experience of trying, come to understand why taken-for-granted assumptions and beliefs practitioners hold are so difficult to change.

The vast majority... of values and assumptions from which our... professional behaviour is governed are implicit. They're inarticulate, they're nebulous, they're buried someplace in our guts and they're not always very accessible... We can't always rationalise exactly what we're doing... We can't always make explicit the justifications for the acts we perpetrate... Only after these things have been made explicit, have been brought to the point where you can enunciate the damn things, can we begin to value those that seem to have some... integrity and disregard those that seem to be inane (cited in, Ghaye \& Ghaye, 1998: p.45).

\subsubsection{Taken-for-granted Assumptions in the Private Sphere: a necessary type of learned ignorance?}

Although taken-for-granted assumptions are dangerous in professional practice, some taken-for-granted assumptions are needed in everyday private life (PD: 30-08-04). 
Unfortunately, I have learnt this at my own expense. On the $8^{\text {th }}$ August 2004, I was beaten up by three men for no apparent reason and I ended up in hospital. The following is an extract from the journal entry of the following day.

While lying down in bed, I had nothing to do except think about what had happened. I tried to find an explanation, a reason for this incident, but try as I might, I could not. I must say that I am frightened at the moment... and what frightens me most is this lack of explanation. Had I done something to them in the past, this might be some sort of vendetta. Had I said something to them and tempers arose, that would have been a different explanation. Had they wanted to rob me, that I would have understood. Yet, none of the above are possible explanations. And this is what hurts most; having no explanation for what happened.

And here, I started realising that we need taken-for-granted assumptions. One of the assumptions humans hold is that other human beings would not attack you in broad daylight for no reason whatsoever. Yet, it did happen. And I now feel afraid and uncertain, for who can assure me that this won't repeat itself? Yet, I have to live my life and I cannot think about this incident for too long, for... we need taken-forgranted assumptions in life, if life is to be more tranquil. Hence, in the near future I will have to assume once again, that the person walking next to me has no reason to beat me up and thus will not do so (PD: 09-08-04).

Yes, assumptions are indeed necessary to make our lives tolerable. The pain that came along with the constant analysis of issues in my private life made me feel that sometimes ignorance is bliss (Clark, 1995). For example:

It is not always comfortable to know. It is not always desirable either since we sometimes need taken-for-granted assumptions. Thus, as regards my new relationship I make an informed choice not to be informed. I don't want to analyse and systematically inquire into my relationship; how it is and how it could be; how it was and how it should be. I choose to move forward in ignorance without formulating possible hypotheses. I want to live my relationship day-by-day (PD: 05-11-04).

A year after my beating, I argued that 'for the first time since I embarked on this reflective odyssey, I aim to forget a particular experience, rather than remembering it and reflecting upon it' (PD: 08-08-05). I did this with the aim that the assumptions that crumbled after such an experience would begin to be reconstructed. I felt that 'for the first time, I need to construct a taken-for-granted assumption rather than deconstruct it' (PD: 08-08-05). Taking Mills' (1959) words below, and applying them to the context of 
the above personal experience helped me in confirming my point that we do need to have assumptions and values in our private lives, and that these should be shared amongst those living in society.

When people share the same values, they tend to behave in accordance with the way they expect one another to behave... As such, they bind a society together, for what is socially expected becomes individually needed (p.31).

In reality then, we act on the basis of unquestioned assumptions and we also expect others to act according to the assumptions we ourselves hold (Becker, 1996). It is when others did not react as I expected them to, that my assumptions were put under a critical eye, or maybe crumbled altogether. Thus, it seems that humans tend to build taken-forgranted assumptions, and the deconstruction of such assumptions throws everyday life into apparent chaos. Yet, these assumptions are so strong that after some time, they are unconsciously reinforced. For example, when a friend's mother dies young, or a friend's partner dies in an accident, I end up questioning myself about whether I will find everything as I assume when I go back home or if I would survive the day to remeet my girlfriend. Unconsciously, my assumptions would have been dented by such experiences, and this I have also observed in people experiencing similar situations. This feeling lasts for some time, but after a while, my taken-for-granted assumptions begin to regain some ground and everything goes back to normal. This is why people argue that time is a great healer. Hence, it comes naturally to me to try and rebuild assumptions that were damaged by some experience as regards my private life.

Yet, the unconscious rebuilding of taken-for-granted assumptions is not desirable in professional practice, because the frustration and uncertainty endured while questioning our beliefs and assumptions would be in vain if taken-for-granted assumptions are simply rebuilt and re-ingrained over time. Hence, we should continuously question our values, beliefs and assumptions as we must keep these under permanent conscious control. This does not mean that we should have no professional assumptions. In fact, I started realising through the course of this research that assumptions are also needed in the professional sphere. Before the incident of being beaten up, I was totally against the formation of assumptions regarding professional practice, but this was a critical 
incident that helped me change my point of view. According to Kelchtermans \& Vandenberghe (1994), when faced by a critical incident, 'assumptions, opinions and ideas about oneself or one's subjective educational theory are thoroughly questioned' (p.48). As I have previously argued, while in a classroom, the teacher cannot carefully analyse every situation that presents itself, while calmly deciding what action to take. This is because the number of variables to be taken into account is infinite.

\subsubsection{Professional Assumptions as Dynamic Rather than Fixed and Unchanging}

In the professional sphere we need to make informed choices while trying to predict and forecast the outcomes of our actions. We must continuously learn and develop while shedding light on the next step to take; and this includes questioning our takenfor-granted beliefs and modifying them where necessary. Thus, we must do exactly the opposite of what a teacher with 28 years of experience said: 'If it ain't broke, don't break it to mend it!' (Armour \& Yelling, 2004: p.81). Had I followed the line of thought of such a teacher, I would only have made an effort to change when large problems were perceived, and probably my assumptions and practices would have undergone minute changes, if any. This, according to Mills (1959) happens because 'when people cherish some set of values and do not feel any threat to them, they experience well-being' (p.11). But what if the values held are unconscious? In such a case, possible threats are not even detected, as we are inattentive to them or dismiss them as abnormal occurrences. This, Mills (1959) calls indifference and in this state, possibilities for learning and improvement are minimal; even non-existent. The main point behind all this is that I still have personal theories, beliefs, and assumptions. Yet, instead of these being fixed, taken-for-granted, and maybe also undefined to myself, through reflective self-study I have managed to make them dynamic, constantly evolving and changing, and known to myself. This is what Ghaye \& Ghaye (1998) have termed a state of dynamic equilibrium where 'you do not become attached to one set of unchanging values but that your values tend to move around and become modified as you develop more experience and insight' (p.36). If like Peshkin (2000) we understand that learning and interpretation are always incomplete and provisional, then according 
to Johnson (2003), our understanding of ourselves and our assumptions should be similar; always in an evolving state.

Throughout the study, I wanted to take nothing for-granted. In this way, my assumptions, beliefs, and personal theories formed what Schön (1983) calls theories-inaction, and through my constant analysis, these were continuously shifting. Also, as theories-in-action changed, my practice changed accordingly. Hence from Gestalts, I moved onto what Korthagen \& Kessels (1999) call Schema; these being more consciously held beliefs that also originate from prior learning, but have been formed through the analysis of Gestalts. It is then from these Schema that personal theories are formed. Nevertheless, my assumptions and personal theories (although not for-granted) still were the basis upon which my practice was based. This is because the consciously held assumptions and theories do not need a lot of conscious control after a while. Although conscious, they still make life in classroom tolerable, while changing who we are and how we act. What is important is that these theories and assumptions do not become totally for-granted once again. They need little conscious control while inaction, but need to be constantly questioned and reflected upon while reflecting-onaction.

\subsection{Reflecting on Private Life}

My professional life did affect my private life throughout my engagement with this study. What is interesting though is that before engaging myself with reflective selfstudy, my professional life did not affect my private life much; or if it did, I didn't realise it. I agree with Glaze (2002) therefore, that it is my engagement in reflective inquiry that has encouraged me to look more closely at my life; both professionally and privately. As Mills (1959) contends, 'the most admirable thinkers... do not split their work from their lives... They want to use each for the enrichment of the other' (p.195). 


\subsubsection{Questioning is Seeping into My Private Life}

Questioning and reflection in my professional sphere seeped into my private sphere. As a reflective practitioner, I somehow found myself questioning all that was around me. This caused me discomfort and frustration as it made me dislike a lot of things that previously seemed acceptable (Heikkinen, 2001). I have come to understand that such a situation is difficult at best and dangerous at worse. However, lessons learned from reflecting on the private sphere can illuminate dark-spots and provide further insight in understanding professional issues (PD: 03-01-04; PD: 09-08-04). Hence, although I reflect on private issues, the main focus is still firmly embedded within professional understanding. As argued by Hunt (2001):

While engagement in reflection for professional purposes can require the practitioner to re-examine... personal experiences that may well have taken place outside the professional arena, the distinctiveness of a professional reflective practice seems to me to be that its focus and finishing point remain firmly within a professional context ( $\mathrm{p} .283)$.

Yet, questioning my private life was not a conscious move as the following extract illustrates:

Did embarking on a reflective odyssey in my professional life lead me to be reflective on every aspect of my life and also on what goes on around me?' Probably, the answer to this question is affirmative... Thinking about it, both my professional and my private lives have changed. (PD: 25-04-04).

The main point here is that as a reflective practitioner, I could not separate my private and my professional lives. I am one person and the experiences and learning that originate from one sphere inevitably affects the other. The two spheres are inextricably linked (Zembylas, 2004; Conle, 2000; Day, 2000).

\subsubsection{My Private Life affects my Professional Sphere}

What I experienced in my private life also had a huge effect on my experiences in the professional sphere. As Day et al. (2006) argue, there are 'unavoidable interrelationships between professional and personal identities' (p.603). On a positive note I argue that the private sphere can offer valuable insights regarding the 
professional sphere. One example is when through private life experiences I changed my viewpoint and realised that assumptions are also needed in professional practice.

However, the private does not always affect the professional sphere in a positive way. On one particular occasion when experiencing a difficult time as regards my private life, I argued that:

My threshold has lowered incredibly and I'm getting angry very quickly. I'm yelling at students and although these students have a lot of behavioural problems, I'm just getting angry for the slightest things. I'm literally losing control of myself and must get back to normal soon. Otherwise, my life at work is going to turn into a nightmare (PD: 23-10-03).

Such an example highlights the importance of understanding how instances in private life can affect professional practice. Sometimes, I did not even realise that private issues affected my professional life before analysing the situation. Reflective writing seems to help here because as Glaze (2002) contends, by keeping a reflective journal, 'development might not only be academic but also in other areas of my life' ( $p .155)$.

Also, I sometimes felt that when personal worries and problems that I could do nothing about were present, there existed a possibility that I might be using my professional world and my reflections as a way to put my mind off some serious issues that I wanted to escape. One question I posed to myself was the following:

Are my work, my teaching, my learning, and maybe my reflections, serving as an alienation from my problems and my worries? I sincerely don't know. If this is the case, I must say that it really helps because my work sometimes puts my mind off some serious worries (PD: 01-10-03).

\subsubsection{Integrating the Private and Professional Spheres: an important but mined territory}

The end result is that developing as a person in a general sense also helps me in developing as a teacher because both spheres are closely connected and cannot be separated by an imaginary line (Armour \& Fernandez-Balboa, 2001; Day, 2000; 
Fitzgerald et al., 2002; Parker, 1998; Pomson, 2004; Conle, 1996, 2000). Yet, as argued earlier, such reflection on private issues should be controlled, as throwing everything into chaos might be detrimental rather than beneficial. On numerous occasions, I encountered problems in my private life that could not be solved. In such cases, the frustration and the pain felt affected my actions and thoughts while teaching and while reflecting. For example, similar to Meriläinen \& Syrjälä's (2001) experience, on some occasions 'the events and crises in my own life became too overwhelming to leave me any space for writing about my work' (p.2). It is this and similar examples that made me realise the necessity of understanding factors in my private life that might directly and/or indirectly affect my professional world, if I wanted to gain a deep understanding of the latter. After all, through experiencing teacher-research through reflective selfstudy, I do agree with Bass et al.'s (2002) statement that 'meaningful learning requires integration and transformation of my personal and professional selves' (p.63). Reflective self-study allowed me to do this, because as a researcher I was ever present in what I experienced, both in the private and professional arenas. Consequently this again resonates with Bass et al.'s (2002) statement that 'self-study allows me to integrate my personal and professional selves' (p.63).

\subsection{A Blinded Perspective}

The mere act of observing and reflecting on our own practices can be an enlightening experience, enabling us to see ourselves more clearly and to formulate ways of working that are more effective and that enhance the lives of the people with whom we work (Stringer, 1996: p.143).

Through reflective self-study I was capable of noticing and understanding what was going on around me. It brought certain things to consciousness that might have been easily missed had I not embarked on this study. This I have come to see as true but however much I reflect and try to analyse the situations I find myself in, I cannot objectively argue that I can see all possible viewpoints. However much I try to keep an open-mind while also questioning the assumptions that shape the way I interpret my own experiences, I cannot presumptuously argue that no blind-spots exist in my past 
and present understandings. Therefore, I did not ignore the possibility of self-deception. While referring to the works of Crites (1979), Conle (2001) argues that 'it seems silly to argue with someone's experience. But self-deception is always a possibility and probably never completely avoidable' (p.28). This is one of the reasons why throughout this study I have questioned my own knowledge, understanding, values, beliefs and assumptions. The fact that my inquiry is ongoing underlines the possibility of partial understanding, of unexplored areas, and of blinded perspectives; also highlighting the importance of ongoing learning and professional development.

Yet, it is important for the teacher-researcher to try and see what is usually unseen, for we cannot deeply understand what we do not notice and we cannot act on a problem if such a problem is not perceived by the practitioner (Loughran, 2002a). What I consciously or unconsciously exclude will affect my interpretations of lived situations (Peshkin, 2000). For example, when I felt a general sense of sadness, frustration or failure, I could easily interpret immediate situations negatively, while when happy, motivated, or enthusiastic about something, I could straightforwardly view the same situations positively. For example, during a bright and happy period in my research, I asked myself if my confidence and enthusiasm were blinding me, i.e. seeing what I want to see through the positive state I was in (PD: 25-09-03). My questions resonate with Mason's (2002) question: 'Might I not just be fooling myself, wanting to see some improvement?' (p.89). Such a question could obviously not be answered in a definite way, since if I knew I was blinded I would have consciously and honestly evaluated other possible viewpoints too, thus rendering the possibility of having a closed-mind inappropriate. However, questioning myself if I could have been the victim of a blinded perspective was useful, as in this way I was continuously reminding myself of such a possibility and 'if we are open to the possibility of vigilant critique, then at least we have a fighting chance of avoiding similar oversights the next time around' (Fendler, 2003: p.23). Consequently, I strived to analyse a situation from various angles, trying not to leave out any possibilities. 


\subsubsection{Factors that Influence what I can See}

One factor that might blind the reflective practitioner is for him/her not to acknowledge that external factors can limit what s/he can actually do in the professional sphere. 'The practitioner will often be unable to see the constraints of the institutional settings on his professional practice' (Laursen, 1994: p.130). But, even when the reflective practitioner is able to detect such constraints, s/he must accept that they do exist and not blind him/herself to them. Thus, although it is desirable for the reflective practitioner to continually want to improve, we have to recognise that this is never simple and sometimes not possible. As I argued in my journal:

Although her statement 'the system is much bigger than you are' is very true, I feel too proud to accept it. Right now, I'm saying to myself that I can always try to change small things that can better my students' life in the future, and I feel that all teachers should do this. If we don't, that would mean that we're happy with everything in education. Well, I'm not (PD: 12-12-03).

First of all, the fact that the system is much bigger than the individual, had to be pointed out to me. Although I always knew it, it seemed to me that I did not want to accept it. Yet, as reflective practitioners we must pay attention for there is a subtle line between accepting that you cannot change everything, and simply being comfortable with the status quo, as will be discussed in Chapter 5.

Another factor that promotes a blinded perspective is when what we experience in practice does not fit our values, beliefs, and assumptions. As previously argued, it is of paramount importance for the reflective practitioner not to fall into the trap of consciously or unconsciously being inattentive to such experiences, as these often promote learning while highlighting erroneous previous understandings. Hence, as Ghaye \& Ghaye (1998) argue, reflective practitioners:

Need to avoid turning a blind eye to evidence which challenges and confronts currently held values and practices. A teacher's inability to be open to this kind of threat will affect, and perhaps distort, their understanding of their practice and the context in which it is situated (p.94-95). 
Another possible blinker is the fact that when we are too concentrated on one or more aspects, we might become inattentive to other aspects of our lives. This is only normal as it is impossible for any individual to study every aspect or issue that presents itself contemporaneously. The reflective practitioner, however attentive $s /$ he is to his/her surroundings must acknowledge that 'you cannot get it all' (Wolcott, 1995: p.97). Although this is expected, it is just one other factor that lends a hand to our becoming blind to certain issues (Gergen \& Gergen, 2002).

Yet, although reflective self-study is neither fool proof nor guarantees to shed light on every aspect of our lives, it is still desirable since through it we are less able to fool ourselves while being better able to notice what goes on around us. On the other hand, as Schön (1983) argues, technical rationality together with 'a high degree of specialisation can lead to a parochial narrowness of vision' ( $p .60)$.

\subsubsection{An Example of being Blinded}

One example of when something happened to me, but I did not realise it myself, was when a friend pointed out that I continuously reflect and analyse my lived experiences that are not directly related to the professional sphere. My friend 'says that I always analyse things as much as possible and always ask for clarifications. He continued to say that I try to reflect, analyse and question all that is around me' (PD: 25-04-04). However much I reflected, up to that very moment I had never realised that reflective practice had seeped into my private life had it not been pointed out by somebody else. This highlights the fact that it is erroneous on the reflective practitioner's side to believe that $\mathrm{s} / \mathrm{he}$ is capable of noticing every little thing that is going on. Up to this very day, I realise that blind-spots exist in my understanding of teacher knowledge, reflective practice, and professional development, even though I strive to analyse and understand things from multiple viewpoints. Some things inevitably escape our attention because after all, we are only human. During that same conversation with a friend 'he pointed out that he rarely realises certain things if I never point them out to him' (PD: 25-04-04). Although he was admitting that he was blind to certain things, unknowingly he was pointing out to me that I was also blind to certain issues. It is here 
that I started realising the potential that professional conversation and collaboration can have as regards professional development, since through such professional activities, practitioners are more exposed to varying viewpoints that can lead to diminishing blind spots while increasing the analysis of possibly flawed assumptions. Such an aspect will be discussed in Chapter 7.

\subsection{Summary}

Although before this study I used to think that I know myself well, I must say that I was mistaken. I was literally shaped by my past experiences and most of my held values, assumptions and beliefs were inculcated in me either by people who had a direct impact like teachers and my own parents, or by wider society. Hence, reflective self-study not only helped me learn about professional practice, but also about an unexplored territory; i.e. myself. Learning about the self and about my tacit learning also helped me better understand how these have an impact on my professional practice. Henceforth, I was also learning how my practice was being unconsciously shaped by prior understandings. I learned about my own development and how important it is for the teacher to keep personal development under conscious control as much as possible. However, the perilous path of giving-up prior beliefs and assumptions, both in the private and the professional spheres has been highlighted in this chapter. Hence, learning about the self should not be mistakenly seen as straightforwardly easy.

I have also tackled the close bond existing between my professional and private spheres of my life, and how both unconsciously and/or consciously influence each other. Also, the fact that the reflective practitioner cannot possibly see all viewpoints and perspectives has been highlighted. Although reflective self-study helps us in being better informed decision-makers, some things inevitably elude our attention. This should not diminish the importance of reflective practice, since the more we look for varying viewpoints, the less blind we become. 


\section{Chapter 5 \\ Moving through Rough Roads}

\subsection{Introduction}

It is probably clear to the reader by now that the path towards professional learning and development through reflective self-study is not straightforward. Although I would argue that the benefits outweigh the costs, it would be irresponsible to omit information about the difficulties faced when engaging in reflective practice. Two major difficulties are reported in this chapter: threatening your comfort zone by disrupting habitual routine, and facing uncertainties in everyday practice. Comfort zone here refers to the comfortable practice that emerges from the ongoing repetition of unanalysed routines that arise from tacit knowledge, unquestioned assumptions and intuition.

\subsection{Habit Vs Change}

During my first year of full-time teaching, I did not reflect on my own teaching. At the end of every single day I returned home with a headache and without much energy left for planning future lessons. I literally felt I was in alien waters because I was not used to what I was doing; I had no previous experience teaching such students; and so, every single thing was new to me. In such a situation, my main aim was to survive, and I wanted to survive by copying what other teachers did that seemed to work. I realise I was not unique in this because Brouwer \& Korthagen (2005) point out that the main issue on any beginning teachers' agenda is survival. Also, this survival strategy of copying established practices seems to be common among new teachers, especially where they copy the ways in which they themselves have been taught in compulsory schooling (Griffin, 2003; Weiss \& Weiss, 2001; Hatton \& Smith, 1995). 


\subsubsection{The Formation of Habitual Routines}

Over time, I managed to adapt to my new role as a full-time teacher, and in less than a scholastic year I felt more comfortable with what I was doing. Without knowing it, I had created a comfort zone comprising habitual routines where I did not have to think much about my practice. Gaining experience without reflecting on it helped me do this, because as Mason (2002) contends, 'a great deal can be learned from getting in and doing things, but after a while the learning is supplanted by ingrained habits learned from experience' (p.8). At this stage I didn't even question myself about whether I was doing the best for my students because I felt that if it worked for others it should work for me. Thus, my taken-for-granted assumptions and my habitual practice were formed very early on in my teaching career in order to make teaching easier. After some time, if unanalysed and unchallenged, these become taken-for-granted to the point that the beginning teacher gets stuck in his/her own habits, unable to articulate the assumptions that lead to such routine practice. Dewey (1938) warned of the dangers of this process: 'experience may increase a person's automatic skill in a particular direction and yet tend to land him in a groove or rut; the effect again is to narrow the field of further experience' (p.13). This happens because habitual practice blocks us from seeing possible alternatives as we constantly repeat our practice; thus closing-down, rather than opening-up, to new experiences (Day, 1999; 2004; Mason, 2002; Oosterheert \& Vermunt, 2003). This is one way of being blinded, as discussed in Chapter 4 .

The formation of such routines seems to be normal because according to Mason (2002) teaching 'is such a complex activity that it is essential to develop stratagems and tactics for dealing with common situations, which then become habitual' (p.8). Like Stringer (1996), only when new, out-of-the-ordinary situations cropped up did I have to rethink what I was doing.

\subsubsection{Tacit Learning Promotes Technical Routines}

It must be accepted that the formation of early, habitual routines was priceless in helping me cope with the complexities I faced as a beginning teacher. According to Yinger (1979) these routines include: 'routine patterns of working; rapid intuitive 
responses to classroom situations and events; and taken-for-granted assumptions which frame normal practice and discourse' (cited in Day, 1999: p.23). Such practice is based on tacit knowledge that according to Schön (1983) has the following properties:

- There are actions, recognitions, and judgements which we know how to carry out spontaneously; we do not have to think about them prior to or during their performance.

- We are often unaware of having learned to do these things; we simply find ourselves doing them.

- In some cases, we were once aware of the understandings which were subsequently internalised in our feeling for the stuff of action. In other cases, we may never have been aware of them. In both cases, however, we are usually unable to describe the knowing which our action reveals (p.54).

This type of routine action supports teachers in the early years of teaching. The only thinking that is necessary from the practitioner here is:

Shallow, technical 'thinking about teaching', the kind of thinking that makes the day run more smoothly and pleasantly, that often demands little cognitive effort on the part of the teacher and little questioning of deeply-held beliefs about teaching and learning (Grant, 2001: p.238).

Consequently, tacit knowledge and routine action lead us away from the need to improve. This becomes a vicious circle where our own habitual practice limits what we see and consequently our own development. According to Connelly \& Clandinin (1995), 'the classroom can become a place for endless, repetitive, living out of stories without possibility for awakenings and transformations' (cited in, Day, 1999: p.36). This is very powerfully expressed by Bourdieu's (1989) argument that 'practical mastery is learned ignorance' (p.19).

\subsubsection{Routine Promotes Comfort and Mediocrity}

Through my own experience, I argue that the tendency of not changing habitual practice is also promoted by the working conditions of teachers. The following extract which I reproduce at length illustrates this issue. It is important to note that these are rooted in the contextual conditions of the Maltese teaching profession. While driving 
under the hot summer sun one day, it occurred to me that "routine and lack of incentives promote mediocrity":

Although I believe that no two human beings are the same and no situation is exactly reproducible, teachers tend to view teaching as a routine. Weekly timetables and routine activities help in promoting this idea. After all, teaching is such a hectic job and includes teachers moving from one class to another, marking attendance lists, covering the syllabus, going home to mark students' work, etc. Seen in this way, teaching is indeed a routine...

What about lack of incentives? Well, teaching does not offer a lot of personal incentives. Promotion is almost non-existent and the incentives are usually linked to the good results students obtain. However, teachers are easily demoralised if students do not perform well. As a reflective practitioner, my main incentive is to learn from my own experience, but like many teachers, I do not have a lot of channels to share my experiences and learn from other teachers' work. Thus, incentives in teaching are minimal, not to say non-existent.

So if teaching is seen as a routine and offers lack of incentives, I would argue (according to the above statement) that teaching levels are mediocre. And here is my explanation. When something is a routine and not many unpredictable and new things occur, there is little will from the person to change. For example, I never changed my driving habits because driving has become a routine; and when something out-of-the-ordinary occurs, I quickly dismiss it as a one-off occurrence. Similarly, if a person is not offered incentives to improve, his/her performance would remain greatly unchanged. For example, if a person is offered the possibility of promotion, s/he might be tempted to improve, or if a person is afraid of losing his/her job, his/her performance has to be kept constantly at a high level so as to keep his/her job. However, if a teacher is sure of keeping his/her job (as most of Maltese teachers are) and there are lack of incentives in the form of promotion, his/her teaching would remain greatly unchanged.

I might say that I am lucky. Although teaching is a routine and offers no real personal incentives, I have other personal incentives. First of all, I'm fond of learning. I love to learn and I also feel the urge to always learn something new. I have learnt that as a teacher I always need to improve what I do. The second incentive is academic qualification. Without doubt, wanting to obtain a doctoral qualification has made me want to understand my situation better; but would I have done the same had I lacked such an incentive? Probably yes; but would my reflections be as detailed if I had no academic qualification to obtain? (PD: 15-0904).

Through routine practice, I can become 'selectively inattentive to phenomena that do not fit the categories of [my] knowing-in-action' (Schön, 1983: p.61), thus giving 
attention solely to aspects of experience that tend towards self-confirmation (Oosterheert \& Vermunt, 2003). Similarly, before engaging in reflective self-study, when facing professional dilemmas I used to find arguments that put the blame on others (like for example student culture and student deficits) rather than focusing on possible deficits in my teaching skills (Harry et al., 2005). By blaming others without questioning myself, I am able to keep the status quo because as Ward \& McCotter (2004) contend, 'placing blame on others is not likely to lead [the teacher] to change practice or perspective' (p.252). Consequently, Oosterheert \& Vermunt (2003) argue that 'teaching experiences fail to be educative when the desire to see something new is absent' (p.165). The reflective practitioner, on the other hand, is working towards taking responsibility and not blaming others for perceived inadequacies. Yet, neither should s/he put the blame solely on the self. Many factors affect our professional practice, and although we must analyse our own practice thoroughly, we must never forget that a number of external forces impinge on what we do. Such forces might open-up, as well as limit possibilities for change. What is important is that the reflective practitioner analyses both personal practice and external factors, and through the emerging insights and understandings, attempts to see how s/he can improve to the best of his/her possibilities. This is the work of teacher-researchers.

\subsubsection{The Importance of Motivation}

Just as teachers need to motivate students for learning to occur, so must teachers be motivated to learn. As was illustrated earlier, I feel that present working conditions in Malta do little to motivate teachers. Yet, if as Day (1999) suggests, there is a 'necessity for all teachers who wish to improve their practice to engage, routinely, in inquiry' (p.23), then it is important to encourage teachers to become teacher-researchers. Moreover, their practice-oriented inquiry must be accorded value and status. Financial incentives and a supportive culture inside schools are also important in facilitating change. In order to flourish, the teacher-researcher should be surrounded by likeminded professionals who want to improve (Garet, Porter, Desimone, Birman \& Yoon, 2001). This seems a long way from the present situation found in Maltese schools, but I believe that such a change is necessary to promote teacher change. As the African 
proverb says: 'The best time to plant a tree is twenty years ago. The next best time is today' (cited in, Sparks, 2002b: p.8).

\subsubsection{Finding Myself in Alien Waters: needing to change - needing to learn}

It was the introduction of a new PE syllabus that shook my certainties in teaching. Similar to my first appointment as a teacher, the new syllabus had me swimming in alien waters again; but this time it was worse. None of my colleagues had previous experience of teaching this syllabus and so I could not simply copy what seemed to work for them. The reform, therefore, acted as a critical incident where 'the teacher has to change a habitual approach to cope with new challenges' (Kelchtermans \& Vandenberghe, 1994: p.48). As Schuck (2002) contends, lacking critical incidents, our practice remains largely unchallenged and we keep on doing what we currently do. Facing such a critical incident helped me realise that change was no easy process. After about six months teaching this new syllabus I wrote that:

I used to think that I needed to teach what others taught before me. Change is difficult to achieve and thus, it is much easier for teachers to move along the lines of tradition. But now, the introduction of SEC PE is relatively new and as a result, nobody had the excuse of doing what others did before. This is how I embarked on a reflective odyssey (PD: 16-03-03).

It was through reflective self-study that I started changing my habitual practice because I started questioning what was previously taken-for-granted. After all, the main hallmark of reflection-on-action is when the practitioner starts to question accepted routines, and consequently challenging the status quo (Ghaye \& Ghaye, 1998). Through better understanding my practice, I was able to perceive deficiencies in my own teaching and I felt the need to change; to continuously improve my habitual practice. After all, 'teachers who are reflective inquirers need to recognise that inquiry is likely to raise issues of change' (Day, 1999: p.41). Hence, throughout this study, learning and the need for change progressed in parallel; both were ongoing, because if we are to change we need to learn, and learning through reflection indeed facilitates change (PD: 20-06-03; ISO: 22-04-04). I have come to realise that deeper understanding and learning are precursors to change because through the former, the 
latter is seen as desirable. This is further confirmed by Day (2000) and Clarke \& Hollingsworth (2002) as they argue that informed change is a complex process that inevitably involves learning. On the other hand, Adelman (1989) and McIntyre (1993) contend that non-reflective practitioners find it hard to deliberately change and make adjustments to their practice through informed judgement.

\subsubsection{Dynamic Beliefs Promote Continuous Change}

Throughout the process of this study I have realised that for me, the most important aspect of teacher learning that promotes change is the examination of one's own takenfor-granted assumptions. I contend that as I go deeply into critically analysing and questioning my own beliefs and assumptions, I realise that deficiencies exist and I try to reframe them. This is indeed the basis of transformative learning (Ward \& McCotter, 2004; Mezirow, 1991; Kraft, 2002) because as I altered my beliefs, I increasingly realised that my practices must also change. This provides further support for the work of Sparks (2002b) and Coburn (2003) who argue that there is a correlation between changes in beliefs and assumptions, and changes in professional practice.

Through reflective self-study, it was not only my practice that was undergoing change; I felt that I was changing as a whole person. In Feldman's (2003) words, 'for us to change how we teach requires us to change who we are as teachers' (p.27). I also realised this with hindsight with the help of my reflective journal, since as one's life, experiences, assumptions, knowledge and understandings change, the stories one constructs also change (Conle, 2003; Kelchtermans \& Vandenberghe, 1994). As argued by Ghaye \& Ghaye (1998):

Becoming involved in 'improvement' is not only about becoming 'better' but also to do with becoming 'different' through questioning the taken-for-grantedness, the habits, the comfort blankets that we wrap around ourselves from time to time and by adopting a more problem-posing teaching posture... It is about questioning practice with confidence so as to open up new possibilities and new directions for action (p.67). 


\subsubsection{Ongoing Relevant Learning and Continuous Change}

The importance of learning being directly relevant to my needs became increasingly evident as the study progressed. If new learning seems relevant to my needs, for example, is linked to a problem I perceive, I already feel the need to change. Hence, this new learning can impact upon my practice. However, when learning does not appear to be immediately relevant, it is either ignored or just accommodated within my comfort zone and it rarely challenges habitual routines. Thus, such new learning will rarely result in change of practice.

It is my continuous learning through engagement with reflective self-study that challenged my comfort zones. I experienced the learning emerging from reflective selfstudy as immediately relevant and applicable to my needs. In such a way, it was difficult for me to become a prisoner in my own cage (WestEd, 2000). Also, keeping a journal was a way of documenting the process of change itself (Glaze, 2002). What is important is that 'if learning stops, change stops too and we will keep on doing a hundred years from now, what we are doing now' (PD: 12-05-05). This is exactly how it felt before engaging myself in reflective self-study, and my experience resonates with Lockford's (2002) statement that:

With time, the actors become accustomed enough, habituated enough, to live within their roles and to play that script on demand, playing it even when that drama has no catharsis, where the only comfort is the familiarity of habit (p.78).

\subsubsection{To Change or Not to Change: the case for determination}

Of course, change was not at all easy. In order to change and develop professionally, we take risks as we deviate from the comfort of familiarity while embracing the unfamiliar (Lockford, 2002; Stringer, 1996; Freedman, 2001; WestEd, 2000; Edwards \& Nicoll, 2006). However, although we inevitably face the insecurities and uncertainties brought about by change, the end result can be personal growth and development (MacLeod \& Cowieson, 2001; Day, 1999). So if keeping the status quo is much easier than embarking on a project to change, courage and determination are needed on the part of the practitioner (PD: 14-11-03). 
As such, even when teachers feel frustrated with the results of their habitual practices, it is far easier and comfortable 'continuing to cultivate those habits... than accepting the challenge to take the risk of changing direction and venturing into new domains' (Lockford, 2002: p.81). Throughout my research, although I wanted to change, like Dewey (1938) I argue that, 'the easiest course was to follow the line of least resistance' (p.21) i.e. continue with my habitual practice. Still, I resisted as I was determined to develop professionally and continuously improve, and like Schuck (2002) I did not want 'to be seduced by the easy route' (p.336). Nevertheless, sometimes, in difficult periods, just like Clark (1995) warns, I did regress back to habitual practice and that is why I sometimes argued in my reflective journal that good habits like reflective writing are difficult to pick up but easy to lose, especially if the practitioner is lacking determination (PD: 01-12-03). Yes, determination on the part of the teacher-researcher is required here as 'change is the most difficult thing - it's slow, and you can lose faith' (WestEd, 2000: p.38). According to Hunt (2001) 'yesterday's sense of direction can often be lost in the struggle to survive in the quicksand of today's imperatives' (p.283).

\subsubsection{Consciously Abandoning the Easy Route}

Ongoing change offers further opportunities to learn, while 'lack of change would offer us no new visions and no new experiences... [Thus] if you always do what you do, you'll only get what you've got' (PD: 21-01-04). This is how the status quo is reinforced. Hence, I agree with Dewey's (1938) statement that 'the consequence of formation of such habits is inability to control future experiences' (p.14). As I commented in my personal diary:

It is always easier to forget about the past and just move blindly into the future. However, although non-reflective teachers have a comparatively easy present (keeping the status quo), their teaching in the future will be very similar to the past and the present... thus, no or little improvement (PD: 15-03-04).

This lack of alteration to professional practice is what Sparks (2002b) calls the road towards a slow death, reinforcing 'the importance of combating habitual, mechanical behaviour' (Mason, 2002: p.56). Furthermore, these recurring practices offer the practitioner a relatively high degree of feelings of success, especially if these same 
practices are not critically scrutinised. Therefore, in summary, I argue that examining past experiences to inform and change present and future practices is a stronghold of reflective practice, but this is hard work and requires considerable effort from the teacher-researcher, as it goes against the natural tendency of creating routines that make life easier. According to Mason (2002):

We have to develop implicit theories of action in order to make professional life tolerable. There are too many variables to take into account all at once, so we develop routines and decision habits to keep mental effort at a reasonable level. To change the routine or question the theory is to reverse the process, to draw attention once more to myriads of additional variables... Not to change, modify, experiment is to be stuck in the rut of habit (p.7).

Analysing our own experiences through reflective self-study is a desirable trait, because as Mason (2002) continues:

An important source of pleasure comes from participating in a moment of choice, by making an informed decision, to act non-habitually, to respond professionally rather than just react (p.8).

\subsubsection{Changing Established Practice or being Changed by Established Practice?}

Although I soon recognised many aspects of my professional practice that could be changed for the better, I knew that it was not possible to change everything (Wildman et al., 1990). This is especially true when according to Husu \& Tirri (2003) 'the organisation was not supportive... and [my] individual influence was not sufficient to change the situation' (p.353). In the words of Brouwer \& Korthagen (2005), 'the overall picture arising from studies on teacher socialisation remains that it is quite difficult for an individual to really influence established practice in schools' (p.155). This was true in my case and, upon entry to the school where I teach, rather than influencing established practice, the school context influenced me and my practice as 'self-beliefs are influenced by social and power relations and values in the school culture' (Zembylas, 2004: p.197) and these self-beliefs then shape our practice. But why does this happen? 
Bouwer \& Korthagen (2005) contend that beginning teachers feel a need in the first year of teaching to be accepted by colleagues and, after that, they become a member of the club. This is how newly-qualified teachers are socialised into the profession. Zembylas (2004) argues that a teacher can feel emotionally forced to teach in the way others in the same school do. Certainly this would provide a partial explanation for what happened to me in the first year of teaching, but it is not the whole story. Moreover, even when I did engage in reflective self-study, there were no routes available for professional exchange and collaboration, and I was thus unable to have any impact on colleagues' professional practice. Nonetheless, aiming to change by engaging oneself in continuous learning is still valuable, as I have at least managed to change my own teaching.

\subsubsection{A Deeper Understanding does not Automatically Result in Change}

Better understanding is a precursor to changing habitual practice, but simply 'understanding something does not imply change' (PD: 01-07-03). As Clark (1995) argues, 'it is one thing to point out a danger or an opportunity, and quite another to do something about it' (p.27). This is especially true when factors like societal values and assumptions made it hard for me to change practice, even though I realised that change was desirable (PD: 29-05-03). As pointed out by Johnson \& Golombek (2002), becoming more aware, learning, and understanding are the first steps but:

Another step must be taken after this in order to change practices and to make practices align more with beliefs about teaching... I am able to describe classroom incidents, even to categorise them, and to articulate my beliefs about and the influences on my teaching. I am now working on determining the methods to use to institute change in my teaching practices (cited in, Golombek \& Johnson, 2004: p.315).

In this study, the method I have used to promote change in my teaching practice is action-research. Here new ideas and insights that come from reflective self-study are implemented and then analysed through reflection once again. Yet, not all emergent insights could be easily implemented and as argued in Chapter 3, on such occasions I found myself 'swimming against the tide' (PD: 12-02-04). For example, on a number of occasions 'I find myself accusing myself of focusing too much on examinations' 
(PD: 22-06-03). This happened as I became aware that a conflict existed between my values and what was actually happening in practice. I felt that I was sacrificing a holistic education for the majority of students in order to provide a few students with the opportunity to pass national exams and get their certification. However:

Maltese society puts a lot of value on academic achievement. At the age of nine, children begin to be streamed [according to their academic achievements]. At the age of ten, all the children in state schools have to sit for five examinations. If they fail one or more of these exams they are placed in area secondary schools while if they manage to pass all five exams, they are placed in junior lyceum schools. In most cases these examinations seal the students' future. Apart from all this, academic certificates in Malta are very important. In a small but overpopulated country, jobs are scarce. Thus, every certificate obtained by a student can make a whole lot of a difference. I teach in an area secondary school and students in these schools are seen as low achievers. I am not prepared to jeopardise any chances these students have of obtaining a secondary education certificate... and I am sure that one or maybe two of the students have a chance of making it. How can I play with my students' academic achievement and with their job opportunities?

I'm writing all of this while feeling a lot of anger inside of me. I'm angry because I'm stuck between two opposite philosophies. I believe that teachers should not just teach subject matter. Teachers' first objective is to educate for life, to help and prepare students to face the world in a period of rapid change. I believe firmly in this. But I feel defeated. I cannot just forget the syllabus and the final examination (PD: 22-06-03).

Before engaging myself with reflective self-study, I had never questioned myself about what was really valuable for my students. I never even questioned myself about what is valued by wider society, and whether this is also valued in the students' local community. Indeed, in taking societal values as 'given', I used to argue that there was a problem with community influences and student deficits. Yet, I could not just forget the syllabus and the final examination and hence, I was stuck in between two philosophies of education. Although I was constantly trying to integrate the two philosophies, I had to accept what my supervisor (acting as a critical friend) once suggested; i.e. that the system is much bigger than me, and it is difficult to change what is taken-for-granted by the system (PD: 12-12-03). The main lesson I learned from this episode is that what makes change really difficult is the attempt to depart from tradition and alter what is accepted and taken-for-granted by wider society. As such, I argued in my journal that 
'when two forces are working against each other, change is extremely difficult' (PD: 03-01-04).

\subsubsection{Change: a lengthy process}

Hiebert et al. (2002) argue that there is a tendency in society to value results that can be measured and obtained quickly. The converse of this is that what cannot be measured easily, and what takes a long time to obtain, is accorded less value and as Ghaye \& Ghaye (1998) argue, this presents a problem within the education system. What is valued 'gets narrowed down to the knowledge and skills that can be quantitatively assessed. This impoverishes the richness of the curriculum and limits the pedagogic practices of teachers' (Radnor, 2002: p.18).

Such arguments also hold for teacher learning and the process of change. As a lecturer argued during an in-service session I attended, 'change is a process so we must be patient enough. We must not be impatient and pretend to reap fruits in the short-term' (ISO: 19-04-04). Due to our socially inherited beliefs, 'most of the time, we are not ready to invest in the long-term since we need to see immediate results to continue with our efforts' (ISO: 19-04-04). I think it is clear that a practitioner who engages in reflective self-study with the aim of changing practice quickly is bound to be disappointed. As Hiebert et al. (2002) put it; the history of education contains 'a graveyard of good ideas condemned by pressure for fast results' (p.13).

Of course change is an ongoing process and not a specific one-time occurrence. Thus, reflective self-study:

Makes me and my teaching change little by little and since change is a process one can only see a difference after a relatively long period. To cut a long story short, it is unlikely (not to say impossible) to see a big difference in your teaching in just a few days, but it is likely to be able to observe such changes throughout the years (PD: 20-06-03).

This gradual change, although not immediately detectable, is beneficial to teachers. Wooden (1997) offers some words of advice when arguing that: 
When you improve a little each day, eventually big things occur... Not tomorrow, not the next day, but eventually a big gain is made. Don't look for the big, quick improvement. Seek the small improvement one day at a time. That's the only way it happens - and when it happens, it lasts (cited in, Hiebert et al., 2002: p.13).

Thus, the process of change is often detected retrospectively in hindsight (Conle, 2003). If a practitioner engages in reflective self-study with the aim of quickly changing, such a practitioner will probably dismiss reflective self-study as another ineffective method, while missing all the real benefits of such a process. One of the most important lessons I have learned from embarking on a reflective odyssey is the fact that reflective selfstudy is indeed an odyssey as described in Chapter 3.

Another factor to be taken into account is that our surroundings; colleagues, students, as well as ourselves, are continuously changing (DeMulder \& Rigsby, 2003; Richert, 2001; Houston \& Clift, 1990). If I am happy with my routine practice, then I am unconsciously assuming that the situations I face never change, and this is far from the truth. Inside the classroom, I am not dealing with machines but with different human beings, and 'human beings continuously change' (PD: 21-01-04) and so too do the societies we live in (Radnor, 2002). Likewise, 'teachers are not technicians and like all other professionals, we need to evolve in accordance with our surroundings and our clients' (PD: 20-06-03), and as the word evolve implies, this should be a slow but ongoing process. It would be an unforgivable mistake to forget that 'the process of change is subtle' (Conle, 1996: p.317). Through my experience I contend that by engaging myself in ongoing professional development through self-study I embarked on an interminable process of change aimed at improvement.

\subsubsection{Reflection as a Corrective to Experiential Over-Learning}

In conclusion, I do not mean to argue that the creation of habitual practice is always an evil. What is harmful to professional practice is that if such habitual routines and professional beliefs are never analysed and modified where necessary, our practice never changes whether or not these practices are achieving the results they are set to achieve. Also, lack of change will result in lack of learning. In summary: 
If we allow our theory of action to remain unexamined indefinitely, our minds will be closed to much valid information and the possibilities for change will thus be minimal. In effect, if we are content with maintaining our field of constancy we... only see what we want to see (Day, 1999: p.24).

According to Schön (1983) 'when this happens, the practitioner has over-learned what he knows... [and] reflection can serve as a corrective to over-learning' (p.61). This is exactly why in Chapter $3 \mathrm{I}$ have argued that although experience offers learning opportunities, experience alone is not enough. In fact it seems that:

Learning from direct experience of practice alone indicates at best limited growth. The development of routines, the presence of tacit knowledge and the resistance to disclosure and feedback act to control rather than free teachers from the burden of unexamined, accumulated practice (Day, 1999: p.52).

This happened because through my first year of full-time teaching, before embarking on a reflective odyssey, I gained experience that affected how I went about my teaching; my actions; my teaching skills; my thoughts; and my decisions. As argued by Polkinghorne (1995):

People are historical beings retaining as part of themselves their previous experiences. Past experiences manifest themselves in the present as habits... Embedded habits present themselves not only as motor skills and body movements but also as patterns of thought (p.17).

Through my experience as a teacher-researcher I have come to agree with Parker's (1997) statement that in postmodernity, sameness should be viewed as failure. My reflective self-study is precisely this; a personal 'struggle to change habitual behaviours and to act differently' (Polkinghorne, 1995: p.17).

\subsection{Uncertainty: dealing with inconclusiveness}

New learning and new insights emerging from my study with the help of existing literature have made me an informed decision-maker; since my practice and decisions were backed by my own learning. However, the reader should not get the mistaken idea 
that the reflective practitioner is one who knows exactly what is happening and exactly what courses of action to take, since this is far from the reality I have experienced. As a practicing teacher, I have not taken the assumptions surrounding reflective practice as given (Edwards \& Nicoll, 2006). In fact Hunt (2001) claims that 'engagement with reflective practice can sometimes be both uncomfortable and disorientating' (p.275) while Fitzgerald et al. (2002) assert that 'self-study work did not always solve immediate problems' (p.77).

The argument reproduced below originally brought forward by Parker (1998) made me realise that many are those who encounter problems of uncertainty.

It is often disempowering and disheartening to encounter research texts which make the process of research sound smooth and tidy... One needs a certain confidence to shore oneself up against the struggle of being in a recurring state of 'not knowing'. Hearing that others have coped and survived against difficulty and distress can strengthen one's own resolve (p.120).

This is an important point for without that realisation, consciously or unconsciously omitting such negative aspects of inquiry (in this case reflective self-study) can lead beginners in reflective self-study to convince themselves that they are not up to the task when they encounter problems, as 'experts' never seem to encounter such problems. My experience confirms, however, that rough and bumpy roads are more common than smooth highways in a journey towards learning and deeper understanding.

Uncertainty was present even before the study itself commenced, and it was uncertainty that originated my desire to learn. As previously explained, facing a new situation like teaching a new syllabus was a critical incident, and before such a critical incident:

I used to see teaching as something 'normal'. Teaching was part of my everyday life. Thus, I never felt the need to analyse what I was doing. It was second nature to me. Yet, the introduction of a new syllabus made me realise that I should now analyse the situation and my teaching. I did this because I did not know what to do; I did not know what was expected of me as a teacher teaching this new syllabus (PD: 27-05-03). 
As I wrote the above extract, the main cause of my uncertainties was inexperience, and I believed that by gaining experience, my uncertainties would vanish. However, with such a philosophy in mind, uncertainty and inconclusiveness should have long disappeared by now, considering that I have now taught such a syllabus for four years. Yet, it was throughout this study that confusion and uncertainty reigned in my head. As I sometimes argued, 'confusion reigns in my head. It's like I've got fireworks in my head' (PD: 11-03-03). Like Chetcuti (2002) 'at first it was scary to admit that I did not have all the answers and that reflection was leading to even more questions' (p.164). Yet, my experience with reflective self-study resonates with Renner's (2001) statement that 'doing data collection and analysis alongside interpretation exposed me to selfdoubt, pain, and confusion - but also rewarded me with moments of clarity and understanding' (p.2).

\subsubsection{Reflection does not try to Simplify the Complex Nature of Teaching}

Reflection is a tricky, complex and confusing terrain (Grimmett et al., 1990). This should come at no surprise since reflection on teaching opens-up the educative and learning processes, where according to Richert (2001) and Valli (1990), life in classrooms is dynamic, chaotic, indefinite and uncertain (Richert, 2001; Valli, 1990) while for Borko (2004) 'meaningful learning is a slow and uncertain process for teachers' (p.6). Therefore, the major two spheres that I reflected upon (classroom practice and teacher learning) are both uncertain terrains. Hence, my life as a professional is full of dilemmas, incompleteness and uncertainties, but most of these went unnoticed before engaging in reflective self-study.

It is interesting to note that unlike the creation of habitual routines, reflection does not try to simplify the educative and learning processes. On the contrary, reflection made me realise the complexities of a teacher's life. This I managed to do through questioning accepted beliefs and routines through reflective writing. As such, I soon realised that at times 'the more I write, the more confused I feel' (PD: 27-08-03). As the practitioner questions his/her assumptions and tacit knowledge, s/he allows him/herself to experience confusion and puzzlement as the practitioner searches for 
possible explanations (Schön, 1983). I have personally experienced questioning and the alteration of personally held assumptions as a learning process, but as discussed in Chapter 4 , the resultant uncertainty is not a pleasurable experience.

\subsubsection{Reflection is a Suspended State of Not Knowing}

Unfortunately or fortunately (depending on how you see it), uncertainties are still present now as I am writing my findings. As a Ph.D. student using a reflective diary, Glaze (2002) argued that 'self-doubt existed right up to completion of the viva' (p.157), and I argue that as a reflective practitioner, such self-doubt should exist long after the viva as well. As can be observed in this final write-up, I still pose questions, and more often than not, the answers to these questions are plausible, for now, but hardly definitive.

As previously argued, embarking on a project of ongoing change brings with it risk because we have to leave the familiarity of habit to explore the unknown. This is why I have personally experienced change to be difficult as I prefer inhabiting the familiarity of the known to venturing into the unknown. Thus, by engaging in reflective self-study, 'the old certainties of tradition, custom, [and] technical efficiency... are rejected as rational grounds for practice and replaced with a process of dynamic interrogation' (Parker, 1997: p.122). The following extract highlights how difficult change is, and although I had decided to change something, I was not at all certain whether my decision was the right one. Although this extract is about a major change in my private life, the argument also holds for decisions to change in the professional sphere.

[Change] is difficult because nobody has any certainty that this change will bring about the desired effects. We can only presume what will happen but not be certain about the future. Thus, many-a-time I personally do not change because of lack of certainty. Uncertainty is a frightening thing, and that is one thing I have learnt from this experience (PD: 03-01-04).

Thus, uncertainty and inconclusiveness also affected my emotions. Often I felt exasperated when, try as I might, I could get no correct and definite answers to the questions I posed. On such occasions, my only possibility was to suspend the need for 
answers, because 'reaching understanding is not always possible here and now' (Oosterheert \& Vermunt, 2003: p. 162). I would engage in further observations, reflect on my past and new observations, and re-tackle the unanswered questions (PD: 29-0503). This is because according to Oosterheert \& Vermunt (2003), 'new information is often needed... and this information is not always available in the present' (p.62), and in such situations, every little guideline or indication can be very important (LO: 09-0104). This is a suspended state of not knowing.

One such example of uncertainty, confusion, and inconclusiveness is illustrated by my earlier argument about whether or not to focus primarily on the exam. Right after writing in my reflective journal about such a dilemma, I argued that 'my own arguments make me feel more confused' (PD: 22-06-03). Consequently I realised that sometimes it was the reflective process itself that increased rather than decreased my uncertainty and lack of conclusions.

Although this dilemma has been going on for quite a while in my head, it seems that reflection and writing about it never gave me a clear answer. Today I wanted to write what I think, but instead of answers, my reflective practices offered me more anger, frustration, and lack of change even though I know that change is needed. What shall I do? My thoughts answer: 'I don't know!!' (PD: 22-06-03).

Such confusion and uncertainty are also compounded by the conflicting messages we get from wider society. The following extract shows how after seven months, I was still battling with myself as regards the same dilemma when I argued that:

As teachers, we get conflicting messages from education authorities in Malta. We also get conflicting messages from societies around the world too. Let me explain myself better!!! One message we get from society in general and also during my undergraduate course in education, is that all students are important and that even students who do not sit for their ordinary level exams are important because education is not only made up of certificates and academic achievement. However, as a student, I was always taught how important certificates are in today's world. This was further confirmed whenever I applied for a job, or even to further my studies. It is obvious to me that present and future teachers are getting conflicting messages... What about the statistics given by education authorities and newspapers regarding the pass rates of students in their ordinary level examinations? What about the craze for the 'Junior Lyceum' examination (where most students are 10-11 years old)? Why would it be so worrying if pass rates are 
lower than the year before? Why would it be so rewarding if pass rates are always on the increase? All the above-mentioned give me the impression that a teacher's main job is to help students acquire certificates and pass their exams (PD: 23-0104).

As regards this dilemma, I have argued that 'I'm starting to think that this question is unanswerable. There are arguments in favour and against but... the question is still unanswered' (PD: 26-08-03). As a matter of fact, I have not reached a definite conclusion up to this present day. Hence, I had to learn to live with uncertainty and inconclusiveness since they are an integral part of the learning process through reflective self-study, and as Schön (1983) argues, professional practice comprises uncertainty and conflicts over various issues, and these include values, beliefs, goals, purposes, etc. No simple solutions exist to complex problems faced by teachers in whatever context, and what seem to be simple solutions are very often inappropriate (Houston \& Clift, 1990). Thus I do agree with Campbell's (2002) statement that on various occasions the teacher-researcher must have:

The confidence to admit 'I've looked at the evidence, it has increased my knowledge and understanding, it has affected my practice but I've hit a wall - I don't know what to do next'. And living with uncertainty: 'it feels so messy. You don't think you are going anywhere or doing anything' (p.30).

I must point out here, that although in the initial stages, I could not stand having suspended states of not knowing, I later realised that such suspended states promote further reflection. It is doubt and discontent that make me look further and deeper into issues at hand, and uncertainty and inconclusiveness powered my need to learn further. They were in fact the reason why I embarked on a reflective odyssey in the first place. This is harmonious with Dewey's (1910) argument that doubt stimulates inquiry.

In the suspense of uncertainty, we metaphorically climb a tree; we try to find some standpoint from which we may survey additional facts and [get] a more commanding view of the situation... Demand for the solution of a perplexity is the steadying and guiding factor in the entire process of reflection (p.11).

As a matter of fact, when I realised that uncertainty aliments my need to learn, I constantly took the stance of what Grant (2001) calls the uncertain inquirer, where I 
continuously doubted my own understandings. Kroll (2004) reports a reflective practitioner making the following argument:

I now swim in my confusion; I am no longer drowning in it. I almost hope my disequilibrium continues throughout my career, only temporarily cleared by new understandings because the best blessing I can imagine is to always find new ideas with which I can struggle (p.210).

\subsubsection{Uncertainty as a Positive Component of Reflective Self-Study}

Hence, although at times they are frustrating and can be viewed negatively, lack of conclusions and feelings of uncertainty can actually be positive aspects that keep the reflective teacher-researcher striving for deeper understanding of problematic issues. As Metzger (1986) contends, 'part of the finding is in the getting lost. [For] if you're lost, you really start to look around and listen' (cited in, Oliver, 1998: p.244). This is why I have previously argued that we must not be impatient with our own learning. We must not aim for the quick change and/or conclusion through reflective self-study, because learning is accompanied by a suspended state of inconclusiveness and uncertainty, since making sense is not a split-second event but a process requiring substantial time (MacLeod \& Cowieson, 2001; Czarniawska, 2004).

According to Elbaz (1983), being patient with our own learning and accepting periods of incoherence and uncertainty is ultimately rewarding. I myself realised that 'sometimes it takes months or even years to get a possible answer to a question you once asked' (ISO: 23-04-04), and such an answer may prove itself implausible after a while. But when do we know when an interpretation is the most plausible? As Taylor argues, when 'what is strange, mystifying, puzzling, contradictory is no longer so' (cited in, Peshkin, 2000: p.5). This is until new situations and observations throw our apparent certainties back into a state of confusion. Hence, my conclusions to specific issues I reflect upon are temporary, as I always leave room for possible error that can be highlighted by the acquisition of new understanding and learning. 


\subsubsection{A Tolerance of Uncertainty Promotes Ongoing Inquiry}

As Grant (2001) states, tolerance of ambiguity is one factor that helps improve teaching practices. Hence, if we cannot tolerate uncertainty and inconclusive states, we will miss most of the benefits that reflective self-study has to offer. Similarly, Dewey (1910) argues that:

The most important factor in the training of good mental habits consists in acquiring the attitude of suspended conclusion and in mastering the various methods of searching for new materials to corroborate or to refute the first suggestions that occur; to maintain the state of doubt and to carry on systematic and protracted inquiry - these are the essentials of thinking (p.13).

Through this study, I have come to realise that there is no ultimate need to get answers quickly. What is of most importance is the process of inquiry, the search itself; for in searching for plausible answers, many possibilities are imagined and taken into consideration, reflected upon, and tried out in practice. This is what makes reflective self-study an ongoing and never-ending process. In Elliott's (1998) words:

The intelligent response to the complexities and paradoxes of living in advanced modern societies is one of imaginative experimentation based on a tolerance of ambiguity and risk (cited in, Tickle 2000: p.28).

Such imaginative experimentation is reflective practice combined with action-research. On the other hand, as maintained by Schön (1983), many practitioners who do not engage in systematic reflection:

Become too skilful at techniques of selective inattention, junk categories, and situational control, techniques which they use to preserve the constancy of their knowledge-in-practice. For them, uncertainty is a threat; its admission is a sign of weakness (p.69).

Therefore, while uncertainty is seen as a sign of weakness for the technical expert, uncertainty is a sign of constant growth, development, and learning for the reflective practitioner. This is why the reflective practitioner 'must be willing to enter into new confusions and uncertainties' (Schön, 1983: p.164). In summary: 
From the perspective of inquiry as stance, professional development is associated more with uncertainty than certainty, more with posing problems and dilemmas than with solving them, and more with the recognition that inquiry both stems from and generates questions (Cochran-Smith \& Lytle, 2001: p.56).

\subsection{Summary}

Throughout this chapter I wanted to show the reader that reflective self-study is a journey through bumpy roads. The first major difficulty tackled was the problematic, although desirable, nature of change. First of all, change is not a one-time occurrence but a process. It has been argued here that change is difficult because unlearning previous learning while also going against tradition are aspects inherent in efforts to change which can easily cause discomfort. This is exactly why I have argued that determination is a valuable attribute that the reflective practitioner must have in order not to give-up when facing difficult periods in his/her process towards professional development.

In this chapter I have also argued that the reflective practitioner should learn to live with a suspended state of not knowing. Furthermore, I have come to appreciate such a suspended state, because it is such a state that makes me reflect further. If I thought I knew it all, I would not search for new understandings; but realising deficiencies in my own understandings makes me strive to better observe and better understand. 


\section{Chapter 6}

\section{Continuous and Relevant Professional Development}

\subsection{Introduction}

Throughout this research, I was learning and extending my own professional knowledge. Consequently, I was engaging in professional development, since according to Day (1999), professional development is the extension of teachers' professional knowledge. It is suggested that teachers develop through a variety of means, including school-based and off-site courses of varying durations, actionresearch, self-study, teaching experience, and personal reflection (Craft, 1996; MacLeod \& Cowieson, 2001). Similarly, throughout this study, my professional development came from a variety of sources and I aim to describe and critically reflect upon them in this chapter. For the sake of clarity, professional development will be divided into two forms. The first type of professional development I will be discussing is formal professional development and this includes short in-service courses, staff development meetings, a once-weekly in-service course over the period of two scholastic years, as well as a one-week off-site course organized by the Council of Europe. In all the above, teachers attended lecture-type courses to learn about specific issues.

The second type of professional development I have experienced is informal professional development. This is closely linked to my engagement in reflective practice and includes my learning from engaging in inquiry as a teacher. Learning here is of a personal nature and is specifically relevant to my needs as a teacher working with specific students, in a specific culture, in a specific school. Hence I will refer to this type of professional development as personal professional development.

This chapter addresses the ways in which these forms of professional development aided my learning as a teacher. My starting point in all this is similar to that of Falk 
(2001) who argues that professional development should be viewed as an integral part of the job of teaching rather than as an optional add-on activity.

\subsection{Formal Professional Development}

Finding myself in a completely new situation with the introduction of SEC PE, I attended organized courses with an open-mind, convinced that I had a lot to learn. Unlike my previous experience with learning as a student, I was not in search of good grades and certification. Some of the courses I attended were compulsory while others were not, but still, my goal did not change: I wanted to learn about teaching and I had high hopes - very high hopes! Unfortunately, as Fishman et al. (2003) contend, little is known about how teachers experience formal professional development, and what they learn from these programs. Thus, in this section, I aim to share how I experienced formal professional development.

\subsubsection{A Teacher's Perspective on Formal Professional Development}

Despite my initial enthusiasm for formal professional development, my colleagues were less optimistic. After just three months of attending a once-weekly in-service course, some colleagues were describing the sessions as a 'waste of time' even though in the initial stages they thought that they were of value. In fact, I could observe that both teachers and providers were losing motivation, and soon I was no different although I was determined to persist. Nonetheless, after five months, teacher attendance had diminished drastically.

During today's in-service session, [a provider] pointed out that attendances have diminished. They did in fact diminish. I would argue that those who do not value the significance of such courses would find it tempting not to attend (even though this is a compulsory in-service course)

Another probable reason is that some of the teachers are getting tired of these courses... Yet, I still attend these courses because I can learn a lot from them. I must say that although not all of them were well prepared or interesting, these 
courses offer opportunities to learn from direct presentation, or by simply talking and discussing certain issues with colleagues (PD: 21-05-03).

Mostly, I valued such courses because I believed that meeting other teachers who were in my same situation as myself would be valuable. In my diary I argued that 'these meetings are important for teachers who like me feel isolated' (PD: 26-03-03). Maybe, I thought, change would be easier with the support of colleagues. Discussion and collaboration with colleagues did in fact promote informal learning.

\subsubsection{Informal Learning in Formal Professional Development}

Informal learning came through 'exchanging experiences with those from other schools' (Craft, 1996: p.14). In fact, when some in-service sessions had to be skipped, I argued that 'the lack of these meetings is making me feel more isolated than before... and it might be a coincidence... but my last entry highlighted my feelings about me being lost in space' (PD: 26-03-03). I realised that I was hungry to understand other people's perspectives, viewpoints, and ideas, and my colleagues seemed to have the same inclination as they could be constantly observed discussing various issues together, even though there was no planned time for such discussion to take place. As I noted in my journal, 'I've learned more through interacting with other teachers than from the session itself' (ISO: 28-05-03). My experience reverberates with Garet et al.'s (2001) following statement:

Professional development activities encourage professional communication among teachers who are engaged in efforts to reform their teaching in similar ways. An ongoing discussion among teachers who confront similar issues can facilitate change by encouraging the sharing of solutions to problems, as well as by reinforcing the sense that, with time, improvement is possible... In addition, by sharing methods, discussing written work, and reflecting on problems and solutions, teachers may foster a better understanding of the goals for student learning that proposed changes in teaching imply (p.928).

Ironically, teachers were sometimes prevented from discussing issues between themselves during a lecture. Yet, in my experience, when a session is planned without allowing time for teachers to work together and contribute their own ideas, a lot of learning possibilities are lost. Keating (2001) argues that teachers evaluated formal 
professional development as effective when they were given time to share ideas, thoughts, and feelings in a supportive, collaborative learning environment. Hence, although it is desirable for a professional development session to be well-planned 'it might diminish participation and the input of ideas by the teachers present. This is because the planned session has to fit a set time frame' (ISO: 05-03-03). This seems to support Stringer's (1996) statement that 'an army of experts is unlikely to be able to meet people's needs if the people themselves remain merely passive recipients' (p.34). For me, discussion has become a core feature of meaningful professional development and, consequently, I contend that in-service courses should provide teachers with ample time for collaboration and discussion. In short, my experience is well-described by Williams' (2003) statement that 'the course itself did not help but talking to the other [teachers] did!' (p.210).

\subsubsection{Technical Rationality and Formal Professional Development}

All the courses I attended were based on technical rationality; thus assuming 'that a body of theoretical knowledge is learnt and applied in practice situations, and... that what is learnt in one place can then be applied elsewhere' (Edwards \& Nicoll, 2006: p.119), making such courses become short, quick fix activities where teachers learn how to teach (Day, 1993). However, as pointed out by Laursen (1994) this assumption is flawed. This is especially true when keeping in mind that 'there is no one correct way of teaching, no one specific set of skills, techniques and procedures that you must master and apply mechanically' (Capel, Leask \& Turner, 2001: p.1). Unfortunately though, teachers attended such courses and were told how to teach; what to teach; when to teach. Such in-service courses made me feel that I was just a link in a chain. I had to understand what was expected of me and what the students were expected to learn, and I simply had to implement what I was told to do. This made teaching look like 'cooking from a recipe book' (Winch, 2004: p.188), since the message I got from such courses is that 'teachers can't think but are there to simply put policies into practice' (ISO: 17-1104). However, teaching is much more complex than the simple application of policies and strategies (Loughran, 1996). As time went by, such feelings were exacerbated and the style of the in-service courses meant that I did not feel professional at all. 
I'm sorry to say that in-service courses in Malta (at least the ones I have been attending for the past 3 years) are organised to sell to teachers a mode of doing things... and teachers are indeed viewed as mere technicians that should put into practice whatever these people tell us to do. As if teachers cannot think... (ISO: 1011-04).

Trying to implement what others had devised did not produce the desired results because context was not given its due importance. This is especially true when inservice activities are highly prescriptive (Stringer, 1996; Mason, 2002; Sparks, 2002b; Moore, 1999; Mills, 1959; Ghaye \& Ghaye, 1998; Fishman et al., 2003; Zeichner, 1994). It seems important to bear in mind that whatever we do, think, learn, and feel is never free from contextual influences (Day, 1999; Bass et al., 2002). However:

Most approaches for bringing research to teachers assume that researchers' knowledge is the best foundation upon which to build a professional knowledge base because of its generalisable and trustworthy (scientific) character (Hiebert et al., 2002: p.3).

At one level, this view appears to make sense, but my experience of professional learning suggests that such an assumption should be thoroughly questioned if we recognise that teacher learning and understanding are closely related to the context of practice (Dadds, 1995; Humphreys \& Susak, 2000; Verloop et al., 2001). However, the idea that knowledge is constructed and is dependant on the context of practice seems to be too easily forgotten in formal professional development. What Campbell (2002) calls 'the power of the personal in professional development' (p.29) should never be forgotten in professional development because instead of developing practice, such courses irritated and discouraged me. In Stringer's (1996) words:

It is not difficult to understand the source of these frustrations. Centrally devised and controlled programs and services cannot take into account the multitude of factors that impinge on people's lives. Professional practitioners... feel compelled to implement programs and services according to formally sanctioned practices and procedures, despite their ineffectiveness in achieving the goals they were designed to accomplish (p.20).

Also, on many occasions during formal professional development activities, teachers were offered little explanation about why things should be done in one way rather than 
another. This may not be surprising given that some teachers take a similar approach with their students (Garet et al., 2001). On those few occasions where explanations were provided, it made a real difference because explanations aroused my interest (ISO: 08-01-03). Also, it is worth recalling Dewey's (1910) advice that only when things have practical meaning for us can we deliberately understand and control them. Hence, implementing a directive without understanding it fails to empower the teacher and offer the prospect of deliberate control; and in this context I began to wonder whether teachers stopped attending the abovementioned in-service courses for this reason.

To add insult to injury, some of the courses I attended were compulsory and they turned out to be repetitions of previous courses; both my colleagues and I felt that such repetition 'was an infernal waste of time' (ISO: 22-10-03). It was as if the empty vessels (teachers) were not well-filled and providers were trying to refill them. On such occasions, 'nothing new was on offer' (ISO: 19-11-03) and, like Garet et al. (2001) I contend that this has a negative association with altering teaching practice.

I also noticed that on some occasions, when teachers critiqued or questioned what was presented at in-service courses, they were 'scolded' for doing so. The same happened when some teachers tried to propose ways of doing things differently. Some sessions ended up in hot arguments. 'What frustrated me once again is the fact that when teachers started discussing and giving some ideas, the people in charge... started dismissing most of the ideas as irrelevant' (ISO: 17-11-04). Through these experiences, I have come to loathe top-down models of training where teachers are simply viewed as passive recipients of others' knowledge (Weiss \& Weiss, 2001). I felt that such courses insulted me both as a teacher and as a person (Armour et al., 2001) for their structure implied a deficit in teacher knowledge, skills, but most of all, intelligence. No wonder that professional development so conceived has been strongly criticised in the wider CPD research literature (Lieberman \& Wood, 2001; Fishman et al., 2003; Ball \& Cohen, 1999; Borko, 2004; Armour \& Yelling, 2004; Clarke \& Hollingsworth, 2002). 
In summary, therefore, I concur with Sparks' (2002a) conclusion that such traditional forms of professional development are often ineffective. Stringer (1996) puts it well:

People in positions of authority already have defined the problem and formulated a solution. They fail to grasp that others may interpret the situation and/or significance of the problem in ways very different from their own, or may have different agendas in their lives, with other matters having much higher priority (p.43).

On one occasion, I felt strongly enough to argue that I would prefer to use the time allocated to in-service sessions for reflective self-study (ISO: 26-05-04). Unsurprisingly perhaps, attendances at the courses continued to decline, even when sessions became more interesting. By this stage, most teachers had lost faith in the system: 'I really learned a lot from this session and... it was well-planned, interesting, and fun. Yet, attendances are diminishing further' (ISO: 28-05-03). Unfortunately, such negative sentiments are widespread among Maltese teachers. For example:

During an informal discussion that was taking place in the staffroom [a teacher] argued that she feels great apathy when she is called to attend an in-service course. [She] is an extremely dedicated teacher. However, she feels that these courses are useless... At this point, everyone present in the staffroom agreed (approximately 15 people) (PD: 07-04-05).

\subsubsection{The Necessity for Professional Development to be Relevant to my Needs}

When topics discussed were relevant to my immediate needs as a teacher, I viewed them through a completely different lens, as the following journal extract illustrates:

The usual staff development meeting: Boring, irrelevant, tiring, etc. etc. This is what I thought. However, it turned out to be completely different because the topic seems to be one of my problems at the moment...

Although this staff meeting was in the boring form... i.e. a lecture given by somebody who works outside the school (and usually does not know the real situation) some of the things he said made me think about what is happening to me (PD: 19-11-03). 
Armour \& Yelling (2004) and Loughran (2002a) contend that professional development must be relevant and closely linked to the teacher's experiences and dilemmas faced in their daily teaching and my experience supports this.

Reflecting upon the in-service courses, I have come to the conclusion that neither the well-planned, interesting sessions nor the boring and irrelevant sessions had much impact on my teaching practice. This is not to say that new learning did not occur, but that the new learning was difficult to apply to practice. In essence, the core feature of effectiveness for me was relevance. If topics addressed in a course had immediate relevance to my sphere of practice, then the chances of applying new knowledge in practice were much enhanced. Hence, no matter how well-planned in-service courses are, it is always the individual teacher who must determine effectiveness based on teachers' and pupils' needs. Therefore, I would agree with Armour \& Yelling (2004) and Day (2004), and contend that professional development should be structured around teachers' needs. Unfortunately however, 'experts hired to provide these opportunities know little about the teachers they are supposed to be developing and the culture of their schools' (Lieberman \& Wood, 2001: p.174). This is a fundamental problem. According to Sykes (1996) the inadequacy of such conventional professional development is 'the most serious unsolved problem for policy and practice' (cited in, Borko, 2004: p.3). Also, having site-based courses seems not to have bettered the identification of individuals' needs, and thus relevance has not been advanced (Day, 2004). What $I$, and teachers like me need are new perspectives through which we can analyse practice, and new insights that can help in adapting practice.

\subsubsection{One-Size-Fits-All}

I think that most of the people that delivered presentations and speeches live in a world of ideals. They are miles away from everyday realities found inside schools. The sessions were rather boring. It was just reading a number of, or a collection of arguments found in the literature (PD: 23-04-04).

According to Nias (1989): 'since no two people have the same life experiences, we all learn to perceive the world and ourselves as part of it in different ways' (cited in, Kelchtermans \& Vandenberghe, 1994: p.46). No wonder then, that one-size-fits-all 
solutions readily available in formal professional development seem to be too ideal and not directly relevant to the everyday reality faced by teachers in schools. In the words of Sparks (2002b): 'a lot of times we take a good practice that somebody has created and bring it to other people in another place and find that those people are not particularly eager to do it' (p.5). There are several examples of this in my diaries. For example, when a course presenter asked the audience if we had tried any of the new ideas presented to us during the previous session; all teachers responded... NO!!! According to Stringer (1996): 'teachers... will be unresponsive to staff development programs that have been mandated for them' (p.122). In such programs, change is seen as 'something that is done to teachers [rather than] as a complex process that involves learning' (Clarke \& Hollingsworth, 2002: p.948). In this sense, I do agree with Clarke \& Hollingsworth (2002) when they argue that teacher growth is more important than teacher change thus conceived.

This is not to say, however, that I did not intend to use new learning acquired in such programs to inform my teaching. As one of my journal entries illustrates: 'I will use some of the activities we used during the in-service course with next year's group... This session would act as a big bonus in terms of new ideas and activities' (ISO: 30-0403). The only problem was that such motivation to make changes only happened rarely and, even then, the good intentions rarely translated into actual changes in practice. It would appear that something was missing because I was eager to learn and to develop. As suggested earlier, this missing something is relevance, and relevance for the teacher is where theory and practice inform each other. The relationship between relevant theory and personal practice will be investigated in-depth in Chapter 7.

\subsubsection{Dissatisfaction with Traditional Formal Professional Development: is there a need for change?}

Throughout my research, I constantly gathered the views of other teachers attending the same courses I attended. All seemed to hold a pessimistic view of formal professional development. However, I also sought wider views. For example, I consulted a colleague teaching a different subject in a different school. After I had described my 
experiences of professional development, she commented: "You could not have described my feelings as regards in-service courses in a better way; had I told you my own views".

There is evidence that knowledge cannot be technically transmitted to the learner simply through the presentation of theory since learning for professional practice is mostly experiential (Oosterheert \& Vermunt, 2003; Stevenson, 2002; Laursen, 1994; Elbaz, 1983; Mayes, 2001). Also, as Day (1999) argues, 'teachers cannot be developed (passively). They develop (actively)' (p.2). Then why do most formal professional development opportunities remain traditional in nature? Why is the technical-rationalist view still prevalent today (Parker, 1997; Mayes, 2001)? Is change so difficult to embark on? Is it so difficult to break away from the accepted, albeit mistaken ways of doing things? Once again, I do not know the answers to these questions, but I do try envisaging a better future for the education of teachers in the concluding chapter. This I do by taking into account all that I learned about both formal and personal professional development.

As Clandinin's (1995) words illustrate, not being able to see alternative ways of doing things inhibits change:

As a student in my teacher education classes, I was a student character in what we call the sacred theory-practice story. I was there to be filled with theory that I could then apply to my teaching practice... As I began work as a university teacher educator, the same plot outline continued to shape the way I lived that story. Without being able to step outside to try to imagine competing plot lines, I could vary the story only in small ways (cited in, Loughran, 2002b: p.242).

Another problem may be that 'there is a tendency for people in positions of power to assume that, being organisationally superior, they have superior knowledge' (Stringer, 1996: p.23). This is a perilous path for the improvement of teaching. Yet, there is something even more dangerous. The real problem is that even a number of practitioners believe this; in the sense that research is not to be conducted by the teacher but by the researcher, and that writing about the self is not worthy knowledge. The following words by Armour et al. (2001) highlight such beliefs. 
In a poignant moment on the M.Sc. module, students voiced their concerns that stories about themselves could not possibly be worthy of postgraduate credits even accepting that they were cloaked in as much traditional academic paraphernalia as possible (readings, references, etc.) (p.6).

Ironically enough, I was one of those students in this course that was concerned about such a thing. Through such beliefs, technical rationality is being unconsciously reinforced and until we are able to challenge such beliefs, self-study and knowledge produced from experience will not be valued as highly as formal and propositional knowledge. According to Craft (1996), 'being a professional means taking responsibility for identifying and attempting to meet the professional development needs of oneself' (p.7). On the contrary, through formal professional development ' $I$ was told how to develop myself' (Armour et al., 2001: p.6).

\subsection{Personal Professional Development: a road towards lifelong learning}

Historically, teacher learning and teacher change have been viewed as possible solely through traditional forms of formal professional development. But how would one 'account for the demonstrable occurrence of teacher professional growth independent of participation in in-service activities' (Clarke \& Hollingsworth, 2002: p.961)? Like Ghaye \& Ghaye (1998), through my own experience I assert that teachers inevitably learn through daily experience, and the development of a teacher should not be seen as an isolated activity. This rests on the premise that we do not learn solely by engaging in formal educational processes (Lave \& Wenger, 1991). Unfortunately however, Marczely (1996) points out that:

Unlike other professions, education gives teachers few personal options when it comes to professional development. Too much of what we presently do is collective in-service, not personalised professional development. In-service education is oriented toward immediate collective training objectives, whereas professional development implies engagement in persistent and personally significant activities (cited in, Day, 2004: p.132). 


\subsubsection{Personal Professional Development: directly relevant to my needs}

When considering that professional development has to be relevant and closely linked to the teacher's need, practitioner research, such as that conducted in this study, is one form of learning that was immediately relevant to the context of practice (Hamilton, 2002; Stringer, 1996). For example: reflective writing, as described in Chapter 3, demands that I write about myself, my experiences, my emotions and my thoughts; and as Richert (2001) affirms, this content 'is necessarily relevant as it is about me' (p.171). As argued by Conle (2000) and MacLeod \& Cowieson (2001) when this is done with the intention of deeper understanding, it has strong links to developing professionally.

Practitioner research however, has been rarely thought of as sufficient professional development (Sparks, 2002a), although 'teacher self-initiated professional development has been increasingly advocated' (McQuillan \& Muncey, 1994: p.265). The relevance of new learning acquired by teachers inquiring into their practice is vividly depicted by Campbell's (2002) words:

Teachers researching their own classrooms have the potential to locate development where it arguably should be, in the hearts and minds of the teachers, in their everyday lives and work (p.31).

Unlike the formal professional development I experienced, instead of being provided with theory with the hope of implementing it in practice, problems emerged from practice itself and theory was then used as an additional viewpoint; as a guide to professional practice. Unfortunately, 'planned or pre-meditated development can often be ineffective when it does not address teachers' personal-professional agendas' (Day, 2004: p.109). The personal professional development described in this study originates from real problems and real issues in real settings. After all, learning needs emerge in real contexts, and any attempt at improving teaching should be based on the reality of everyday teaching (WestEd, 2000; Tom, 1987). This is similar to what Berkel \& Schmidt (2000) term problem-based learning; being:

An approach to professional education that stresses the use of real-life problems, and, in the course of discussing them, formulates goals for self-directed learning. 
The learning resulting from these activities is considered constructive and contextually meaningful (cited in, Basile et al., 2003: p.293).

The use of theory to inform real-life practice will be discussed in Chapter 7, but what is important at this stage is that:

It's not enough to be exposed to new ideas, we have to know where they fit, and we have to become skilled in using them. These formal professional development structures can't ensure that the new knowledge will translate into strong classroom practice, that the skills will be honed (WestEd, 2000: p.20).

\subsubsection{The Tools for Lifelong Personal Professional Development}

It is important to establish at the outset that although certain types of professional development are criticised in the education literature (Lieberman \& Wood, 2001; Fishman et al., 2003; Ball \& Cohen, 1999; Borko, 2004; Armour \& Yelling, 2004; Clarke \& Hollingsworth, 2002), this does not mean that none of it is needed, nor that one model holds all the answers to all teachers' needs. In any professional sphere, practitioners need to continually develop if improvement is desired, and teaching is no different (Borko, 2004; Day, 2000; Garet et al., 2001). Hence, 'we simply cannot rely on what we learned at university' (ISO: 19-04-04) because teacher education as we know it today provides the future teacher with what Winch (2004) terms functional competence. We need to continuously learn and develop; otherwise we remain at this level of functional competence and as Stringer (1996) points out: 'other capacities are required' (p.3). According to Edwards \& Nicoll (2006), it is the model of technical rationality that 'assumes a front-end model of learning, that is, all you need to know will be provided through initial education and training' (p.119). However, we today realise that such an assumption is flawed and that is why there have increasingly been 'calls for continuing professional development' (Edwards \& Nicoll, 2006: p.119). Perhaps what is required, therefore, is for pre-service teacher education to provide the tools necessary for teachers to engage in lifelong learning through personal professional development (McIntyre, 1993; Zeichner, 1994). Pre-service teacher education should be regarded as a first important step towards ongoing professional development that does not terminate prior to retirement; a lifelong stance (Tickle, 2000; 
Capel et al., 2001; Capel \& Taylor, 2001; Imants, 2002; Cochran-Smith \& Lytle, 2001; Checkley \& Kelly, 1999; Day, 2000; Kelchtermans \& Vandenberghe, 1994). In the words of UNESCO Director General:

The purpose of learning can no longer be regarded as no more than an initial preparation for the remainder of one's life. Learning in the twenty-first century will be a continuous requirement (cited in, Day, 2000: p.106).

Therefore:

A key requirement for a system to meet changing needs is to not just to train teachers like technicians to implement lessons developed by others, but to nurture intellectual flexibility and creative professionals who construct their own way of doing things to suit their context (Radnor, 2002: p.19).

This leads me to think of an ongoing form of professional development; the same type of ongoing development I have experienced myself throughout this study.

\subsubsection{A Need for Professional Development to be Ongoing}

Throughout the document 'Teachers who Learn Kids who Achieve' (WestEd, 2000) it is evident that teachers and school staff felt the need for professional development at times where major problems were perceived. Some perceived problem is sometimes necessary to shake the practitioner and wake him/her up to realise that new learning is possible and desirable for improvement (Loughran, 2002b). As such 'this new syllabus helped me realise how important it is for teachers to learn about themselves, the situation, the students, etc.' (PD: 20-05-03). It is also important to realise that professional development so conceived should be ongoing; a continuous quest for new learning, because the self, the context, and the students are continuously changing (PD: 25-09-03; ISO: 26-02-03). As Mason (2002) contends, no solution will work in every context with all students. In this sense, similar to Fottland's (2004) and Heikkinen's (2001) arguments, I can never consider myself an expert for I can never be fully competent and fully developed; this being a good reason why professional development should be ongoing. Also, a sustained focus over time is a key feature of the professional teacher if effective learning is to occur (Sweeney, 2003; DeMulder \& Rigsby, 2003; 
WestEd, 2000). Hence, 'it is now generally understood that teacher learning takes place over time rather than in isolated moments in time' (Cochran-Smith \& Lytle, 2001: p.46).

\subsubsection{Reflective Self-Study: highlighting the personal nature of professional development}

All my above arguments imply that I have come to view professional development to be a somewhat personalised endeavour rather than a public one. As was noted earlier, just like their pupils, teachers differ from each other in many ways, including philosophy, working context, background, etc., and no formal program can be optimal for all teachers. Unfortunately:

We have been persuaded that new and improved knowledge is gained from external sources and 'experts' rather than from personal experience, by listening rather than by acting (Russell, 1993: p.145).

However, I have come to value the process whereby I engaged in personal professional development through reflective self-study. As argued in the literature, reflection should be seen as having long-term learning potential leading to ongoing professional development rather than solely short-term influential value (Ward \& McCotter, 2004; Chetcuti, 2002; Clark, 1995; McIntyre, 1993; Russell, 2002). Reflection should henceforth not be seen as a goal in itself, but a tool for professional learning and understanding (McIntyre, 1993; Zeichner, 1994; MacLeod \& Cowieson, 2001). Such a 'version of professional growth challenges the developmental model that implies that teachers improve simply with experience' (Bass et al., 2002: p.59). Additionally, in Zeichner's (1994) words:

Reflection can be seen as a reaction against a view of teachers as technicians who merely carry out what others, removed from the classroom, want them to do; a rejection of top-down forms of educational reform that involve teachers merely as passive participants (p.10). 


\subsubsection{Reflective Self-Study: a priceless and handy tool towards ongoing development}

Reflective self-study is a form of professional development that is always at hand and this is important when considering that every instance is a potential moment for new learning (PD: 11-05-05). Perhaps the key thing about reflection is that when I face a problem, I don't have to wait for an in-service course hoping that it will tackle my particular concern. Instead, I conduct my own personal professional development. Furthermore, the results of personal professional development are immediately evident in practice. Various authors suggest that engaging oneself in reflection and action research leads to positive changes in classroom practices and can thus be regarded as developmental (Loughran, 2002a; DeMulder \& Rigsby, 2003; Chetcuti, 2002; Craft, 1996; Schuck, 2002; Bullough \& Pinnegar, 2001; Feldman, 2003). Thus, for a teacher to engage in reflective self-study, it is already apparent that there is a commitment to learn and a will to change.

I put into practice newly acquired learning and new insights that emerge from reflective self-study. This is not to say that everything works out fine immediately, but I analyse my changed practice through an action research process where I evaluate and make necessary changes to new methods of teaching with the intent of growing professionally (Craft, 1996; Griffin, 2003). Hence, like Tillema (2000), I see teacher learning as a 'dual process of practice immersion and reflection' (p.575). Some insights do not leave the desired effects and have to be completely discarded or postponed to a later date, until fresh observations can better inform my decisions. Henceforth, I agree with Stringer (1996) that 'my inquiring mind engages, examines, explores, formulates answers, and devises responses designed to overcome the educational problems that confront me' (p.5). All in all however, I can confidently say that 'I see my change in teaching as a major step forward' (LO: 09-03-04).

Teaching demands a continuous cycle of learning, trial, and evaluation. Rather than providing preset answers to generic problems... teachers [should] articulate their own dilemmas and pursue means to resolve them (Lieberman \& Wood, 2001: p.175). 
As previously argued, such development does not happen as if by magic, but is a complex and challenging process (Ben-Peretz, 2002; Ghaye \& Ghaye, 1998; Russell, 2002). Also, a lot of patience is needed on the part of the reflective practitioner. Like LaBoskey (1992), 'my lack of patience for my own learning process is significant. To learn, it requires that each step be endured, not skipped in favour of an easier path' (p.186). Also, through my experience with reflective self-study I assert that for effective personal professional development to take place, one has to learn how to learn before actually learning from reflective self-study.

Learning how to teach is a hard job. However, learning how to learn is a much more difficult and complex job... Learning how to teach is tackled in all teacher education programs and thus, people learn how to teach at tertiary level. Yet, learning how to learn is only done at a deep personal level. I think that nobody can teach you how to learn... Learning how to learn is introspective. One has to analyse something and understand his/her feelings about that particular thing, shed light on it and study it from all angles. It is like being a detective... trying to learn about something and not leaving any possibilities out... Being reflective can help me learn... about new things. It can help me learn and improve things I never thought about [before] (PD: 27-05-03).

Thus, 'teachers should learn how to learn... and that is a very powerful tool for their profession' (ISO: 19-04-04). It is interesting to speculate, as I do in the concluding chapter, where and how teachers (especially future teachers) can learn how to learn. Personally, my undergraduate and postgraduate courses have helped me become a teacher: a good teacher I hope. Yet, my doctoral studies are helping me become a learner (PD: 19-01-04). Hence I argue that if professional development is to be literally continuous and relevant to our needs, and 'if we are to encourage lifelong learning, we have to be lifelong learners ourselves and this we can do through reflective practice and self-study' (PD: 20-06-03). The teacher as a lifelong learner should have a commitment towards continuous and systematic inquiry for career-long learning; reflection being the core of teacher inquiry (Kroll, 2004, Day, 1999, 2004).

\subsubsection{Personal Professional Development as a Never-Ending Quest}

As argued in Chapter 3, one question leads to another and this makes reflection an ongoing and sustained endeavour. Understanding one aspect of personal practice 
immediately highlights my lack of understanding of other related aspects, and I consequently realise that there is more to learn; much more to learn. Consequently, like my own development, 'my research will be an unfinished piece of work' (PD: 19-0104) since I can never objectively say that I know everything about reflective self-study and everything about my teaching. This happens because new learning changes my practice, and changed practice raises new questions. Thus, 'the problem develops, shifts, and changes in response to the continual shifts in the teaching' (Loughran, 2002b: p.243). As argued by Chetcuti (2002):

After a number of years teaching, I sometimes feel that I know all there is to know... but every time I sit down and reflect on a new teaching experience, on a new conversation with a colleague or on a new classroom observation I realise that there is much that I can learn (p.163).

Similarly, I have argued that:

Learning is lifelong. I think that we never know enough and we thus must strive to learn all the time. We must always try to improve since what we know today might change due to what we learn tomorrow (PD: 12-05-05).

Hence, I was constantly in search of new information while conducting reflective selfstudy (Schön, 1983; Golombek \& Johnson, 2004; Renner, 2001; Meriläinen \& Syrjälä, 2001). One of the most important lessons I have learned is that 'the more I learn, the more I realise how much more there is to learn' (PD: 19-01-04).

Personal professional development should be seen as the search for the Holy Grail. We have to analyse the past to try and find it in the future. But if the Holy Grail represents perfection, then it will never be found because perfection is never reached. As such 'we must try to get as close as possible... We have to look backwards, reflect and learn from the past, and try to improve as much as possible in whatever we do' (ISO: 23-0404). 


\subsubsection{Perceived Problems: a driving force towards deep-rooted change}

Problems too can be seen as learning opportunities (Hiebert et al., 2002; Mason, 2002)

and I thus made the most of perceived problems rather than sweeping them under the carpet (Bass et al., 2002), as I had done before engaging myself in reflective self-study.

The more problems encountered, the more one tries to find an explanation, and the more one tries to change. If things seem to work well, one usually doesn't question himself about what is going on. If on the other hand problematic situations are plentiful, the practitioner has opportunities to try and improve the problematic situation by understanding the situation better and acting upon that new understanding. That is where learning occurs. But although many argue that reflection is desirable and valuable, few seem to engage in systematic reflection as professional development. Why are some people so afraid when they encounter problematic situations? Why do a good number of newly-qualified teachers... as well as experienced teachers leave our school within days of personally experiencing the problems faced in this school? Do teachers need to start seeing problems as new possibilities of learning... rather than hardship?... If newly qualified teachers learn to appreciate reflection and the learning that comes from perceived problems... maybe the dropout rate of teachers in difficult schools would be less... (PD: 18-10-05).

I do acknowledge that teachers feel under pressure to perform and get it right from the start due to wider structures of education and schools; i.e. inspections, head teachers, education policies etc. Yet, this presents a problem because when teachers are evaluated for their efficiency, they will not have much patience with their own learning and personal professional development. Nonetheless, something must be done to provide structures that promote rather than inhibit personal professional development (see section 6.3.9).

Another important point is that personal professional development does not solely incorporate learning: it also incorporates unlearning past learning, and this is challenging to say the least (Freidus, 2002). While formal professional development tries to build on what is already present, through personal professional development I was constantly questioning the beliefs and foundations upon which my practice was based, which on many occasions were hidden even from myself. This is one of the main differences between personal and formal professional development, and this is the hardest part since 'it takes time to learn and more time to unlearn the things you do' 
(PD: 25-03-04), especially when on some occasions I had to unlearn years of learning (PD: 12-05-05). Thus, through reflective self-study, my learning was not based on previously existing foundations. On the contrary, I had to excavate, build new foundations, and build upon these new foundations. It is the changing of these foundations through professional development that have a strong effect on changing teaching practice (Richardson, 1996; Fishman et al., 2003; Mezirow, 1991). Hence, through engagement in inquiry I was continuously learning, and through continuous learning, changes in my personal practical theories, as well as my practice, had occurred (Sweeney, 2003; Kosnik, 2001; Day, 2000).

The story does not stop here though, because these new foundations were open to further questioning, and at times, they also had to be altered. This happens when past interpretations and understandings are challenged by future events (Elliott, 2005; Oosterheert \& Vermunt, 2003; Usher, 1998). The following statement by Fottland (2004) resonates with my experience: 'I now feel my own previous understandings were partial, provisional, in a state of flux and in need of criticism... these things can be said about my present understanding as well' (p.657). This reconsideration of previously held beliefs and assumptions is a sign of effective professional development, and this is possible through continuous critical reflection (Hashweh, 2004). Openmindedness is important here because challenging our own beliefs, ideologies and assumptions, and unlearning them to replace them is impossible if we blind ourselves with the comforts of status quo (Pollard, 2002).

My experience with reflective self-study is well-described by Fishman et al. (2003) as they maintain that:

Professional development should fundamentally be about teacher learning: changes in the knowledge, beliefs, and attitudes of teachers that lead to the acquisition of new skills, new concepts, and new processes related to the work of teaching (p.645). 


\subsubsection{The Main Difference between Formal and Informal Professional Development}

One major difference between formal and personal professional development is that in the latter form of professional development 'focus is placed on the process of learning, rather than on outcomes alone' (Ward \& McCotter, 2004: p.243). When focusing on outcomes alone, the only important aspect is the end result, and the ends themselves are given and unquestioned (Ghaye \& Ghaye, 1998). This is technical rationality. However reflective self-study is a different story. Everything is questioned, and both means and ends are continuously under critical scrutiny. In short, it is recognised by teachers that taking courses is not enough for deep learning to take place (WestEd, 2000). It is argued that deep and meaningful learning is supported by a constructivist perspective (Johnson, 2001; Imants, 2002; Basile et al., 2003; Allender, 2002; Noel, 2000), and reflective self-study is indeed constructivist learning; not at all technical. According to Cochran-Smith \& Lytle (2001), this is how teacher learning should be, and I have come to agree with this statement through my own experience with both formal and personal professional development. In short:

We must change our vision... from one of professional as mechanic/technician to one of professional as creative investigator and problem solver. This new vision rejects the mindless application of standardised practices across all settings and contexts, and instead advocates the use of contextually relevant procedures formulated by inquiring and resourceful practitioners (Stringer, 1996: p.3).

In summary, the rationale for promoting personal professional development is the fact that through my research I have come to understand that as a human being, I need to value my own thinking, interpretations as well as meaning-making (PD: 12-05-05). I have also argued in my reflective journal that:

Learning must not always take the form of traditional learning. I used to think that in order to learn, somebody has to give you information and the learner's part is to study... and I was quite good at learning so conceived. Yet, the learning that can happen in this way is limited... We can learn a lot of things about teaching while attending lectures... but it is experience that is the best teacher. What we need is to find a link... an effective link... that amalgamates the learning in lecture theatres and the learning from experience (PD: 10-12-04). 


\subsubsection{Conditions Inside Schools need to Change if Personal Professional}

Development is to be Promoted

Unfortunately, conditions inside schools militate against personal professional development as conceived in this study (Sweeney, 2003; Russell, 1993; Metz \& Page, 2002; Cole, 1997; Kosnik, 2001; Day, 1993, 1999, 2000; Richert, 1992, 2001; Labaree, 2003). For example, the process of conversing with oneself and questioning that is at the heart of reflection, is conflicting with the coverage mentality found in schools, where teachers are employed to cover entire syllabi and little time is available for teachers to question themselves about their teaching and student learning (Wildman et al., 1990). Teachers' working lives are also fast-paced and saturated, and workloads have been on the increase (Day, 2000; Metz \& Page, 2002; Eisenhart, 2001). In schools:

Teachers... will be immersed in the pressures of standards-driven curriculum and closely examined student outcomes. How will the habits of reflection and questioning survive under these conditions? (Ward \& McCotter, 2004: p.244).

Consequently, due to lack of available time 'the outcomes of the powerful personal learning that comes from the teaching experience... are rarely analysed' (Sweeney, 2003: p.124). As argued in Chapter 3, reflection is time-consuming, and if teachers are to be encouraged to take charge of their own development, it is important that this is not added to their already hectic and busy daily work. Hence, it is evident that either teachers work under added pressures to embrace personal professional development through reflective self-study, or things need to change inside schools themselves, where more time is deliberately devoted to teachers' professional development and research (WestEd, 2000). It is expected then that in most schools, according to Stokes (2001): 'inquiry remains less a reality than a phantasmagorical ideal' (p.142).

Although reflective self-study is focused on the individual self, sharing, collaborating, and discussing with colleagues in learning communities is desirable since, as will be discussed in Chapter 7, this can increase learning opportunities (Schuck, 2002; Armour \& Yelling, 2004; Craft, 1996; Lieberman \& Miller, 1999; Cobb, 2002). However, this is also very time-consuming and little time is afforded to teachers to engage in such 
activity (Richert, 1992; Sweeney, 2003; WestEd, 2000). In short, it all comes down to one important point: for teachers; time is indeed lacking for engaging in research and personal professional development (Armour et al., 2001; Clegg et al., 2002; McNamara, 2002).

Hence, for teachers to engage in research, better and more favourable conditions are required. Campbell (2002) claims that teachers experienced involvement in research as 'worthwhile professional development which had affected their teaching and their thinking' (p.34). As one participant argued in Kraft's (2002) study:

Inservice money could be much better spent if the money supported teachers doing teacher research in their building and getting the people there to be on the same page, rather than the traditional inservice provided to teachers (p.186).

\subsubsection{The Role of Literature in Personal Professional Development}

Another aspect of personal professional development is the use of relevant educational literature. Although this aspect will be discussed in further detail in Chapter 7, it is important at this stage to highlight how the use of literature in personal professional development is very different from its use in formal professional development. In reflective self-study, educational literature is used to inform problems perceived in practice, and it is thus my analysis of practice that affects what I look for, rather than being presented with theory and then trying to implement it in practice. In short, I move from practice to theory to practice, rather than simply from theory to practice (Korthagen \& Kessels, 1999). According to McNamara (2002), engaging with the existing literature is fundamental to the teacher-researcher, as it offers varying viewpoints on the issues under question. It is a way of gaining further insight.

It is assumed that the knowledge teachers need to teach well is generated when teachers treat their own classrooms and schools as sites for intentional investigation at the same time that they treat the knowledge and theory produced by others as generative material for interrogation and interpretation (Cochran-Smith \& Lytle, 2001: p.48). 


\subsubsection{Integrating Formal and Personal Professional Development}

This chapter informs the reader how I, as a teacher, have experienced professional development. The model of personal professional development through reflective selfstudy is an example of continuous and relevant professional development that is controlled by the professional teacher him/herself. After all, according to Feldman (2003): 'self-study is the natural direction for all of us who seek ways to improve schooling' (p.27). Mason's (2002) following statement resonates with how I have come to see effective professional development:

Professional development... is about questioning and perhaps changing habitual reactions which were developed in order to cope in certain situations. Thus professional development is a form of personal enquiry in order to broaden and deepen professional sensitivities to notice and to act (p.1).

Also, personal professional development can identify areas of weakness where the practitioner feels that s/he needs extra help. It is at this stage that the teacher should be able to select what type of formal professional development is required to support professional learning. In this model, the more formal acquisition of knowledge is of immense value to the teacher-researcher as no professional can be regarded as selfsufficient (Williams, 2003; Day, 2000). The point to be made is that all such formal learning so selected would automatically be relevant, based as it is, on practice (Freedman, 2001). As such, 'professional development should involve teachers in the identification of what they need to learn' (Armour \& Yelling, 2004: p.82).

\subsection{The Teacher-Researcher}

At the heart of personal professional development is the advancement of critical forms of inquiry on what works in the local context (WestEd, 2000; Cochran-Smith \& Lytle, 2001) where teachers question and reflect on what should and is indeed happening and not happening, while looking for theory and research to aliment their reflective thinking (Clegg et al., 2002; McNamara, 2002). Therefore, practitioners who take responsibility 
for their own personal professional development are engaging in practitioner-research, and engaging in practitioner research such as reflective self-study seems to contribute positively to learning, professional growth and personal development (Humphreys \& Susak, 2000; Conle, 2003; Anderson, 2002; Day, 1999; Loughran, 2002a, 2002b; Fitzgerald et al., 2002; Sweeney, 2003; Campbell, 2002; Clarke \& Hollingsworth, 2002; Kosnik, 2001; Ghaye \& Ghaye, 1998; Miller, 1990; Freidus, 2002; Kraft, 2002; Hashweh, 2004; Bullough \& Pinnegar, 2001; Clark, 1995; Russell, 1997; Mason, 2002). In the words of Fueyo \& Koorland (1997):

Teachers as researchers observe and analyse... [They] make informed decisions about what to change and what not to change. They can and do solve their own problems. They link prior knowledge to new information. Risk takers, they accept failures as learning experiences. Teachers as researchers ask questions and systematically find answers... They make data-based decisions, validating their practice. They implement change. Teachers as researchers are professionals (p.337).

I have indeed learned and developed as a teacher while engaging myself in self-study research. Unfortunately however, this is very different from what happens in formal professional development because this stance of inquiry by the practitioner is often missing in formal approaches to professional development.

The content of personal professional development is chosen by the teacher him/herself, as 'it must be self-managed'; strategies used are observation, reflection and reflective writing; the duration is lifelong (Day, 2000); while the site where such development occurs is everywhere, because in reflective self-study opportunities for learning and understanding are all around me. Through personal professional development teachers can see a connection between their learning and their actions (WestEd, 2000). By engaging in personal professional development, the teacher is seen as 'being a kind of self-teacher who learns through reflecting on experience gained in the fire' (MacLeod \& Cowieson, 2001: p.242).

\subsubsection{Teacher-Research can be Useful to the Wider Community}

As highlighted by Metz \& Page (2002), such insider research can have public usefulness rather than solely valuable for the individual. 
Although research carries honorific status, it has a questionable record in shaping practice, public understanding, and policy... Practitioner inquiry, may be critically useful in a time when the complexity of schools is not well understood (p.27).

However, this chapter does not present an ultimate truth, and I do not present it as generalisable either. What I present here is my experience and my views; an example of how one teacher-researcher has engaged in ongoing personal professional development through reflective self-study. It is up to the reader to think and evaluate, compare his/her experiences, and reflect on the issues presented here. Yet, I also know from my reading of the literature that I am not unique, and hopefully this research can offer valuable insights when realising that:

We have much work to do and many questions to answer in order to provide highquality professional development to all teachers. It will take many different types of inquiries and a vast array of research tools to generate the rich source of knowledge needed to achieve this goal (Borko, 2004: p.13).

After all, as Fishman et al. (2003) contend: 'there is a pressing need for high quality professional development' (p.644), and we indeed know little about how teachers develop and learn personally (Ben-Peretz, 2002; Imants, 2002). Yet, using teachers' views and understanding teachers' personal learning can help in developing effective teacher professional development (Sweeney, 2003). What I can say is that if effective professional development 'promotes continuous inquiry and improvement embedded in the daily life of schools' (WestEd, 2000: p.2), then I can safely argue that reflective self-study is an effective form of professional development. No wonder than that 'reflective practice is becoming the favoured paradigm for continuing professional development' (Clegg et al., 2002: p.131) as through reflection it is indeed 'possible to structure professional development opportunities for teachers that transform their personal and professional lives and their classroom practice' (DeMulder \& Rigsby, 2003: p.288). Hopefully, professional development activities that view the practitioner as a passive learner will become outmoded soon. Instead, as Armour \& Yelling (2004) imply, 'the focus should be upon professional learning, with all that the term implies' (p.87-88). I must say that I totally agree with Bass et al. (2002) when they argue that 
'self-study appears to us as simply the way our professional lives should be continually filled with meaningful learning' (p.66).

\subsection{Conclusion}

Finally, I must say that for personal professional development to be of good quality, the practitioner undertaking self-study research should be able to critically question personal beliefs and practices; be able to understand and take note of thoughts and emotions; value personal experience; consider problems of practice as opportunities to learn, rather than threats; keep an open-mind when reflecting and analysing various issues; and use relevant literature to further inform personal thinking. Also, my experience resonates with Guðjónsdóttir \& Dalmau's (2002) contention that personal professional development 'is a never-ending activity and self-study has become for us the way in which we keep working at this in transformative ways' (p.95).

At this point I do conclude that the original assumption underpinning this study that reflection helps me in learning and in developing professionally is indeed true for me. Although a lengthy and turbulent process, I have developed in ways that would have not been possible had I not engaged in reflective self-study. 


\section{Chapter 7 \\ Ways of Enhancing Professional Learning}

In the previous chapter I have argued for teachers to take full responsibility for their own personal professional development. In this chapter, I concentrate on two aspects that can further enhance personal professional development through reflective selfstudy; these being the formation of learning communities and the ability to integrate theory and practice.

\subsection{Combating Isolation}

For many teachers, 'cooperation in small groups is one important work form suitable for enhancing pupils' activity and responsibility in learning' (Brouwer \& Korthagen, 2005: p.163). Yet, if teachers do value group-work, then why do teachers appear, at times, to be so isolated?

\subsubsection{Me: an isolated professional}

I engaged in personal professional development in total isolation because as argued in Chapter 3, as a new teacher, 'I felt as if I was alone in the desert' (PD: 16-03-03). This seems to be a common phenomenon experienced by teachers (Little, 2002; Houston \& Clift, 1990; Ward \& O'Sullivan, 1998; Hiebert et al., 2002; Sweeney, 2003; Campbell, 2002; Imants, 2002; DeMulder \& Rigsby, 2003; WestEd, 2000) as 'most toil in relative isolation, unable to share their stories and benefit from each other's wisdom' (Renner, 2001: p.1). However, it is widely recognised that sharing, collaborating, and discussing with colleagues can increase learning opportunities (Schuck, 2002; Armour \& Yelling, 2004; Craft, 1996; Lieberman \& Miller, 1999; Cobb, 2002). In reality, I did feel the need to communicate ideas and thoughts, and I did this with a virtual other through conversing with myself. Ironically, I learned about the importance of a learning community through the lack of it, for I found isolation to be limiting my development. 
I was the only teacher teaching SEC PE in my school, so I was inevitably isolated. This is why I argued in my journal that 'I cannot compare my work to other teachers' work' (PD: 23-03-03). Yet, we can learn a lot from other teachers teaching other subjects, since teacher knowledge is not only made up of content knowledge. However, the working conditions faced by teachers, certainly in Malta, inhibit such interaction. For example, a heavy workload 'does not give us much time to interact with our colleagues' (PD: 12-01-03). As such, a group of teacher-researchers collaborating to learn and engage in inquiry together need regularly planned time to work together in a sustained way (Cochran-Smith \& Lytle, 2001; Armour \& Yelling, 2004; WestEd, 2000). Notwithstanding:

One important point I want to put forward is that it is very important to talk to colleagues about various things. I find it very helpful when I find time to do this. I try to share my worries, my successes and failures while teaching... Exchanging ideas and experiences is a big learning opportunity and I feel that I can learn a lot in this manner. It is important for teachers to make use of this since it is also a way of feeling less isolated than we in fact are (PD: 04-04-03).

\subsubsection{Valuing Professional Communication}

The only opportunity to talk to other teachers experiencing my same situation was during in-service sessions. Yet, as pointed out in Chapter 6, communication and the exchange of ideas were not actually planned, even though it was the best type of professional development I experienced during such sessions (PD: 21-05-03; ISO: 0502-03; Heikkinen, 2001). It is interesting to note that 'any opportunity for conversation can spontaneously turn into an occasion for learning' (WestEd, 2000: p.22). Sometimes I discussed issues with other colleagues attending in-service courses that were not even topics on the course's agenda (ISO: 22-01-03).

It is interesting to note that people experiencing similar situations tend to automatically share their stories (Conle, 2003). It is reported in the literature that engaging in professional conversation with colleagues, and exchanging ideas, is a form of learning and a powerful form of professional development that will benefit those engaged (Bencze, Hewitt \& Pedretti, 2002; Cochran-Smith \& Lytle, 2001; Armour \& Yelling 
2004; Tillema, 1997; Shulman, 1992; Coburn, 2003; Hashweh, 2004; Guilfoyle, Placier, Hamilton \& Pinnegar, 2002; Metz, 2001; Brouwer \& Korthagen, 2005; WestEd, 2000; Fottland, 2004; Fuller et al., 2005; Tickle, 2000; Richert, 2001; Borko, 2004; Little, 2002). And teachers can indeed work collaboratively. On one occasion, a particular in-service session had to be improvised by the teachers themselves since the course leader was unable to be present. I was amazed to see how the teachers worked together exchanging ideas and talking about their experiences of what works for them and what doesn't. During such instances I realised how valuable the exchange of ideas and experience between teachers really is (ISO: 26-02-03). As such, I learned to value planned courses that promoted discussion amongst teachers, rather than lecture-type courses (ISO: 10-03-04), for discussion seems to me to be a productive learning exercise (ISO: 16-11-04).

\subsubsection{Reflective Self-Study and Collaborative Inquiry}

If teachers engage in personal professional development through reflective self-study, the new learning acquired through such a process can be shared with colleagues. This is of value since collaborative inquiry is a way of enhancing reflective self-study (Kraft, 2002; Minnett, 2003). Hence, new and unforeseen insights, knowledge, perspectives, and viewpoints can be acquired through such interaction (Basile et al., 2003). This could be beneficial to all teachers involved, but if time is specifically allotted to the creation of such learning communities, the level and quality of learning could be increased. Hence, professional development would still be personal because it starts from reflective self-study, but it would then be shared with others, and the sharing process would lead to further personal reflection. I have experienced this through informal exchanges I had with colleagues, and such a cycle is also evidenced by Guilfoyle et al. (2002) when they argue that 'the dialogue seemed to run in cycles of personal reflection, professional interchanges and public analysis, followed by private analysis' (p.98). As Coia \& Taylor (2002) argue, 'the discussions that arise from the sharing of our autobiographies encourage a critical examination and analysis of our teaching experiences, beliefs, and practices' ( $p .48$ ). In summary, if systematic reflection promotes learning, so does systematic interaction with colleagues because the latter 
promotes further reflective thought both during the actual interaction and afterwards (Ghaye \& Ghaye, 1998; Imants, 2002; Pugach \& Johnson, 1990; Humphreys \& Susak, 2000; Griffin, 2003).

\subsubsection{My Search for a Companion throughout my Odyssey}

Hamilton (2002) argues that 'usually in self-study work the researcher has a critical friend or a colleague to support the thoughtful process of the self-study' (p.110), but like Hamilton I missed that at my institute. However, Elbaz (1983) points out that 'the second party... might be another teacher, a non-teaching but curious friend, or a notebook' (p.170). Lacking critical friends at my workplace, I had to turn to writing as my sole companion, where my reflective journal played the role of my critical friend as it helped me enter a continuous conversation with myself (PD: 20-06-03). Such journal writing is useful in reflective self-study but I still believe that being able to share it with others is of inestimable value (Minnett, 2003; Johnson, 2001).

With this philosophy in mind, I have asked a number of colleagues to observe my teaching in order to get their feedback, even though they teach a different subject (LO: 11-11-03). After all, one component of effective learning is the opportunity for teachers to be observed teaching by colleagues and obtain feedback (Garet et al., 2001; LaBoskey, 1992). Although they were willing to offer their views, they were less willing to being observed themselves. In fact, they never asked any colleague to observe them and give them feedback. At this point, I gave up my relentless search for a critical friend because as Kosnik (2001) contends, 'if both parties aren't willing to work collegially there is no point in adopting this stance' (p.72).

Unfortunately, teachers seem to fear the idea of being evaluated (Richert, 1992; LaBoskey, 1992; DeMulder \& Rigsby, 2003). Maybe being evaluated by university tutors on a pass-fail system during pre-service teacher education has left its mark; if we failed our teaching practice rounds, we were in danger of being removed from the course. An unintended effect of this was to make pre-service teachers become as 
secretive as possible and quickly hide their shortcomings. The following words by Clark (1995) which I reproduce at length, highlight such fears:

Some of us have lived in or come to know about a family or a village, or a school or a society in which to confess a mistake, a weakness, a failure brings punishment and rejection. 'One mistake and you're dead' is the way my wife describes such situations. In such circumstances, people become fearful, controlling, dishonest and secretive. This is even more the case when punishment comes for errors of belief, thought, or ideology. But when an ethos of acceptance has been cultivated, you and I are free to admit our mistakes, to substitute learning from experience for the fear of retribution, and to receive moral support for avoiding such mistakes in future (p.29).

With the formation of learning communities which Clark (1995) calls professional development support groups, the idea is 'for teachers to have a safe and supportive audience for their stories, cautionary tales, questions, and personal dilemmas' (p.29). To be honest, I was not always comfortable while being observed, but my uneasiness eased away after some time. Unfortunately, the type of feedback I received was always positive and not at all critical in nature. I had the feeling that my colleagues would not even dare point out negative aspects so that they would not hurt my feelings. If this is true, it would be unfortunate because in this way valuable learning opportunities are lost. In LaBoskey's (1992) words: 'I need to seek out another's insight into what I do not see, hear, or feel during class. I need to know, in spite of any possible embarrassment' (p.185). I sometimes also asked school administration personnel to observe me and make their expertise available both to myself and the students, and their help was much appreciated by both students and myself (LO: 25-02-03).

\subsubsection{A Critical Friend}

Conducting doctoral research, I did however have a critical friend. My research supervisor helped me in questioning my learning, offering different viewpoints, proposing existing literature that could help me with inquiring into my practice, and also suggesting possible solutions to perceived problems. This role of a critical friend was extremely useful to me, especially when my supervisor took on the role of a partner in my personal professional development, as illustrated in this journal extract: 
I've just met my critical friend... and one of her suggestions struck me... What she said struck me for the simple reason that I never thought of this reason as being a possible cause for my [problem] (PD: 12-12-03).

Yet, I would have still greatly appreciated having a critical friend experiencing my same teaching context. I would have loved being in a learning community where I could be a member through the mutual construction of professional knowledge. Teachers experiencing such communities reported that opportunities to engage in collaborative learning through professional communication with colleagues were fantastic (Guðjónsdóttir \& Dalmau, 2002; Mason, 2002; Armour \& Yelling, 2004; Borko, 2004). Yet, like Russell (2002) 'even though I have had informal discussions with individuals... I did not identify someone who could serve as a long-term critical friend for this self-study' (p.77). One cause is that 'the pressures of teaching and administration make it virtually impossible for individuals, or even a small group, to initiate and sustain collective enquiry into their practices' (Mason, 2002: p.220). This means that through the resulting isolation, little help is afforded to the teacherresearcher (Sweeney, 2003).

According to Day (1999) 'the critical friend is recognised as having knowledge, experience and skills which are complementary' and the aim of such a role is to provide support and challenge within a trusting relationship' (p.44). Will a colleague lacking the attitude of critical reflection suffice? Will s/he have the skills necessary to help the reflective practitioner in deepening his/her understanding? What would happen if all or the majority of teachers engage themselves in reflective self-study? Would they look for each other's collaboration? Schuck (2002) argues that a major obstacle is when one engages in reflective self-study in isolation, especially when colleagues lack interest and engagement in such personal development, as they may obstruct rather than help. On the other hand, the teacher-researcher, when surrounded by other like-minded professionals, does not have to work in isolation. On the contrary, collaboration is valued and desired since 'collaborative exploration helps practitioners' (Stringer, 1996: p.10). Also, having a supportive environment with like-minded professionals facilitates reflective inquiry (Houston \& Clift, 1990; Schuck, 2002; Armour \& Yelling, 2004; 
Fottland, 2004). Unfortunately however, I identify myself in Clarke \& Hollingsworth's (2002) argument that reflective professionals are often disappointed because as Ghaye $\&$ Ghaye (1998) argue, 'critical friends are often hard to find' (p.95).

\subsubsection{Aspects that might Hinder Professional Collaboration}

Despite such difficulties in finding critical friends, I planned to join forces with another teacher who teaches in another school and who also is preoccupied by the situation' (PD: 23-03-03) since at the time I argued that 'two minds worrying about a problem and thinking about a solution is obviously better than one' (PD: 07-05-03). I personally evaluated such a partnership as useful (PD: 21-06-03). Yet, this planned collaboration did not last long. Although we both valued each others' insights, we were very different from each other. Although I have no obvious reasons why such collaboration had such a short life, some of the hypotheses are the following:

- The other teacher engaged into collaboration with the aim of resolving a particular problem of practice, and not with a view of ongoing professional development. When the particular problem was effectively tackled, he deemed that there was no reason for the collaboration to continue;

- Our viewpoints were very different. His approach to tackling perceived problems was technical in nature. My stance of questioning the ends themselves irritated him on a number of occasions;

- We both lacked available time to meet. Any planned meeting had to occur after school hours. Teachers' workload is already high, and not all teachers are willing to give up the little free time available.

As regards the final hypothesis, it is clear by now that lack of time is a factor that inhibits teachers' personal professional development in all of its forms, and this does include collaboration with colleagues (Brouwer \& Korthagen, 2005; Borko, 2004; Freedman, 2001; WestEd, 2000). When considering the first two hypotheses above, I realised that individual teachers must value personal inquiry and reflection as important 
components for ongoing professional development prior to the formation of learning communities. Otherwise, such an endeavour would make little sense to them.

On another occasion, I suggested to another teacher working in a different school that we join forces in our bid to learn about our new teaching challenges. Although he initially agreed, the idea never materialised even though I tried my very best (ISO: 0312-03). However, I never stopped looking for help. On certain occasions I also looked for help from specific professionals who could provide me with important information. For example, when I was uncertain about a particular aspect, I contacted 'one particular person who sits on the [examinations] board. This person can obviously shed new light on our situation' (PD: 14-05-03). This I did and new information acquired was helpful.

\subsubsection{Teacher Isolation: a harsh reality}

At this point I ask myself: Although teacher isolation is a reality, can part of the blame fall on the teachers themselves? Is isolation self-inflicted? The following journal extract written after an in-service session illuminates my frustration and why I ask such questions.

What I noticed once again is that is seems impossible for the teachers present in such groups to learn from each other. Nobody seems to be capable of accepting some constructive criticism. Providers are easily seen dismissing any form of criticism... and apart from that, when teachers talk about the difficulties they encounter in schools, it seems that these people argue that we teachers exaggerate our hardships. Today I realised that it is this latter aspect... that makes me feel extremely frustrated during these meetings. Actually, today I was so frustrated that I simply decided not to contribute to the discussion... since I felt offended on a number of occasions...

Learning requires openness from the part of those who are learning. What is missing here is this openness... since most of those present (and sometimes that includes me) come to these meetings with fixed ideas and beliefs of how things should be, and thus attend these meetings with the aim of confirming their view...

This is why a culture of cooperation between teachers and openness to learning, constructive criticism and dialogue, is best nurtured at pre-service teacher education level. I always felt that most teachers felt and actually were isolated... but is this isolation also self-inflicted? Can teacher education help in such a way as to diminish this feeling of isolation? I am amazed at how grown-up people who are all 
teachers, and thus have quite a high level of education, are not capable of discussing things calmly with the aim of: learning from each other; knowledge production; and moving forward in a sense of cooperation (ISO: 24-11-04).

Issues of how teacher education can help in minimising isolation and increasing collaborative learning will be discussed in the concluding chapter. This issue has become central for me through this thesis because, as Stringer (1996) argues, professional collaboration is essential in order to:

Develop increasingly sophisticated understandings of the problems and issues that confront [teachers]. As they rigorously explore and reflect on their situation together, they can repudiate social myths, misconceptions, and misrepresentations and formulate more constructive analyses of their situation (p.10).

\subsubsection{Collaboration: a tool for diminishing blind-spots while increasing exposure to different viewpoints}

Collaboration can be a way of highlighting our blind-spots (Hunt, 2001). I have argued in Chapter 4 that we are not immune to unconsciously fooling ourselves. However, if other teacher-researchers in a learning community question our claims and our newly acquired understandings, we feel obliged to answer such questions. This ethical obligation makes us reflect in order to answer such questions in a plausible manner. Other people's questioning has exactly the same effect as the personal questioning I mentioned in Chapter 3, where a question elicits an answer, and in order to find a plausible answer we enter into reflection. However, no matter how hard we try, no matter how much effort we put in critically questioning ourselves, it is next to impossible and naïve to think that we are capable of questioning everything that is around us. As such, in reflective self-study, some aspects will proceed unquestioned. Hence, other teacher-researchers questioning our own professional understanding and our own inquiry can offer moments of reflection that would have been missed when engaging in inquiry in isolation, especially when considering that 'interaction inevitably enlarges the subject's vision and stimulates fresh thinking' (Hayes, 2001: p.28). In this way, the individual reflective practitioner can become more aware of his/her professional assumptions, beliefs, and understandings, as they are questioned by 
colleagues (Kraft, 2002; Hashweh, 2004; DeMulder \& Rigsby, 2003; Golombek \& Johnson, 2004). They can also offer new lenses through which new ways of seeing are made available (Meriläinen \& Syrjälä, 2001). On one particular occasion, I argued in my reflective journal that although I'm constantly analysing what I do, some important issues had to be pointed out to me by others, as I did not realise them myself (PD: 2504-04). My argument here resonates with Conle's (1996) claim that 'others often see something in our stories that is hidden to us. Shared narrative work, particularly, promotes such recognitions' (p.317). Hence, interaction with other people can offer food for thought (PD: 18-10-05).

Collaborating with other teachers however, does not solely promote the recognition of hidden aspects of practice; it can also lead to the realisation of new perspectives and the exposure to different viewpoints. Getting the viewpoints and insights of others working in the field is valuable and can be at least helpful and at best inspiring (Loughran, 2002b; Cochran-Smith \& Lytle, 2001; Schuck, 2002). Hence, I agree with Heikkinen's (2001) statement that 'group discussion... opened up spheres you perhaps never could have found out alone' (p.5).

\subsubsection{The Building of Learning Communities}

It is argued in the literature that communication among teachers also seems to promote change in teachers' practice (Garet et al., 2001; Borko, 2004; WestEd, 2000). But if communication among teachers promotes teacher change, then learning communities should promote ongoing change and development.

Schools can be such places where learning communities are formed and developed, but structures and contexts need to be created that support and sustain these learning communities (Armour \& Yelling, 2004; WestEd, 2000). Also, a commitment towards peer collaboration should be developed in teachers very early in their careers (Clark, 1995; Rasmussen, 1997; Pollard, 2002; Laursen, 1994). As I once argued in my journal: 
Lack of communication highlights the isolation and lack of collaboration seen in Maltese schools. This can only be overcome in my opinion by creating learning communities of practice where teachers collaborate with each other. This commitment to collaboration and learning is best instilled in pre-service teachers, I firmly believe (LO: 06-10-04).

In such a way, if teachers learn how valuable personal professional development is for the teaching profession and for the teacher him/herself, and if teachers engage in inquiry with the aim to learn, collaborative inquiry is the way forward.

Through my experience, I concur with Campbell's (2002) contention that teachers embarking on personal professional development seek the collaboration, feedback and active support of colleagues. Day (2004) argues that reflective teachers become 'aware that learning from their own experience of teaching, while valuable, will ultimately be limiting. They will wish to learn from others directly and indirectly or vicariously' (p.123). Yet, it is important that such collaborative learning stems from continuous reflective self-study conducted by every individual of a learning community (Allender \& Manke, 2002; Guilfoyle et al., 2002) because we must never forget the personal nature of professional development as conceived in this study. 'Collegiality should not suffocate teachers' individuality' (Day, 2004: p.138). As noted by a student-teacher:

We can develop our understanding... through discussion and reflection, but in the end, the knowledge that we construct is unique to ourselves. It is as individualistic as a fingerprint (Kroll, 2004).

Also, communication among colleagues without first engaging in personal professional inquiry can have its set-backs because in such a way taken-for-granted assumptions could be reinforced rather than questioned (Little, 2002). As highlighted by Richert (1992):

In the culture of any profession there is considerable tacit knowledge that facilitates communication among colleagues. Relying only on tacit understandings among colleagues, however, creates trade-offs. One is that we become less precise in our thinking and less careful and thorough in our problem solving. Tacit understandings, while necessary, are not sufficient for professional communication. Given teachers' knowledge and intelligence, they can move their profession forward if they are able to talk about what they do and what they know. Writing 
about a professional issue or dilemma in a clear and precise form, and then sharing that case with colleagues who consider it with them, is thus conceived of as a step toward professional development (p.157).

Bass et al. (2002) contend that combining self-study with collaborative learning is a powerful tool that promotes priceless learning for teachers. This is also confirmed by Richert (1992) and Fottland (2004) as they observed that when professionals share their own stories and their own work, their scholarship developed further through the development of a forum. Hence, for teacher-researchers, what learning communities would promote is:

A truly democratic process where all members take on various roles of writers, readers, reflectors, and researchers; our unique autobiographical process where we write, share, and reflect on our personal narratives within a community of writers; and the utilisation of an unusual research methodology that has each member act as both the researcher as well as the researched... [This] was further enhanced by the human elements that emerged as we continued to build our community: our dedication to meeting regularly over time; the development of strong rapport, and our genuine interests in each another's narratives (Coia \& Taylor, 2002: p.51).

Guilfoyle et al. (2002) and Coia \& Taylor (2002) report that all these aspects emerged naturally when engaging in collaborative learning; contributing towards combating isolation and improved opportunities for critically examining the work of individual members.

However, a commitment for lifelong professional development is at the heart of learning communities if these are to survive in the face of hardships confronted by teachers. Other important elements are: trust (Day, 1999; Bohm, 1990; Cochran-Smith \& Lytle, 2001; Minnett, 2003); being able to accept constructive criticism (Guilfoyle et al., 2002); and being able to view the teacher holistically as a person (including emotions and feelings) rather than solely in a professional role. Hence, such learning communities offer contexts to teachers that are more intimate than what they are used to (DeMulder \& Rigsby, 2003). This is what Fitzgerald et al. (2002) have termed professional intimacy. 
For us, professional intimacy means we have created a community where we can talk and care about teaching, and speak about our teaching lives and what they are like for us, sharing how we fail and what we struggle with in teaching (p.77).

It seems to me that what I have written about in this chapter could be regarded as a dream; an ideal. However, seeing it work in practice would be a long process to say the least, but then, change is rarely easy. Both reflective self-study by the individual, and the formation of learning communities with critical friends are challenging tasks (Schuck \& Segal, 2002). On the other hand, as Bass et al. (2002) point out, teachers may be predisposed to this form of learning:

What a great way of life. Many of us became teachers because we loved learning and self-study challenges us to continue to learn. We became teachers because we loved discussion and ended up isolated in our classrooms (p.68).

\subsubsection{A Constant Need to Check My Understandings}

Finally, I want to answer the question put forward by Guilfoyle et al. (2002): 'Does self-study always require community, collaboration, and response from the other?' (p.99). My answer to such a question is no; but it is surely valuable in strengthening and enhancing learning opportunities (Schuck, 2002; Pollard, 2002; Ghaye \& Ghaye, 1998; Minnett, 2003; Basile et al., 2003) and in combating isolation (Clark, 1995; Chetcuti, 2002). Also, testing my understandings and interpretations is important (Fottland, 2004), but since I lacked critical friends at my workplace, I did this by using all that was around me, and this included informal conversations with students and colleagues, collaboration with my research supervisor, the media (including magazines, newspapers, television, internet, etc.) and most of all, existing educational literature. My experience is extremely similar to Schuck's (2002) statement:

While I did not directly have a 'critical friend' to interpret my data with me, my reading, feedback from my research supervisor and comments by my students all served as checkpoints for my reflection and analysis of my data about my practice (p.328).

As regards educational literature, my views are in harmony with Tickle's (2000) contention that 'while such sources appear to be distrusted by teachers as academic and 
non-practical, or else given little attention because of the time they demand, they are a large educational resource' (p.122). This was indeed true for my particular case as can be seen in the following section.

\subsection{Integrating Theory and Practice}

One way, and a very important way of enhancing my personal professional development was through the use of formal theory found in existing literature. Both my inquiry into practice and the use of relevant educational literature were continuous throughout the study. Yet, I have come to see the use of such literature not simply as an enhancement of the reflective self-study process, but as a central component of it.

\subsubsection{The Use of Literature: not simply an aid but a central component of the research process}

The reader might ask him/herself what is so special about me using literature in my research. After all, most formal research projects make use of existing literature. However, I did not use literature in a conventional way. As previously argued, I used literature in the role of critical friend and as such, the search for readings and articles depended entirely on my reflections. Hence, the review of literature was an ongoing process and what I looked for changed according to issues I was reflecting upon. It was literally part of the research process. This is why I have included it continuously throughout this thesis and decided not to confine it to a literature review chapter as traditionally done. As Conle (2000) points out:

Theory in turn becomes a part of the story. After all, our encounters with ideas, readings, and theories are experiences as well and the meaning we make of them can become part of our narrative (p.58).

At the outset of the study, my use of literature was limited because, to be honest, it wasn't even clear to me what I was looking for. My research interest at the start was quite general: I just wanted to learn more about reflection, and if and how it can help 
the practitioner develop. However, as the research developed and entered into deeper inquiry, specific literature was used, depending on the direction the study was taking. Educational literature and theory became part of the process because they affected the outcome of my own learning.

\subsubsection{A Negative View towards Educational Literature}

To be honest, like most teachers, at the start of this research I distrusted educational research as too academic, not practical, too ideal, and largely irrelevant to my daily teaching (Tickle, 2000; Sweeney, 2003; Schuck, 2002; Ghaye \& Ghaye, 1998; Hiebert et al., 2002; Stringer, 1996; Anderson, 2002). However, my perception has changed while embarking on this reflective odyssey. Now I see it as relevant, because through its use I am continuously exposed to new ideas and viewpoints, and it is also a way through which I can check my present understandings. But if existing literature did not suddenly change, this change of perception surely resides in me. So what happened to instigate such a change?

On reflection, I firmly believe that it is the way I used educational literature and research that changed my perceptions. Throughout my previous studies I had always learned from books. I learned from books throughout compulsory schooling in order to pass my examinations. Also, as a graduate I was in the same situation, with the added burden of trying to put into practice that which is found in the literature, as this was obviously expected of me. Hence, I believed that learning was simply acquiring knowledge that was present in books, as these were the tools through which the knowledge of elders was passed to the new generations. I was excellent at learning so conceived and I never had any problems with passing my exams. Yet, my first problems began to emerge when literature that was presented to me, both as an undergraduate and as a postgraduate student, seemed to be irrelevant to the actual world of practice. This also happened in in-service sessions. Authors like Campbell (2000) and Hashweh (2004) argue that there is doubt about the relevance and usefulness of theoretical knowledge to teachers. I felt rebellious because I had so little experience and 
I could not possibly argue against great writers, philosophers, educationalists, etc; so this negative feeling was strong.

So what happens to teachers when 'in trying to apply theory to their practice, the theory fails both to solve their teaching problems and explain their practice to them?' (Ghaye \& Ghaye, 1998: p.4). I personally was very unhappy with the situation and after intitial teacher education had consciously decided never to touch educational literature again. Similarly, most teachers do not use educational research to inform their practice (Hiebert et al., 2002; Sweeney, 2003; Armour et al., 2001; McNamara, 2002). As such, Laursen (1994) contends that 'if theories conflict with reality teachers will view the theories as irrelevant and these theories have no possibility to contribute to the development of the quality of teaching' (p.126). I used to argue that what is found in books is there not to help me as a practitioner, but to make me feel irritated and inadequate. It seems that I am not unique here since as Clark (1995) argues: 'teachers hold preconceptions about a distant activity and community called research that they've had some exposure to; often an exposure that makes them feel inadequate' (p.35). I felt that 'there was a huge gap between the ideals learned about at University and the reality found in schools and society in general' (PD: 22-06-03). Hunt (2001) made a similar point that 'there is stark difference between knowing the theory... and experiencing the reality' (p.279).

As I experienced the harsh reality of teaching, the idealistic views acquired as a university student were washed out. Hence, I would argue that any assumptions made about applying theory from graduate classes to real classrooms should be questioned. Like Whitbeck (1997), 'I have evidence to the contrary' (p.49).

Unfortunately, all this led me, as a beginning teacher, to lose faith in the knowledge base of teaching. I once argued to a friend who is also a teacher that doctors and lawyers appear to read about new research and new cases because it helps them in the immediacy of their work. Most teachers I know do not because it doesn't. He nodded in agreement. It comes as no surprise then that many have described their teaching 
practice rounds as the best part of their teacher education program because they learn about the real thing, while arguing that other components are mostly irrelevant (Attard, 2001; Bencze et al., 2002) A plausible explanation for this is offered by Schön (1983) in his well-known comment that:

There is a swampy lowland where situations are confusing 'messes' incapable of technical solution. The difficulty is that the problems of the high ground, however great their technical interest, are often relatively unimportant to clients or to the larger society, while in the swamp are the problems of greatest human concern (p.42).

\subsubsection{Questioning the Assumptions Surrounding the Use of General Theory}

As argued in Chapter 6, the assumption that professional knowledge and practice should be based on generalisable formal research is strong (Hiebert et al., 2002). For example, the following are the words of a co-operating teacher describing an incident with a student-teacher.

Alice is a very intuitive student teacher. She seems to have a gift for knowing the right thing to do at the right time, especially when it comes to children's social behaviour. I asked her what she had read about social learning that was of help to her. I guess that I put her on the spot because she turned red (Weiss \& Weiss, 2001: 137).

Thus, instead of reflecting on why and how things were working well for the student, thus maximising the learning potential for her and others, the co-operating teacher made it evident that learning should occur through the use of theory and applied in practice. It is also believed that 'schools are not the best place for teachers to acquire theory, which needs specialist teachers to teach it' (Winch, 2004: p.190). But has anybody questioned this belief? And if yes, did traditional teaching of theory to teachers change? After all, as Brouwer \& Korthagen (2005) assert, 'theory offered by teacher educators before field experiences often does not really have an impact on prospective teachers' (p.216). What if prospective teachers learn how to look for and use theory for their personal learning, rather than having it readily presented to them with the sole aim of making them learn about it? I think this is a very important question that I aim to tackle in the concluding chapter. 
The main issue here would appear to be the tendency to assume that by applying scientific theory we are able to provide answers to the problems faced in the fields of practice (Schön, 1983, Stringer, 1996; Ghaye \& Ghaye, 1998; Verloop et al., 2001; Cochran-Smith \& Lytle, 2001; Bartels, 2003). This might help, but professionals do not develop their expertise solely through studying the theories of their respective fields. As argued by White (2002) 'I do not believe that humans are born with the predisposition to have particular views of the nature of knowledge' (p.316), but unluckily we have been socialised to assume that what is really of value is theory; its status boosted when the theory is increasingly general and abstract (Schön, 1987). This is how technicalrationality is promulgated, and universities help in the dissemination of this view by providing general theory to be applied in practice without acknowledging the value of practical knowledge held by the individual about specific contexts (Schön, 1983, 1987; Grimmett et al., 1990). Korthagen \& Kessels (1999) contend that:

In teacher education, the desire to use as much of the available knowledge as possible has led to a conception of teacher education as a system in which experts, preferably working within universities, teach this knowledge to prospective teachers. In the best case, they also try to stimulate the transfer of this knowledge to the classroom, for example, by the use of assignments to be carried out during field experiences (p.4).

This indeed rests on the view of technical-rationality. The following example however, is the exact opposite:

I recently asked a young teacher to speak to a university class about the work she was doing in her classroom. At first she hesitated, recommending that instead I ask another person who is an 'expert' in the field. 'Amy', I said, 'I've heard you talk about your work and really like the ideas you have and the way you link them to the practical, daily realities of teaching. I think you would be much better for the job than an 'expert' who may have many good ideas, but can't make the direct links you can' (Stringer, 1996: p.106).

Such an example shows that theoretical and practical knowledge should develop in a related manner (Korthagen, 2001). Through my own experience I have learned that one without the other is at best incomplete and at worse irrelevant. In Russell's (2002) words: 'theory informs practice and practice informs theory. If you don't have the two 
things working together, then there's no point to it' (p.82). However, it is the dichotomy created between theory and practice that has produced the notion of a theory-practice gap. Such a gap is actually produced by the way we have been socialised to view theory and practice as two distinct activities conducted by two different professionals. In fact, it could be argued that it has become the business of university researchers and scholars to do research and create theory, and the job of school practitioners to apply it (Schön, 1983; Hiebert et al., 2002; Ghaye \& Ghaye, 1998). In this way, teachers feel that a barrier exists between theoretical and practical knowledge, as many perceive the former to be 'beyond [their] abilities and therefore unavailable' (Elbaz, 1983: p.104). This should not be the case. As argued by Loughran $(2002 a)$, reflection is a good way of integrating theory and practice.

Educational literature is saturated with arguments about the problematic disconnection between research and practice, and ways and efforts to reduce this theory-practice gap have been numerous (Korthagen \& Kessels, 1999; Cochran-Smith \& Lytle, 2001; McNamara, 2002; DeMulder \& Rigsby, 2003; Stringer, 1996; Ross, 1990; Winch, 2004; Schön, 1983, 1987; Tillema, 2004; Craft, 1996; Weiss \& Weiss, 2001; Hiebert et al., 2002; Korthagen, 2001; Bartels, 2003; Cobb, 2002; Day, 1999; Campbell, 2000; Hashweh, 2004; Phillips, 1994; Laursen, 1994; Metz \& Page, 2002; Kroll, 2004). However, no effective solution has ever been found; otherwise, such efforts to bridge the gap would have stopped long ago. As argued by Brouwer \& Korthagen (2005) 'searching for ways of optimising the integration between practice and theory... would appear a highly relevant endeavour' (p.216). However:

If the problems between the theory of teacher education and the practice of teaching have been known for some time... why has the lack of acceptance and understanding of these differences persisted over time? (Bartels, 2003: p.749).

The answer might be that ironically, in parallel to the view of technical-rationality, throughout the years, researchers have tried to solve the problem without questioning what is exactly causing such a problem. In fact, the problem that there is a gap to bridge between theory and practice is taken as given. I did not try to find a solution to this never-ending problem in education, but through the way I used relevant theory to 
inform real problems I experienced through reflective self-study, I realised that what appeared to be so irrelevant to my needs, suddenly became indispensable. The only thing that changed was how I used such an important resource. Hence, the real problem is how available research and literature is used to inform practice. In this context, Gorard's (2002) argument makes sense when stating that what is needed is not to have more research, but to make it 'count in the real world' (p.8). Korthagen \& Kessels's (1999) statement offers food for thought:

The traditional approach, in which teacher educators make an 'a priori choice' about the theory that should be transferred to student teachers, represents a very dominant line of thought... The fundamental conception inherent in this line of thought is that there is a gap to be bridged. One often forgets that it was the a priori choice that created this gap in the first place (p.6).

This implies that it is not educational theory and research that should change (although it can always improve), but the way we should look at it. There is 'a need to look differently at the relationship between theory and practice. Combining, integrating, and exchanging the two components become more important' (Verloop et al., 2001: p.445). As Sarah, a teacher in Elbaz's (1983) study comments, 'I sometimes get the impression that there's a whole vast area of material that is behind some closed door, and we don't quite know how to get to the door' (p.106). This is exactly how I felt before engaging myself in reflective self-study. So I ask myself: "Is reflection the key to this door?" In my case, it was. Also, as soon as Sarah herself started reflecting about her own experiences and practical knowledge, 'her conception of theory also appeared to change as it became possible for Sarah to make use of theoretical knowledge of learning which she had previously been reluctant to consider' (p.128). Therefore, having teacherresearchers conducting their own personal professional development might be the answer to the following question put forward by the National Research Council (1999): 'How can the use of research knowledge be increased in schools and school districts?' (cited in, Gorard, 2002: p.7). In fact, Miller (1990) contends that teacher-researchers are more likely to become critical consumers of educational research, as it helps with their own inquiry. 
Brouwer \& Korthagen (2005) have argued for the need to investigate whether practiceto-theory or theory-to-practice models can better ensure 'that practical competence and professional knowledge develop hand in hand' (p.216). I am confident in arguing that in the way I have conducted my own personal professional development, practical competence and professional knowledge developed harmoniously in a symbiotic manner.

\subsubsection{The Importance of Contextual Knowledge}

One of the main reasons why traditional educational research is perceived as so faraway from the realities found in school is because most studies have not given due importance to context; and this is of utmost importance to the classroom teacher (Ghaye \& Ghaye, 1998; Day, 1999; Clandinin \& Connelly, 1995; McNamara, 2002; Metz \& Page, 2002). Therefore, like Donmoyer (2000) I contend that as a teacher concerned with individual students, generalised research often appeared rather irrelevant to my particular needs. However:

Embedded in much traditional educational research is a conception of teaching and learning that envisions teachers as technicians who implement decontextualised instruction to undifferentiated children (DeMulder \& Rigsby, 2003: p.269).

This is why I argue that teachers also need to be researchers working in context, because as a teacher-researcher, I am involved in context-specific ongoing inquiry.

It is argued in the literature that when generalised knowledge is seen as irrelevant and inadequate by teachers because it adds little to their daily practice (as often happens), teachers reject educational research (Stringer, 1996; Mayes, 2001; Bartels, 2003; Humphreys \& Susak, 2000; Ratcliffe, Bartholomew, Hames, Hind, Leach, Millar \& Osborne, 2001; Berliner, 2002; Elbaz, 1983; Clark, 1995). Traditionally, research projects have also studied specific variables of teaching while controlling others. The message here is that if teachers can simply acquire the specific items that make up teaching so conceived, they can become effective teachers (Moore, 1999). I would challenge this view. Controlling for certain variables and for context in research terms, simply means that the resulting study fails to represent the reality of teaching (Verloop 
et al., 2001). In real social practices, everybody operates within a context, including teachers, and teachers want to learn about real-life situations with all their complexities because in real-life situations we face events holistically and context cannot be controlled for (Berliner, 2002; Parker, 1997). In fact, authors like Moore (1999) and Seddon (1994) contend that many of those who seem to be competent in the acquisition of these specific items of practice still have huge difficulties when faced by the reality inside classrooms because teaching is more than the putting together of these specific competencies.

\subsubsection{The Unconscious Creation of a Theory-Practice Gap}

According to Kolb (1984), there are two modes of learning. One is concretely experiencing something while the other is the abstract conceptualisation of it. I have previously argued that without the former, the latter is incomplete at best and irrelevant at worst. The following extract from my personal diary shows how both modes of learning described by Kolb (1984) are important.

I was thinking to myself that somebody who has never smelt rotten eggs does not know how they actually smell due to the lack of experiencing the fact. However, if this same person smells a foul smell and somebody near him states that this smell smells like rotten eggs...than the former person learns how rotten eggs smell like... even though $\mathrm{s} / \mathrm{he}$ has never smelt them.

At this point I realised that most (although not all) of the learning in schools is similar to the episode I described above. I try to teach students about bones, muscles, joints, circulation, drugs, lungs etc. etc. However, the students never (or rarely) have the opportunity to see the abovementioned in their natural working environment. The students can never experience hyaline cartilage. All I can do is show pictures. Thus, most of the learning that takes place is indirect learning... not through direct experience.

This also happens at tertiary level as regards teacher education. Most teacher education courses present prospective teachers with theories about education and teaching methods... as well as research literature... but most of the time these are disconnected from the direct experiences of teachers and/or prospective teachers. Thus learning is not through direct experience. It is here that the gap between theory and practice is created... and that is why a lot of literature argues for the need to bridge this gap. What if this gap is not created in the first place? Then there would be no need to bridge it (PD: 18-11-04). 
According to Stevenson (2002), 'there is already evidence that knowledge for professional activity is actually practice-based, rather than learned theory-based' (p.12). However, some teacher educators perceive 'prior educational experiences... [as] potential barriers that preservice teachers face in implementing the knowledge and skills learned in their teacher education programs' (Griffin, 2003: p.207). This is especially true if we try to move from theory to practice, because the future teacher cannot be easily shaped according to educational theory due to prior experiences. After all:

Students who are studying to become teachers begin their studies with personal, preconceived notions about the nature of teaching and learning. They bring with them anywhere from 16 to 20 years of personal experience as students themselves (Kroll, 2004: p.200).

When keeping this in mind, is it wise to neglect students' prior experiences and throw educational theory at them? If our own experiences are the lens through which we understand theories that are highly abstract (Kroll, 2004), then for theory to be used effectively, there would be a need to somehow delete any experiential learning that had occurred from previous exposure to educational practices; an impossible task.

\subsubsection{Moving from Practice to Theory to Practice}

As Shulman (1992) affirms, through methods that neglect personal experience, prospective teachers 'were surely not learning to connect theory to action, nor were they coming to think analytically or critically' (p.1). Hence, we should focus on and take as a starting point the beliefs and values that prospective teachers already hold, rather than trying to change them unquestioningly (Brouwer \& Korthagen, 2005; Korthagen \& Kessels, 1999). As, Loughran (2002a) argues, 'appropriate focus on experience in teacher education can be influential in the development of effective reflective practice' (p.40). This would consequently promote the tools necessary for ongoing and effective personal professional development. Such argument also holds for in-service teachers, for these have unique and valuable expertise and perspectives as regards teaching (DeMulder \& Rigsby, 2003; Labaree, 2003). 
Therefore, my argument is that if the use of literature is to be relevant, it must be called for by the individual teacher, depending on what areas $s /$ he needs to develop professionally. Hence, 'eclecticism and flexibility seem most important in deciding what [theories] can fruitfully be used' (McIntyre, 1993: p.50). The following example shows how existing literature should be used by a teacher-researcher:

We can think about research as published as we think about a set of encyclopedia. We don't use an encyclopedia by starting on the first page of volume A and reading all the way to $Z$, nor do we open a volume at any odd page and hope to be enlightened. Rather, we use an encyclopedia when we have a need for information about a topic that arises from practice, from life (Clark, 1995: p.43).

Moving from practice to theory to practice came naturally to me when conducting reflective self-study research. Hence, my engagement with reflection led me to integrate practical and theoretical knowledge. On the other hand, Russell (2002) explains that 'linking practice with theory is a longstanding personal interest that I believed led naturally to reflective practice and learning from experience' (p.74). So, Russell's (2002) interest in integrating theory and practice led naturally to reflective practice while my interest with reflective practice led me to naturally integrate theory and practice. In whichever direction we move, it seems that reflective practice is the way to bridge the gulf created between research and practice because it is a way of facilitating the integration of formal and practical knowledge (Hashweh, 2004).

Therefore, like all forms of professional development presented in this study, the use of literature should thus be very personal and relevant to the practitioner's needs. Chetcuti's (2002) experience with reviewing existing literature is similar to mine when she says that:

As I reflected on my experiences and those of my students I sometimes turn to books and articles... and think about what research tells me about particular issues I am interested in. I try and relate this with my own experiences and this helps me to construct new meanings and understanding (p.164). 


\subsubsection{Acting on my New Understandings: integrating theory and practice}

As I realised all of this, I tried moving from practice to theory with my SEC PE classes too. I wanted to teach according to my new understandings. Hence, I opted to start from what students experience in practical sessions and the real world, and then move to theory and back to practice, as this diary extract illustrates: 'I am now linking theory to practical events... and practical events to theory. I'm really happy about it' (PD: 01-1003). This I did with the intention of showing students 'that what we do in class is directly related to what is happening actually on the field of play' (LO: 29-10-03). Being able to move from students' own experiences to theoretical knowledge increased students' interest in the subject, as their motivation increased drastically. Thus, on numerous occasions I felt that students found lessons interesting when they could see direct relevance to their daily experiences, and uninteresting when there was no direct relevance. 'I also believe that this type of teaching simplifies learning... since concepts are not dealt with in the abstract but through concrete situations' (LO: 30-09-03). This is not plain-sailing however since the syllabus is fixed and as I highlighted before, certain topics cannot be experienced in real-life (e.g. the circulatory system). However, by moving from practice to theory, I managed to motivate even the most difficult of students as I have indeed noticed that 'when students discuss something they have experienced personally, they do it with fervour and passion... unlike when they discuss some abstract concept' (LO: 04-11-04). Consequently, students seemed to better appreciate theoretical knowledge when presented to them in such a manner because even though 'the pace of the lesson is slower... students are showing a deeper understanding of topics discussed (PD: 05-10-05).

Through trying to develop this kind of teaching in my classroom, I learned a lot that also applies to teacher learning. Through experiencing this method of teaching, I reinforced my view that the use of theory and existing literature is made relevant and useful if it emerges from practical problems encountered by the individual him/herself.

Hence, although reflective self-study leads to personal professional development, and the development is indeed personalised, outside sources of knowledge should not be 
dismissed. If this is the case, huge learning opportunities would be consciously discarded because 'awareness of the literature about the area being studied, as well as the context of the self-study, is essential for the self-study... to have any far-reaching benefits' (Schuck, 2002: p.335). Research and theory thus become tools or instruments to utilise for ongoing professional development (Stevenson, 2002; Clark, 1995; McNamara, 2002). Therefore:

The relationship of knowledge and practice in professional development cannot be understood in terms of a universe of knowledge that divides formal knowledge, on one hand, from practical knowledge, on the other (Cochran-Smith \& Lytle, 2001: p.48).

\subsection{Conclusion}

When keeping in mind the personal professional development I underwent throughout this study, I realised that a number of factors are important for my development as a teacher-researcher. These factors listed below are identical to those highlighted by Hashweh (2004).

1. The actual teaching and learning in and about practice was an essential factor for me to embark on a reflective odyssey, and consequently take full responsibility for my own personal professional development.

2. Writing was an important tool because the process itself demanded that $I$ describe my experiences and reflect upon them. This facilitated my development.

3. Interacting and acquiring information and viewpoints from others enhanced my own understandings. Although planned interaction and collaboration are not obligatory for a teacher-researcher to develop professionally, they are valuable in increasing learning opportunities.

4. The use of theory can also offer valuable insights while aiding the teacherresearcher in checking his/her understandings to those of a wider 
community. If my search for educational literature is based on my own inquiry and emerges from my own questions to further inform my own understandings, then the chance of it leaving an impact on my own development is enhanced.

All of the above points enhance the reflective process leading to personal professional development. Hence, it could be argued that such factors should be positioned at the heart of teacher education, both at in-service and pre-service levels. These might tentatively take the form of: observing practice and reflecting on experience; reflective writing; group reflection; and the use of relevant literature. All of these should be fused together where one component is based on, and leads to, other components. For practising teachers, inviting an expert to conduct a session to offer further insights into certain troubling issues could also be an option, as the expert would enter a professional collaboration and take the form of an external critical friend. What is of importance is the fact that once again it is not the provider that chooses the issues to be explored. On the contrary, it is the teachers (the learners) who choose the issues collaboratively.

The model presented in figure 1 (pg.215) is how I have come to see the advancement of personal professional development after engaging in reflective self-study. 


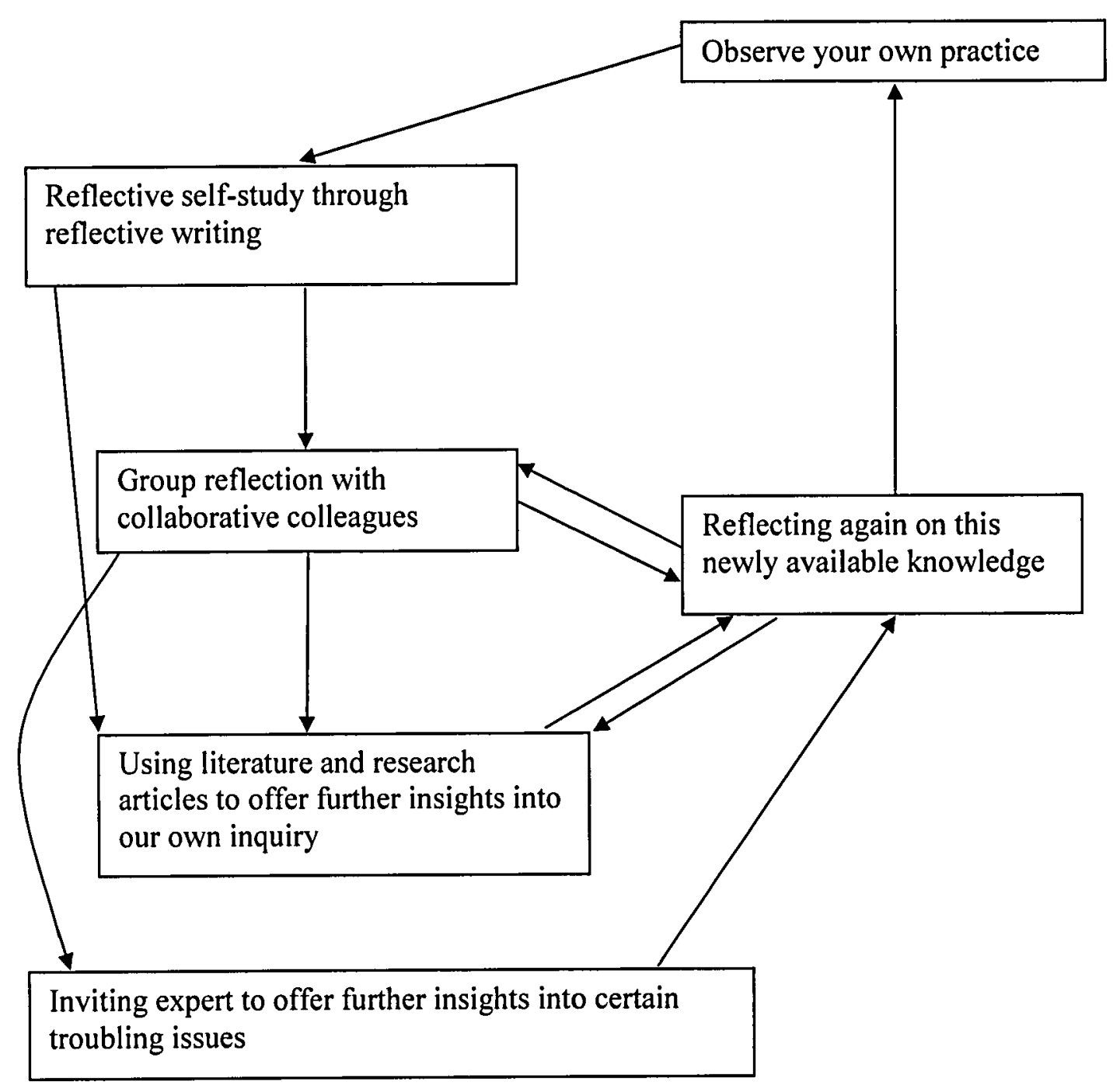




\section{Chapter 8}

\section{Conclusions - Visions for an Improved Future}

\subsection{Important Aspects of This Study}

In this research I have used various types of research methods to inquire into my own professional practice. Through such methods I engaged in teacher-research; taking full responsibility for my own professional development. Such methods also helped me inquire and learn how I developed as I embarked on this project.

The starting point was reflection. I initially used reflection to help me develop my teaching. However, I soon became interested in understanding reflection as I turned my inquiring mind towards understanding the process of ongoing reflection. Thus, I aimed to understand reflection through experiencing reflection. In this way, I was able to view the entirety of the reflective process; i.e. the way a practitioner experiences reflective practice. Yet, I came to realise that the term reflection was too generic, to describe the totality of my own ongoing professional development. In fact, I used various methods (e.g. self-study; action-research; narrative writing) to inquire into my practice, but reflection was the glue that kept the entire research process together.

I engaged in systematic reflection as I closely observed myself as a teacher-researcher. Not only did I take notice of my actions while teaching, but I also took notice of my thoughts and emotions both inside and outside the classroom. The keeping of a reflective journal aided my reflections since at every opportunity I wrote about my experiences and my interpretations; thus, incorporating my reflections into the text. The text thus served important functions: it was a record of my own professional development; a capturing of the complexity of the life of a teacher; a record of my reflections; and a record of how I developed my reflective awareness. These were precious data for the final grounded theory analysis. Hence, it is worth noting that this type of research has various forms of analysis; these being, reflective analysis, narrative 
analysis, analysis of narratives, and grounded theory analysis (as discussed in Chapter 2).

Finally, I will restate the main and secondary research questions here, as these should be kept in mind while analysing the study's conclusions.

(Main)

- How did one teacher learn about his professional practice, in the early years of teaching, through reflection and self-study?

\section{(Secondary)}

- Can critical reflection on practice help to bridge the theory/practice gap?

- What are the implications of this research for continuing professional development for teachers as well as the preparation of future teachers?

\subsubsection{Experience: essential but not sufficient for professional development}

Finding myself in my early career and facing a radical change in policy and practice, I soon realised the importance of teaching experience. Lacking it, I felt lost and confused, and my initial aim was to make the most of my daily experiences so that my future practice would be better informed. I did so through reflective writing, as I systematically reflected upon my daily experiences and wrote about them. I found this to be extremely important for my own professional understandings to evolve, as I realised that experience alone is not enough; I had to analyse it if I was to explicitly learn from it. This is not to say that experiential learning is not possible if experiences are not reflected upon. However, such learning would be mostly tacit, and it is difficult for the practitioner to be fully in control of tacit knowledge. Even worse, tacit understandings control the way a person views his/her future experiences. This I understood when realising that I possessed knowledge that was difficult to make explicit to myself, and thus difficult to control and change. Thus, I argue that experience is essential for reflective practice to proceed; and reflection is fundamental 
to consciously learn from professional experience. For the teacher-researcher, they form a symbiotic relationship.

\subsubsection{The Reflective Process}

My reflective awareness developed in stages, even though these stages are not distinct but merge into each other. Such stages are spontaneous reflection, followed by what Ward \& McCotter (2004) and Day (1999) term technical reflection, dialogic reflection and transformative/critical reflection; the latter being the deepest level of reflection. These are described in detail in Chapter 3. However, one must not mistakenly understand the reflective process as a sequence of steps or procedures to follow, nor as a succession of levels to be reached by the reflective practitioner. As a matter of fact, I have wandered, back and forth, through all of these stages. However, it takes time as a reflective practitioner to develop, and one cannot pretend to engage in, for example, transformative/critical reflection, at the very beginning of his/her reflective journey. This is why I have argued that a systematic approach towards reflective thinking is preferred, rather than as a one-off spontaneous survival mechanism. The more one reflects, the greater the potential for professional understanding, and the better the chance of developing one's own reflective awareness.

I point out however, that reflection is not fool proof, and the reflective practitioner can still, unwillingly, be fooling him/herself. On certain occasions I was also partially blinded; i.e. I did not perceive all there was to perceive. This is only normal though, because as argued in Chapter 4, no matter how hard I try, I cannot objectively make the claim that I can see everything that happens around me and that while reflecting I can see all possible viewpoints. Thus, no reflective practitioner should mistakenly view his/her analysis as final. Through my own experience I have learned that on many occasions, I went back to re-analysing past experiences, especially when new observations pinpointed deficits in my previous analysis. The notion of keeping an open-mind and realising the possibility of multiple interpretations is of extreme value here, because new evidence should constantly put our understandings under a critical 
light. Notwithstanding, reflective practice afforded me a greater sense of control over my professional life.

\subsubsection{Reflective Writing and Conversing with Oneself}

Writing was my main tool throughout this research process that helped me capture my experiences into tangible form. However, writing was not a mechanistic activity. While writing, I engaged in reflection, and I now consider writing as a form of thinking (Meriläinen \& Syrjälä, 2001). When I write, my thinking moves in unforeseen directions; leading me to reflect on various issues (Attard \& Armour, 2005). Hence, writing did not only capture what was visible through observation, but also included my thoughts and emotions upon my experiences; in short, writing was a tool that aided and captured my reflections. Thus, my reflective journal became a longitudinal record of reflective thinking.

It is through my writing that I was able to question myself, and calmly analyse situations to try and offer plausible answers to perceived dilemmas. It is this process of question and answer that made me engage in an internal dialogue, as I was constantly conversing with myself. Actually, this is what reflective self-study is all about: a continuous quest for understandings through questioning, hypothetical answering, and further questioning.

\subsubsection{Learning about Tacitly Held Professional Assumptions}

Spending so much time in a classroom as a student, I obviously held assumptions about teaching practice. Similarly, more assumptions were continuously being formed during my teaching practice rounds and my first year as full-time teacher. Such assumptions are formed through tacit learning from experience. Through my experience with reflective self-study, I have come to understand that my actions are based on my professional knowledge and assumptions. Thus, if I aim to develop professionally and improve my practice, my assumptions should not be taken-for-granted and fixed, but must be constantly changing; i.e. dynamic. 
Thus, I started questioning my own assumptions and I believe this to be very important for the teacher-researcher because, as previously argued, only by making explicit my hidden understandings was I able to challenge and transform my understandings, and consequently my practice. This analysis and consequent transformation of held assumptions is what moves professional development forward. Leaving pre-existing assumptions and understandings unquestioned would result in lack of new and deeper understandings and lack of change, since professional assumptions shape our actions that are usually self-confirmatory. This is no easy task however, for as I described it in Chapter 4 , it is a mined territory. The reflective professional should not question too many assumptions at once, since this would make professional life become intolerable, making the reflective practitioner lose heart, and consequently returning to old ways of practice. If this happens, reflective practice would have backfired.

\subsubsection{Moving Towards a Habit of Change}

As previously argued, unanalysed experience leads to tacit learning, and professional assumptions rest on tacit learning. However, I have also argued that my actions while teaching are based on my professional assumptions, and these become selfconfirmatory if not reflected upon. Thus, learning from unanalysed experience tends to lead to habitual, unchanging practice. However, embarking on a reflective odyssey had the opposite effect. As a reflective teacher, my actions were still largely based on my professional knowledge and assumptions, but these were ever-changing. As a consequence, my practice began to change too. Thus, new learning promoted change. As I pointed out in Chapter 5, systematic engagement with reflective practice served as a corrective to over-learning.

I have also realised that routine practice is extremely comfortable. Like any other routine, practice makes perfect, and one soon becomes proficient in what s/he does; many-a-time without even the need to think. On the other hand, leaving the comfort of habitual routine to engage in change is frightful. The most frightful thing was venturing into the unknown, because moving away from the status quo means that I never had any certainty of what I would find next. This made ongoing change become an 
emotional, apart from an intellectual endeavour. No wonder that I experienced change as being much harder than habitual practice; needing determination from my part not to regress back to my previous teaching habits.

\subsubsection{Uncertainty and Inconclusiveness}

Uncertainty was not only present when venturing into new practice. Uncertainty and inconclusiveness were also present throughout reflective thinking. As a matter of fact, my diaries are full of inconclusive arguments. My reflections are never final, and most perceived problems have to be postponed until further observations and analysis. This is what $\mathrm{I}$ have described in Chapter 5 as a suspended state of not knowing. This suspended state is not to be seen negatively, as it promoted further inquiry to try and answer my unresolved questions regarding professional practice. Subsequently, I soon realised that reflection was not a magical process that simplified teaching. On the contrary, it highlighted the complex nature of teaching; something that I had forgotten before engaging in reflective practice.

\subsubsection{Paying Attention to My Own Professional Development}

Throughout this research, I engaged in two different forms of professional development. These, I described as formal professional development and personal professional development. Although the focus of this research was strictly on the latter, as a full-time teacher I was expected to engage in formal professional development. This was a unique opportunity to compare the two.

As is evident in Chapter 6, my preferred type of professional development is personal professional development, and I gave a number of reasons for this. This is not to say that formal professional development did not promote learning, but ironically, what I appreciated most was the informal learning that occurred during formal courses. However, it is important to highlight how formal in-service sessions frustrated me due to the view of technical rationality they promoted. I sometimes felt as if I was a blank paper for others to write on at will; as if I had no prior knowledge and my job was to 
put others' ideas into practice. Through personal professional development, it is me who devises ideas that are relevant to my context.

Relevance, as argued in Chapter 6, is what makes professional development effective. However, I did not perceive many of the compulsory sessions I had to attend as relevant to my needs. In contrast to this, practitioner research, being one type of personal professional development is relevant to my immediate needs, because issues emerge directly from practical problems experienced by myself; and the use of wider educational literature becomes crucial here. While in formal professional development (including pre-service and in-service training), the literature and theories to be used are pre-determined, in personal professional development they are not. First, a problem of practice must emerge, and only after that do I search for relevant literature and educational theory.

As a teacher-researcher I have come to see the significance of lifelong professional development, and the best way to do this is to take responsibility for my own professional learning. If we assume that the preparation acquired through pre-service teacher education is enough for teachers to teach through their careers, then we are horribly mistaken. Instead, as I argued in Chapter 6, as teachers we need to learn how to learn from everyday engagement with teaching. In this way, teachers' daily experiences offer potential for professional learning, rather than having to wait for formal in-service courses.

\subsubsection{An Isolated Teacher-Researcher?}

I engaged in personal professional development in total isolation. Although I have tried to combat this isolation (as discussed in Chapter 7), I had no critical friends apart from my research supervisor. As none of my colleagues engaged in teacher-research, discussions in the staffroom normally revolved around student behaviour, timeconstraints, and personal problems. However, I still tried to encourage informal communication, as I was constantly searching for other teacher's views. This resonates with Campbell's (2002) contention that teacher-researchers feel the need for 
collaboration and active support from colleagues. Yes, engaging in practitioner-inquiry in isolation made me realise how important professional communication with colleagues is, especially if time is specifically allocated to collaborative inquiry. I would have liked to have the possibility of forming part of a learning community where teachers could share their reflections and reflect on various issues together. After all, working collaboratively with other teacher-researchers can diminish blind-spots as it increases the avenues of exposure to different viewpoints.

Although there are various factors that might inhibit professional collaboration, one main factor might be that teachers lack the tools to learn with and from each other. This is why in Chapter $7 \mathrm{I}$ asked if teacher isolation is self-inflicted. It is interesting to speculate whether pre-service teacher education could promote collaborative learning as one of the much needed tools for future teachers to embark on ongoing personal professional development.

\subsubsection{Educational Literature in Personal Professional Development}

Although personal professional development through reflective self-study is indeed personal, I found the use of wider literature to be crucial for my own development. This is why in Chapter 7 I have described my use of educational literature as a central component rather than simply an aid to my learning. However, throughout this study, I used literature in a completely different way when compared to my previous experiences. Rather than learning about general theory to be applied to practice, I analysed practice and looked for relevant theory that could shed light onto my perceived problems. For the first time in my entire life, I did not sense the frustration that gripped me upon realising that the world of practice was light years away from general theory. This is because no gap was perceived as theory was immediately relevant to practice. Of interest is the fact that the way I used literature to inform my practice came somewhat naturally through reflective practice. My hypothesis here is that this happened naturally, simply because reflective self-study starts from the analysis of practical activities rather than vice-versa. 


\subsection{Key Recommendations from the Study}

Throughout the study, I was constantly thinking about educational improvement, since I wanted to develop professionally and improve my practice. However, reflecting about future possibilities did not only focus on me personally. Since, reflective self-study and personal professional development were put under critical examination, it is expected that improvements and possibilities for teacher learning in the future were also reflected upon. In aiming to improve or change, imagining future possibilities is an important component of reflective practice, for what is learned from the past has to inform the future (Pollard, 2002; Ghaye \& Ghaye, 1998). After all, 'experiential stories... bring into view possible futures' (Conle, 2000: p.56). Thus, aspects like personal professional development, teacher learning, and teacher education are all linked up in this chapter to highlight how newly acquired personal theories shape the ways in which I envisage teacher professional development in the future. Just like Eisenhart (2001) 'I can't help feeling that I have some responsibility to speak about what I think would be best in circumstances about which I have some special knowledge' (p.20); and as a teacherresearcher engaged in reflective self-study, I do assume that this study has afforded me some special insight into personal professional development and teacher learning. However, it is also important to acknowledge that my views have limitations and so 'I believe that this research is just a starting point to understand how teachers learn. Much more can, and should be done' (PD: 10-12-04).

It is important to highlight here that I do not claim that the ways in which I learn are typical of all teachers. However, I do believe that the portrayal of my learning processes offers important insights into the ways that teachers can develop through reflective self-study.

\subsubsection{Should Pre-service Teacher Education Develop Teacher-Researchers?}

Considering all that I have learned from engaging myself in reflective self-study, I argue that the best place to start introducing the concept of teacher-research and 
reflective practice is at the very early stages of a teacher's career, i.e. pre-service teacher education (Loughran, 2002a). As McIntyre (1993) contends:

Learning to reflect must surely be an important goal for student-teachers, since it is through reflection on their own teaching that they will increasingly with experience be able to continue learning (p.44).

In addition, Thurlow \& Stuart (2004) report that teacher candidates argue that, engaging in reflection would have been unlikely had it not been introduced in their preservice education. This is why I argued in my journal that teacher educators should encourage prospective teachers to learn how to engage in continuous learning and introspection (PD: 27-05-03). Rasmussen (1997) and Harris \& Cale (2006) argue that the value of promoting the development of healthy professional attitudes in the early stages of teachers' careers cannot be overestimated. This is fundamental if teacherresearchers are to become the norm rather than the exception in the future. Unfortunately, through my own experience as a student-teacher I realised that although I was prepared to face a classroom full of students, I was not well-prepared to engage in lifelong professional development. I could teach others but not myself.

Engaging in ongoing professional development made me realise that pre-service teacher education should not be seen as the end-point of teacher learning. On the contrary, it should be seen as simply the very first step; a preparation for a long-journey towards lifelong professional development. Like LaBoskey (1992) I contend that such a preparation should include the learning tools a teacher needs to develop professionally till the end of his/her career. I certainly believe that the following words put forward by Corno \& Snow (1986) apply to any learner, from children in their early stages of schooling, to university preparation for any profession and beyond.

Especially in a rapidly changing society, the promotion of aptitudes for learning, problem solving, and future problem finding takes precedence over the teaching of today's facts and skills as a central role for education. Effective learning-to-learn and transfer, not just effective learning, is the goal (p.606). 
My present belief resonates with claims made by Loughran (1996) and Zeichner (1994) as they contend that teachers need to experience reflection by engaging in activities in their pre-service teacher education programs that actually foster a reflective stance, if this is to become an integral component of their own professional practice. In summary, 'reflection... is a worthy aim in teacher education' (Grimmett et al., 1990: p.22). However:

Institutionalised practices - those commonly accepted as 'the way things are done' - seem so pervasive and normal that we often cannot envisage any other ways of working, even when those practices are ineffective or, in some cases, detrimental to our purposes (Stringer, 1996: p.143).

Traditional teacher education that hopes to inculcate technical approaches and practices is often criticised in the literature as ineffective (Mayes, 2001; Day, 2000; Checkley \& Kelly, 1999; Kroll, 2004; Korthagen \& Kessels, 1999; Brouwer \& Korthagen, 2005; Shulman, 1992; Fottland, 2004; Houston \& Clift, 1990; Parker, 1997; Clark, 1995; Griffin, 2003; Moore, 1999; Sweeney, 2003; Weiss \& Weiss, 2001). Yet, if we desire deep and significant educational change, teachers themselves have to undergo change, and one way in which this can happen is by preparing future teachers in a different way; and developing teacher-researchers is important because:

A key requirement for a system to meet changing needs is to not just to train teachers like technicians to implement lessons developed by others, but to nurture intellectually flexible and creative professionals who construct their own way of doing things to suit their context (Radnor, 2002: p. 19).

However, as Houston \& Clift (1990) contend, pre-service and in-service teacher education need restructuring if they are to promote and support teacher reflectivity.

\subsubsection{The Importance of Experiencing Teaching in Pre-service Teacher} Education

It could be argued that there is little point in submitting student-teachers to presentations and lectures that attempt to 'give' theoretical knowledge to them if they have little experience of teaching themselves. Also, if we aim to encourage prospective 
teachers to become engaged in reflective practice, they have to reflect on something and that something is experience gained in the reality of the classroom. According to Korthagen \& Kessels (1999):

In order to learn anything during teacher education, student teachers must have personal concerns about teaching or they must have encountered concrete problems. Otherwise the fruitfulness of the theory is not clear to them and they are not motivated to study it. In fact, this is nothing more than a concretisation of the wellknown principle that learning only takes place if the learner has some personal goal (p.5).

And when such personal goals do exist, it is important for the learner to be able to connect formal theoretical knowledge to the actions they experience in real practical situations. If this does not happen, formal theoretical knowledge will still be viewed as something of an abstraction; not connected to the reality and practicality needed for daily teaching (Joyce \& Showers, 1988; Korthagen \& Kessels, 1999; Thurlow \& Stuart, 2004).

Here, importance is not only given to formal learning but also to what is learned informally. According to Conle (2003), this includes 'not only what is explicitly learned but also what is learned practically, at a more tacit level, touching not only the intellect but the moral, practical, imaginative realm' (p.3). Thus, teaching-practice is needed as a basis upon which to build further knowledge. Unfortunately however, like Russell (1993) I found that the traditional teacher education practices I encountered did not make the most of experiential learning.

It seems clear that teaching-practice episodes should be extensive in order to enable experiential learning to become the foundation of teacher learning. In the case of my experience as a student-teacher in Malta, there should surely be more than the one sixweek practicum each year. The more one experiences real classrooms, the greater the opportunity to engage in reflection, and consequently, the greater the opportunity for learning (Loughran, 2002a; Griffin, 2003; Weiss \& Weiss, 2001). Brouwer \& Korthagen (2005) highlight that 'while in college, the students felt the student teaching 
periods were too short... As beginning teachers, they maintained this judgement' (p.193).

It could also be argued that the traditional model of teaching practice rounds, as experienced by me, is questionable. As Richardson-Koehler (1988) contends:

The degree to which the university supervisor can affect the classroom practices of student teachers, given the structure of the experience, is questioned by supervisors themselves... I felt that as a supervisor I was not affecting the student teachers' classroom practices very much... Short observation and feedback sessions once every two weeks do not constitute adequate supervision (cited in, Russell, 2002: p.75).

Also, as a student-teacher in Malta, my tutors pinpointed my strengths and weaknesses. This was helpful in trying to reproduce my strengths while working on my weaknesses for future teaching practice. Yet, something was missing. This was especially evident in my first year of full-time teaching where I suddenly had no teaching practice tutor to pinpoint my strengths and weaknesses. What if, as a pre-service teacher, I was given the responsibility for identifying my own strengths and weaknesses? In Ghaye \& Ghaye's (1998) words, 'being told where strengths and weaknesses lie is one thing; being able to identify and articulate these yourself is quite another' (p.70). Hence, experience should be reflected upon; and this, integrated with theoretical learning and help from university tutors could be a priceless way of learning and developing as a teacher.

\subsubsection{Educational Theory in Pre-service Teacher Education}

Similar to Loughran, Brown \& Doecke (2001), and as I argued in Chapter 6, 'what we need is to find a link, an effective link that amalgamates the learning in lecture theatres and the learning from experience' (PD: 10-12-04). Through experiencing reflective self-study, the perceived gap between theory and practice has disappeared as discussed in Chapter 7. While aiming to use such a beneficial aspect for teacher preparation programs, Loughran (2002a) argues that as regards theory and practice, 'effective reflective practice is one way of beginning to help teacher preparation programs integrate the two in meaningful ways' (p.41). Yes, reflection indeed aids the integration 
of theory and practice; but if we are able to move (as much as possible) from practice to theory rather than vice-versa, the better the learning experience for student-teachers as no gap is perceived in the first place (Thurlow \& Stuart, 2004). In this sense, I think that it is important to move in the same direction that Zeichner (1994) has outlined when saying that he has 'tried to feed externally generated literature into student teachers' deliberations when it becomes appropriate rather than starting with the analysis of others' experiences' (p.14). In this way, theory is immediately relevant to the students' practical needs, especially when keeping in mind that teachers validate what is contained in the literature according to the connections these have to their particular teaching practice experiences and to the contribution such information can make to their own knowledge of personal practice (Bartels, 2003; Fottland, 2004). In the words of Thurlow \& Stuart (2004):

There is no 'gap' between theory and practice to be bridged; rather, teacher candidates [and teachers] move from a less sophisticated to a more sophisticated understanding of the complexity of educational issues inherent in the teaching learning process. 'Theory' allows [them] to bring greater awareness to classroom practice, and 'practice' informs and further refines theoretical understanding (p.289).

Brouwer \& Korthagen (2005) argue that student-teachers themselves seem to prefer tackling theoretical knowledge after and in relation to practical experience. This is why I have argued that relevant literature should be looked for after individual reflection and/or collaborative reflection has taken place. Evidence exists that shows that practiceto-theory models work better in the preparation of future teachers (Korthagen \& Kessels, 1999). All this should lead to a revaluation of the use of theory in teacher education, and focus on how theory can guide rather than try to predetermine teachers' development. In such a way, theory should leave a greater impact on prospective teachers then it left in the past (Winch, 2004). Hopefully, experiencing educational literature to be relevant and useful might also encourage prospective teachers to be consumers of educational research even when their teacher preparation programs are over. 


\subsubsection{The Creation of Learning Communities}

The argument being developed here is that in pre-service teacher education, an environment is needed where open discussion is the norm, and where non-formal experiential learning is valued. This is in contrast to what according to Cooper \& Olson (1996) is the prescribed role teachers are usually encouraged to take, which 'entails suppressing personal voice in favour of an objective and distanced voice' (cited in Day et al., 2006: p.608).

Hashweh (2004) and Cochran-Smith \& Lytle (1996) argue that the building and sustaining of learning communities of teacher-researchers is an ideal setting for learning, and thus, a desirable issue. So where best can they learn about the potential such communities can have as regards professional development, if not during preservice education? As a student-teacher, I was told that teachers should promote groupwork as children can benefit from collaborative work. If this is so, the same argument should also hold for teacher educators, i.e. promote structures that encourage collaborative learning between student-teachers. Like Williams (2003), I argue that members of learning communities, including the assigned tutor, should 'engage in flexible discussion about recent experiences and the learning that these might have created' (p.217). Hence, this is why I have argued for the need to have extensive teaching practice rounds. Only in such a way can group meetings and teaching practice move in parallel (Korthagen \& Lagerwerf, 1996) and a link between the two is fundamental for the promotion of reflective-inquiry.

Brouwer \& Korthagen (2005) report that students felt that having university-based and teaching practice periods in alternate fashion promoted their development. However, it would be even more beneficial had these two components progressed simultaneously; i.e. student-teachers having allotted time to meet together even during teaching practice rounds. After all, when they become full-time teachers, their teaching practice is ongoing (they cannot stop for a number of weeks), and if they are to form part of learning communities, they must find slots of time to do so and integrate it with fulltime teaching. In such a way, experience aliments individual and group reflection while 
this reflection aliments teachers' actions in classrooms. I agree with Oosterheert \& Vermunt (2003) when they say that 'this should occur right from the start of teacher education, or at least as soon as possible' (p.168). What is important here is that:

Students engage in extended conversations about past and present classroom experiences... The goal is to nurture the formation of a group of critical friends engaged in a collaborative process of reflective practice... The interconnections of personal and professional issues serve as the grist for professional development. Participants are given an opportunity to engage in a model of 'critical' support that can be taken with them to the work site... As participants reflect upon and critique their colleagues' work as well as their own, they begin to assume responsibility for their own professional development (Freidus, 2002: p.82).

It is also important that in such learning communities there is no point in 'proving your point by defeating another' (Fitzgerald et al., 2002: p.78). Members should agree to disagree, as the more they disagree, the more they reflect and the greater the potential for further learning.

\subsubsection{The Role of Writing in Learning Communities}

In such learning communities, reflective journals have an important role. Individual teacher-researchers should still reflect individually on their experiences; otherwise, the personal nature of professional development as conceived in this study would be undermined. The narratives individual members write are then shared and serve as a starting point for group reflection and discussion. The initial process of individual reflective writing is not to be undervalued, because it is this that stimulates discussion during meetings (Pugach \& Johnson, 1990). While writing about an earlier study of hers, Richert (1992) argued that 'the social exchange that followed the writing could not have occurred in the same form without the written material to stimulate it' (p.163). The subsequent discussion is an important aspect, as others' narratives and cases also help us reflect on similar experiences we might have had ourselves, while also sharing varying interpretations and viewpoints (Heikkinen, 2001; Conle, 2003; Shulman, 1992). Thus, as a member of a learning community I am also able to check my own understandings and to highlight possibilities of self-fooling (Mason, 2002). In short: 
Writing about a professional issue or dilemma in a clear and precise form, and then sharing that case with colleagues who will consider it with them, is thus conceived of as a step toward professional development (Richert, 1992: p.157).

\subsubsection{Self-Censorship and Emotions}

Yet, parts of students' stories might not be shared with the rest of the community. After all, students have the right to keep certain aspects private if they wish (Ghaye \& Ghaye, 1998). Hence, the concept of self-censorship can exist in such communities, especially in the early stages. Such self-censorship is regulated depending on trust, as trust seems to be an important factor in collaborative learning (Coia \& Taylor, 2002; Conle, 1996; Bohm, 1990; Day, 1999). In later stages though, members tend to open-up more as trust begins to be formed, and trust-building and being able to open-up seem to be promoted by being part of a team of learning professionals (DeMulder \& Rigsby, 2003; Basile et al., 2003). However, even if parts of the students' autobiography are not shared with the rest of the members, learning still occurs. Let us remember that we engage in writing and reflection with a specific purpose. 'Without being too simplistic, this purpose is meaning making for the author' (Coia \& Taylor, 2002: p.48). In such a way, through individual reflection and group reflection, prospective teachers would be experiencing personal professional development.

Also, trust seems to be an important factor that helps such self-study communities to remain functional even after graduation (Chaffee, Cuddeback, Damon, Faught, Greene, Happeny, Kim, Lau-Smith, Marioni, Noon-Toledo, Platt \& Sagmiller, 2002) as one of the purposes of such communities 'is for teachers to have a safe and supportive audience for their stories, cautionary tales, questions, and personal dilemmas' (Clark, 1995: p.29). This trust is built in a learning environment that is characterised by openness, consideration and responsibility, and the use of personal narratives in learning communities seems to contribute to such characteristics (Elbaz-Luwisch, 2001; Sim, 2004). When considering all this, I align myself with Kosnik (2001) as she argues that: 
Many writers on reflective practice either take this element, the class as a learning community, for granted or ignore the necessity of it; we on the other hand felt it was essential to develop a safe, supportive environment that would sustain and encourage reflection (p.67).

Teacher educators should also give due importance to emotions since these cannot be separated from the teacher, since emotions affect their interpretations of lived situations (Jersild, 1995). 'Once these are acknowledged and understood, teacher education methods can be transformed to help people to become teachers not just learn to teach' (Feldman, 2002: p.69). Hence, emotions like frustration, sadness, satisfaction, joy, and fear, amongst others, should be discussed in such learning communities. We should not try to avoid them as they form part of a teacher's everyday experience both inside and outside the classroom.

\subsubsection{Should the Formation of Learning Communities be Part of the Official Pre-service Curriculum?}

My arguments are in favour of having the formation of small learning communities as part of the official curriculum in teacher education, especially if such an endeavour is seen as desirable for learners and practicing teachers. Unfortunately however, Sweeney (2003) and Heikkinen (2001) argue that universities do not provide ideal conditions for nurturing the attitudes towards collaborative learning between teachers, and Fottland (2004) contends that regrettably, prospective teachers tend to see teaching practice and university-based lectures as separate entities. As argued by Heikkinen (2001):

Those discussions with my friends were of vital importance for my development as a teacher. I still appreciate them as the most significant learning experiences during my teacher education. They gave me a vision for the future, a soul for my profession. But, paradoxically, all that happened outside the official curriculum (p.2).

So why don't we take advantage from such knowledge and make the creation and maintenance of learning communities part of the official pre-service curriculum? Students who had the chance to experience the use of personal journals and learning communities described them as having 'great relevance in... teacher education... [and] 
were considered to be a starting point for developing qualities useful for a teacher' (Heikkinen, 2001: p.9).

\subsubsection{The Tutor's Role in Learning Communities}

University tutors responsible for the creation and maintenance of learning communities have a delicate role to play. First of all, it is important that tutors should not fall into the trap of teaching students about reflective self-study, as 'reflection should not be taught as a process or algorithm ready and waiting to be applied at every possible opportunity' (Loughran, 1996: p.17). This is an ever-present temptation because it is the easiest way to go about it; but it is surely not an effective way. Unknowingly or knowingly, we tend to make what is immeasurable and not easily teachable into something technical, measurable, and easily teachable, like for example creating a checklist and following a number of predetermined steps. When this happens, student-teachers see reflection as just following a number of procedures, and this surely does not lead to critical reflection. Thus, we must avoid turning the stance of teacher-researcher and reflective practice into a technical approach as this may hinder rather than promote professional growth (Richardson, 1990; Houston \& Clift, 1990).

Therefore, it is important that students learn about reflective practice and the tools needed to become teacher-researchers through experience rather than by being taught about them. This is the philosophy behind the recommendations being presented here. It is this that makes the tutor's role become that of a facilitator who supports, challenges, and learns with the rest of the members, rather than the traditional-type expert professor delivering a lecture (MacLeod \& Cowieson, 2001; Schuck, 2002; Kosnik, 2001; Tillema, 2004; Noel, 2000). As such, tutors must take care not to dominate the discussion as this would prevent students from learning how to question themselves while also trying to study issues from various angles. Attention must also be paid not to impose one's own views; not to provide easy answers to unsettling issues; and to show students the importance of tolerating ambiguity and suspended states of not knowing since, as Oosterheert \& Vermunt (2003) contend, learning is not always 
immediate. I would thus agree with Schuck's (2002) statement that in such learning communities 'my practice involved virtually no telling or lecturing' (p.331).

It is also interesting to note that the tutor, in taking the role of a member in such learning communities, may also develop professionally. As argued by Freidus (2002), 'in seeking to enhance our students' professional development, we have enhanced our own as well... [through] working together to learn from and with each other' (p.86). By engaging in group reflection, the tutor inevitably engages him/herself in reflection through trying to understand members' stories while offering and picking up alternative viewpoints (Fuller et al., 2005). A journal kept by tutors can help them in reflecting about their own involvement in such learning communities, and Miller (1990) contends that embarking in self-study research seems to come naturally to teacher educators who aim to assist teachers in studying and reflecting upon their practice. Consequently, through reflecting about their own work, tutors can better understand in what ways they can help individual students reflect about their own experiences (Mason, 2002). This is an important aspect since I do agree with Richardson's (1990) argument that 'the habits of reflection desired in teacher education students should also be apparent in their teacher educators' ( $p .13)$. There is no better thing than practicing what you preach if you want the students in front of you to really appreciate the benefits of reflective practice.

\subsubsection{The Results that Lead to Such Recommendations}

In conclusion, Russell (2002) seems to have similar views to mine and summarises the nature of learning to teach through the following points: (1) Teaching cannot be told since learning to teach is active; (2) Experience can, and should be analysed and understood; (3) Personal reactions to teaching are the starting point for exploration; (4) Discussion, opinion and sharing of experiences are crucial in increasing learning opportunities; (5) Goals for student-teachers must definitely apply personally in order to be relevant; (6) Theory also should be relevant to student-teachers' needs. In short, such recommendations seek to: 
Open new avenues for learning and social support that will serve teachers long after they have completed the requirements. In effect, the program is designed to foster the development of reflective practice, classroom based research and the capacity to engage in critical dialogue with colleagues and with the professional literature (DeMulder \& Rigsby, 2003: p.272).

\subsection{Limitations of This Study}

My experience with reflecting on reflective self-study led me to the conclusions I have made in this chapter, but much more can be done and much more can be learned. An important aspect is that I cannot objectively make the claim that my experiences are identical to those of other teacher-researchers. Hence, the reader should not mistakenly see the process I describe as given; a general process through which all teacherresearchers and reflective practitioners progress. Also, being a self-study, one cannot devise policy on the knowledge emerging from this study. Thus, although such a study should make us realise the need to change, and move us to action, we simply cannot act basing our actions on just one self-study. Hence, further studies are required.

Another limitation is that although I craved being part of a learning community, it was impossible for me (due to various circumstances as described in Chapter 7) to experience being a member of such communities. Ironically however, I have learned about the value of learning communities through the lack of them; as this situation imposed a limit on my personal professional development, and consequently, my study.

Alas, since this study is a form of teacher-research and consequently, a type of personal professional development, there is 'the need to recognise that if I am to continue to learn I shall have to accept my current account as partial and relatively naïve' (Parker, 1998: p.124). 


\subsection{Future Research Questions Stemming from this Study}

Considering that 'the end of a story is best seen as an invitation to begin a new phase in the conversation' (Barone, 1995: p.72), I aim to better understand related issues in the future. Given the chance, my aim is to test my personal theories and analyse my beliefs in practice in the near future.

1. One of the most interesting research questions I aim to pursue is how teacherresearchers learn from engagement in learning communities; i.e. what factors aid and/or inhibit collaborative learning.

2. The role of pre-service teacher education in developing reflective teacherresearchers is also an important aspect that needs further studying. Arguing for reflective practitioners and teacher-researchers without knowing the best way of promoting such professional attitudes to future teachers leaves the educational community with a large gap to be filled.

3. Another important aspect that needs to be studied is how school life and the present structures of schooling help and/or inhibit personal professional development. Only in such a way can structures that aid teachers with their personal professional development be promoted in tomorrow's schools (Zeichner, 1994). This is even more important when considering that claims have been made that present school conditions militate against and do not support reflective practice with the aim of professional growth (Russell, 1993; Wildman et al., 1990; Cole, 1997; Brouwer \& Korthagen, 2005; Day, 2004).

\subsection{Experiencing this Research Project}

Although tiring and frustrating at times, embarking on a reflective odyssey has afforded me insights that I would have missed had I missed this journey towards ongoing personal professional development. Endurance was needed on my part, but this was well-rewarded by keeping my enthusiasm for learning on a life-time high. I do believe 
that engaging in reflective practice without the pressures of doctoral study is a much more pleasant experience, even though I must admit that doctoral qualification was one of the major factors that kept me striving for the achievement of better understanding. Ridding myself of such pressures would allow me some free time; at least during school holiday periods. However, the benefits outweigh the costs and as such, I aim to continue being a teacher-researcher through reflective self-study throughout my teaching career. This is because the major lesson I have learnt from my engagement in this research is that: No Change is Equal to No Improvement. 


\section{Reference List}

Adelman, C. (1989). The Practical Ethic Takes Priority over Methodology. In W. Carr (Ed.) Quality in Teaching: arguments for a reflective profession. (pp. 173-182). London: Falmer Press.

Agar, M. (1995). Literary Journalism as Ethnography: exploring the excluded middle. In J. Van Maanen (Ed.) Representation in Ethnography. (pp. 112-129). London: Sage Publication.

Allender, D. (2002). Just Who is Responsible for My Learning? Available online at http://educ.queensu.ca/ russellt/sstep4/volume1.pdf Accessed on 2nd June 2003

Allender, J. \& Manke, M. (2002). Reflecting and Refracting Self-Study Artifacts: jazz poetry. Available online at http://educ.queensu.ca/russellt/sstep4/volume1.pdf Accessed on 2nd June 2003

Alvesson, M. \& Sköldberg, K. (2000). Reflexive Methodology: new vistas for qualitative research. London: Sage.

Anderson, G. (2002). Reflecting on Research for Doctoral Students in Education. Educational Researcher, 31 (7), 22-25.

Anderson, G., Herr, K. \& Nihlen, A. (1994). Studying Your Own School: an educator's guide to qualitative practitioner research. Thousand Oaks CA: Cowin.

Armour, K. \& Fernandez-Balboa, J.M. (2001). Connections, Pedagogy and Professional Learning. Teaching Education, 12 (1), 103-118.

Armour, K. \& Yelling, M. (2004). Professional Development and Professional Learning: bridging the gap for experienced physical education teachers. European Physical Education Review, 10 (1), 71-93.

Armour, K., Moore, G. \& Stevenson, L. (2001). Autoethnography and Continuing Professional Development in Physical Education. Available online at http:www.lboro.ac.uk/departments/sses/postgraduate/teachertraining/autoethno.htm 1 Accessed on $29^{\text {th }}$ May 2003

Ashley, H. (2001). Playing the Game: proficient working-class student writers' second voices. Research in the Teaching of English, 35, 493-497.

Atkinson, P. \& Hammersley, M. (1998). Ethnography and Participant Observation. In N. Denzin \& Y. Lincoln (Eds.) Strategies of Qualitative Inquiry. (pp.110-136). London: Sage Publications. 
Attard, K. (2001). PETE Program Evaluation in Malta: students' perspectives. Masters Dissertation: Loughborough University.

Attard, K. \& Armour, K. (2005). Learning to Become a Learning Professional: reflections on one year of teaching. European Journal of Teacher Education, 28 (2), 195-207.

Atwell, N. (1991). Side by Side: essays on teaching to learn. Portsmouth NH: Heinemann.

Bain, J.D., Mills, C., Ballantyne, R. \& Packer, J. (2002). Developing Reflection on Practice Through Journal Writing: impacts of variations in the focus and level of feedback. Teachers and Teaching: theory and practice, 8 (2), 171-196.

Ball, S.J. (1990). Introducing Monsieur Foucault. In S.J. Ball (Ed.) Foucault and Education: disciplines and knowledge. (pp. 1-8). London: Routledge.

Ball, D.L. \& Cohen, D.H. (1999). Developing Practice, Developing Practitioners: towards a practice-based theory of professional education. In L. Darling-Hammond \& G. Sykes (Eds.) Teaching as the Learning Profession: handbook of policy and practice (pp. 3-32). San Francisco CA: Jossey-Bass Publishers.

Barone, T. (1995). Persuasive Writings, Vigilant Readings, and Reconstructed Characters: the paradox of trust in educational storysharing. In J.A. Hatch \& R. Wisniewski (Eds.) Life History and Narrative. (pp. 63-74). London: Falmer Press.

Bartels, N. (2003). How Teachers and Researchers Read Academic Articles. Teaching and Teacher Education, 19, 737-753.

Basile, C., Olson, F. \& Nathenson-Mejía, S. (2003). Problem-Based Learning: reflective coaching for teacher educators. Reflective Practice, 4 (3), 291-302.

Bass, L., Anderson-Patton, V. \& Allender, J. (2002). Self-Study as a Way of Teaching and Learning. In J. Loughran \& T. Russell (Eds.) Improving Teacher Education Practices Through Self-Study. (pp. 56-69). London: RoutledgeFalmer.

Beach, D. (2001). Artistic Representation and Research Writing. Reflective Practice, 2 (3), 313-329.

Becker, H.S. (1996). The Epistemology of Qualitative Research. In R. Jessor, A. Colby \& R. Schweder (Eds.) Ethnography and Human Development: context and meaning in social inquiry. (pp. 53-71). Chicago: University of Chicago Press.

Becker, H.S. (2000). Cases, Causes, Conjunctures, Stories and Imagery. In R. Gomm, M. Hammersley \& P. Foster (Eds.) Case Study Method. (pp. 223-233). London: Sage Publications. 
Ben-Peretz, M. (2002). Retired Teachers Reflect on Learning from Experience. Teachers and Teaching: theory and practice, 8 (3/4), 313-323.

Bencze, L., Hewitt, J. \& Pedretti, E. (2002). The Niche Concept in Curriculum and Professional Development in Science Teacher Education: collaboration or individualization? Available online at http://educ.queensu.ca/russellt/sstep4/volume1.pdf Accessed on 2nd June 2003

Berliner, D.C. (2002). Educational Research: the hardest science of all. Educational Researcher, 31 (8), 18-20.

Blumenfeld-Jones, D. (1995). Fidelity as a Criterion for Practicing and Evaluating Narrative Inquiry. In J.A. Hatch \& R. Wisniewski (Eds.) Life History and Narrative. (pp. 25-35). London: Falmer Press.

Bochner, A. \& Ellis, C. (1996). Talking over Ethnography. In C. Ellis \& A. Bochner (Eds.) Composing Ethnography: alternative forms of qualitative writing. (pp. 1345). Walnut Creek CA: AltaMira.

Bohm, D. (1990). Meaning, Purpose and Exploration in Dialogue. Available online at http://www.muc.de/ heuvel/dialogue/dialogue exploration.html Accessed on 26th February 2002

Borko, H. (2004). Professional Development and Teacher Learning: mapping the terrain. Educational Researcher, 33 (8), 3-15.

Bourdieu, P. (1989). Outline of a Theory of Practice. Cambridge: Cambridge University Press.

Brighouse, H. (2003). How Dumb is Educational Research? A response to John Wilson. Educational Research, 45 (2), 129-133.

Brockbank, A. \& McGill, I. (1998). Facilitating Reflective Learning in Higher Education. Buckingham: Open University Press.

Brophy, J.E. \& Good, T.L. (1986). Teacher Behaviour and Student Achievement. In M.C. Wittrock (Ed.) Handbook of Research on Teaching. (pp. 328-375). New York: Macmillan.

Brouwer, N. \& Korthagen, F. (2005). Can Teacher Education Make a Difference? American Educational Research Journal, 42 (1), 153-224.

Brownlee, J., Purdie, N. \& Boulton-Lewis, G. (2001). Changing Epistemological Beliefs in Pre-Service Teacher Education Students. Teaching in Higher Education, $6,247-268$. 
Brunner, D.D. (1994). Inquiry and Reflection: framing narrative practice in education. New York: State University of New York Press.

Bruner, E.M. (1986). Ethnography as Narrative. In V.W. Turner \& E.M. Bruner (Eds.) The Anthropology of Experience. (pp. 139-155). Urbana: University of Illinois Press.

Bruner, J. (1986). Actual Minds, Possible Worlds. Cambridge MA: Harvard University Press.

Bruner, J. (1990). Acts of Meaning. Cambridge MA: Harvard University Press.

Bruner, J. (1996). The Culture of Education. Cambridge MA: Harvard University Press.

Buchmann, M. \& Schwille, J. (1983). Education: the overcoming of experience. American Journal of Education, 30-51.

Bullough, R.V. \& Pinnegar, S. (2001). Guidelines for Quality in Autobiographical Forms of Self-Study Research. Educational Researcher, 30 (3), 13-21.

Burr, V. (1995). An Introduction to Social Constructionism. London: Routledge.

Calderhead, J. \& Gates, P. (1993). Introduction. In J. Calderhead \& P. Gates (Eds.) Conceptualising Reflection in Teacher Development. (pp. 1-10). London: Falmer Press.

Campbell, A. (2000). Fictionalising Research Data as a Way of Increasing Teachers' Access to School-Focused Research. Research in Education, 63, 81-88.

Campbell, A. (2002). Research and the Professional Self. In O. McNamara (Ed.) Becoming an Evidence-Based Practitioner. (pp. 27-36). London: Routledge-Falmer.

Capel, S. \& Taylor, A. (2001). Developing Further as a Teacher. In S. Capel, M. Leask \& T. Turner (Eds.) Learning to Teach in the Secondary School: a companion to school experience. (pp. 381-394). London: RoutledgeFalmer.

Capel, S., Leask, M. \& Turner, T. (2001). Introduction. In S. Capel, M. Leask \& T. Turner (Eds.) Learning to Teach in the Secondary School: a companion to school experience. (pp. 1-5). London: RoutledgeFalmer.

Carr, D. (1997). Narrative and the Real World: an argument for continuity. In L.P. Hinchman \& S.K. Hinchman (Eds.) Memory, Identity, Community: the idea of narrative in the human sciences. (pp. 7-25). New York: State University of New York. 
Carter, K. (1993). The Place of Story in the Study of Teaching and Teacher Education. Educational Researcher, 22 (1), 5-12.

Chaffee, J., Cuddeback, M., Damon, M., Faught, S., Greene, W.L., Happeny, M., Kim, Y.M., Lau-Smith, J.A., Marioni, J., Noon-Toledo, T., Platt, J. \& Sagmiller, K. (2002). A Self-Study Model for Reflective Inquiry: teacher educators and classroom teachers examine critical issues of mutual interest. Available online at http://educ.queensu.ca/ russellt/sstep4/volume1.pdf Accessed on 2nd June 2003

Charmaz, K. (2000). Grounded Theory: objectivist and constructivist methods. In N. Denzin \& Y. Lincoln (Eds.) Handbook of Qualitative Research. (pp. 509-535). London: Sage Publications.

Checkley, K. \& Kelly, L. (1999). Toward Better Teacher Education: a conversation with Asa Hilliard. Educational Leadership, 56 (8), 58-62.

Chetcuti, D. (2002). Becoming a Reflective Practitioner. In C. Bezzina, A. Camilleri Grima, D. Purchase \& R. Sultana (Eds.) Inside Secondary Schools: a Maltese reader. (pp. 154-165). Malta: Indigobooks.

Clandinin, D.J. \& Connelly, F.M. (1991). Narrative and Story in Practice and Research. In D. Schön (Ed.) The Reflective Turn: case studies in and on educational practice. (pp. 258-281). New York: Teachers' College Press.

Clandinin, D.J. \& Connelly, F.M. (1995). Teachers' Professional Knowledge Landscapes. New York: Teachers' College Press.

Clandinin, D.J. \& Connelly, F.M. (2000). Narrative Inquiry: experience and story in qualitative research. San Francisco CA: Jossey-Bass Publishers.

Clark, C.M. (1995). Thoughtful Teaching. London: Cassell.

Clarke, D. \& Hollingsworth, H. (2002). Elaborating a Model of Teacher Professional Growth. Teaching and Teacher Education, 18, 947-967.

Clegg, S., Tan, J. \& Saeidi, S. (2002). Reflecting or Acting? Reflective Practice and Continuing Professional Development in Higher Education. Reflective Practice, 3 (1), 131-146.

Cobb, N.B. (2002). Complexities of Collaboration. Available online at http://educ.queensu.ca/russellt/sstep4/volumel.pdf Accessed on 2nd June 2003

Coburn, C.E. (2003). Rethinking Scale: moving beyond numbers to deep and lasting change. Educational Researcher, 32 (6), 3-12. 
Cochran-Smith, M. \& Lytle, S.L. (1996). Communities for Teacher Research: fringe or forefront? In M.W. McLaughlin \& I. Oberman (Eds.) Teacher Learning: new policies, new practices. (pp. 92-114). New York: Teachers' College Press.

Cochran-Smith, M. \& Lytle, S.L. (2001). Beyond Certainty: taking an inquiry stance on practice. In A. Lieberman \& L. Miller (Eds.) Teachers Caught in the Action: professional development that matters. (pp. 45-58). New York: Teachers' College Press.

Cockrell, K., Placier, P., Burgoyne, S., Welch, S. \& Cockrell, D. (2002). Theater of the Oppressed as a Self-Study Process: understanding ourselves as actors in teacher education classrooms. Available online at http://educ.queensu.ca/russellt/sstep4/volume1.pdf Accessed on 2nd June 2003

Coia, L. \& Taylor, M. (2002). Autobiography and Community: an exploration of the use of autobiographical reflection by and with teachers. Available online at http://educ.queensu.ca/russellt/sstep4/volume1.pdf Accessed on 2nd June 2003

Cole, A. (1997). Impediments to Reflective Practice: toward a new agenda for research on teaching. Teachers and Teaching: theory and practice, 3 (1), 7-27.

Cole, A.L. \& Knowles, J.G. (1993). Shattered Images: understanding expectations and realities of field experiences. Teaching and Teacher Education, 9, 457-471.

Coles, R. (1989). The Call of Stories: teaching and the moral imagination. Boston: Houghton Mifflin.

Conle, C. (1996). Resonance in Preservice Teacher Inquiry. American Educational Research Journal, 33 (2), 297-325.

Conle, C. (2000). Narrative Inquiry: research tool and medium for professional development. European Journal of Teacher Education, 23 (1), 49-63.

Conle, C. (2001). The Rationality of Narrative Inquiry in Research and Professional Development. European Journal of Teacher Education, 24 (1), 21-33.

Conle, C. (2003). An Anatomy of Narrative Curricula. Educational Researcher, 32 (3), 3-15.

Connelly, F.M. \& Clandinin, D.J. (1990). Stories of Experience and Narrative Inquiry. Educational Researcher, 19 (5), 2-14.

Connelly, F.M. \& Clandinin, D.J. (1999). Shaping a Professional Identity: stories of educational practice. New York: Teachers' College Press. 
Cooper, K. \& McNab, S. (2002). Aesthetic Dissonance: fear and courage in questioning. Available online at http://educ.queensu.ca/russellt/sstep4/volumel.pdf Accessed on 2nd June 2003

Corno, L. \& Snow, R.E. (1986). Adapting Teaching to Individual Differences Among Learners. In M.C. Wittrock (Ed.) Handbook of Research on Teaching. (pp.605629). New York: Macmillan.

Costa, A.L. (1998). Teaching and Assessing Habits of Mind. Davis CA: Search Models.

Craft, A. (1996). Continuing Professional Development. London: Routledge.

Cronbach, L.J. (1982). Prudent Aspirations for Social Inquiry. In W. Kruskal (Ed.) The Social Sciences: their nature and uses. (pp. 61-81). Chicago: University of Chicago Press.

Czarniawska, B. (2004). The Uses of Narrative in Social Science Research. In M. Hardy \& A. Bryman (Eds.) Handbook of Data Analysis. (pp. 649-666). London: Sage Publications.

Dadds, M. (1995). Passionate Enquiry and School Development: a story about teacher action research. London: Falmer Press.

Dalmau, M., Hamilton, M. \& Bodone, F. (2002). Communicating Self-Study Within the Scholarship of Teacher Education: a herstmonceux working group. Available online at http://educ.queensu.ca/ russellt/sstep4/volume1.pdf Accessed on 2nd June 2003

Day, C. (1993). Reflection: a necessary but not sufficient condition for professional development. British Educational Research Journal, 19, 83-93.

Day, C. (1999). Developing Teachers: the challenges of lifelong learning. London: Falmer Press.

Day, C. (2000). Teachers in the Twenty-First Century: time to renew the vision[1]. Teachers and Teaching: Theory and Practice, 6 (1), 101-115.

Day, C. (2004). A Passion for Teaching. London: RoutledgeFalmer.

Day, C., Kington, A., Stobart, G. \& Sammons, P. (2006). The Personal and Professional Selves of Teachers: stable and unstable identities. British Educational Research Journal, 32 (4), 601-616.

DeMulder, E.K. \& Rigsby, L.C. (2003). Teachers' Voices on Reflective Practice. Reflective Practice, 4 (3), 267-290. 
Denzin, N.K. (1989a). Interpretive Biography. London: Sage Publications.

Denzin, N.K. (1989b). Interpretive Interactionism. Newbury Park CA: Sage.

Denzin, N.K. (1993). On Hearing the Voices of Educational Research. Urbana: University of Illinois.

Denzin, N.K. (1997). Interpretive Ethnography: ethnographic practices for the $21^{\text {st }}$ century. Thousand Oaks CA: Sage.

Dewey, J. (1910). How We Think. New York: D.C. Heath \& Co., Publishers.

Dewey, J. (1938). Experience and Education. New York: Macmillan.

Donmoyer, R. (1985). The Rescue from Relativism: two failed attempts and an alternative strategy. Educational Researcher, 14 (10), 13-20.

Donmoyer, R. (2000). Generalisability and the Single-Case Study. In R. Gomm, M. Hammersley \& P. Foster (Eds.) Case Study Method. (pp. 45-68). London: Sage Publications.

Doyle, W. (1990). Themes in Teacher Education Research. In W.R. Houston (Ed.) Handbook of Research on Teacher Education. (pp. 3-23). New York: Macmillan.

Eco, U. (1992). Interpretation and Overinterpretation. Cambridge: Cambridge University Press.

Edwards, R. \& Nicoll, K. (2006). Expertise, Competence and Reflection in the Rhetoric of Professional Development. British Educational Research Journal, 32 (1), 115 131.

Eisenhart, M. (2001). Educational Ethnography Past, Present, and Future: ideas to think with. Educational Researcher, 30 (8), 16-27.

Eisner, E. (1991). The Enlightened Eye: qualitative research and the enhancement of educational practice. New York: Macmillan.

Elbaz, F. (1983). Teacher Thinking: a study of practical knowledge. London: Croom Helm.

Elbaz, F. (1991). Research on Teachers' Knowledge: the evolution of a discourse. Journal of Curriculum Studies, 23 (1), 1-19.

Elbaz-Luwisch, F. (2001). Personal Story as Passport: story telling in border pedagogy. Teaching Education, 12 (1), 81-101. 
Elliott, J. (2005). Using Narrative in Social Research: qualitative and quantitative approaches. London: Sage Publications.

Ellis, C. (1995). Final Negotiations. Philadelphia: Temple University Press.

Ellis, C. \& Bochner, A. (2000). Autoethnography, Personal Narrative, Reflexivity: researcher as subject. In N. Denzin \& Y. Lincoln (Eds.) Handbook of Qualitative Research. (pp. 733-768). London: Sage Publications.

Elmore, R.F. \& McLaughlin, M.W. (1988). Steady Work. Santa Monica CA: Rand.

Emihovich, C. (1995). Distancing Passion: narratives in social science. In J.A. Hatch \& R. Wisniewski (Eds.) Life History and Narrative. (pp. 37-48). London: Falmer Press.

Erben, M. (1998). Biography and Research Method. In M. Erben (Ed.) Biography and Education: a reader. (pp. 4-17). London: Falmer Press.

Falk, B. (2001). Professional Learning through Assessment. In A. Lieberman \& L. Miller (Eds.) Teacher Caught in the Action: professional development that matters. (pp. 118-140). New York: Teachers' College Press.

Feldman, A. (2002). Bec(o/a)ming a Teacher Educator. Available online at http://educ.queensu.ca/russellt/sstep4/volume1.pdf Accessed on 2nd June 2003

Feldman, A. (2003). Validity and Quality in Self-Study. Educational Researcher, 32 (3), 26-28.

Fendler, L. (2003). Teacher Reflection in a Hall of Mirrors: historical influences and political reverberations. Educational Researcher, 32 (3), 16-25.

Fenstermacher, G.D. (1994). The Knower and the Known: the nature of knowledge in research on teaching. In L. Darling-Hammond (Ed.) Review of Research in Education, Vol.20. (pp. 3-56). Washington: AERA.

Fernandes, L. (2002). Improving Science Education through Reflection. Available online at http://educ.queensu.ca/russellt/sstep4/volumel.pdf Accessed on 2nd June 2003

Feur, M.J., Towne, L. \& Shavelson, R.J. (2002). Scientific Culture and Educational Research. Educational Researcher, 31 (8), 4-14.

Fishman, B.J., Marx, R.W., Best, S. \& Tal, R.T. (2003). Linking Teacher and Student Learning to Improve Professional Development in Systematic Reform. Teaching and Teacher Education, 19, 643-658. 
Fitzgerald, L., East, K., Heston, M. \& Miller, C. (2002). Professional Intimacy: transforming communities of practice. Available online at http://educ.queensu.ca/ russellt/sstep4/volumel.pdf Accessed on 2nd June 2003

Fottland, H. (2004). Memories of a Fledgling Teacher: a beginning teacher's autobiography. Teachers and Teaching: theory and practice, 10 (6), 639-662.

Freedman, S.W. (2001). Teacher Research and Professional Development: purposeful planning or serendipity. In A. Lieberman \& L. Miller (Eds.) Teachers Caught in the Action: professional development that matters. (pp. 188-208). New York: Teachers' College Press.

Freeman, D. (1994). The Use of Language Data in the Study of Teachers' Knowledge. In I. Carlgren, G. Handal \& S. Vaage (Eds.) Teachers' Minds and Actions: research on teachers' thinking and practice. (pp. 77-92). London: Falmer Press.

Freeman, M. (1993). Rewriting the Self: history, memory, and narrative. London: Routledge.

Freidus, H. (2002). Through a Murky Mirror: self study of a program in reading and literacy. Available online at http://educ.queensu.ca/ russellt/sstep4/volumel.pdf Accessed on 2nd June 2003

Frijda, N.H. (1986). The Emotions. Cambridge: Cambridge University Press.

Fueyo, V. \& Koorland, M.A. (1997). Teacher as Researcher: a synonym for professionalism. Journal of Teacher Education, 48 (5), 336-344.

Fuller, A., Hodkinson, H., Hodkinson, P. \& Unwin, L. (2005). Learning as Peripheral Participation in Communities of Practice: a reassessment of key concepts in workplace learning. British Educational Research Journal, 31 (1), 49-68.

Garet, M.S., Porter, A.C., Desimone, L., Birman, B.F. \& Yoon, K.S. (2001). What Makes Professional Development Effective? Results from a National Sample of Teachers. American Educational Research Journal, 38 (4), 915-945.

Garratt, D. \& Hodkinson, P. (1998). Can There Be Criteria for Selecting Research Criteria? A Hermeneutical Analysis of an Inescapable Dilemma. Qualitative Inquiry, 4, 515-539.

Geertz, C. (1973). The Interpretation of Cultures. New York: Basic Books.

Gelter, H. (2003). Why is Reflective Thinking Uncommon? Reflective Practice, 4 (3), 337-344.

Gergen, M.M. \& Gergen, K.J. (2002). Ethnographic Representation as Relationship. In A. Bochner \& C. Ellis (Eds.) Ethnographically Speaking: autoethnography, 
literature, and aesthetics. (pp. 11-33). Walnut Creek CA: Rowman \& Littlefield Publishers.

Ghaye, A. \& Ghaye, K. (1998). Teaching and Learning through Critical Reflective Practice. London: David Fulton Publishers.

Glaser, B. \& Strauss, A. (1967). The Discovery of Grounded Theory. New York: Aldine.

Glaze, J. (2002). Ph.D. Study and the Use of a Reflective Diary: a dialogue with self. Reflective Practice, 3 (2), 153-166.

Golombek, P.R. \& Johnson, K.E. (2004). Narrative Inquiry as a Mediational Space: examining emotional and cognitive dissonance in second-language teachers' development. Teachers and Teaching: theory and practice, 10 (3), 307-327.

Gomm, R., Hammersley, M. \& Foster, P. (2000). Case Study and Generalisation. In R. Gomm, M. Hammersley \& P. Foster (Eds.) Case Study Method. (pp. 98-115). London: Sage Publications.

Goodson, I.F. (1999). Representing Teachers. In M. Hammersley (Ed.) Researching School Experience: ethnographic studies of teaching and learning. (pp. 122-133). London: Falmer Press.

Gorard, S. (2002). Warranting Research Claims from Non-Experimental Evidence. Available online at http://www.cf.ac.uk/socsi/capacity/Papers/warranting.pdf Accessed on 9th December 2004.

Gordon, C. (1991). Governmental Rationality: an introduction. In G. Burchell, C. Gordon \& P. Miller (Eds.) The Foucault Effect: studies in governmentality. (pp. 151). London: Harvester Wheatsheaf.

Grant, P.A. (2001). The Power of Uncertainty: reflections of pre-service literacy tutors. Reflective Practice, 2 (2), 237-248.

Griffin, M.L. (2003). Using Critical Incidents to Promote and Assess Reflective Thinking in Preservice Teachers. Reflective Practice, 4 (2), 207-220.

Griffiths, M. \& Windle, J. (2002). Helping Teacher Educators Learn to Research: bread and roses - and a phoenix. Available online at http://educ.queensu.ca/russellt/sstep4/volume1.pdf Accessed on 2nd June 2003

Grimmett, P.R., Mackinnon, A.M., Erickson, G.L. \& Riecken, T.J. (1990). Reflective Practice in Teacher Education. In R.T. Clift, W.R. Houston \& M.C. Pugach (Eds.) Encouraging Reflective Practice in Education: an analysis of issues and programs. (pp. 20-38). New York: Teachers' College Press. 
Guba, E.G. (1981). Criteria for Assessing the Trustworthiness of Naturalistic Inquiries. Educational Communications and Technological Journal, 29 (2), 75-91.

Guba, E.G. (1996). Forward. In E. Stringer, Action Research: a handbook for practitioners. (pp. ix-xiii). London: Sage Publishers.

Guilfoyle, K., Placier, P., Hamilton, M. \& Pinnegar, S. (2002). Exploring the Concept of Dialogue in the Self-Study of Teaching Practices. Available online at http://educ.queensu.ca/russellt/sstep4/volume1.pdf Accessed on 2nd June 2003

Guðjónsdóttir, H. \& Dalmau, M. (2002). Professional Working Theory Revisited: international self-study conversations. Available online at http://educ.queensu.ca/russellt/sstep4/volume1.pdf Accessed on 2nd June 2003

Gusfield, J. (1976). The Literary Rhetoric of Science: comedy and pathos in drinking driver research. American Sociological Review, 4, 16-34.

Ham, V. \& Davey, R. (2002). Is Virtual Teaching, Real Teaching? Available online at http://educ.queensu.ca/russellt/sstep4/volume1.pdf Accessed on 2nd June 2003

Hamilton, M. (2002). Using Pictures at an Exhibition to Explore my Teaching Practices. Available online at http://educ.queensu.ca/russellt/sstep4/volumel.pdf Accessed on 2nd June 2003

Hamilton, M.L. \& LaBoskey, V. (2002). Delineating the Territory: reclaiming and refining the self-study of teaching practices. Paper presented at the annual conference of the American Educational Research Association, New Orleans $\left(1^{\text {st }}-5^{\text {th }}\right.$ April).

Harris, J. \& Cale, L. (2006). Good Practice Guidelines in Physical Education Teacher Education. The British Journal of Teaching Physical Education, 17-19.

Harry, B., Sturges, K.M. \& Klingner, J.K. (2005). Mapping the Process: an exemplar of process and challenge in grounded theory analysis. Educational Researcher, 34 (2), 3-13.

Hashweh, M.Z. (2004). Case-Writing as Border-Crossing: describing, explaining and promoting teacher change. Teachers and Teaching: theory and practice, 10 (3), 229-246.

Hatton, N. \& Smith, D. (1995). Reflection in Teacher Education: towards definition and implementation. Teaching and Teacher Education, 11, 33-49.

Haydon, G. (2001). Aims of Education. In S. Capel, M. Leask \& T. Turner (Eds.) Learning to Teach in the Secondary School: a companion to school experience. (pp. 327-337). London: RoutledgeFalmer. 
Hayes, D. (2001). Reflections on the Meaning of 'Non-Participation' in Research. Research in Education, 65, 20-30.

Heikkinen, H. (2001). Telling Stories in Teacher Education. A Narrative-Biographical View on Portfolio Work. Available online at http://wwwedu.oulu.fi/homepage/life/isathann.htm Accessed on 2nd June 2003

Hiebert, J., Gallimore, R. \& Stigler, J.W. (2002). A Knowledge Base for the Teaching Profession: what would it look like and how can we get one? Educational Researcher, 31 (5), 3-15.

Hollway, W. \& Jefferson, T. (2000). Doing Qualitative Research Differently: free association, narrative and the interview method. London: Sage.

Holt, N.L. (2003). Representation, Legitimation, and Autoethnography: an autoethnographic writing story. Available online at http://www.ualberta.ca/ iiqm/backissues/2_ 1 final/html/holt.html Accessed on 2nd June 2003

Hoover, L.A. (1994). Reflective Writing as a Window on Preservice Teachers' Thought Processes. Teaching and Teacher Education, 10 (1), 83-93.

Houston, W.R. \& Clift, R.T. (1990). The Potential for Research Contributions to Reflective Practice. In R.T. Clift, W.R. Houston \& M.C. Pugach (Eds.) Encouraging Reflective Practice in Education: an analysis of issues and programs. (pp. 208-222). New York: Teachers' College Press.

Humphreys, K. \& Susak, Z. (2000). Learning how to Fish: issues for teachers engaging in self-evaluation and reflective enquiry in school. Research in Education, 64, 7890.

Hunt, C. (2001). Shifting Shadows: metaphors and maps for facilitating reflective practice. Reflective Practice, 2 (3), 275-287.

Husu, J. \& Tirri, K. (2003). A Case Study Approach to Study One Teacher's Moral Reflection. Teaching and Teacher Education, 19, 345-357.

Imants, J. (2002). Restructuring Schools as a Context for Teacher Learning. International Journal of Educational Research, 37, 715-732.

Jersild, A.T. (1995). When Teachers Face Themselves. New York: Teachers' College Press.

Johnson, H. (2001). The PhD Student as an Adult Learner: using reflective practice to find and speak in her own voice. Reflective Practice, 2 (1), 53-63. 
Johnson, K.A. (2003). 'Every Experience is a Moving Force': identity and growth through mentoring. Teaching and Teacher Education, 19, 787-800.

Joyce, B. \& Showers, B. (1988). Student Achievement through Staff Development. White Plains NY: Longman.

Keating, I. (2001). The Efficacy of CPD: its impact upon classroom practice. Professional Development Today, 4 (2), 73-78.

Kelchtermans, G. (1994). Biographical Methods in the Study of Teachers' Professional Development. In I. Carlgren, G. Handal \& S. Vaage (Eds.) Teachers' Minds and Actions: research on teachers' thinking and practice. (pp. 93-108). London: Falmer Press.

Kelchtermans, G. \& Vandenberghe, R. (1994). Teachers' Professional Development: a biographical perspective. Journal of Curriculum Studies, 26 (1), 45-62.

Kemp, M. (2001). Fictioning Identities: a course on narrative and fictional approaches to educational practice. Reflective Practice, 2 (3), 345-355.

Kincheloe, J. (1991). Teachers as Researchers: qualitative inquiry as a path to empowerment. London: Falmer.

Koch, T. (1996). Implementation of a Hermeneutic Inquiry in Nursing: philosophy, rigour and representation. Journal of Advanced Nursing, 24 (1), 174-184.

Kolb, D.A. (1984). Experiential Learning: experience as the source of learning and development. London: Prentice-Hall.

Korthagen, F.A.J. (2001). Linking Practice and Theory: the pedagogy of realistic teacher education. Hillsdale NJ: Lawrence Erlbaum.

Korthagen, F.A.J. \& Kessels, J.P.A.M. (1999). Linking Theory and Practice: changing the pedagogy of teacher education. Educational Researcher, 28 (4), 4-17.

Korthagen, F.A.J. \& Lagerwerf, B. (1996). Reframing the Relationship Between Teacher Thinking and Teacher Behaviour: levels in learning about teaching. Teachers and Teaching: theory and practice, 2, 161-190.

Kosnik, C. (2001). The Effects of an Inquiry-Oriented Teacher Education Program on a Faculty Member: some critical incidents and my journey. Reflective Practice, 2 (1), 65-80.

Kraft, N.P. (2002). Teacher Research as a Way to Engage in Critical Reflection: a case study. Reflective Practice, 3 (2), 175-189. 
Kroll, L.R. (2004). Constructing Constructivism: how student-teachers construct ideas of development, knowledge, learning, and teaching. Teachers and Teaching: theory and practice, $10(2), 199-221$.

Kuhn, A. (1995). Family Secrets: acts of memory and imagination. London: Verso.

Labaree, D.F. (2003). The Peculiar Problems of Preparing Educational Researchers. Educational Researcher, 32 (4), 13-22.

LaBoskey, V.K. (1992). Case Investigations: preservice teacher research as an aid to reflection. In J.H. Shulman (Ed.) Case Methods in Teacher Education. (pp. 175193). New York: Teachers' College Press.

LaBoskey, V.K. (1995). Teaching to Teach with Purpose and Passion: pedagogy for reflective practice. In J. Loughran \& T. Russell (Eds.) Teaching about Teaching: purpose, passion and pedagogy in teacher education. (pp. 150-163). London: Falmer Press.

Laursen, P.F. (1994). Teacher Thinking and Didactics: prescriptive, rationalistic and reflective approaches. In I. Carlgren, G. Handal \& S. Vaage (Eds.) Teachers' Minds and Actions: research on teachers' thinking and practice. (pp. 125-135). London: Falmer Press.

Lave, J. \& Wenger, E. (1991). Situated Learning. Cambridge: Cambridge University Press.

Leask, M. (2001). Improving Your Teaching: an introduction to action research and reflective practice. In S. Capel, M. Leask \& T. Turner (Eds.) Learning to Teach in the Secondary School: a companion to school experience. (pp. 278-285). London: RoutledgeFalmer.

Lieberman, A. \& Miller L. (1999). Teachers Transforming Their World and Their Work. New York: Teachers' College Press.

Lieberman, A. \& Wood, D. (2001). When Teachers Write: of networks and learning. In A. Lieberman \& L. Miller (Eds.) Teachers Caught in the Action: professional development that matters. (pp. 174-187). New York: Teachers' College Press.

Lincoln, Y.S. \& Guba, E.G. (2000). The Only Generalisation is: There is No Generalisation. In R. Gomm, M. Hammersley \& P. Foster (Eds.) Case Study Method. (pp. 27-44). London: Sage Publications.

Liston, D.P. \& Zeichner, K.M. (1990). Teacher Education and the Social Conditions of Schooling. New York: Routledge. 
Little, J.W. (2002). Locating Learning in Teachers' Communities of Practice: opening up problems of analysis in records of everyday work. Teaching and Teacher Education, 18, 917-946.

Lockford, L. (2002). Breaking Habits and Cultivating Home. In A. Bochner \& C. Ellis (Eds.) Ethnographically Speaking: autoethnography, literature, and aesthetics. (pp. 76-86). Walnut Creek CA: Rowman \& Littlefield Publishers.

Loughran, J. (1996). Developing Reflective Practice: learning about teaching and learning through modelling. London: Falmer Press.

Loughran, J. (2002a). Effective Reflective Practice: in search of meaning in learning about teaching. Journal of Teacher Education, 53 (1), 33-43.

Loughran, J. (2002b). Understanding Self-Study of Teacher Education Practices. In J. Loughran \& T. Russell (Eds.) Improving Teacher Education Practices Through Self-Study. (pp. 239-248). London: RoutledgeFalmer.

Loughran, J., Brown, J. \& Doecke, B. (2001). Continuities and Discontinuities: the transition from pre-service to first-year teaching. Teachers and Teaching: Theory and Practice, 7 (1), 7-23.

MacLeod, D.M. \& Cowieson, A.R. (2001). Discovering Credit Where Credit is Due: using autobiographical writing as a tool for voicing growth. Teachers and Teaching: Theory and Practice, 7 (3), 239-256.

Mason, J. (2002). Researching Your Own Practice: the discipline of noticing. London: RoutledgeFalmer.

Mauthner, N. \& Doucet, A. (1998). Reflections on a Voice-Centred Relational Method: analysing maternal and domestic voices. In J. Ribbens \& R. Edwards (Eds.) Feminist Dilemmas in Qualitative Research: public knowledge and private lives. (pp. 119-146). London: Sage.

Mayes, C. (2001). Deepening our Reflectivity. Teacher Educator, 36 (4), 248-264.

McIntyre, D. (1993). Theory, Theorising and Reflection in Initial Teacher Education. In J. Calderhead \& P. Gates (Eds.) Conceptualising Reflection in Teacher Development. (pp. 39-52). London: Falmer Press.

McNamara, O. (2002). Evidence-Based Practice Through Practice-Based Evidence. In O. McNamara (Ed.) Becoming an Evidence-Based Practitioner. (pp. 15-26). London: Routledge-Falmer.

McNiff, J. (1993). Teaching as Learning: an action research approach. London: Routledge. 
McQuillan, P.J. \& Muncey, D.E. (1994). 'Change Takes Time': a look at the growth and development of the Coalition of Essential Schools. Journal of Curriculum Studies, 26 (3), 265-279.

Meriläinen, H. \& Syrjälä, L. (2001). Autobiographical Writing as a Self-Construction. Available online at http://wwwedu.oulu.fi/homepage/life/heliisat.htm Accessed on 2nd June 2003

Metz, M.H. (2001). Intellectual Border Crossing in Graduate Education: a report from the field. Educational Researcher, 30 (5), 12-18.

Metz, M.H. \& Page, R.N. (2002). The Uses of Practitioner Research and Status Issues in Educational Research: reply to Gary Anderson. Educational Researcher, 31 (7), 26-27.

Mezirow, J. (1991). Transformative Dimensions of Adult Learning. San Francisco CA: Jossey-Bass.

Miles, M.B. \& Huberman, A.M. (1994). Qualitative Data Analysis. Beverly Hills CA: Sage.

Miller, J. (1990). Creating Spaces and Finding Voices: teachers collaborating for empowerment. Albany NY: State University of New York Press.

Mills, C.W. (1959). The Sociological Imagination. New York: Oxford University Press.

Mills, G.E. (2002). Action Research: a guide for the teacher researcher. Englewood Cliffs NJ: Prentice-Hall.

Minnett, A.M. (2003). Collaboration and Shared Reflections in the Classroom. Teachers and Teaching: theory and practice, 9 (3), 279-285.

Mitchell, J.C. (2000). Case and Situation Analysis. In R. Gomm, M. Hammersley \& P. Foster (Eds.) Case Study Method. (pp. 165-186). London: Sage Publications.

Moore, A. (1999). Beyond Reflection: contingency, idiosyncrasy and reflexivity in initial teacher education. In M. Hammersley (Ed.) Researching School Experience: ethnographic studies of teaching and learning. (pp. 134-152). London: Falmer Press.

Mullen, C. (1994). A Narrative Exploration of the Self I Dream. Journal of Curriculum Studies, 26 (3), 253-263.

Munhall, P. (1994). Revisioning Phenomenology: nursing and health science research. New York: National League for Nursing Press. 
Newman, F. \& Holzman, L. (1997). The End of Knowing: a new developmental way of knowing. London: Routledge.

Noddings, N. (1994). Postmodern Musings on Pedagogical Uses of the Personal. Journal of Curriculum Studies, 26 (4), 355-360.

Noel, K. (2000). 'Experiencing the Theory': constructivism in a pre-service teacher preparation program. Teachers and Teaching: Theory and Practice, 6 (2), 183-196.

Oliver, K.L. (1998). A Journey into Narrative Analysis: a methodology for discovering meanings. Journal of Teaching in Physical Education, 17, 244-259.

Oosterheert, I.E. \& Vermunt, J.D. (2003). Knowledge Construction in Learning to Teach: the role of dynamic sources. Teachers and Teaching: theory and practice, 9 (2), 157-173.

Osterman, K.F. (1990). Reflective Practice: a new agenda for education. Education and Urban Society, 22 (2), 133-152.

Packwood, A. \& Sikes, P. (1996). Adopting a Postmodern Approach to Research. Qualitative Studies in Education, 9 (3), 1-11.

Pajares, M.F. (1992). Teachers' Beliefs and Educational Research: cleaning up a messy construct. Review of Educational Research, 62, 307-332.

Pallas, A.M. (2001). Preparing Education Doctoral Students for Epistemological Diversity. Educational Researcher, 30 (5), 6-11.

Parker, S. (1997). Reflective Teaching in the Postmodern World: a manifesto for education in postmodernity. Buckingham: Open University Press.

Parker, Z. (1998). PhD Students and the Auto/Biographies of Their Learning. In M. Erben (Ed.) Biographies and Education: a reader. (pp. 116-129). London: Falmer Press.

Patton, M.Q. (1990). Qualitative Evaluation and Research Methods. Newbury Park CA: Sage Publications.

Peshkin, A. (2000). The Nature of Interpretation in Qualitative Research. Educational Researcher, 29 (9), 5-9.

Phillips, D.C. (1994). Telling it Straight: issues in assessing narrative research. Educational Psychologist, 29 (1), 13-21.

Phillips, E. \& Pugh, D. (2000). How to Get a PhD. Buckingham: Open University Press. 
Pidgeon, N. \& Henwood, K. (2004). Grounded Theory. In M. Hardy \& A. Bryman (Eds.) Handbook of Data Analysis. (pp. 625-648). London: Sage Publications.

Pierson, W. (1998). Reflection and Nursing Education. Journal of Advanced Nursing, $27(1), 165-170$.

Polkinghorne, D.E. (1988). Narrative Knowing and the Human Sciences. Albany NY: State University of New York Press.

Polkinghorne, D.E. (1995). Narrative Configuration in Qualitative Analysis. In J.A. Hatch \& R. Wisniewski (Eds.) Life History and Narrative. (pp. 5-23). London: Falmer Press.

Pollard, A. (2002). Reflective Teaching: effective and evidence-informed professional practice. London: Continuum.

Pomson, A.D.M. (2004). Loosening Chronology's Collar: reframing teacher career narratives as stories of life and work without end. International Journal of Qualitative Studies in Education, 17 (5), 647-661.

Posner, G. (1996). Field Experience: a guide to reflective teaching. White Plains NY: Longman.

Pugach, M.C. \& Johnson, L.J. (1990). Developing Reflective Practice Through Structured Dialogue. In R.T. Clift, W.R. Houston \& M.C. Pugach (Eds.) Encouraging Reflective Practice in Education: an analysis of issues and programs. (pp. 186-207). New York: Teachers' College Press.

Putnam, R.T. \& Borko, H. (1997). Teacher Learning: implications of new views of cognition. In B. Biddle, T.L. Good \& I.F. Goodson (Eds.) International Handbook of Teachers and Teaching, Vol.2. (pp. 1223-1296). Boston: Kluwer Academic Publishers.

Radnor, H. A. (2002). World Class Education in England: a possibility? Research Intelligence, $81,12-21$.

Rasmussen, K. (1997). Creating Professional Pathways for Tomorrow's Teachers. Available online at http://www.ascd.org/readingroom/edupdate/1997/1nov.html Accessed on 29th May 2003

Ratcliffe, M., Bartholomew, H., Hames, V., Hind, A., Leach, J., Millar, R. \& Osborne, J. (2001). Understanding the Researcher-User Interface. Paper presented at BERA annual conference, Leeds $\left(13^{\text {th }}-15^{\text {th }}\right.$ September). Available online at http://www.tlrp.org/dspace/retrieve/798/BERA2001_P4.pdf 
Reason, P. \& Bradbury, H. (2001). Handbook of Action Research, Practitioner Inquiry and Practice. London: Sage Publications.

Renner, P.G. (2001). Evocative Narrative as Educational Research. Available online at http://www.peter-renner.com/papers/01_03/aerc.htm Accessed on 2nd June 2003.

Richardson, L. (1995). Narrative and Sociology. In J. Van Maanen (Ed.) Representation in Ethnography. (pp. 198-221). London: Sage Publications.

Richardson, L. (2000). New Writing Practices in Qualitative Research. Sociology of Sport Journal, 17, 5-20.

Richardson, L. (2002). Writing: a method of inquiry. In N. Denzin \& Y. Lincoln (Eds.) Handbook of Qualitative Research. (pp.923-948). Thousand Oaks CA: Sage.

Richardson, V. (1990). The Evolution of Reflective Teaching and Teacher Education. In R.T. Clift, W.R. Houston \& M.C. Pugach (Eds.) Encouraging Reflective Practice in Education: an analysis of issues and programs. (pp. 3-19). New York: Teachers' College Press.

Richardson, V. (1996). The Role of Attitudes and Beliefs in Learning to Teach. In J. Sikula, T. Buttery \& E. Guyton (Eds.) Handbook of Research on Teacher Education. (pp. 102-119). New York: Simon \& Schuster Macmillan.

Richardson, V. \& Hamilton, M.L. (1994). The Practical-Argument Staff Development Process. In V. Richardson (Ed.) Teacher Change and the Staff Development Process: a case in reading instruction. (pp. 109-134). New York: Teachers' College Press.

Richert, A. (1992). Writing Cases: a vehicle for inquiry into the teaching process. In J.H. Shulman (Ed.) Case Methods in Teacher Education. (pp. 155-174). New York: Teachers' College Press.

Richert, A. (2001). The Narrative as an Experience Text: writing themselves back in. In A. Lieberman \& L. Miller (Eds.) Teachers Caught in the Action: professional development that matters. (pp. 159-173). New York: Teachers' College Press.

Ross, D.D. (1990). Programmatic Structures for the Preparation of Reflective Teachers. In R.T. Clift, W.R. Houston \& M.C. Pugach (Eds.) Encouraging Reflective Practice in Education: an analysis of issues and programs. (pp. 97-118). New York: Teachers' College Press.

Roth, R. (1989). Preparing the Reflective Practitioner: transforming the apprentice through the dialectic. Journal of Teacher Education, 40 (2), 31-35. 
Russell, T. (1993). Critical Attributes of a Reflective Teacher: is agreement possible? In J. Calderhead \& P. Gates (Eds.) Conceptualising Reflection in Teacher Development. (pp. 144-153). London: Falmer Press.

Russell, T. (1997). Teaching Teachers: how I teach is the message. In J. Loughran \& T. Russell (Eds.) Teaching About Teaching: purpose, passion and pedagogy in teacher education. (pp. 32-47). London: Falmer.

Russell, T. (2002). Guiding New Teachers' Learning from Classroom Experience: selfstudy of the faculty liaison role. In J. Loughran \& T. Russell (Eds.) Improving Teacher Education Practices Through Self-Study. (pp. 73-87). London: RoutledgeFalmer.

Sanders, D.P. \& McCutcheon, G. (1986). The Development of Practical Theories of Teaching. Journal of Curriculum and Supervision, 2 (1), 50-67.

Scheffler, I. (1991). In Praise of Cognitive Emotions. New York: Routledge.

Schön, D.A. (1983). The Reflective Practitioner: how professionals think in action. London: Temple Smith.

Schön, D.A. (1987). Educating the Reflective Practitioner. San Francisco CA: JosseyBass.

Schuck, S. (2002). Using Self-Study to Challenge my Teaching Practice in Mathematics Education. Reflective Practice, 3 (3), 327-337.

Schuck, S. \& Segal, G. (2002). Learning About Our Teaching from Our Graduates, Learning About Our Learning with Critical Friends. In J. Loughran \& T. Russell (Eds.) Improving Teacher Education Practices Through Self-Study. (pp. 88-101). London: RoutledgeFalmer.

Schwandt, T.A. (2000). Three Epistemological Stances for Qualitative Inquiry. In N. Denzin \& Y. Lincoln (Eds.) Handbook of Qualitative Research. (pp. 189-213). London: Sage Publications.

Seddon, T. (1994). Context and Beyond: reframing the theory and practice of education. London: Falmer Press.

Shulman, L.S. (1992). Toward a Pedagogy of Cases. In J.H. Shulman (Ed.) Case Methods in Teacher Education. (pp. 1-30). New York: Teachers' College Press.

Shusterman, R. (1991). Beneath Interpretation. In D.R. Hiley, J.F. Bochman \& R. Shusterman (Eds.) The Interpretive Turn. (pp. 102-128). New York: Cornell University Press. 
Sim, C. (2004). The Personal as Pedagogical Practice. Teachers and Teaching: theory and practice, $10(4), 351-364$.

Smith, B.A. (1999). Ethical and Methodologic Benefits of Using a Reflexive Journal in Hermeneutic Phenomenologic Research. Image: The Journal of Nursing Scholarship, 31 (4), 359-363.

Smith, J. \& Deemer, D. (2000). The Problem of Criteria in the Age of Relativism. In N. Denzin \& Y. Lincoln (Eds.) Handbook of Qualitative Research. (pp.887-896). London: Sage.

Smith, L. \& Geoffrey, W. (1968). Complexities of an Urban Classroom. New York: Holt, Rinehart \& Winston.

Smythe, W.E. \& Murray, M.J. (2000). Owning the Story: ethical considerations in narrative research. Ethics and Behaviour, 10, 311-336.

Sparkes, A.C. (2000). Autoethnography and Narratives of Self: reflections on criteria in action. Sociology of Sport Journal, 17, 21-41.

Sparkes, A.C. (2002). Autoethnography: self-indulgence or something more? In A. Bochner \& C. Ellis (Eds.) Ethnographically Speaking: autoethnography, literature, and aesthetics. (pp.209-232). Walnut Creek CA: Rowman \& Littlefield Publishers.

Sparks, D. (2002a). Designing Powerful Professional Development for Teachers and Principals. Available online at http://www.nsdc.org/sparksbook.html Accessed on 5th October 2002.

Sparks, D. (2002b). Taking Personal Responsibility for Professional Development that Improves Student Learning. Available online at http://www.nsdc.org/educatorindex.htm Accessed on 12th December 2002

Stake, R.E. (2000). The Case Study Method in Social Inquiry. In R. Gomm, M. Hammersley \& P. Foster (Eds.) Case Study Method. (pp. 19-26). London: Sage Publications.

Stanley, L. (1993). On Auto/Biography in Sociology. Sociology, 27, 41-52.

Stevenson, J. (2002). Concepts of Workplace Knowledge. International Journal of Educational Research, 37, 1-15.

Stokes, L. (2001). Lessons from an Inquiring School: forms of inquiry and conditions for teacher learning. In A. Lieberman \& L. Miller (Eds.) Teachers Caught in the Action: professional development that matters. (pp. 141-158). New York: Teachers' College Press. 
Strauss, A. \& Corbin, J. (1990). Basics of Qualitative Research: grounded theory procedures and techniques. London: Sage Publications.

Stringer, E.T. (1996). Action Research: a handbook for practitioners. London: Sage Publishers.

Stringer, E.T. \& Guba, E.G. (1999). Action Research. New York: Corwin.

Sweeney, A.E. (2003). Articulating the Relationships Between Theory and Practice in Science Teaching: a model for teacher professional development. Teachers and Teaching: theory and practice, 9 (2), 107-132.

Sykes, G. (1992). Foreword. In J.H. Shulman (Ed.) Case Methods in Teacher Education. (pp. vii-ix). New York: Teachers' College Press.

Taggart, G. \& Wilson, A. (1998). Promoting Reflective Thinking in Teaching. Thousand Oaks CA: Corwin Press.

Talbot, M. (2002). Reflective Practice: new insights or more-of-the-same? Thoughts on an autobiographical critical incident analysis. Reflective Practice, 3 (2), 225-229.

Thurlow, D. \& Stuart, C. (2004). Supporting Higher Levels of Reflection Among Teacher Candidates: a pedagogical framework. Teachers and Teaching: theory and practice, 10 (3), 275-290.

Tickle, L. (2000). Teacher Induction: the way ahead. Buckingham: Open University Press.

Tillema, H.H. (1997). Reflective Dialogue in Teams: a vehicle to support belief change in student teachers. European Journal of Teacher Education, 20 (3), 283-296.

Tillema, H.H. (2000). Belief Change towards Self-Directed Learning in Student Teachers: immersion in practice or reflection on action. Teaching and Teacher Education, 16, 575-591.

Tillema, H.H. (2004). The Dilemma of Teacher Educators: building actual teaching on conceptions of learning to teach. Teaching Education, 15 (3), 277-291.

Tom, A.R. (1987). Replacing Pedagogical Knowledge with Pedagogical Questions. In J. Smyth (Ed.) Educating Teachers: changing the nature of pedagogical knowledge. (pp. 9-17). London: Falmer.

Turner, B.A. (1981). Some Practical Aspects of Qualitative Data Analysis: one way of organising the cognitive processes associated with the generation of grounded theory. Quality and Quantity, 15, 225-247. 
Turner, T. (2001). Reading Classrooms. In S. Capel, M. Leask \& T. Turner (Eds.) Learning to Teach in the Secondary School: a companion to school experience. (pp. 50-64). London: RoutledgeFalmer.

Usher, R. (1998). The Story of the Self: education, experience and autobiography. In M. Erben (Ed.) Biography and Education: a reader. (pp. 18-31). London: Falmer Press.

Usher, R. \& Edwards, R. (1994). Postmodernism and Education. London: Routledge.

Valli, L. (1990). Moral Approaches to Reflective Practice. In R.T. Clift, W.R. Houston \& M.C. Pugach (Eds.) Encouraging Reflective Practice in Education: an analysis of issues and programs. (pp. 39-56). New York: Teachers' College Press.

Van Maanen, J. (1988). Tales of the Field: on writing ethnography. Chicago: The University of Chicago Press.

Van Manen, M. (1977). Linking Ways of Knowing with Ways of Being Practical. Curriculum Inquiry, 6, 205-228.

Van Manen, M. (1990). Researching Lived Experience: human science for an action sensitive pedagogy. New York: State University of New York Press.

Van Manen, M. (1991). The Tact of Teaching: the meaning of pedagogical thoughtfulness. Albany, New York: State University of New York Press.

Verloop, N., Van Driel, J. \& Meijer, P. (2001). Teacher Knowledge and the Knowledge Base of Teaching. International Journal of Educational Research, 35, 441-461.

Ward, J.R. \& McCotter, S.S. (2004). Reflection as a Visible Outcome for Preservice Teachers. Teaching and Teacher Education, 20, 243-257.

Ward, P. \& O'Sullivan, M. (1998). Similarities and Differences in Pedagogy and Content: 5 years later. Journal of Teaching in Physical Education, 17, 195-213.

Weiss, E.M. \& Weiss, S. (2001). Doing Reflective Supervision with Student Teachers in a Professional Development School Culture. Reflective Practice, 2 (2), 125-154.

WestEd. (2000). Teachers who Learn - Kids who Achieve: a look at schools with model professional development. San Francisco CA: WestEd.

Whitbeck, C. (1997). Against All Odds: creating possibilities for children to invent and discover. In E. Duckworth, Teacher to Teacher. (pp. 48-53). New York: Teachers' College Press.

White, B.C. (2002). Constructing Constructivist Teaching: reflection as research. Reflective Practice, 3 (3), 307-326. 
Wildman, T.M., Niles, J.A., Magliaro, S.G. \& McLaughlin, R.A. (1990). Promoting Reflective Practice among Beginning and Experienced Teachers. In R.T. Clift, W.R. Houston \& M.C. Pugach (Eds.) Encouraging Reflective Practice in Education: an analysis of issues and programs. (pp. 139-162). New York: Teachers' College Press.

Williams, A. (2003). Informal Learning in the Workplace: a case study of new teachers. Educational Studies, 29 (2/3), 207-219.

Wilson, J. (2003). Dumbing Down Educational Research. Educational Research, 45 (2), 119-127.

Winch, C. (2004). What do Teachers Need to Know About Teaching? A critical examination of the occupational knowledge of teachers. British Journal of Educational Studies, 52 (2), 180-196.

Wolcott, H.F. (1995). Making a Study 'More Ethnographic'. In J. Van Maanen (Ed.) Representation in Ethnography. (pp. 79-111). London: Sage Publications.

Yin, R.K. (2003). Case Study Research: design and methods. London: Sage Publications.

Young, R. (1992). Critical Theory and Classroom Talk. Clevedon: Multilingual Matters.

Yung, B.H.W. (2001). Examiner, Policeman or Students' Companion: teachers' perceptions of their role in an assessment reform. Educational Review, 53 (3), 251260.

Zeichner, K.M. (1994). Research on Teacher Thinking and Different Views of Reflective Practice in Teaching and Teacher Education. In I. Carlgren, G. Handal \& S. Vaage (Eds.) Teachers' Minds and Actions: research on teachers' thinking and practice. (pp. 9-27). London: Falmer Press.

Zeichner, K.M. \& Liston, D.P. (1996). Reflective Teaching: an introduction. Mahwah NJ: Lawrence Erlbaum.

Zembylas, M. (2004). The Emotional Characteristics of Teaching: an ethnographic study of one teacher. Teaching and Teacher Education, 20, 185-201. 
